TESIS DOCTORAL

\title{
SISTEMAS ÓPTICOS CON MULTIPLEXACIÓN POR DIVISIÓN EN CÓDIGO (OCDMA) EMPLEANDO REDES DE DIFRACCIÓN DE BRAGG SOBRE FIBRA ÓPTICA.
}

\author{
Waldimar Alexander Amaya Ocampo \\ Director: \\ Dr. Daniel Pastor Abellán \\ Doctor Ingeniero de Telecomunicación
}

Departamento de Comunicaciones

UNIVERSIDAD POLITÉCNICA DE VALENCIA

Valencia 2008 

A mis padres $y$ hermanos. 

Los años de búsqueda en la oscuridad de una verdad que uno intuye pero que no puede expresar, el intenso deseo y las alternancias de confianza en si mismo $y$ de duda, hasta que uno llega a la comprensión, solo los conoce quien los ha experimentado por si mimo 



\section{Agradecimientos}

Kavafis decía que lo importante no era Itaca, si no el camino para llegar a ella, hoy que siento haber conseguido uno de los objetivos mas importantes de mi vida y miro hacia atrás el camino recorrido, se cuanta razón tenía.

Para llegar al final de esta meta me he apoyado en grandes personas y amigos, sin los cuales no lo hubiese conseguido. A todos y cada uno de ellos quiero darles las gracias por el apoyo recibido y en especial:

A mi director de tesis, D. Daniel Pastor Abellán por guiarme con paciencia y sabiduría durante la elaboración de esta tesis y al D. José Capmany Francoy por la confianza brindada y permitirme trabajar con tan prestigioso grupo.

A mis padres y hermanos, porque siempre he contado con su incondicional apoyo y animo constante.

A mis amigos José, Rai, Gustavo, Pascual e Ivana por su invaluable ayuda en todo momento y a todos los demás miembros del Grupo de Comunicaciones Ópticas y Cuánticas por estar ahí siempre que lo he necesitado.

Por último agradecer al Instituto de Telecomunicaciones y Aplicaciones Multimedia iTEAM, y al Departamento de Comunicaciones (Profesores, personal administrativo y técnicos de laboratorio) porque siempre he contado con su ayuda. 



\section{Resumen}

Los avances de los últimos años en dispositivos ópticos han permitido que las tecnologías de codificación y decodificación óptica sean hoy en día una realidad. Existen múltiples aplicaciones en las que es posible utilizar los procesos de cod/decodificación óptica, pero la más conocida es el acceso múltiple por división en código dentro de un entorno óptico, conocida como OCDMA por sus siglas en ingles. En esta tesis doctoral se presenta un estudio de los sistemas OCDMA de tipo coherente, abarcando dos aspectos fundamentales; el modelado del ruido que interfiere con la señal objetivo y el diseño e implementación de las redes de difracción de Bragg como dispositivos Cod/decodificadores. Dentro del modelado del ruido se han incluido la mayor cantidad de variables posibles, con el objeto de conseguir un modelo lo más acertado posible. De esta manera, se considera desde el ancho de banda del receptor hasta el estado de polarización de las señales, pasando por el uso de los dos tipos de modulación más importantes en estos sistemas, como son OOK (On-Off Keying) y DPSK (Differential Phase Shift Keying). Por otra parte, las redes de difracción de Bragg se presentan como los dispositivos más prometedores para ser usados en OCDMA, gracias a su versatilidad y a estar construidas sobre fibras ópticas. Por ello se ha dedicado especial atención a estudiar sus características, destacando en especial, su dependencia con la temperatura y la relevancia de la reflectividad sobre su comportamiento al cod/decodificar señales. A partir de allí se presenta un novedoso método de diseño, realizado mediante un proceso de síntesis, que da como resultado un dispositivo con excelentes prestaciones. En esta tesis también se estudia la codificación y decodificación todo óptica de etiquetas en redes de conmutación de paquetes. Esta aplicación busca reducir los tiempos de proceso que se tienen en la actualidad en un nodo óptico y ha sido propuesta hace ya un par de años. Aquí nos enfocamos en dos aspectos, el primero, proponer que los picos de autocorrelación que se obtienen al procesar la etiqueta óptica se reutilicen para la conformación de la nueva etiqueta asignada al siguiente paquete que se va a enviar. Con esta propuesta se consigue reducir la latencia y los costes de implementación. Y segundo el estudio del efecto de la dispersión sobre las señales codificadas que viajan a través de la fibra óptica. En el último apartado de la tesis se realizó una descripción de los sistemas OCDMA de tipo incoherente, y se seleccionó un código en 2 dimensiones para mostrar la forma de diseño y una parcial implementación del sistema para verificar el efecto de la interferencia sobre la señal objetivo. 



\section{Abstract}

Advances in recent years on optical devices have enabled optical encoding-decoding technologies to be a reality nowadays. There are many applications where it is possible to use the processes of cod/decoding optics, but the best known is code division multiple access working on optical environment, known as OCDMA. This thesis presents a study of coherent OCDMA systems, covering two key aspects; modeling noise that interferes with target signal and design and implementation of fiber Bragg gratings devices as encoders/decoders. The noise modeling includes as many variables as possible in order to achieve a more accurate model. In this way, it considers from the bandwidth receiver until the state of signal polarization through the use of two types of modulation techniques in these systems, such as OOK (On-Off Keying )and DPSK (Differential Phase Shift Keying). Moreover, the fiber Bragg gratings are presented as the most promising devices for use in OCDMA, thanks to its versatility and optical fiber based device characteristics. For this reason, it has dedicated special attention to study its characteristics, emphasizing in particular its dependence with temperature and the relevance of the reflectivity on their behaviour to cod/decoded signals. Then a novel method of design, done through a process of synthesis, is presented, obtaining a high performance cod/decoding device. This thesis is also studying the encoding and decoding all optical labels in packet-switched networks. This application seeks to reduce processing times in currently optical nodes and it has been proposed a couple of years ago. Here we focus on two aspects, the first is based on the fact that autocorrelation peak obtained by the optical label processing can be reused for the formation of the new label assigned to the following packet to be sent. This proposal reduces the latency and costs of implementation. And second, the study of the dispersion effect on the encrypted signals that travel through fibre optics. In the last chapter of the thesis was carried out a description of the incoherent OCDMA systems, and a code in 2 dimensions was selected to show how is designed and its partial implementation of the system to verify the effect of interference on the target signal. 



\section{Resum}

El progrés dels últims anys en dispositius òptics ha permés que les tecnologies de codificació i decodificació òptica siguen a dia de hui una realitat. Hi han múltiples aplicacions on és possible emprar procesos de codificació/decodificació òptica, però la més coneguda es el accés múltiple per divisió en el còdig dins d'un entorn òptic, conegut com OCDMA per les seues sigles en anglès. En esta tesi doctoral es presenta un estudi dels sistemes OCDMA denominats coherents, comprenent dos aspectes fonamentals; el modelat del soroll interferent sobre el senyal objectiu i el diseny i la implementació dels filtres de difracció de Bragg com a dispositius codificadors/decodificadors. Dins del modelat del soroll s'han inclós la major cantitat de variables possibles, perseguint com objectiu obtindre un model el més encertat possible. D'esta manera, es considera des de l'ample de banda del receptor fins l'estat de polarització dels senyals, passant per l'ús de les dos tècniques de modulació més importants en estos sistemes, com són OOK (On-Off Keying) y DPSK (Differential Phase Shift Keying). Per altra banda, els filtres de difracció de Bragg es presenten com els dispositius prometedors per ser emprats en OCDMA, gràcies a la seua versatilitat i a estar contruits sobre fibres òptiques. Per tant, s'ha dedicat especial atenció a estudiar les seues característiques, destacant en especial, la seua dependència en la temperatura i la relevància de la reflectivitat sobre el seu comportament en la coficació/decodificació dels senyals. A partir d'este punt, es presenta un mètode novedós de disseny, emprant un procés de síntesi, que dona com a resultat un dispositiu de excel.lents prestacions. En esta tesis també s'estudia la codificació i decodificació totalment òptiques d'etiquetes en xarxes de conmutació de paquets. Esta aplicació busca reduir els temps de procés que es tenen en la actualitat dins dels nodes òptics, i ha sigut proposta fa un parell d'anys. Es tracten dos aspectes, el primer, proposar que els màxims de l'autocorrelació que s'obtenen al processar l'etiqueta òptica es reutilitzen per la conformació de la nova etiqueta assignada al següent paquet que es va a enviar. Esta proposta aconseguix reduir la latència i el cost de la implementació. El segon estudi és sobre l'efecte de la dispersió en els senyals codificats que viatgen a través de la fibra òptica. L'últim apartat de la tesi descriu els sistemes OCDMA incoherents, seleccionant un codi en 2 dimensions per mostrar el procediment de disseny i una implmentació parcial del sistema per verificar el efecte de la interferència sobre el senyal objectiu. 



\section{Índice general}

1. INTRODUCCIÓN 1

1.1. Introducción a los Sistemas OCDMA . . . . . . . . . . . . 1

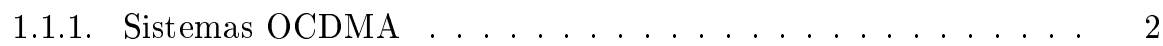

1.1.2. Dispositivos Cod/Decodificadores . . . . . . . . . . 5

1.1.3. Aplicaciones . . . . . . . . . . . . . . 6

1.1.3.1. Técnica de Acceso al Medio. . . . . . . . . . . 6

1.1.3.2. Codificación Óptica . . . . . . . . . . . . . . 7

1.2. Justificación . . . . . . . . . . . . . . . . . . . . . 9 9

1.3. Objetivos y Estructura de la Tesis . . . . . . . . . . . . . 11

2. MODELADO DEL RUIDO EN SISTEMAS OCDMA 13

2.1. Introducción . . . . . . . . . . . . . . . . . . 13

2.2. Modelo Básico del Ruido en Sistemas
DS-OCDMA con On-Off Keying . . . . . . . . . . . . . . . . . . . 14

2.3. Modelo Generalizado del Ruido en Sistemas

2.4. Modelo del Ruido en Sistemas OCDMA con

Modulación DPSK . . . . . . . . . . . . . . . . 25

2.5. Modelo del Ruido Bajo Hipótesis Asíncrona . . . . . . . . . . . . . . 32

2.6. Efecto del Uso de Técnicas de Thresholding en Sistemas DS-OCDMA 37

2.7. Efecto de la Polarización de las Señales

Interferentes . . . . . . . . . . . . . . . . . . . . . 40

2.8. Resultados de la Simulación y Discusión . . . . . . . . . . . . . . . 43

2.8.1. Sistemas OCDMA con Modulación OOK vs. Sistemas OCDMA con Modulación DPSK . . . . . . . . . . . . . . . 43

2.8.2. Evaluación del Modelo Generalizado de los Sistemas OCDMA. 44

2.8.3. Evaluación del Modelo Bajo Hipótesis Asíncrona . . . . . . . . 46

2.8.4. Efecto del Uso de Técnicas de Thresholding. . . . . . . . . . . 49

3. SISTEMA OCDMA BASADO EN REDES DE DIFRACCIÓN DE BRAGG SUPERESTRUCTURADAS UNIFORMES $\mathbf{5 3}$

3.1. Introducción . . . . . . . . . . . . . . . . . 53

3.2. Teoría de las FBGs . . . . . . . . . . . . . . . . . . 54

3.2.1. Redes de Difracción de Bragg Superestructuradas . . . . . . . . 59 


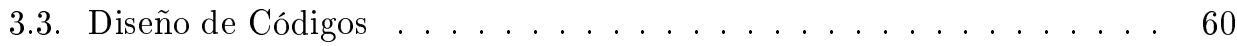

3.3.1. M-sequences . . . . . . . . . . . . . . . 6 61

3.3.2. Generación de una Familia de Códigos Gold. . . . . . . . . . 64

3.4. Fabricación de las Redes de Difracción SSFBGs para OCDMA . . . . 65

3.5. Codificación y Decodificación Óptica Mediante SSFBG Bipolares Uni-

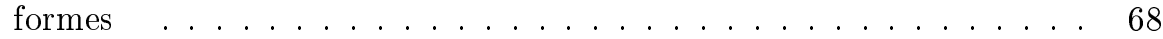

3.6. Técnicas de Estabilidad en Temperatura . . . . . . . . . . . 76

3.7. Determinación de la Desintonía Máxima y su Relación con la Longitud de la SSFBG . . . . . . . . . . . . . . . . . . . 79

3.7.1. Modelo Experimental . . . . . . . . . . . . . . . . 82

3.8. Propuesta de Técnica de Desintonía para la

Reutilización de Códigos . . . . . . . . . . . . . . . . . 84

4. DISPOSITIVOS SSFBG DE ALTA REFLECTIVIDAD PARA SISTEMAS OCDMA. $\quad 89$

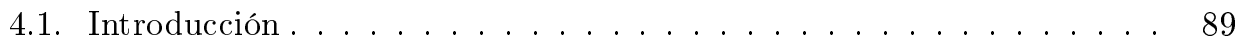

4.2. Simulaciones de las SSFBGs en Diferentes

Regímenes de Trabajo. . . . . . . . . . . . . . . . . . . . 91

4.3. SSFBG con Apodización del Índice de

Refracción . . . . . . . . . . . . . . . . . . 92

4.4. Diseño de SSFBG-HR Empleando Métodos de Síntesis . . . . . . . 95

4.4.1. Procedimiento de Síntesis Empleado . . . . . . . . . . . . 98

4.4.2. Diseño y Resultados de la Simulación . . . . . . . . . . . . 98

4.4.3. Resultados Experimentales . . . . . . . . . . . . . . 101

5. CODIFICACIÓN Y DECODIFICACIÓN TODO ÓPTICA DE ETIQUETAS EN REDES DE CONMUTACIÓN DE PAQUETES. 109

5.1. Introducción . . . . . . . . . . . . . . . . . . . . . . . . 109

5.2. Principios de la Recodificación de Pulsos . . . . . . . . . . . . . . 112

5.3. Simulación en Matlab y VPI . . . . . . . . . . . . . . . . 113

5.4. Demostración Experimental . . . . . . . . . . . . . . . . 116

5.5. Efecto de la Dispersión en la Transmisión de Señales Codificadas . . . 125

5.6. Resultados de las Simulaciones . . . . . . . . . . . . . . 127

5.7. Verificación Experimental . . . . . . . . . . . . . . . . 131

6. SISTEMAS OCDMA INCOHERENTES 2D 137

6.1. Introducción . . . . . . . . . . . . . . . . . . . 137

6.2. Diferencia Mínima de Frecuencia Entre Canales para Sistemas Incoherentes . . . . . . . . . . . . . . . . . . . . 139

6.3. Sistemas OCDMA Incoherentes 2-D . . . . . . . . . . . . 147

6.3.1. Diseño de Códigos 2-D (Longitud de Onda/Tiempo) para Sistemas OCDMA . . . . . . . . . . . . . . . . 148

6.3.2. Demostrador Experimental _ . . . . . . . . . . . . . 151 
7. CONCLUSIONES Y LÍNEAS ABIERTAS 161

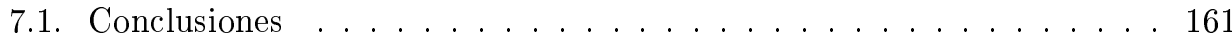

7.2. Líneas Abiertas . . . . . . . . . . . . . . . . . . . . . . . . 164

7.2.1. Modelado de Sistemas OCDMA. . . . . . . . . . . . . . . 164

7.2.2. Diseño, Fabricación e Implementación de Dispositivos Codificadores y Decodificadores . . . . . . . . . . . . . . . . 165

7.2.3. Aplicaciones de las Tecnologías de Cod/decodificación Todo Óptica . . . . . . . . . . . . . . . . . 165

7.2.4. Sistemas Incoherentes . . . . . . . . . . . . . . . 165

A. PUBLICACIONES CIENTÍFICAS DEL AUTOR 179

A.1. Publicaciones en Revistas Internacionales . . . . . . . . . . . . . . 179

A.2. Publicaciones en Congresos Internacionales . . . . . . . . . . . . . . 179

A.3. Publicaciones en Congresos Nacionales . . . . . . . . . . . . . 180

B. PUBLICACIONES INTERNACIONALES (Texto Completo) 



\section{Índice de figuras}

1.1. Diagrama de Bloques de un sistema OCDMA típico. . . . . . . . 2

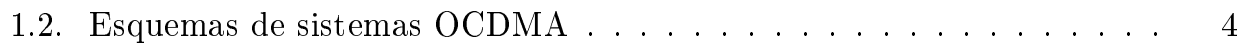

1.3. Montaje básico para realizar los procesos de codificación y decodifi-

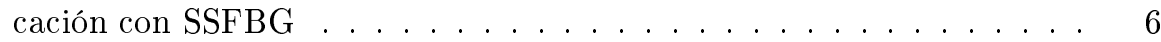

2.1. Diagrama de bloques del sistema OCDMA y fuentes de ruido $\ldots . . .14$

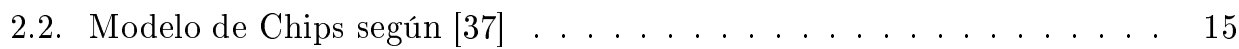

2.3. Modelo con pulsos de forma gausiana. . . . . . . . . . . . . 21

2.4. Diagrama de bloques para el sistema OCDMA con modulación DPSK 25

2.5. Detector diferencial con Interferómetro Mach-Zehnder . . . . . . 26

2.6. Sistema DS-OCDMA Asíncrono . . . . . . . . . . . . . . . 33

2.7. Función de Distribución de Probabilidad de que $M_{B 1}$ chips interferentes sobrelapen el chip de datos . . . . . . . . . . . . . . . 36

2.8. Resultados espectrales para un thresholder basado en HNLF de un pulso decodificado incorrectamente (línea negra) y uno decodificado correctamente (línea gris) y la respuesta del filtro (línea a trazos)[11].

2.9. Thresholder óptico . . . . . . . . . . . . . . . . .

2.10. a). Representación de la esfera de Poincare, b).Descripción del área que cubre la variación del ángulo de la señal interferente . . . . . . . . . .

2.11. Comparación del rendimiento entre los sistemas OCDMA con modulación a) DPSK y b) OOK. $B E R=1 \times 10^{-9}$. 1) Time gating ideal, solo un tiempo de chip $(\bar{\Gamma}=1)$. 2) Time gating no ideal, $5 \%$ del total de chips interferentes dentro de un tiempo de bit. 3) Time gating no ideal, pero empleando thresholding óptico con $G_{t h}=5 d B$. . . . . . .

2.12. Penalización de potencia MUI (dB) vs. relación de crosstalk $10 \log _{10}(\xi)$ para diferente número de usuarios totales $(\mathrm{K})$. Solapamiento perfecto entre señales de datos y señales interferentes. . . . . . . . . . . . .

2.13. Penalización de potencia MUI (dB) frente a la relación de crosstalk $10 \log _{10}(\xi)$. Para 10 usuarios. Modelos síncrono, para diferentes valores

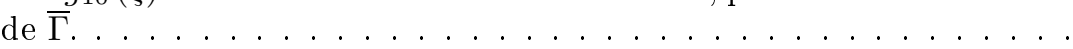

2.14. Penalización de potencia MUI (dB) frente a la relación de crosstalk $10 \log _{10}(\xi)$. Diferente número de usuarios $(\mathrm{K})$ en el sistema. Modelo asíncrono con $\mathrm{L}=6 \ldots \ldots \ldots \ldots \ldots \ldots \ldots \ldots$ 
2.15. Máximo Crosstalk permitido vs. número de usuarios (K). Las curvas corresponden con diferentes valores de razón de $\mathrm{L}\left(L=\frac{T_{c}}{\sigma_{c}}\right)$ para el

2.16. Máximo número de usuarios posibles (K) vs. Razón de $\mathrm{L}\left(\dot{L}=\frac{T_{c}}{\sigma_{c}}\right)$ para el modelo asíncrono. Se usa el Crosstalk $\left(10 \log _{10}(\xi)\right)$ como parámetro.

2.17. Penalización de potencia MUI (dB) vs. relación de crosstalk $10 \log _{10}(\xi)$. 10 usuarios. Modelo síncrono para diferentes valores de ganancia de thresholding $\left(G_{t h}\right) \ldots \ldots \ldots \ldots \ldots \ldots$

2.18. Penalización de potencia MUI (dB) vs. relación de crosstalk $10 \log _{10}(\xi)$. 10 usuarios. Modelo síncrono para diferentes valores de $G_{t h}$ con un $\bar{\Gamma}=8.50$

2.19. Penalización de potencia $(\mathrm{dB})$ frente a relación de crosstalk $10 \log _{10}(\xi)$. 10 usuarios. Modelo síncrono para diferentes valores de $\bar{\Gamma}$, con $G_{t h}=$ $10 d B$.

3.1. Representación esquemática del principio de operación de una FBG

3.2. Descomposición de una FBG en términos de múltiples matrices fundamentales [61].

3.3. Perfiles típicos de FBGs para diferentes índices de refracción: a) uniforme, b) apodizada con variación del índice DC, c) apodizada sin variación del índice DC, d) Con chirp, e) Desplazada en fase, y f) Superestructurada [61].

3.4. Feedback Shift Register correspondiente al polinomio primitivo $h(x)$ de la expresión 3.16.

3.5. Tecnología de fabricación basada en máscara de Fase, [70]. . . . . . . . 66

3.6. Perfiles del índice de refracción de las SSFBGs. . . . . . . . . . . 67

3.7. Espectros de la SSFBG para un diseño con perfil uniforme (azul) y perfil gausiano (rojo) . . . . . . . . . . . . . . . 68

3.8. Diagrama de bloques básico del sistema OCDMA. . . . . . . . . . . 69

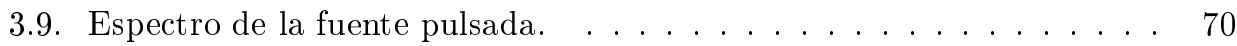

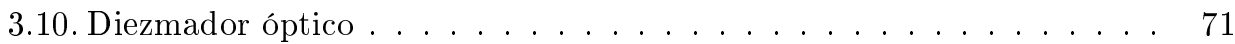

3.11. Señal de la fuente MLLD a $1.25 \mathrm{GHz} \ldots \ldots \ldots \ldots \ldots \ldots$

3.12. Sistema OCDMA básico con SSFBG . . . . . . . . . . . . 71

3.13. Simulación de la respuesta impulsiva de la SSFBG codificadora. . . . . 72

3.14. Medida de la respuesta impulsiva con el CSA . . . . . . . . . . . . 73

3.15. Pérdidas de inserción introducidas por una SSFBG codificadora. . . . 74

3.16. Salida del decodificador. (azul) Decodificada con código correcto, (rojo) con código incorrecto.

3.17. Señal decodificada, medida con el CSA. (azul) Decodificada correctamente, (rojo) Con el decodificador incorrecto. . . . . . . . . . . . .

3.18. Efecto del filtrado sobre la señal decodificada. $30 \mathrm{GHz}$ (traza roja), 12.5 $\mathrm{GHz}$ (traza azul) y $2.5 \mathrm{GHz}$ (traza violeta) . . . . . . . . . . .

3.19. Variación de la longitud de onda con la temperatura en una SSFBG

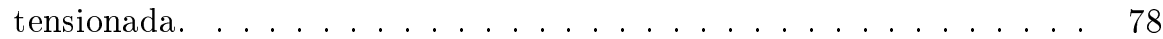

3.20. Diagrama de la Caja Controladora de Temperatura. . . . . . . . . . 79

3.21. SSFBG simplificada . . . . . . . . . . . . . . . . 80 
3.22. Curva de eficiencia vs. $N \Delta \phi_{c o / d e c o} \ldots \ldots \ldots \ldots \ldots \ldots \ldots \ldots$

3.23. Espectros de las SSFBGs. $1 \mathrm{~mm}$ (izq), $0,6 \mathrm{~mm}$ (der) . . . . . . . . 83

3.24. Curvas de eficiencia vs. Desintonía en longitud de onda. SSFBGs de $1 \mathrm{~mm}$ (rojo), de $0.6 \mathrm{~mm}$ (negro) . . . . . . . . . . . . . 84

3.25. Multiplexación por variación en temperatura. . . . . . . . . . . 85

3.26. Señal decodificada por el receptor con el decodificador sintonizado a $\lambda_{2}$ desde los tres diferentes transmisores. a) Transmisor @ $\lambda_{2}$ activo. b) Transmisor @ $\lambda_{1}$ activo. c) Transmisor $@ \lambda_{3}$ activo. .......... . 86

3.27. Potencia pico-pico máxima normalizada detectada después de decodificar barriendo en longitud de onda. Transmisores a $\lambda_{1}, \lambda_{2} y \lambda_{3}$ (espaciado de $\sim 50 \mathrm{pm}$ ) fueron activados consecutivamente. (a), (b) y (c) corresponden a las ventanas de la figura $3.26 \ldots \ldots \ldots . \ldots . \ldots 87$

4.1. Degradación de potencia en SSFBGs de alta reflectividad . . . . . . 90

4.2. Efecto de múltiples reflexiones en SSFBGs de alta reflectividad . . . . 91

4.3. Espectros de SSFBG para tres valores diferentes de reflectividad y sus respectivas respuestas impulsivas normalizadas. a). SSFBG-LR, b) SSFBG-MR, c) SSFBG-HR . . . . . . . . . . . . . . . . 93

4.4. Diferentes perfiles del Îndice de Refracción usados en [76]. . . . . . . . 94

4.5. Pico de autocorrelación, $\frac{P}{W}$ y $\frac{P}{C}$ Vs, índice de refracción [76]. . . . . . 95

4.6. Modelo discreto de una FBG, Propagación de campos hacia adelante $\left(R_{j}\right)$ y en reflexión $\left(S_{j}\right)$ asociados con cada una de las franjas del dibujo. 96

4.7. Diagrama de flujo del método estándar de diseño . . . . . . . . . . 98

4.8. Diagrama de flujo usando para el diseño el método de síntesis. . . . . 98

4.9. Coeficiente de Acoplamiento Complejo (q(z)). a) método estándar, y b) obtenida mediante el método de síntesis DLP. . . . . . . . . . . . 99

4.10. Respuesta impulsiva obtenida a partir de la función $\mathrm{q}(\mathrm{z})$ sintetizada. 100

4.11. Perfiles del coeficiente de acoplamiento complejo para una pareja codificador/decodificador basados en SSFBGs sintetizadas . . . . . . . . 101

4.12. función $q(z)$ sintetizada antes y después de discretizar. . . . . . . . 102

4.13. Efecto del incremento de la reflectividad sobre la respuesta impulsiva. $\left.a) . \Delta n=3 \times 10^{-5}(S S F B G-L R), b\right) . \Delta n=5 \times 10^{-5}(S S F B G-$ $\left.M R 1), c) . \Delta n=7 \times 10^{-5}(S S F B G-M R 2), d\right) . \Delta n=9 \times 10^{-5}(S S F B G-$ $H R) \ldots \ldots \ldots \ldots \ldots \ldots \ldots \ldots \ldots$

4.14. Espectros de las SSFBGs fabricadas, alta y baja reflectividad y con la función q sintetizada. . . . . . . . . . . . . . . . . . . . 104

4.15. Montaje para medir la respuesta impulsiva de las SSFBGs. . . . . . 105

4.16. Señales codificada con cada una de las SSFBGs construidas . . . . . 105

4.17. Respuesta impulsiva de la SSFBG codificadora diseñada mediante síntesis, obtenida con el OVA . . . . . . . . . . . . . . . 106

4.18. Señales Decodificadas con el código correcto y con un decodificador incorrecto para cada tipo de SSFBG . . . . . . . . . . . . 107

5.1. Nodo basado en etiquetas ópticas . . . . . . . . . . . . . . 110

5.2. Diagrama del modelo de codificador/decodificador basado en SSFBG realizado en VPI. . . . . . . . . . . . . . . . . . . . . . . . . . . 114 
5.3. Resultados del primer salto. 1 pareja cod/decodificador. $\mathrm{AB}=30 \mathrm{GHz}$. Matlab (izq), VPI (der). . . . . . . . . . . . . . . . . . 115

5.4. Resultados del segundo salto. 2 parejas cod/decodificador. $\mathrm{AB}=30 \mathrm{GHz}$. Matlab (izq), VPI (der) . . . . . . . . . . . . . . . . 116

5.5. Resultados del tercer salto. 3 parejas cod/decodificador. . . . . . . . . 117

5.6. Resultados del cuarto salto. 4 parejas cod/decodificador. . . . . . . . 118

5.7. Montaje en laboratorio de la cascada de 8 SSFBGs . . . . . . . . . . . 119

5.8. Diagrama del experimento. 4 procesos de codificación y decodificación en cascada, basados en dispositivos SSFBG. . . . . . . . . . . . . . . 119

5.9. Señal ACP y de correlación cruzada medida en los puntos M1, M2 y M3.121

5.10. Señal ACP y de correlación cruzada medida en el punto M4. . . . . . 122

5.11. Señal ACP y de correlación cruzada medidas en los puntos M1 ,M2 y M3, empleando un detector con ancho de banda de $2.5 \mathrm{GHz}$. . . . . . 122

5.12. Espectros de los 4 códigos de las 4 nuevas parejas de E/D's. . . . . . 123

5.13. Señal ACP y de correlación cruzada medida en los puntos M1, M2 y M3 cuando se usan códigos diferentes en cada salto. . . . . . . . . .

5.14. Señales codificadas. Arriba SSFBGs con chip de $0.6 \mathrm{~mm}\left(T_{c} \approx 6 p s\right)$ y pulsos de 3,5 y 6 ps. Abajo SSFBGs con chip de $1 \mathrm{~mm}\left(T_{c}=9,6 p s\right)$ y pulsos de 3,5 y 8 ps.

5.15. Señal de autocorrelación (azul) y correlación cruzada (rojo) para un sistema DS-OCDMA basado en SSFBGs con $L_{c}=0,6 \mathrm{~mm}$ y pulsos de entrada con $t_{p}=3 p s$ (Izq) y $t_{p}=6 p s$ (Der). Las distancias entre TX y RX van desde 0 hasta $8.4 \mathrm{~km} . \ldots \ldots \ldots \ldots \ldots$. . . . . . .

5.16. Picos de Autocorrelación y correlación cruzada para los códigos 2 (Izq) y 3 (Der) después de recorrer desde 0 hasta $8.4 \mathrm{Km} . L_{c}=1 \mathrm{~mm}$. . . .

5.17. Señal decodificada en un sistema DS-OCDMA basado en SSFBGs de $1 \mathrm{~mm}$ de chip con pulsos de entrada de $t_{p}=3 p s$ (izq) y $t_{p}=8 p s$ (der). Las distancias entre TX y RX van desde 0 hasta $8.4 \mathrm{~km}$. . . . . . . .

5.18. Curvas de Ensanchamiento vs. Longitud y de Decremento del pico de potencia vs. Longitud cuando se propaga la señal a través de una fibra óptica monomodo con un parámetro dispersión de $16 \mathrm{ps} \cdot \mathrm{nm} / \mathrm{km}$. . .

5.19. Diagrama de bloques del montaje realizado para medir el efecto de dispersión. . . . . . . . . . . . . . . . .

5.20. Comparación entre los resultados experimentales y los simulados para $\mathrm{E} / \mathrm{Ds}$ con $l_{c}=0,6 m m$ y $t_{p}=5 p s \ldots \ldots \ldots \ldots \ldots \ldots$

5.21. Comparación entre los resultados experimentales y los simulados para $\mathrm{E} / \mathrm{Ds}$ con $l_{c}=1 m m$ y $t_{p}=5 p s \ldots \ldots \ldots \ldots$

6.1. Diagrama de bloques para medir la separación mínima de frecuencia entre canales y el efecto de batido en campo. . . . . . . . . . . . . 141

6.2. Espectros de los canales de los AWG's utilizados. . . . . . . . . . . . 142

6.3. Posición inicial del los espectros del canal de datos y el canal interferente (Izq). Batido de la señal de datos e interferente (Der). $\Delta \lambda=168 \mathrm{pm} .143$

6.4. Canal de datos (a) e interferente en el dominio temporal (b). . . . . . 143

6.5. Espectros del canal de datos e interferente (Izq) y batido de la señal de datos e interferente (Der). $\Delta \lambda=12 p m \ldots \ldots \ldots \ldots$ 
6.6. Espectros del canal de datos e interferente (Izq) y batido de la señal de datos e interferente (Der). $\Delta \lambda=264 p m \ldots \ldots \ldots \ldots \ldots$

6.7. Espectros del canal de datos e interferente (Izq) y batido de la señal de datos e interferente (Der). a). $\Delta \lambda=492 \mathrm{pm}, \mathrm{b}) \cdot \Delta \lambda=570 \mathrm{pm}, \mathrm{c}$ ) $\cdot \Delta \lambda=$ $720 \mathrm{pm}, \mathrm{d}) . \Delta \lambda=810 \mathrm{pm} \ldots \ldots \ldots \ldots \ldots \ldots \ldots$

6.8. Penalización en la apertura de ojo cuando existe ruido de batido producido por la interferencia entre canales adyacentes. . . . . . . . . . 147

6.9. Diagrama de Bloques del Sistema Incoherente con dos códigos . . . . . 152

6.10. Montaje en laboratorio del Sistema Incoherente . . . . . . . . . . 153

6.11. Espectro de los 8 canales modulados a 1.25 Gbps. . . . . . . . . . . 153

6.12. Espectro de los canales de los AWGs asignados a cada código . . . . . 154

6.13. Secuencia de bits periódica, codificada con la matriz de código 9 y 22 , y decodificada. . . . . . . . . . . . . . . . 155

6.14. a). Secuencia de bits aleatoria, b). Codificada con la matriz de código 9 más canal interferente en frecuencia, c) Señales interferentes (codificada con M22 más canal interferente en frecuencia) y d) Decodificada. . . . 157

6.15. a). Codificada con la matriz de código 9 más canales interferentes en frecuencia y tiempo, b) Señales interferentes (codificada con M22 más canales interferentes en frecuencia y tiempo), c) Decodificada y d) Correlación cruzada. . . . . . . . . . . . . . . . . 15 



\section{Índice de cuadros}

2.1. Crosstalk para obtener una penalización máxima de $1 \mathrm{~dB}$, para diferentes números de usuarios y sistema síncrono. . . . . . . . . . . . 45

2.2. Crosstalk según número de usuarios para obtener una penalización máxima de $1 \mathrm{~dB}$ con $\mathrm{L}=6 \ldots \ldots \ldots \ldots$. . . . . . . . . . 4 47

3.1. Tabla de valores de $M_{m}$ y $R_{\max } \ldots \ldots \ldots \ldots \ldots \ldots$. . . . . 64

3.2. 5 primeros valores de un familia de secuencias Gold para $N=63 \ldots \quad$. 65

5.1. Funciones de transferencia para las mediciones usando la misma palabra código. . . . . . . . . . . . . . . . . . . . 120

5.2. códigos Gold usados para construir las 4 nuevas parejas de SSFBG . . 123

5.3. Resumen del Factor de Ensanchamiento (FE) del pulso y del decremento de la amplitud del pico de potencia (D) causado por efecto de la dispersión, para señales de entrada de 3 y 6 ps. $l_{c}=0,6 \mathrm{~mm} \ldots$. .

5.4. Resumen del factor de ensanchamiento (FE) del pulso y del decremento de la amplitud del pico de potencia (D) causado por efecto de la dispersión, para señales de entrada de 3 y 8 ps. $l_{c}=1 \mathrm{~mm} \ldots \ldots \ldots$.

5.5. Resultados experimentales vs. los de la simulación, del factor de ensanchamiento (FE) del pulso y del decremento de la amplitud del pico de potencia (D) causado por efecto de la dispersión. $l_{c}=0,6 \mathrm{~mm} \ldots \ldots$.

5.6. Resultados experimentales vs. los de la simulación, del factor ensanchamiento (FE) del pulso y del decremento de la amplitud del pico de potencia (D) causado por efecto de la dispersión. $l_{c}=1 \mathrm{~mm} \ldots \ldots$

6.1. Reducción del ruido de batido (R) a medida que se separan los canales en longitud de onda. . . . . . . . . . . . . . . . . . . . 145

6.2. Matrices código generadas a partir de las reglas de Golomb . . . . . 149

6.3. Matrices de los códigos M9 y M22. . . . . . . . . . . . . . . . 152 



\section{Capítulo 1}

\section{INTRODUCCIÓN}

\subsection{Introducción a los Sistemas OCDMA}

Uno de los puntos neurálgicos para mejorar el rendimiento de las redes ópticas actuales, esta relacionado con la forma como los usuarios accesan a la red. Cuando nos referimos a usuarios estamos hablando no solo del usuario particular que tiene un punto de conexión en su casa, si no incluimos también los grandes proveedores de servicio. Las dos tecnologías más conocidas en la actualidad para dar acceso a los usuarios y brindar solución a la demanda de ancho de banda, son WDMA (Wavelength Division Multiple Access) y OTDMA (Optical Time Division Multiple Access). Estas tecnologías han sido estudiadas durante años con resultados positivos, que han llevado incluso a que se presenten propuestas de sistemas híbridos de estas tecnologías. No obstante desde hace más de una década se iniciaron las investigaciones en una tecnología alternativa, conocida como OCDMA (Optical Code Division Multiple Access), la cual tiene entre sus ventajas poder trabajar de manera complementaria con las tecnologías existentes. OCDMA surge a partir de su similar en comunicaciones móviles, conocida como CDMA (Code Division Multiple Access), técnica que permite que usuarios independientes compartan un mismo ancho de banda, siendo direccionados gracias al uso de un código asignado a cada uno. La codificación puede ser realizada en el dominio del tiempo (DS-CDMA, Direct Sequence CDMA) o de la frecuencia (FHCDMA, Frequency Hopping CDMA). CDMA ha sido llevado al entorno óptico por los beneficios que puede aportar, entre ellos; Alta conectividad, uso más flexible del ancho de banda, alta granularidad y escalabilidad, mejorando; el crosstalk, acceso asincrónico y potenciando las mejoras en seguridad del sistema [1].

En este capítulo de introducción se desglosa someramente la estructura de un sistema OCDMA así como el funcionamiento de cada uno de los bloques que lo componen. También se describen los dispositivos que pueden ser usados como codificadores y decodificares en este tipo de tecnología. Posteriormente se da una justificación de la tesis en general, se plantean los objetivos buscados con el presente trabajo y finalmente la forma como se estructurará el presente libro. 


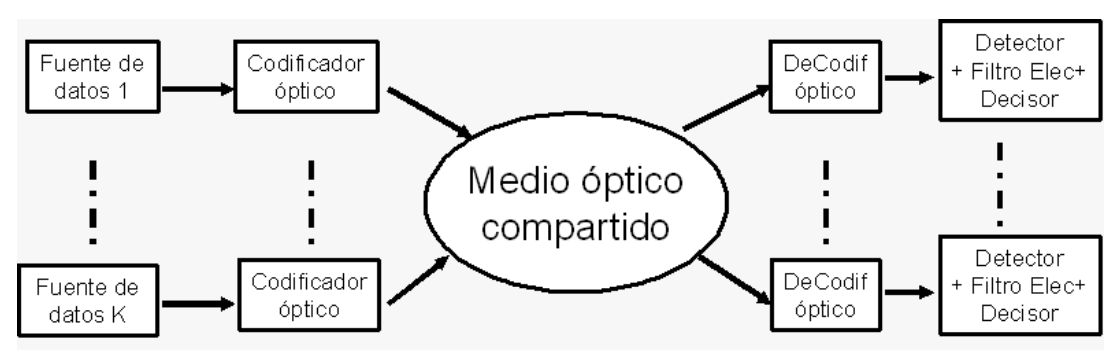

Figura 1.1: Diagrama de Bloques de un sistema OCDMA típico.

\subsubsection{Sistemas OCDMA}

Un típico sistema OCDMA esta constituido básicamente por una fuente de información digital óptica, seguida de un codificador que mapea cada bit de salida en una secuencia con tasa binaria más alta y que se acopla a un canal de fibra. En el receptor la secuencia de pulsos ópticos debe ser comparada con una replica "almacenada" de si misma (proceso de correlación) y un nivel de umbral para la recuperación de los datos.

En los sistemas OCDMA hay K usuarios, incorrelados en su generación de tráfico, cada uno con un par Transmisor/Receptor interconectados mediante un medio óptico compartido. La figura 1.1 muestra una configuración de red en estrella, en donde cada fuente de datos se codifica con una secuencia única que solo podrá entender al otro extremo el receptor que posea dicha secuencia. Como se puede observar todo el procesamiento que se hace de la señal es óptico y por lo tanto se pueden realizar transmisiones asincrónicas sin necesidad de ningún dispositivo electrónico complejo. Esto potencialmente eleva la seguridad de la información, mejora la eficiencia espectral y la asignación de ancho de banda por demanda y proporciona un control de calidad de servicio mejor que las otras técnicas de acceso.

Uno de los objetivos básicos de OCDMA es poder extraer la información del usuario objetivo, aun en presencia de las señales de todos los demás usuarios. Para ello cada código debe cumplir dos condiciones [2, 3]:

1. Ser fácilmente distinguible de una versión desplazada de si misma.

2. Ser fácilmente distinguible de todas las posibles otras secuencias que se hallen en el sistema.

Para cumplir estas dos condiciones se usan códigos con excelentes propiedades de autocorrelación y correlación cruzada, es decir, que la autocorrelación exhiba un pico destacado mientras que la correlación cruzada entre dos secuencias, permanezca siempre baja.

En DS-OCDMA el codificador toma el flujo de datos de cada usuario y lo multiplica directamente por una secuencia o código único, de tal forma que cuando se transmite un bit "1" se envía a la red el código y cuando llega un bit "0" no se envía nada (en otros casos también se puede codificar el "0"), la tasa de bit del código se le llama tasa de chip, y supera en gran medida a la de la señal original. Nótese que en este sistema, durante el proceso de codificación, no existe un ensanchamiento del espectro, si no un ensanchamiento temporal. 
Puesto que el período de bit de la señal de información $\left(T_{b}\right)$ es $\mathrm{N}$ veces mayor que el período de chip del código $\left(T_{c}\right)$, el ancho de banda de la señal resultante $\left(B W_{R}\right)$ es $\mathrm{N}$ veces mayor que el de la señal original $\left(B W_{b}\right)$ :

$$
\begin{aligned}
T_{b} & =N T_{c} \\
B W_{b} & =\frac{1}{T_{b}}
\end{aligned}
$$

De donde podemos deducir que

$$
B W_{R}=\frac{1}{T_{c}}=\frac{N}{T_{b}}=N \cdot B W_{b}
$$

Esto implica que el máximo ancho de banda que puede utilizar el usuario es una n-ésima parte del ancho de banda total.

Las señales codificadas son aplicadas a una fibra óptica a través de un acoplador $K \times K$ de tal manera que los usuarios comparten el medio con otros usuarios que se encuentren transmitiendo en ese mismo instante.

El decodificador por su parte, es una estructura simétrica en términos temporales y de fase óptica a la codificadora, la correspondencia entre líneas de distintos retardos y sus valores de desfase óptico son conjugados. Si el bloque decodificador es el correcto a su salida obtendremos la señal original más el ruido de interferencia producido por los demás usuarios presentes en el sistema, si no es el correcto sólo se obtendrá ruido. La influencia del ruido sobre la señal dependerá del tipo de código usado, del grado de coincidencia temporal que tengan las señales de los demás usuarios y del tipo de sistema DS-OCDMA que se este considerando, el cual puede ser de dos clases; coherente si se codifica la señal en campo ó Incoherente si se codifica la señal sólo en potencia.

Existen múltiples esquemas de sistemas OCDMA que pueden ser resumidos como se muestra en la figura 1.2:

El esquema TS (time spreading) incoherente es sencillo de implementar, sin embargo, al trabajar con códigos unipolares, se tiene un conjunto de códigos disponibles muy pequeño y muy pocos "1"s en la secuencia de código. Por lo tanto tienen una pobre correlación y es difícil encontrar un número suficiente de códigos para redes prácticas. Por ejemplo, un conjunto de códigos que tenga más de 32 palabras código requiere cerca de 1000 chips en la secuencia.

En sistemas OCDMA 2D, la codificación se hace tanto en el dominio óptico como en el dominio temporal. Con este esquema se mejoran las propiedades de correlación y al adicionar otra dimensión se aumenta el número de códigos. No obstante OCDMA 2D ocupa un gran ancho de banda y por lo tanto su eficiencia espectral no es la mejor, además se ve fuertemente afectado por la dispersión cromática $[4,5,6]$.

Los sistemas ópticos OCDMA coherentes tienen un rendimiento superior al de los incoherentes, debido a que usan códigos bipolares. Los códigos bipolares comparados con los unipolares tienen mejores características de correlación y además se consiguen conjuntos de códigos más numerosos. Trabajar con este tipo de códigos permite tener una mayor cantidad de usuarios, conseguir tasas de error de bit mejores y obtener una mejor eficiencia espectral. Sin embargo, estos sistemas están afectados por el ruido de 


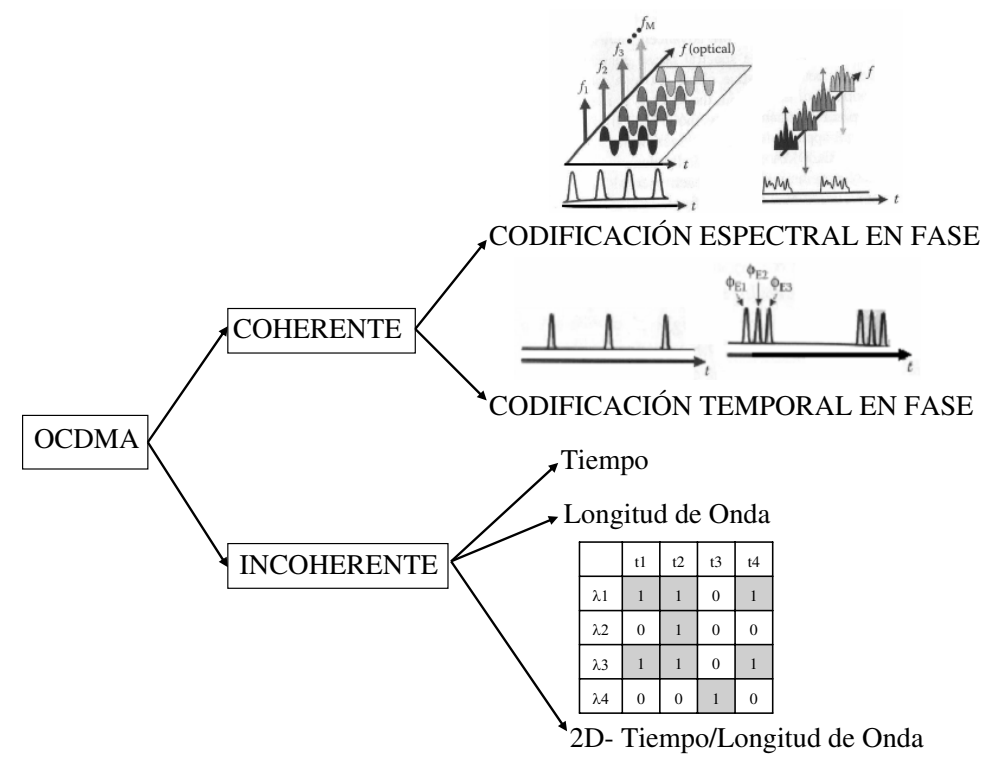

Figura 1.2: Esquemas de sistemas OCDMA

batido, el cual sólo puede llegar a ser mitigado en la práctica mediante correlaciones cruzadas muy bajas, para lo que se requiere que la longitud de los códigos usados sea la mayor posible. En general esto dependerá del tipo de tecnología que se use para su implementación, por ejemplo usando redes de difracción de Bragg se han conseguido códigos de hasta 511 chips [7] o mediante SLM (Spatial Light Modulator) de cristal liquido códigos de hasta 128 chips [8].

La codificación en tiempo requiere por su propia naturaleza el uso de pulsos ultracortos, por lo que la generación y detección de las señales no es fácil. Además la señal se vera afectada por la dispersión y los efectos no lineales durante la transmisión. Para conseguir un rendimiento adecuado, en el receptor óptico, además de hacerse la transducción de la señal óptica a eléctrica, se deben implementar técnicas para distinguir la señal decodificada de la interferencia de los múltiples usuario (MUI). Las dos técnicas más habituales son; el time gating y el thresholding. El time gating consiste en el uso de un filtro de ancho de banda muy grande que pueda discriminar el pulso que lleva la información en el dominio del tiempo, que a su vez es muy estrecho. El time gating tiene el inconveniente de requerir sincronización [9]. El thresholding se basa en el hecho de que el pulso recuperado con un decodificador correcto tendrá una potencia superior al de la interferencia, de tal forma que ese pulso podrá ser discriminado si supera un determinado nivel umbral de potencia óptica. Normalmente el thresholding se implementa mediante el uso de dispositivos no lineales como los dispositivos basados en guías PPLN (Periodically Poled Litio Niobate)[10], o las fibras de alta no linealidad (HNLF), los cuales son buenos candidatos para ser usados en estas aplicaciones [11]. 


\subsubsection{Dispositivos Cod/Decodificadores}

Para llevar a cabo la codificación/decodificación las tecnologías que se pueden usar son muy diversas y han venido evolucionando gracias a las nuevas técnicas de fabricación que se pueden usar en dispositivos ópticos.

Los primeros elementos usados para realizar los procesos de codificación fueron simplemente fibras ópticas de longitudes apropiadas y que actuaban como líneas de retardo temporal, estas líneas manipulaban los bits modificando su instante de llegada y en algunas ocasiones intencionalmente su fase [12]. El problema de usar las fibras ópticas como elemento codificador es que tienen una escalabilidad limitada y además es muy difícil lograr y mantener la precisión adecuada de su longitud física.

Una técnica más reciente utiliza dispositivos integrados ópticos conocidos como PLC (planar lightwave circuits) los cuales hacen de esta alternativa una opción interesante por ser más flexible, al permitir codificadores y decodificadores que puedan ser sintonizados a una longitud de onda determinada. Entre los dispositivos PLC más conocidos y usados en OCDMA están los AWGs (Arrayed Waveguide Gratings) [13]. Estos dispositivos aun son costosos, no obstante, su uso esta cada vez más difundido en aplicaciones que usen códigos de dos dimensiones[14, 15].

Un dispositivo que esta recibiendo atención recientemente por parte de diferentes grupos, es el SLM (spatial light modulator). Este dispositivo realiza la codificación modulando la intensidad del haz luminoso. Con él es posible implementar códigos unipolares o multipolares ya que también es posible modular la fase, o si se desea, ambas características a la vez amplitud y fase [16].

Otros dispositivos con los cuales se puede realizar los procesos de codificación y decodificación en sistemas OCDMA son los basados en redes de difracción de Bragg (FBG - Fiber Bragg Gratings). La red de difracción es una fibra óptica en la cual se ha introducido una variación periódica del índice de refracción $(\Delta n)$. Esta variación es pequeña con respecto al índice medio de la fibra. Se fabrican exponiendo la fibra junto con un patrón o mascara a los rayos ultravioleta, lo cual produce la variación del índice de refracción. Al estar construidas sobre fibra óptica brindan compatibilidad total con el sistema. Adicionalmente estas estructuras son relativamente fáciles de construir y por lo mismo económicas.

Existen unas FBGs más específicas conocidas como SSFBG (SuperStructured Fiber Bragg Gratings). Una SSFBG se define como una red de difracción fabricada con una exposición de luz modulada a lo largo de su longitud, es decir, que en su fabricación además de usarse una mascara, se modula la luz con la cual es iluminada tanto en amplitud como en fase. El uso de las SSFBG ha sido demostrado ya por diferentes autores $[17,1,5]$.

La figura 1.3 muestra la estructura del sistema cuando se emplean SSFBGs. Se observa que la señal de entrada es reflejada en una SSFBG según el perfil del índice de refracción que haya sido implementado en la misma, de esta forma se ocasionan retardos y variaciones de fase, obteniéndose a la salida una señal codificada. Para su posterior decodificación la señal se aplica a una SSFBG de características conjugadas a la primera, que al reflejar la señal devuelve el pulso original. 


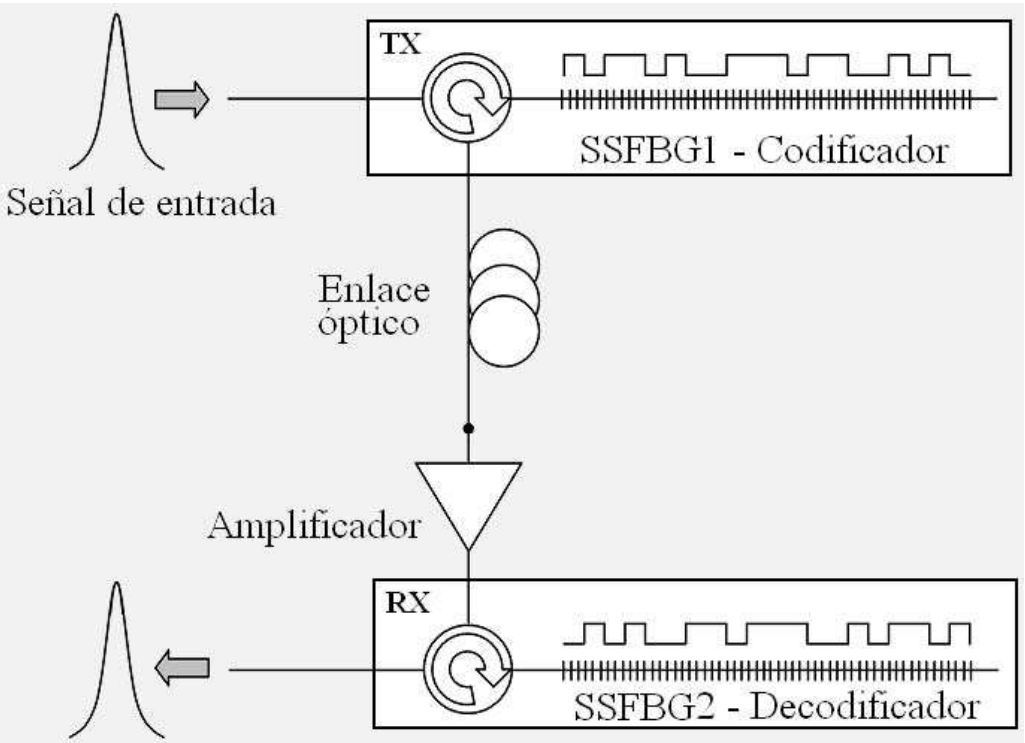

Señal de salida

Figura 1.3: Montaje básico para realizar los procesos de codificación y decodificación con SSFBG

\subsubsection{Aplicaciones}

\subsubsection{Técnica de Acceso al Medio.}

OCDMA esta basado sobre el principio de mapear la información sobre un código particular que permite identificar o direccionar usuarios de acuerdo a una relación código-usuario. De acuerdo a esto, OCDMA fue inicialmente propuesto para la implementación de broadcast LAN (Local Área Network) asíncrono ultrarápido.

Existen tres potenciales ventajas que hacen OCDMA una atractiva tecnología para ser implementada en redes LAN y redes PON (Passive Optical Network). Primero, OCDMA ofrece una mayor cantidad de canales que la división espectral ofrecida por WDMA. Segundo, la transmisión asíncrona simplifica el control de acceso al medio con respecto al usado por ejemplo en TDMA. Finalmente, tráfico de diferentes clases puede ser implementado usando diferentes longitudes de código simultáneamente. Una motivación adicional para implementar OCDMA sobre LAN es que en la actualidad los patrones de tráfico son del tipo ráfaga, y la probabilidad de que todos los usuarios estén accediendo al mismo tiempo es relativamente baja, lo cual favorece técnicas como OCDMA.

Si bien es cierto que DWDM (Dense WDM) puede ofrecer el mismo número de canales que OCDMA, en redes LAN y aplicaciones sencillas, el acceso al medio no puede ser juzgado sólo por dicho parámetro, sino que para seleccionar una técnica de acceso al medio también se debe tener en cuenta la simplicidad, transmisión asíncrona y diferenciación en la calidad de servicio. Razones como las anteriores, son las que 
hacen de OCDMA una prometedora tecnología para brindar el acceso a redes PON $[18,19,20,21]$.

La aplicación más conocida de OCDMA como técnica de acceso a redes es la implementada en redes PON donde se usa una topología en árbol con splitter pasivos. Cada unidad óptica de red (ONU) contiene una pareja cod/decodificador con un único código fijo. El terminal de línea óptico (OLT) puede contener todos los pares cod/decodificadores requeridos para la comunicación con cada ONU [20] o un pequeño número de pares cod/decodificadores sintonizables. En OCDMA PON no sucede lo mismo que en las redes LAN, es decir, no existe un broadcast, porque la señal transmitida por una ONU no llega a ninguna otra ONU. Otras posibles aplicaciones de OCDMA como acceso al medio se han enunciado en [20] donde se proponen redes híbridas OCDMA/WDM o quizás más ambiciosa la del mapeo de direcciones IP universales en códigos OCDMA [22].

Gracias a las ventajas ofrecidas por OCDMA es posible soportar otras aplicaciones, entre ellas, VPN (Virtual Private Network) ópticas a nivel metropolitano y radio sobre fibra, las cuales explicaremos brevemente.

VPN Óptica - Una red metropolitana óptica puede proporcionar caminos ópticos para conexiones VPN. Estos enlaces implican una multitud de señales OCDMA que son multiplexadas y demultiplexadas en los puntos finales. El objetivo más importante de las redes VPN es el de ofrecer conexiones seguras sobre una plataforma insegura. Las señales OCDMA ofrecen seguridad adicional y pueden ser decodificada solo en el punto final. El uso de OCDMA en VPN totalmente ópticas simplifica el diseño de la red reemplazando multiplexación electrónica por divisiones y combinaciones ópticas. La estructura en árbol de la red puede ser usada para establecer VPN multipunto [23].

Radio sobre fibra - En [24] se propone usar una red óptica y mapear individualmente los canales de radio sobre canales OCDMA para interconectar estaciones base inalámbricas. Esta aplicación se puede llevar a cabo gracias a la gran disponibilidad de canales que se obtiene con OCDMA.

\subsubsection{Codificación Óptica}

En codificación óptica, los códigos pueden corresponder a un nuevo nivel de información de la red en lugar de una identificación de usuario. Por ejemplo en MPLS (Multi-Protocol Label Switching) una ruta óptica puede ser indicada mediante información codificada. Los códigos también pueden representar mensajes de control, señalización, detección de errores o mantenimiento en redes de conmutación de ráfagas ópticas (OBS). En tales aplicaciones, se consigue una forma de procesamiento de la información de red de forma óptica. Esto significa traer operaciones de red al medio óptico lo cual permite liberarse del procesamiento electrónico. Con los códigos ópticos se tiene la gran ventaja de estar limitado únicamente por la velocidad de procesamiento, el cual no es más que el tiempo que se demora la luz en recorrer los dispositivos cod/decodificador. Las aplicaciones más importantes de la codificación óptica se resumen a continuación:

Conmutación y enrutamiento totalmente óptico - La conmutación óptica de etiquetas se encuentra entre las implementaciones más prometedoras que se pueden 
realizar con la codificación óptica. En una red de conmutación de etiquetas basadas en códigos ópticos, los pulsos codificados son sumados a un paquete de longitud fija a manera de encabezado, el cual especificara la ruta o LSP (Label Switched Path) que seguirá dicho paquete. En un conmutador de etiqueta óptica codificada (OCLS), cada puerto de salida es controlado por un dispositivo conmutador que analiza cada encabezado, llamado compuerta de código óptico (OC-gate). Cada OC-gate permite la salida de paquetes que tengan encabezados específicos.

En un OCLS se separan los datos de la etiqueta, los datos son enviados a un buffer mientras la etiqueta es enviada a un banco de OC-gates. Solo por uno de los OC-gates se obtendrá un pico de autocorrelación en los demás se obtendrá ruido. Se determina cual fue el OC-gate por el que se obtuvo el pico de autocorrelación, gracias a ello se determina cual será la nueva ruta, y por lo tanto se asigna la nueva etiqueta [25, 26].

Señalización de control óptico y OBS - Los beneficios de la codificación óptica radican en que es posible empaquetar toda la información en un solo pulso codificado mejor que con una longitud de onda. De la misma manera que una etiqueta óptica lleva la información de un paquete en particular, es posible codificar un pulso que lleva información de señalización. Dicha información puede ser del estado del enlace, de mantenimiento de algún equipo, disponibilidad de canales de comunicaciones o comandos de control para conmutadores ópticos. Dispositivos similares a los OC gates realizarían el procesamiento a velocidades ópticas. Con esta aplicación se reduciría el procesamiento electro-óptico y con ello el elevado número de paquetes de control. Un solo código podría contener gran cantidad de información de control y con los diferentes códigos disponibles es posible gestionar la red. En redes OBS los pulsos codificados con información de control seria los encargados de dar prioridad a ciertas ráfagas de tráfico. Encargarse de garantizar que exista el canal y el puerto durante el tiempo necesario para enviar las ráfagas [25].

Monitoreo de red y OTDR (Optical time-domain reflectometry) basados en códigos ópticos - el objetivo de un OTDR es monitorear la calidad de un tendido de fibra y detectar los fallos, en particular los cortes de fibra. Lo que se hace es enviar un pulso de señal y detectar el punto donde el pulso es reflejado al encontrar un corte en la fibra o un cambio drástico en el índice de refracción que produzca su reflexión. En enlaces punto a punto su uso es inmediato, no obstante en redes PON con enlaces punto multipunto es imposible determinar de que rama proviene el fallo después de que la señal ha pasado el punto de división, a menos que el monitoreo se hiciera desde cada ONU. En [27] se propone una forma para poder identificar la rama donde se encuentra la falla. Para ello cada rama de la red es equipada con dispositivos codificadores. Cada uno de estos dispositivos codifica el pulso enviado por el OTDR y lo devuelve hacia la central. En la central deberá haber un conmutador y un banco de decodificadores para identificar cual es la rama que presenta el fallo.

Multicasting todo óptico - La conmutación de etiquetas ópticas puede ser extendida a la implementación de multicast (MC) en redes con arquitectura en árbol. En esta aplicación los códigos ópticos identificarían a cada grupo MC así como a cada usuario final [28]. En una red con topología de árbol se implementa que cada MC sea habilitado por los conmutadores de etiquetas ópticas residentes en cada nodo, excepto los nodos finales. Los paquetes son etiquetados con un pulso codificado que indicara el grupo $\mathrm{MC}$, en los nodos conmutadores se reciben estas señales. Al igual 
que en la conmutación óptica se separan los datos de la etiqueta, se analiza la etiqueta y de acuerdo a tablas de enrutamiento se deciden que puertos son habilitados para enviar los paquetes de datos. De esta manera el paquete puede ser enviado a múltiples destinos a la vez consiguiendo un multicast de alta velocidad.

\subsection{Justificación}

Desde hace ya un par de décadas los servicios teleinformáticos vienen incrementado el consumo de recursos disponibles en la red, de manera casi exponencial. La justificación de dicho fenómeno se basa en dos hechos, uno el incremento de usuarios en la red y dos el índice de tráfico que es producido por los mismos. Para hacerse una idea, la cantidad de usuarios en Internet en el año 1995 era menor a 50 millones, en 2006 estaba alrededor de los 1245 millones y a marzo de 2008 ya alcanzaba el valor de 1408 millones de usuarios con un índice de tráfico del $80 \%{ }^{1}$. El tráfico, por su parte, ha pasado de estar centrado en el intercambio de pequeños archivos a ser hoy día un tráfico de datos de alto volumen generado por usuarios que descargan música, películas, etc, ya sea mediante redes peer to peer o mediante descargas directas. Este nuevo paradigma de red implica la necesidad de nuevas tecnologías que permitan además de optimizar el uso del ancho de banda disponible, realizar una adecuada diferenciación de la calidad de servicio de los usuarios que acceden a la red.

La optimización del uso del ancho de banda se da en todos los niveles de red, es decir, desde las redes troncales hasta los puntos de conexión a usuario, conocidos como redes de última milla. Sin ir más lejos, las redes de última milla han pasado de usar como medio de transmisión par trenzado de cobre en los inicios de la telefonía, a fibra óptica en la actualidad, pasando por el uso de cables coaxiales y soluciones inalámbricas. Aunque el uso de la fibra óptica no es aun generalizado, se considera que solo es una cuestión de tiempo para que al final los usuarios terminen todos interconectados mediante redes ópticas. Siendo entonces la fibra óptica el medio de transmisión con mejores perspectivas a futuro para ser utilizado como soluciones de última milla en redes de banda ancha, surge la necesidad de investigar la forma como mejor podemos llegar a aprovecharla.

Como ya decíamos al principio de este capítulo, uno de los puntos críticos para un uso óptimo del ancho de banda disponible en una red óptica estará determinado por la forma como se accede al medio. Existen tres técnicas para acceder al medio óptico, la más conocida es WDMA en donde a cada usuario le es asignada una longitud de onda para que transmita la información que desea. Con esta técnica se usa eficientemente el ancho de banda y se consiguen realizar transmisiones asíncronas[29, 30, 31]. Sin embargo el número de longitudes de onda disponibles esta limitado normalmente a valores inferiores a 20, siendo que en redes PON (Pasive Optical Networks) típicas, el número de usuarios ronda los 32 [32]. OTDMA por su parte utiliza multiplexación por división en tiempo para realizar el acceso a la red, con ella K slots de tiempo son asignados a $\mathrm{K}$ número de usuarios. No obstante, en esta técnica la tasa de bit esta limitada al ancho de banda de los dispositivos electrónicos, y además solo es posible su implementación en redes síncronas [32]. OCDMA es la tercera opción y se

\footnotetext{
${ }^{1}$ http://www.internetworldstats.com/stats.htm
} 
postula como una prometedora opción para ser usada como técnica de acceso en la siguiente generación de redes. Para hacer tal afirmación nos basamos en el hecho de que potencialmente OCDMA tendrá las terminales ópticas y unidades de red de más sencilla configuración y que no necesitaran sincronización electrónica. Además dentro de las grandes ventajas de OCDMA se encuentran [29, 33, 19, 2, 34, 35]:

- Todo el procesamiento de la señal se hace a nivel óptico.

- Transmisión asincrónica.

- Uso eficiente del ancho de banda

- Ancho de banda por demanda.

- Protocolos y Control de red simplificado.

- Flexibilidad y controlabilidad de la calidad de servicio.

Como se puede ver OCDMA es una tecnología bastante atractiva y que a pesar de su proyección y años de investigación aun tiene muchos aspectos por resolver. Con estos antecedentes en el año 2004 se presentó ante el Ministerio de Educación el proyecto titulado "Sistemas Ópticos con Multiplexación por División en Código (OCDMA) Empleando Redes de Difracción de Bragg Sobre Fibra y Filtros Planares AWG, (SODICO), para ser incluido dentro del plan de financiación de proyectos de I + D en el marco del Plan nacional de Investigación Científica, Desarrollo e Innovación Tecnológica 2004-2007. El presente trabajo se enmarca en dicho proyecto, cuyo objetivo principal es el de realizar un estudio completo de los sistemas OCDMA y contribuir con nuevas propuestas para la optimización del mismo.

En la actualidad OCDMA aun no ha sido implementado en sistemas comerciales, queda todavía un largo camino para que los sistemas OCDMA sean una realidad para los actuales y futuros usuarios de las redes ópticas. Redes del tipo FTTH (Fiber To The Home) o FTTC (Fiber To The Curb) serán en principio las más beneficiadas de los avances que se consigan en OCDMA[29, 20]. Sin olvidar que día a día surgen nuevas aplicaciones relacionadas con el procesamiento óptico de las señales, como por ejemplo, la capacidad de enrutamiento que se puede conseguir mediante la implementación de etiquetas ópticas[36]. Pero para conseguir soluciones basadas en OCDMA, se requiere dar solución a múltiples problemas que aun quedan por cubrir. Entre ellos se encuentran; complementar los modelos de ruido en sistemas OCDMA, optimizar el diseño y las características de los dispositivos usados para codificar y decodificar las señales, comprender el comportamiento de la señal procesada transmitiéndose por la fibra óptica, etc. Los anteriores no son si no una mínima muestra de los aspectos que faltan por resolver y que sin los cuales OCDMA seguirá estando en los escritorios de los grupos de investigación y no con los usuarios. En este contexto, el presente trabajo busca contribuir a la solución de algunos de los problemas mencionados, mediante un análisis teórico de los sistemas OCDMA y realizando propuestas con respecto al diseño y fabricación de los dispositivos cod/decodificadores cuya viabilidad queda demostrada teórica y experimentalmente. 


\subsection{Objetivos y Estructura de la Tesis}

Los objetivos generales de la tesis están centrados en hacer, primero un estudio teórico de los sistemas de Acceso Múltiple por División en Código, dentro del cual se dará especial énfasis al modelado del ruido presente en los sistemas OCDMA de tipo coherente. El segundo aspecto en el que nos concentraremos será en el diseño, simulación, fabricación y testeo de codificadores y decodificadores basados en redes de difracción de Bragg. Para conseguir estos objetivos generales, fue necesario desarrollar paso a paso objetivos específicos que nos permitieran conseguir las metas establecidas, y los cuales citamos a continuación:

- Proponer un modelo de ruido para sistemas de secuencia directa OCDMA de tipo coherente, que describa las diversas causas de limitación o degradación de la transmisión.

- Investigar y documentar las distintas técnicas de codificación/decodificación en redes y sistemas OCDMA, prestando especial interés a aquellas que utilizan o sean susceptibles de utilizar redes de difracción sobre fibra óptica y/o multiplexores AWG (Array Waveguide Gratings).

- Diseñar, fabricar y testear parejas codificador/decodificador para su empleo en redes OCDMA basados en redes de difracción sobre fibra óptica. En este apartado se prestará especial interés a las redes de difracción de tipo súper impuesto con modulación de amplitud y fase para la generación de códigos bipolares DS-CDMA.

- Plantear una nueva alternativa de diseño de dispositivos cod/decodificadores basados en redes SSFBGs que procuren una disminución de las pérdidas de inserción, pero manteniendo las correctas propiedades de codificación y decodificación.

- Comprobar la posibilidad de recodificación de pulsos usados como identificadores de etiquetas en redes de conmutación de paquetes.

- Demostrar el efecto de la dispersión sobre los pulsos codificados y decodificados por dispositivos basados en redes de difracción de Bragg.

El desarrollo de los anteriores objetivos es descrito en los capítulos cuya estructura explico a continuación. En el Capitulo 2 Modelado del ruido en sistemas OCDMA, se plantea una optimización al modelo del ruido de batido presente en los sistemas OCDMA con modulación OOK (On-Off Keying), incluyendo formas arbitrarias de pulso de entrada y considerando uso de receptores de ancho de banda variable. Dentro de este mismo capítulo se hacen dos propuestas adicionales, una que se refiere al modelado en sistemas OCDMA que usan modulación DPSK (Differential Phase Shift Keying) y otra en donde se modela el sistema bajo hipótesis de tráfico asíncrono tanto para OOK como para DPSK. En el capítulo 3, Sistema OCDMA basado en redes de difracción de Bragg superestructuradas uniformes, se empieza enunciando la teoría básica de las redes de difracción de Bragg haciendo hincapié en las redes 
superestructuradas. Se continúa con la descripción de las características y la forma como se diseña una familia de códigos Gold. Posteriormente se resume la forma como se fabrica una red de difracción y los principales parámetros que se tiene en cuenta para la fabricación de una red como dispositivo cod/decodificador. Con los anteriores temas resueltos se procede a explicar la manera como el proceso de codificación y decodificación es llevado a cabo con las redes de difracción de Bragg uniformes y usando códigos bipolares. De acuerdo a los resultados anteriores, se observa que en los dispositivos cod/decodificadores existe una fuerte dependencia de la sintonía en longitud de onda con respecto a la temperatura, por ello en la siguiente parte se explica dicha dependencia. Se concluye este capítulo, mostrando la forma como la dependencia en temperatura puede llegar a ser usada como un factor adicional de multiplexación en sistemas OCDMA. El capitulo 4, Dispositivos de alta reflectividad para sistemas $O C D M A$, muestra en primera instancia la problemática de las altas pérdidas introducidas por los dispositivos SSFBGs como consecuencia de su baja reflectividad. Por su parte las redes de alta reflectividad presentan problemas de deformación de la respuesta impulsiva por causa de las pérdidas en potencia y múltiples reflexiones a lo largo de la SSFBG. De tal forma que se plantea una solución integral mediante el uso de SSFBGs de alta reflectividad compensadas, diseñadas mediante el proceso DLP (Discrete Layer Peeling). El capítulo 5 Codificación y decodificación todo óptica de etiquetas en redes de conmutación de paquetes, aborda el uso de procesos de codificación y decodificación de señales ópticas para la implementación de etiquetas ópticas como identificadores en redes de paquetes o ráfagas. Más exactamente trata acerca del reuso de los picos de autocorrelación obtenidos de proceso anteriores, para ser nuevamente codificados y usados como etiquetas para saltos sucesivos entre nodos de red. Adicionalmente en este capítulo se describe el efecto que tiene la dispersión sobre la respuesta de los sistemas OCDMA cuando se usan fibras ópticas estándar. Para finalizar en el capítulo 6 Sistemas OCDMA incoherentes 2D, se demuestra la diferencia mínima entre canales que debe existir en una sistema OCDMA incoherente que use códigos en 2 dimensiones (2D - Longitud de onda/Tiempo). También allí se muestran los resultados obtenidos al implementar parcialmente un sistema OCDMA incoherente con códigos 2D. 


\section{Capítulo 2}

\section{MODELADO DEL RUIDO EN SISTEMAS OCDMA}

\subsection{Introducción}

Los sistemas OCDMA pueden ser clasificados de múltiples formas de acuerdo al criterio con el que se haga, dos de los más aplicados y que engloban características destacadas son; su principio de trabajo y las dimensiones del código. Según su principio de trabajo podemos tener sistemas OCDMA incoherentes en donde la codificación es hecha sobre la potencia óptica y sistemas OCDMA coherentes en donde la codificación se hace sobre la amplitud del campo electromagnético. Según las dimensiones del código tenemos OCDMA 1-D que usa codificación en tiempo ó en frecuencia y códigos unipolares o multipolares y OCDMA 2-D que usa codificación en tiempo y frecuencia simultáneamente y son usados generalmente en sistemas de tipo incoherente.

Los sistemas OCDMA incoherentes necesariamente usan códigos unipolares $(0,1)$ que puede ser en 1 o 2 dimensiones, no obstante el uso de códigos unipolares trae muchas desventajas, entre ellas; baja eficiencia en el uso de la potencia y del espectro y una pobre relación entre el pico de auto correlación y la correlación cruzada entre distintos códigos o usuarios del sistema $[2,3]$.

Los sistemas OCDMA coherentes tienen la ventaja de poder utilizar la fase de la señal y en consecuencia un rendimiento superior. En estos sistemas se pueden usar códigos bipolares $(1,-1)$ o multipolares con diversos niveles de codificación de la fase. Entre las múltiples posibilidades de OCDMA, el esquema con el que trabajaremos es el DS-OCDMA (Direct Sequence-OCDMA) por ser uno de los que tienen mejores características en términos de propiedades de auto correlación, correlación cruzada, eficiencia en frecuencia y baja dispersión [1].

Para que el sistema sea coherente se debe garantizar que la duración del tiempo de chip sea inferior al tiempo de coherencia de la luz del láser. Esto permite el uso de la fase y por tanto el uso de códigos multipolares, sin embargo, esto conduce al principal problema de estos sistemas, conocido como ruido de batido. Este ruido se produce en el fotodetector por el batido en campo entre la señal deseada y las 


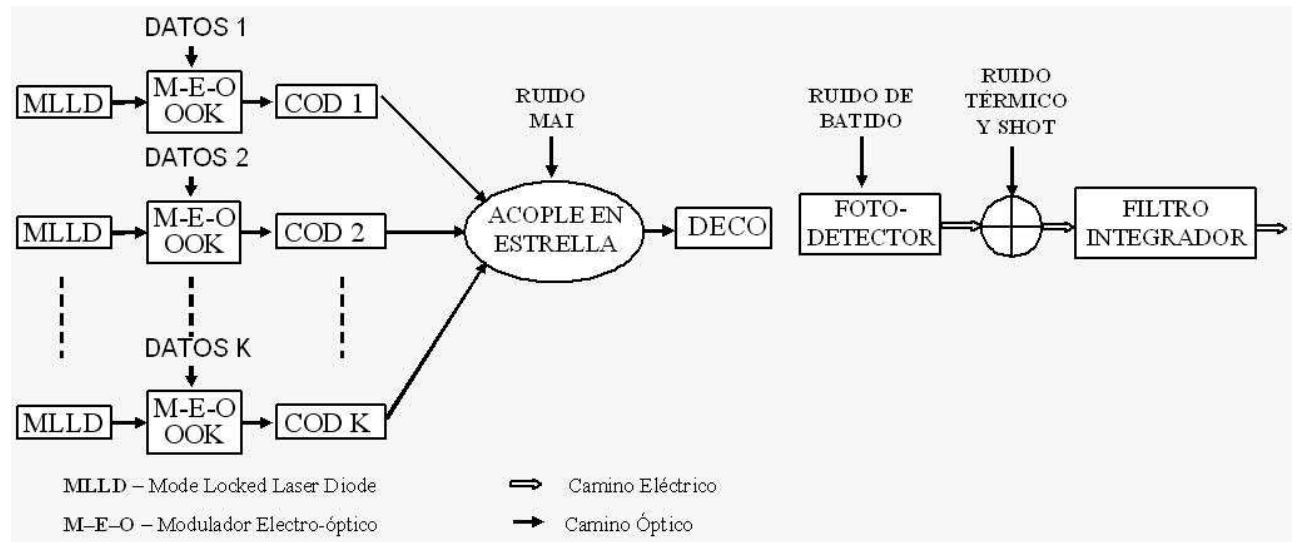

Figura 2.1: Diagrama de bloques del sistema OCDMA y fuentes de ruido

señales interferentes. Como demostraremos más adelante, no es posible eliminar el ruido de batido, sólo es posible reducirlo mediante el uso de códigos más eficientes, por esta razón el estudio del impacto en sistemas OCDMA es de vital importancia para dimensionar los posibles sistemas futuros.

\subsection{Modelo Básico del Ruido en Sistemas DS-OCDMA con On-Off Keying}

En la figura 2.1 se muestra el esquema del modelo planteado en [37] para analizar el alcance que tiene la interferencia dentro del sistema. En esta figura se resaltan las tres fuentes de ruido que deben ser tenidas en cuenta: Ruido MAI (Multiple Access Interference) y el ruido de batido entre señal e interferencia, ambos consecuencia de los múltiples usuarios presentes en la red y el ruido del receptor (ruido térmico, ruido de cuantificación o ruido shot, etc).

Para realizar el análisis del impacto del ruido en los sistemas OCDMA se parte del modelo presentado en [37], el cual tiene en cuenta los diferentes tipos de ruidos enumerados en la figura 2.1. En la figura 2.2 se observa el modelo de chips según [37] en donde resaltan las siguientes consideraciones:

* Se utiliza lo que se conoce como time gating, de tal forma que el MAI y el ruido de batido sólo son considerados dentro del instante o "chip" central del bit, equivalente a un período de chip $T_{c}$.

* Supone los chips constantes durante $T_{c}$.

* Todos los chips, tanto de señal deseada (datos) como de interferencia de múltiples usuarios caen perfectamente solapados.

* Los estados de polarización de la señal de dato e interferente se asumen iguales (peor caso).

* No se incluyen técnicas de thresholding lo que en principio podría mejorar los resultados del modelo. 


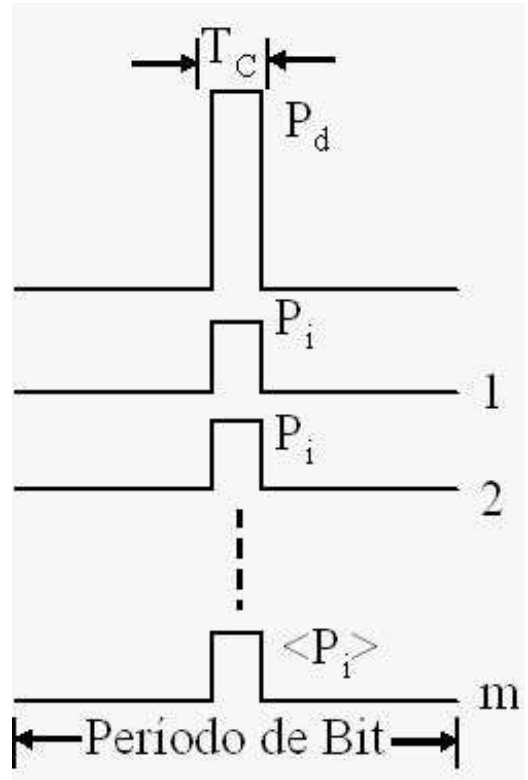

Figura 2.2: Modelo de Chips según [37]

En el sistema se supone inicialmente que existen $\mathrm{K}$ usuarios compartiendo el medio de transmisión y enviando datos, de los cuales $\mathrm{m}(0<\mathrm{m}<\mathrm{K}-1)$ están en un instante determinado activos, es decir, transmitiendo un nivel alto de señal a la red y por lo tanto interfiriendo con el usuario objetivo. De acuerdo a ello podemos decir que el campo eléctrico a la entrada del detector será:

$$
E(t)=\sqrt{P_{d}} \exp j\left(\omega_{d} t+\phi_{d}(t)\right)+\sum_{i=1}^{m} \sqrt{P_{i}} \exp j\left(\omega_{i}\left(t+\tau_{i}\right)+\phi_{i}\left(t-\tau_{i}\right)\right)
$$

donde $P_{d}$ y $P_{i}$ son las intensidades ópticas de la señal objetivo decodificada o señal de datos y de los usuarios interferentes respectivamente, $\omega_{d}$ y $\omega_{i}$ son las pulsaciones ópticas, $\phi_{d}$ y $\phi_{i}$ son las fases ópticas relativas respectivas de estas señales y $\tau_{i}$ es el retardo relativo de tránsito a lo largo de la red óptica entre la señal de datos y cada uno de los diferentes usuarios interferentes. Se asume que $\phi_{d}$ y $\phi_{i}$ son mutuamente independientes y que siguen un proceso estocástico Wiener-Lévy con distribución gausiana.

Los fotodetectores usados en sistemas ópticos normalmente tienen respuesta de ley cuadrática, por lo que podemos decir que la salida después del integrador es:

$$
Z=\int_{0}^{T_{c}} \Re \cdot\left(E \cdot E^{*}\right) d t+\int_{0}^{T_{c}} \eta(t) d t
$$




$$
\begin{gathered}
Z=\underbrace{T_{c} \Re P_{d}}_{\text {Dato }}+\underbrace{T_{c} \Re \sum_{i=1}^{m} P_{i}}_{M A I}+\underbrace{2 \Re \sum_{i=1}^{m} \sqrt{P_{d} P_{i}} \times \int_{0}^{T_{c}} \cos \left(\left(\omega_{i}-\omega_{d}\right) t-\omega_{i} \tau_{i}+\phi_{d}(t)\right) d t+}_{\text {TRMINOS DE BATIDO DE PRIMERORDEN }} \\
+\underbrace{2 \Re \sum_{j=i+1} \sum_{i=1}^{m-1} \sqrt{P_{i} P_{j}} \times \int_{0}^{T_{c}} \cos \left(\left(\omega_{i}-\omega_{j}\right) t-\omega_{i} \tau_{i}+\omega_{j} \tau_{j}+\phi_{i}\left(t-\tau_{i}\right)-\phi_{j}\left(t-\tau_{j}\right)\right) d t}_{T R M I N O S D E B A T I D O D E S E G U N D O O R D E N} \\
+\underbrace{\int_{0}^{T_{c}} \eta_{0}(t) d t}_{R U I D O D E R E C E P T O R}
\end{gathered}
$$

Donde $\Re$ es la responsividad del fotodetector, $T_{c}$ es el tiempo de chip y $\eta_{0}$ es el ruido del receptor.

La ecuación 2.2 reúne todos los términos obtenidos durante el proceso de codificación y decodificación. El primer término corresponde a la señal de datos o señal objetivo. El segundo término es el ruido producido por la múltiple interferencia de los usuarios presentes en la red conocido como MAI (Multiple Access Interference). El tercer término es el ruido de batido de primer orden (PBN), el cual se presenta en el fotodetector. Es llamado de primer orden porque es el ruido producido al batirse en campo la señal objetivo y las m señales interferentes. Este término afecta directamente la señal objetivo. El cuarto término se conoce como ruido de batido de segundo orden (SBN), y se presenta también en el fotodetector. Es llamado de segundo orden porque se produce al batirse en campo las señales interferentes entre si, sin implicar a la señal objetivo o de datos. El último término es el ruido propio del receptor y engloba al ruido térmico y al shot.

En la ecuación 2.2, tanto en el término de batido de primer orden como en el término de batido de segundo orden aparece una función coseno con tres términos en su argumento. El primer término $\left(\omega_{i}-\omega_{j}\right)=(\delta \omega)_{i j}$ indica la diferencia que existe entre las frecuencias de las portadoras de cada uno de los usuarios. Se asume que esta diferencia no supera $1 \mathrm{GHz}$ ya que todos los usuarios se encuentran dentro de la misma banda de frecuencia. También podemos asumir que $T_{c}<10 p s$ [38] ya que uno de los requisitos de trabajar con DS-OCDMA de tipo coherente es el uso de pulsos ultra-cortos. Por lo tanto el término completo $(\delta \omega)_{i j} \cdot t \ll 2 \pi$ dentro del tiempo de integración $T_{c}$, por lo que es un término insignificante. El segundo término es $\omega_{i} \tau_{i}$ es aproximadamente una constante durante la duración de la integral, que también podemos descartar. El tercer término $\phi_{i}\left(t-\tau_{i}\right)-\phi_{j}\left(t-\tau_{j}\right) \equiv \delta \phi_{i j}(t)$ es fuertemente dependiente de la coherencia del pulso óptico dentro del tiempo de integración. En consecuencia podemos tener 3 casos a saber: régimen incoherente, régimen coherente $\mathrm{y}$ régimen parcialmente coherente.

Para nuestro primer caso que es el régimen incoherente, se asume que $T_{c}$ será muy superior al tiempo de coherencia de la luz $\left(\tau_{c}\right)$. En este caso $\delta \phi_{i j}(t)$ es un proceso 
aleatorio uniformemente distribuido sobre $[-\pi, \pi]$, durante el intervalo de integración $T_{c}$. Las integrales de la función coseno son iguales a 0 , con lo que $\mathrm{Z}$ se puede simplificar a:

$$
Z=T_{c} \Re\left(P_{d}+\sum_{i=1}^{m} P_{i}\right)+\int_{0}^{T_{c}} \eta_{0}(t) d t
$$

Se puede ver claramente en la ecuación 2.3 que el ruido dominante será el ruido MAI ya que los términos que corresponden al ruido de batido pueden ser ignorados al promediarse durante el proceso de detección.

En sistemas DS-OCDMA de tipo coherente, la coherencia de la luz debe ser mantenida por lo menos dentro de cada chip, dado que precisamente se busca la interacción coherente de los chips en el decodificador para contribuir al pico de autocorrelación. En esta situación, es decir con $\tau_{c} \geq T_{c}, \delta \phi_{i j}(t)$ es una constante dentro del tiempo de integración, convirtiendo a $\mathrm{Z}$ en:

$$
\begin{aligned}
Z= & T_{c} \Re\left(P_{d}+\sum_{i=1}^{m} P_{i}+2 \sum_{i=1}^{m} \sqrt{P_{d} P_{i}} \cos \left(\triangle \Phi_{i}\right)\right) \\
& \left.+2 T_{c} \Re\left(\sum_{i=1}^{m-1} \sum_{j=i+1}^{m} \sqrt{P_{i} P_{j}} \cos \left(\triangle \Phi_{i j}\right)\right)+\int_{0}^{T_{c}} \eta_{0}(t)\right) d t
\end{aligned}
$$

donde $\Delta \Phi_{i}=(\delta \omega)_{i d} T_{c}+\omega_{i} \tau_{i}+\delta \phi_{i d}$ y $\Delta \Phi_{i j}=(\delta \omega)_{i j} T_{c}+\omega_{i} \tau_{i}+\delta \phi_{i j}$ denotan el ruido de fase total. $\Delta \Phi_{i}$ y $\Delta \Phi_{i j}$ son procesos aleatorios que varían sobre $[-\pi, \pi]$ de bit a bit, lo cual resulta en el ruido de batido de los sistemas coherentes.

En los sistemas incoherentes típicos, la relación entre $\frac{T_{c}}{\tau_{c}}$ no es muy alta. A esta relación la podemos llamar constante de coherencia $k t$ y nos servirá para medir la propiedad de coherencia de la luz dentro de la duración del chip. Como $\tau_{c} \sim \frac{1}{B_{0}}\left(B_{0}\right.$ es el ancho de banda óptico del sistema), $k t \sim T_{c} B_{0}$. En la práctica los sistemas más incoherentes son "parcialmente coherentes" ( $k t>1$ pero no infinito), por ejemplo la razón de coherencia de un sistema con ancho de banda óptico de $250 \mathrm{GHz}$ con anchura de chip de 10 ps es de 2.5, lo que esta lejos de ser un sistema totalmente incoherente. Por lo tanto es importante determinar la relación que existe entre el ruido de batido y la razón de coherencia $k t$ del sistema DS-OCDMA.

En el régimen parcialmente coherente, el modelo se puede simplificar asumiendo que la fase relativa $\Delta \Phi_{i}$ y $\Delta \Phi_{i j}$ se mantienen constantes dentro de cada ranura del tiempo de coherencia $\tau_{c}$, y que son procesos aleatorios mutuamente independientes, distribuidos sobre $[-\pi, \pi]$ para diferentes ranuras de tiempo. Bajo esta suposición podemos decir que $\mathbf{Z}$ puede ser expresado como: 


$$
\begin{aligned}
Z= & T_{c} \Re\left(P_{d}+\sum_{i=1}^{m} P_{i}+2 \sum_{n}^{k t} \sum_{i=1}^{m} \sqrt{P_{d} P_{i}} \cos \left(\triangle \Phi_{i n}\right)\right) \\
& +2 T_{c} \Re \sum_{n}^{k t} \sum_{i=1}^{m-1} \sum_{j=i+1}^{m} \sqrt{P_{i} P_{j}} \cos \left(\triangle \Phi_{i j n}\right)+\int_{0}^{T_{c}} \eta_{0}(t) d t
\end{aligned}
$$

De tal forma que en esta ecuación cuando $k t=1$ es la misma que en un sistema coherente y cuando $k t \rightarrow \infty$ entonces las ecuaciones se convertirían en la mismas de un sistema incoherente.

Las ventajas de uno y otro sistema han sido descritas brevemente al principio de este capítulo, no obstante el interés de nuestro trabajo se centrará especialmente en los sistemas DS-OCDMA coherentes, y por lo tanto a partir de ahora nos concentraremos sólo en este tipo de sistemas.

Los sistemas digitales son juzgados por su tasa de error de bit (BER por sus siglas en ingles), por ser esta la medida más representativa. La BER promedio de un sistema puede ser escrita como:

$$
B E R=\sum_{m=0}^{k-1} p(m) B E R(m)
$$

donde $p(m)$ es la probabilidad de que $m$ de los $K-1$ usuarios interferentes estén simultáneamente enviando un 1 , lo cual obedece a una distribución binomial

$$
p(m)=\frac{(K-1) !}{(K-m-1) ! m !} 2^{-(K-1)}
$$

y $B E R(m)$ es la BER que experimentará el canal de datos con $m$ señales interferentes. Si los bits son equiprobables entonces podemos expresarla como:

$$
B E R(m)=\frac{1}{2}[P e(1 / 0)(m)+P e(0 / 1)(m)]
$$

donde $P e(1 / 0)(m)$ y $P e(0 / 1)(m)$ son las probabilidades de error condicionales de los símbolos cero y uno respectivamente.

Si se asume que la MAI y el ruido del receptor tienen una distribución gausiana, las probabilidades de error son:

$$
\begin{aligned}
& \operatorname{Pe}(1 / 0)(m)=\frac{1}{2} \operatorname{erfc}\left[\frac{P_{d}(D-m \xi)}{\sqrt{2} \sigma_{0}}\right] \\
& \operatorname{Pe}(0 / 1)(m)=\frac{1}{2} \operatorname{erfc}\left[\frac{P_{d}(1+m \xi-D)}{\sqrt{2} \sigma_{1}}\right]
\end{aligned}
$$

donde $0<D<1+m \xi$ es el umbral de decisión. Adicionalmente $\sigma_{0}$ y $\sigma_{1}$ son las varianzas del ruido en un sistema coherente para los símbolos 0 y 1 respectivamente. 


\subsection{MODELO BÁSICO DEL RUIDO EN SISTEMAS DS-OCDMA CON ON-OFF KEYING}

Es importante hacer notar que las expresiones de $P e(1 / 0)(m)$ y $P e(0 / 1)(m)$ se han deducido con base en una aproximación gausiana de la función de densidad de probabilidad del total de la señal recibida, que es valida cuando los valores de $m$ son mayores a 4 [38], lo cual esta bien ya que el objetivo es tener un sistema con la máxima cantidad de usuarios posibles.

las varianzas de los valores 0 y 1 se escriben a continuación:

$$
\begin{aligned}
\sigma_{0}^{2} & =\sigma_{M A I}^{2}+\sigma_{t h}^{2}+\sigma_{0-s h}^{2}+\sigma_{S B N}^{2} \\
\sigma_{1}^{2} & =\sigma_{M A I}^{2}+\sigma_{t h}^{2}+\sigma_{1-s h}^{2}+\sigma_{S B N}^{2}+\sigma_{P B N}^{2}
\end{aligned}
$$

$\sigma_{M A I}^{2}$ es la variación en la relación de crosstalk que se producen en la realidad, es decir, la señal interferente en el punto de muestreo no es cte $=P_{i}$ si no que es una variable aleatoria con valor medio $\left\langle P_{i}\right\rangle$ y con varianza $\sigma_{M A I-0}^{2}$. La relación de crosstalk o interferencia se define precisamente utilizando la media $\left(\xi=\frac{<P_{i}>}{P_{d}}\right)$. Suponiendo que las distintas variables aleatorias $P_{i}$ son independientes, al ser distintos usuarios, la varianza o potencia de ruido MAI total del sistema es $\sigma_{M A I}^{2}=m \sigma_{M A I-0}^{2}$.

En general hay que evaluar el $\sigma_{M A I-0}^{2}$ para cada tipo concreto de código y número de chips. En [37] por ejemplo se indica que para un código de tipo Gold-Sequence de 127 chips $\sigma_{M A I-0}^{2}=6,5 \times 10^{-5} \cdot P_{d}^{2}$.

Los términos $\sigma_{t h}^{2}$ y $\sigma_{s h}^{2}$ son las varianzas de ruido térmico y ruido shot respectivamente.

$$
\begin{aligned}
\sigma_{t h}^{2} & =\frac{4 k_{B} T B_{R}}{R_{L}}=B_{R} N_{t h} \\
\sigma_{s h-0}^{2} & =2 e B_{R} \Re P_{d} m \xi \\
\sigma_{s h-1}^{2} & =2 e B_{R} \Re P_{d}(1+m \xi)
\end{aligned}
$$

$B_{R}=\frac{1}{2 T_{C}}$ es el ancho del receptor, y $N_{t h}$ es la densidad espectral de ruido térmico, que depende de la constante de Boltzman $\left(k_{B}\right)$, la temperatura $(T)$ y la resistencia de carga $R_{L}$, el valor típico para $N_{t h}$ es $1 \frac{p A^{2}}{H z}$, e es la carga del electrón.

En la varianza $\sigma_{0}^{2}$ se ha incluido el término $\sigma_{S B N}^{2}$, el cual corresponde a la varianza del ruido de batido secundario, y podemos deducirlo sabiendo que $P_{i}=P_{j}=\xi P_{d}$ y reemplazando en el 4to término de la ecuación 2.4 tendremos la corriente de ruido de batido secundario

$$
\begin{aligned}
i_{S B N} & =\frac{Z}{\Re T_{c}}=2 \xi P_{d} \sum_{i=1}^{m-1} \sum \cos \left(\Delta \Phi_{i j}\right) \quad \Phi_{i j}=\underbrace{[-\pi, \pi]}_{\text {uniforme }} \\
<i_{S B N}> & =2 \xi P_{d} \sum_{i=1}^{m-1} \sum_{j=i+1}^{m} \underbrace{<\cos \left(\Delta \Phi_{i j}\right)>}_{\rightarrow 0}=0
\end{aligned}
$$




$$
\begin{aligned}
\sigma_{S B N}^{2} & =<i_{S B N}^{2}>-\underbrace{<i_{S B N}>^{2}}_{\rightarrow 0} \\
& =4 \xi^{2} P_{d}^{2} \sum_{i=1}^{m-1} \sum_{j=i+1}^{m} \underbrace{<\cos ^{2}\left(\Delta \Phi_{i j}\right)>}_{\rightarrow \frac{1}{2}}=2 \xi^{2} P_{d}^{2} \frac{m(m-1)}{2} \\
& =\xi^{2} P_{d}^{2} m(m-1)
\end{aligned}
$$

De la misma manera en la varianza de $\sigma_{1}^{2}$ aparece el término $\sigma_{P B N}^{2}$ que corresponde a la varianza del ruido de batido primario, y que de manera similar a lo que se hizo con $\sigma_{S B N}^{2}$ se puede encontrar que es:

$$
\sigma_{P B N}^{2}=2 \xi P_{d}^{2} m
$$

Con este último resultado concluimos las expresiones necesarias para obtener la BER de un sistema OCDMA con modulación On-Off Keying.

Usualmente en redes DS-OCDMA el nivel de crosstalk es muy bajo $(\xi \ll 1)$. La relación entre la varianza del batido primario y el ruido del batido secundario esta alrededor de $\frac{2}{m \xi}$, de tal forma que si m no es muy grande $(m \xi \ll 1)$, el batido secundario puede ser ignorado. En nuestro caso el batido secundario no puede ser ignorado ya que estamos buscando modelar un sistema en donde queremos tener una gran cantidad de usuarios.

\subsection{Modelo Generalizado del Ruido en Sistemas OCDMA con Modulación On-Off Keying}

El modelo del apartado anterior nos permite visualizar la influencia del ruido sobre un sistema OCDMA con On-Off keying. No obstante este modelo adolece de algunas características importantes si se pretende usar en otros entornos, entre ellas:

- Tener en cuenta la forma del pulso. En los sistemas ópticos DS-OCDMA de tipo coherente la señal de entrada son pulsos de corta duración. Estos pulsos pueden tener múltiples formas aunque generalmente son considerados de forma gausiana.

- Dar la posibilidad de variar el ancho de banda del filtro receptor para incluir el ruido fuera del tiempo de chip de la señal objetivo. Considerar el ruido solo para el tiempo de chip de la señal objetivo es válido para sistemas que utilizan "time gating", que requiere tiempos de integración muy bajos y receptores con anchos de banda elevados comparables al tiempo de chip.

- Poder incluir un receptor con respuesta impulsiva $h_{R C}(t)$ arbitraria.

Introduciremos en este punto un conjunto de modificaciones al modelo para considerar una detección más real. Se tomará en cuenta un receptor caracterizado por su función 


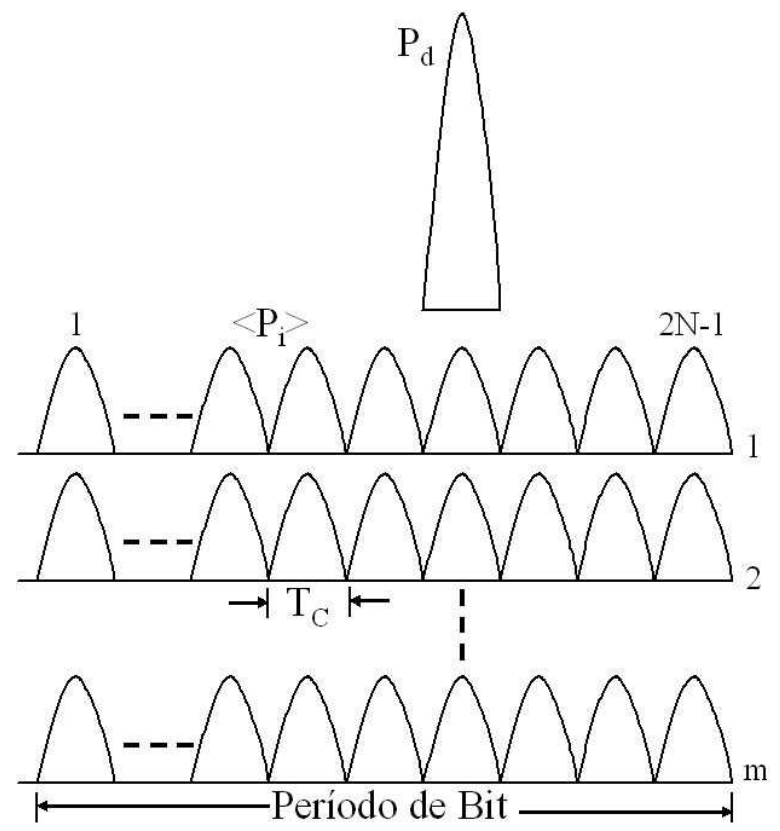

Figura 2.3: Modelo con pulsos de forma gausiana.

de transferencia, forma arbitraria para los "chips" decodificados y el efecto de la interferencia durante todo el tiempo de bit.

En la Figura 2.3 se ilustra con pulsos gausianos las posibles señales que tendríamos después del proceso de decodificación. El proceso de decodificación consiste en correlar la señal original codificada y la respuesta del dispositivo decodificador ubicado en el receptor. Por esta razón, la cantidad de pulsos de la señal interferente es de $2 \mathrm{~N}-1$ en donde $\mathrm{N}$ es el número de chips del código, así mismo, el tiempo de duración de la señal recuperada será $2 \mathrm{~N}-1$ veces el tiempo de chip original.

Teniendo en cuenta que ahora la forma del pulso es arbitraria, la envolvente de campo complejo a la salida del decodificador, puede ser escrita como:

$E(t)=s(t) \sqrt{P_{d}} \exp j\left(\omega_{d} t+\phi_{d}\right)+s(t) \otimes\left(\sum_{k=-(N-)}^{N-1}\left(\sum_{i=1}^{m} \sqrt{P_{i}} \exp j \phi_{k i}\right) \delta\left(t-k T_{c}\right)\right)$

En donde $s(t)$ es la función normalizada que describe la forma del chip y $\phi_{k i}$ es la fase óptica relativa entre los $k$ chips a la salida del decodificador durante el período de bit. En la ecuación 2.18, se observa que la sumatoria de los chips incluye $2 \mathrm{~N}-1$ términos, lo cual corresponde a la longitud de la señal decorrelada.

Para un sistema DS-OCDMA que emplea fotodetección cuadrática (fotodetector seguidor normal), tomando módulo al cuadrado de la ecuación 2.18 y aplicando la respuesta del receptor obtenemos que la fotocorriente esta dada por 


$$
\begin{aligned}
i(t)= & \Re\left(P_{d} \Gamma(t)+\sum_{k=-N}^{N} \sum_{i=1}^{m} P_{i} \Gamma\left(t-k T_{c}\right)\right)+2 \Re \sqrt{P_{d}} \sum_{i=1}^{m} \sqrt{P_{i}} \Gamma(t) \cos \left(\triangle \Phi_{i}\right) \\
& +2 \Re \sum_{k=-(N-1)}^{N-1} \Gamma\left(t-k T_{c}\right) \sum_{i=1}^{m-1} \sum_{j=i+1}^{m} \sqrt{P_{i} P_{j}} \cos \left(\triangle \Phi_{i j k}\right)
\end{aligned}
$$

Esta fotocorriente esta ordenada en los mismos términos de MAI, batido primario y batido secundario que el modelo anterior. Pero tiene términos adicionales, ya que existe una nueva sumatoria que incluye el número total de chips (2N-1). La función $\Gamma(t)$ se define como $\Gamma(t)=s^{2}(t) \otimes h_{R C}(t)$ y $\Delta \Phi_{i j k}$ es la diferencia de fases entre los chips ubicados en la posición temporal $k$ de las señales de los usuarios $i$ y $j$. Nótese que ahora la función $\Gamma(t)$ incluye tanto la forma de los pulsos de la fuente óptica codificada, como la respuesta concreta del receptor empleado. Ambas pueden ser por lo tanto arbitrarias.

Podemos particularizar la fotocorriente para el instante central $(t=0)$, que ha sido tomado como el punto óptimo por ser donde se produce el pico de la señal decodificada $\left(P_{d}\right)$, y normalizando con respecto a $\Re$.

$$
\begin{aligned}
I= & \frac{i(t)}{\Re}=P_{d} \Gamma(0)+P_{i} \sum_{k=-(N-1)}^{N-1} \sum_{i=1}^{m} \Gamma\left(-k T_{c}\right)+2 \sqrt{P_{d} P_{i}} \sum_{i=1}^{m} \Gamma(0) \cos \left(\triangle \Phi_{i}\right) \\
& +2 P_{i} \sum_{k=-N}^{N} \Gamma\left(-k T_{c}\right) \sum_{i=1}^{m-1} \sum_{j=i+1}^{m} \cos \left(\triangle \Phi_{i j k}\right)
\end{aligned}
$$

Asumimos al igual que en [37] que los términos de fase $\Delta \Phi_{i}$ y $\Delta \Phi_{i j k}$ son procesos aleatorios independientes. De esta manera los términos de potencia de ruido son

$$
\begin{aligned}
\sigma_{P B N}^{2} & =2 m \xi P_{d}^{2} \Gamma^{2}(0) \\
\sigma_{S B N}^{2} & =m(m-1) \xi^{2} P_{d}^{2} \sum_{k=-(N-1)}^{N-1} \Gamma^{2}\left(-k T_{c}\right) \\
\sigma_{M A I}^{2} & =m \sigma_{M A I-0}^{2} \sum_{k=-(N-1)}^{N-1} \Gamma^{2}\left(-k T_{c}\right)
\end{aligned}
$$

Para el cálculo de la BER, en este caso, consideramos nuevamente que las distribuciones de ruido de batido, tanto primario como secundario, son de tipo gausiano. Así, podemos aplicar el modelo de detector con umbral de decisión óptimo, cuyo parámetro de calidad se define como

$$
Q=\frac{\left(I_{1}-I_{0}\right)}{\sigma_{0}+\sigma_{1}}
$$


y por lo tanto a partir de éste, la probabilidad de error de bit queda como

$$
\operatorname{BER}(m)=\frac{1}{2} \operatorname{erfc}\left(\frac{Q}{\sqrt{2}}\right)
$$

Las incógnitas por lo tanto son $I_{1}$ e $I_{0}$, es decir las fotocorrientes para el símbolo "1" y el símbolo "0", así como las desviaciones típicas de ruido totales para ambos símbolos. Éstas se deducen a partir de la ecuación (2.20).

$$
\begin{aligned}
I_{1}=\langle I\rangle & =P_{d} \Gamma(0)+P_{i} m \sum_{k} \Gamma\left(-k T_{c}\right) \\
& =P_{d} \Gamma(0)+\xi P_{d} m \sum_{k} \Gamma\left(-k T_{c}\right) \\
& =P_{d} \Gamma(0)\left[1+\xi m \frac{\sum_{k} \Gamma\left(-k T_{c}\right)}{\Gamma(0)}\right]
\end{aligned}
$$

de la misma manera hallamos la expresión para $I_{0}$

$$
I_{0}=P_{d} \xi m \sum_{k} \Gamma\left(-k T_{c}\right)
$$

las desviaciones de ruido siguen la misma forma que en las expresiones 2.11 y 2.12 que junto con las anteriores nos permiten considerar $\mathrm{Q}$ como:

$$
Q=\frac{P_{d} \Gamma(0)}{\sqrt{\sigma_{M A I}^{2}+\sigma_{S B N}^{2}+\sigma_{t h}^{2}+\sigma_{s h-0}^{2}}+\sqrt{\sigma_{M A I}^{2}+\sigma_{S B N}^{2}+\sigma_{P B N}^{2}+\sigma_{t h}^{2}+\sigma_{s h-1}^{2}}}
$$

Dado que el conjunto de ruidos de interferencia de batido se pueden expresar en términos relativos a través de la relación de crosstalk $\left(\xi=\frac{\left\langle P_{i}\right\rangle}{P_{d}}\right)$, resulta de gran interés poder expresar también el resto de términos de ruido con base en la relación de Señal a Ruido (SNR), y alcanzar una descripción más homogénea y manejable.

$$
\frac{1}{S N R_{M A I}}=\frac{\sigma_{M A I-0}^{2}}{P_{d}^{2}}
$$

tomando en consideración el ruido shot sólo para cuando se envía un bit 1, tenemos:

$$
\frac{\sigma_{s h-1}^{2}}{\Re^{2}\left(P_{d} \Gamma(0)\right)^{2}}=\frac{2 e B_{R} \Re P_{d}(1+m \xi)}{\Re^{2}\left(P_{d} \Gamma(0)\right)^{2}}=\frac{2 e B_{R}(1+m \xi)}{\Re P_{d} \Gamma^{2}(0)}=\frac{1}{S N R_{\text {shot }}}
$$

así mismo la relación señal a ruido térmico es

$$
\frac{\sigma_{t h}^{2}}{\Re^{2}\left(P_{d} \Gamma(0)\right)^{2}}=\frac{N_{t h} B_{R}}{\Re^{2}\left(P_{d} \Gamma(0)\right)^{2}}=\frac{1}{S N R_{t h}}
$$


donde $B_{R}$ será el ancho de banda equivalente del receptor calculado sobre la función de transferencia en frecuencia del receptor

$$
\begin{gathered}
\int_{-B_{R}}^{B_{R}}\left|H_{R C}(0)\right|^{2} d \Omega=\int_{-\infty}^{\infty}\left|H_{R C}(\Omega)\right|^{2} d \Omega \\
B_{R}=\frac{\int\left|H_{R C}(\Omega)\right|^{2} d \Omega}{2\left|H_{R C}(0)\right|^{2}}
\end{gathered}
$$

como tanto el ruido shot como el ruido térmico son dependientes del componente electrónico del receptor, y por comodidad, podemos reducir las dos expresiones anteriores a un solo término

$$
\frac{1}{S N R}=\frac{1}{S N R_{t h}}+\frac{1}{S N R_{s h}}
$$

reemplazando las ecuaciones $2.21,2.22,2.23,2.29$ y 2.34 en la ecuación 2.28 hallamos que

$$
Q_{O O K}=\frac{1}{\sqrt{\frac{m \bar{\Gamma}}{S N R_{M A I}}+m(m-1) \xi^{2} \bar{\Gamma}+\frac{1}{S N R}}+\sqrt{\frac{m \bar{\Gamma}}{S N R_{M A I}}+m(m-1) \xi^{2} \bar{\Gamma}+2 m \xi+\frac{1}{S N R}}}
$$

donde definimos el parámetro normalizado $\bar{\Gamma}$ como

$$
\bar{\Gamma}=\frac{\sum_{k=-(N-1)}^{N-1} \Gamma^{2}\left(-k T_{c}\right)}{\Gamma^{2}(0)}
$$

A partir de la expresión 2.35 podemos llegar a unas primeras conclusiones. La primera de ellas es que cuando el valor de crosstalk $\xi$ es bajo y el número de usuarios reducido, el ruido de batido primario es la fuente de ruido dominante. Y la segunda es que el ruido de batido secundario se incrementa en razón de $m(m-1) \bar{\Gamma}$ y el ruido MAI se incrementa con $m \bar{\Gamma}$.

Consideremos ahora dos casos extremos que nos permiten cuantificar el impacto del término $\bar{\Gamma}$ cuando variamos el ancho de banda del receptor. Primero supondremos que usaremos time gating, lo cual implica, suponer un ancho de banda de receptor muy grande. En el caso extremo este ancho de banda será comparable con la tasa de chip $B_{R} \rightarrow \frac{1}{2 T_{c}}$. Por lo tanto asumimos que $\Gamma^{2}\left(-k T_{c}\right) \ll \Gamma^{2}(0) \forall k \neq 0$ y por lo tanto $\bar{\Gamma} \approx 1$. Aquí la contribución de ruido MAI y de ruido de batido secundario al sistema es mínima. Por otra parte podemos suponer que el ancho de banda del receptor es mínimo, en este caso comparable al período de bit, $B_{R} \rightarrow \frac{1}{2 T_{b}}$. En este caso podemos asumir que $\Gamma^{2}\left(-k T_{c}\right) \approx \Gamma^{2}(0) \forall k=[-(N-1),(N-1)]$ y en consecuencia $\bar{\Gamma} \rightarrow(2 N-1)$. para este segundo caso la contribución de ruido MAI y de ruido de batido de segundo orden es la máxima posible.

Los casos que hemos descrito no son prácticos en condiciones reales, lo típico es tener un sistema que usa técnicas de time gating que no son absolutamente perfectas. Por tal motivo lo mejor es considerar un caso intermedio, en donde $\bar{\Gamma}$ integra la 


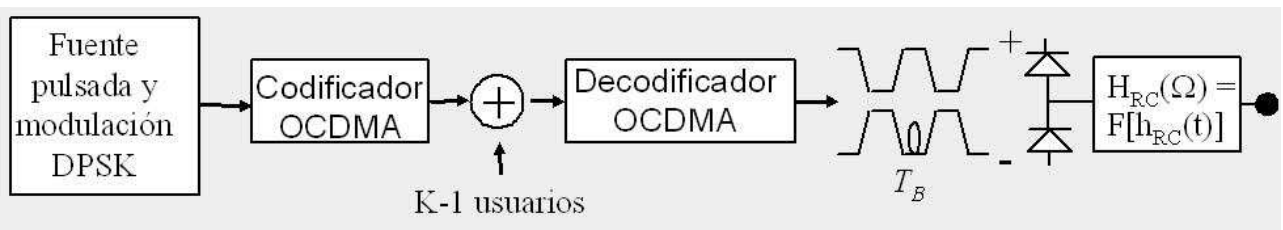

Figura 2.4: Diagrama de bloques para el sistema OCDMA con modulación DPSK

contribución de ruido de los $2 \mathrm{~N}-1$ chips ponderados de acuerdo a la función $\Gamma(t)$. Nótese que $\bar{\Gamma}$ puede ser considerado como el número efectivo de chips que son tenidos en cuenta como contribuyentes al ruido SBN y MAI, y puede variar entre 1 y $2 \mathrm{~N}-1$.

\subsection{Modelo del Ruido en Sistemas OCDMA con Modulación DPSK}

Differential Phase Shift Keying (DPSK), ha sido propuesta y demostrada experimentalmente en sistemas OCDMA [39][40]. DPSK presenta dos ventajas destacables:

1. la relación señal a ruido y la relación señal a interferencia se ven incrementadas porque la energía del símbolo " 0 " ya no es nula y en consecuencia la apertura del diagrama de ojo aumenta en un factor de dos.

2. La apertura del diagrama de ojo después de la detección diferencial proporciona valores simétricos positivos y negativos para los símbolos "1" y " 0 ". Esto permite obtener un nivel umbral óptimo de detección igual a cero, independiente de la potencia óptica promedio que llega al receptor.

En DPSK se reduce la complejidad para determinar el nivel umbral, pero por otra parte requiere dispositivos adicionales, entre ellos el detector diferencial y el interferómetro Mach-Zehnder con un tiempo de retardo entre cada terminal igual a un período de bit.

En el caso concreto de OCDMA se codifica un pulso óptico tanto para el símbolo "1" como para el símbolo "0" y la información de los mismos se modula en la fase. Más concretamente en la diferencia de fase óptica entre un pulso codificado y el inmediatamente posterior. Esta diferencia de fase es de $\pi$ radianes de manera que en nuestro caso vamos a asumirla como:

Para el símbolo "1":

$$
\phi_{d}-\phi_{d_{-} D}=\pi
$$

Para el símbolo "0":

$$
\phi_{d}-\phi_{d_{-} D}=0
$$

El receptor DPSK requiere un Interferómetro Mach-Zehnder (IMZ) con los brazos desbalanceados exactamente un período de bit y con un perfecto ajuste de fase óptica 


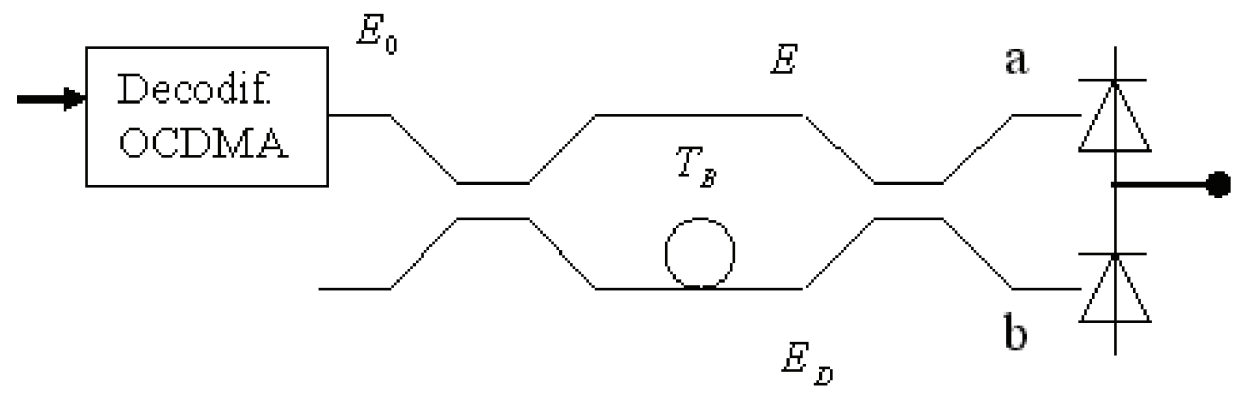

Figura 2.5: Detector diferencial con Interferómetro Mach-Zehnder

entre brazos. Las dos salidas del IMZ se aplican a un par de detectores en configuración diferencial (resta de corrientes), para producir la fotocorriente final, tal como se ve en la figura 2.5 .

Tomando como plano de entrada al nuevo receptor en el punto indicado como $E_{0}$, y por lo tanto igual que en el análisis OOK suponiendo la potencia del pico de señal decodificada como $P_{d}$, los campos $E$ y $E_{d}$ son:

$$
\begin{aligned}
E(t)= & \frac{1}{\sqrt{2}} s(t) \sqrt{P_{d}} \exp \left(j \phi_{d}\right) \\
& +\frac{1}{\sqrt{2}}\left(s(t) \otimes\left(\sum_{k=-(N-)}^{N-1}\left(\sum_{i=1}^{m} \sqrt{P_{i}} \exp j \phi_{k i}\right) \delta\left(t-k T_{c}\right)\right)\right) \\
E_{D}(t)= & \frac{1}{\sqrt{2}} s(t) \sqrt{P_{d}} j \exp \left(j \phi_{d_{-} D}\right) \\
& +\frac{1}{\sqrt{2}}\left(s(t) \otimes\left(\sum_{k=-(N-)}^{N-1}\left(\sum_{i=1}^{m} \sqrt{P_{i} j} \exp j \phi_{k i_{-} D}\right) \delta\left(t-k T_{c}\right)\right)\right)
\end{aligned}
$$

Los términos de fase $\phi_{d}, \phi_{d} D$, son las fase ópticas del pico de señal decodifica para un bit y para el bit adyacente respectivamente. Los términos $\phi_{k i}, \phi_{k i} D$ y son las fase ópticas del pico residual interferente procedente del usuario i-ésimo en la posición k-ésima a lo largo del período de bit, que aparecen en el bit asociado a $\phi_{d}$ y en el bit asociado a $\phi_{d} D$ respectivamente.

En el punto (a) de la figura 2.5 previo al detector, el campo eléctrico es:

$$
\begin{aligned}
E_{a}(t)= & \frac{1}{\sqrt{2}}\left(E(t)+j E_{D}(t)\right) \\
E_{a}(t)= & \frac{1}{2} s(t) \sqrt{P_{d}}\left(\exp \left(j \phi_{d}\right)-\exp \left(j \phi_{d_{-} D}\right)\right) \\
& +\frac{1}{2}\left(s(t) \otimes \sum_{k=-(N-1)}^{N-1} \sum_{i=1}^{m} \sqrt{P_{i}}\left[\exp \left(j \phi_{k i}\right)-\exp \left(j \phi_{d_{-} D}\right)\right] \delta\left(t-k T_{c}\right)\right)
\end{aligned}
$$


de manera análoga en el punto (b) de la figura 2.5 tendremos

$$
\begin{aligned}
E_{b}(t)= & \frac{1}{\sqrt{2}}\left(j E(t)+E_{D}(t)\right) \\
E_{b}(t)= & \frac{1}{2} s(t) \sqrt{P_{d}} j\left(\exp \left(j \phi_{d}\right)+\exp \left(j \phi_{d_{-} D}\right)\right) \\
& +\frac{1}{2}\left(s(t) \otimes \sum_{k=-(N-1)}^{N-1} \sum_{i=1}^{m} \sqrt{P_{i}} j\left[\exp \left(j \phi_{k i}\right)+\exp \left(j \phi_{d_{-} D}\right)\right] \delta\left(t-k T_{c}\right)\right)
\end{aligned}
$$

Procederemos ahora a calcular las fotocorrientes de los detectores en los puntos a y b de la figura 2.5. Como se observa en las expresiones de campo eléctrico anteriores para nuestro caso de receptor DPSK, tanto en el término de "señal", como en los términos del sumatorio de "interferencias", aparecen dos elementos en lugar de uno como en OOK, es decir a cada detector llegan dos copias tanto de la señal como de las interferencias.

Tendremos en cuenta para simplificar los cálculos que los términos de la forma se pueden expresar como

$$
\exp \left(j \phi_{k, i}\right) \pm \exp \left(j \phi_{k, i_{-} D}\right)=\exp \left(j \phi_{k, i}\right)(1 \pm \exp (\varphi))=\exp \left(j \phi_{k, i}\right) a_{i}^{ \pm}
$$

donde $\varphi$ por ser la diferencia de fase entre un bit y el adyacente de la i-ésima fuente interferente, es por tanto una variable aleatoria binaria que tomará valores 0 ó $\pi$ únicamente. Esto simplifica la expresión $1 \pm \exp (\varphi)=a_{i}^{ \pm}$a una variable aleatoria de amplitud que fluctúa entre 0 y 2 (caso + ) con igual probabilidad, para los valores 0 y $\pi$ indicados, o que fluctúa entre 2 y 0 (caso -). En términos más directos esto significa que las "dobles contribuciones" de cada interferente i-ésimo se sumarán en fase en unas ocasiones contribuyendo a doblar el nivel de campo y en otras se anularán a cero.

Procederemos de similar manera que para el sistema OOK con detección directa, tomando los términos de módulo al cuadrado por una parte, así como los términos de batido por otra. De esta manera las expresiones para las corrientes normalizadas con respecto a la responsividad, en el punto a) quedará como

$$
\begin{aligned}
\frac{i_{a}(t)}{\Re}= & \frac{1}{4} P_{d}\left(\Gamma(t)\left|\exp \left(j \phi_{d}\right)-\exp \left(j \phi_{d_{-} D}\right)\right|^{2}\right)+ \\
& +\frac{1}{4} \xi P_{d} \sum_{k=-(N-1)}^{N-1} \Gamma\left(t-k T_{c}\right) \sum_{i=1}^{m}\left|\exp \left(j \phi_{k i}\right)\right|^{2}\left(a_{i}^{-}\right)^{2} \\
& +\frac{1}{2} P_{d} \sqrt{\xi} \sum_{i=1}^{m} \Gamma(t) \cos \left(\Delta \Phi_{i}\right) a_{i}^{-}+ \\
& +\frac{1}{2} \sum_{k=-(N-1)}^{N-1} \Gamma\left(t-k T_{c}\right) \sum_{i=1}^{m-1} \sum_{j=i+1}^{m} \sqrt{P_{i} P_{j}} \cos \left(\Delta \Phi_{i}\right) a_{i}^{-} a_{k}^{-}
\end{aligned}
$$

y de similar forma para el punto b) 


$$
\begin{aligned}
\frac{i_{b}(t)}{\Re}= & \frac{1}{4} P_{d} \Gamma(t)\left|\exp \left(j \phi_{d}\right)-\exp \left(j \phi_{d_{-} D}\right)\right|^{2} \\
& +\frac{1}{4} P_{d} \xi \sum_{k=-(N-1)}^{N-1} \Gamma\left(t-k T_{c}\right) \sum_{i=1}^{m}\left|\exp \left(j \phi_{k i}\right)\right|^{2}\left(a_{i}^{+}\right)^{2} \\
& +\frac{1}{2} P_{d} \sqrt{\xi} \sum_{i=1}^{m} \Gamma(t) \cos \left(\Delta \Phi_{i}\right) a_{i}^{+} \\
& +\frac{1}{2} \sum_{k=-(N-1)}^{N-1} \Gamma\left(t-k T_{c}\right) \sum_{i=1}^{m-1} \sum_{j=i+1}^{m} \sqrt{P_{i} P_{j}} \cos \left(\Delta \Phi_{i}\right) a_{i}^{+} a_{k}^{+}
\end{aligned}
$$

La fotocorriente total a la salida del detector diferencial es

$$
\begin{aligned}
i(t)= & \frac{i_{a}(t)-i_{b}(t)}{\Re} \\
i(t)= & \frac{1}{4} P_{d} \Gamma(t)\left(\left|\exp \left(j \phi_{d}\right)-\exp \left(j \phi_{d_{-} D}\right)\right|^{2}-\left|\exp \left(j \phi_{d}\right)+\exp \left(j \phi_{d_{-} D}\right)\right|^{2}\right) \\
& +\frac{1}{4} \xi P_{d} \sum_{k=-(N-1)}^{N-1} \Gamma\left(t-k T_{c}\right) \sum_{i=1}^{m}\left|\exp \left(j \phi_{k i}\right)\right|^{2}\left\{\left(a_{i}^{-}\right)^{2}-\left(a_{i}^{+}\right)^{2}\right\} \\
& +\frac{1}{2} P_{d} \sqrt{\xi} \sum_{i=1}^{m} \Gamma(t) \cos \left(\Delta \Phi_{i}\right)\left\{a_{i}^{-}-a_{i}^{+}\right\} \\
& +\frac{1}{2} \sum_{k=-(N-1)}^{N-1} \Gamma\left(t-k T_{c}\right) \sum_{i=1}^{m-1} \sum_{j=i+1}^{m} \sqrt{P_{i} P_{j}} \cos \left(\Delta \Phi_{i}\right)\left\{a_{i}^{-} a_{k}^{-}-a_{i}^{+} a_{k}^{+}\right\}
\end{aligned}
$$

y particularizando en el punto de muestreo que consideraremos $t=0$ obtenemos

$$
\begin{aligned}
I= & \frac{1}{4} P_{d} \Gamma(0)\left(\left|\exp \left(j \phi_{d}\right)-\exp \left(j \phi_{d_{-} D}\right)\right|^{2}-\left|\exp \left(j \phi_{d}\right)+\exp \left(j \phi_{d_{-} D}\right)\right|^{2}\right) \\
& +\frac{1}{4} \xi P_{d} \sum_{k=-(N-1)}^{N-1} \Gamma\left(-k T_{c}\right) \sum_{i=1}^{m}\left|\exp \left(j \phi_{k i}\right)\right|^{2}\left\{\left(a_{i}^{-}\right)^{2}-\left(a_{i}^{+}\right)^{2}\right\} \\
& +\frac{1}{2} P_{d} \sqrt{\xi} \sum_{i=1}^{m} \Gamma(0) \cos \left(\Delta \Phi_{i}\right)\left\{a_{i}^{-}-a_{i}^{+}\right\} \\
& +\frac{1}{2} \sum_{k=-(N-1)}^{N-1} \Gamma\left(-k T_{c}\right) \sum_{i=1}^{m-1} \sum_{j=i+1}^{m} \sqrt{P_{i} P_{j}} \cos \left(\Delta \Phi_{i}\right)\left\{a_{i}^{-} a_{k}^{-}-a_{i}^{+} a_{k}^{+}\right\}
\end{aligned}
$$

A partir de este punto calculamos los valores medios de corriente para los símbolos "0" y "1" y las potencias de ruido de interferencia.

Partiendo de la ecuación 2.47, hallamos primero la expresión para el ruido MAI 


$$
I(M A I)=\frac{1}{4} \xi P_{d} \sum_{k=-(N-1)}^{N-1} \Gamma\left(-k T_{c}\right) \sum_{i=1}^{m}\left|\exp \left(j \phi_{k i}\right)\right|^{2}\left\{\left(a_{i}^{-}\right)^{2}-\left(a_{i}^{+}\right)^{2}\right\}
$$

el último término de la ecuación 2.48 depende de las variables $a_{i}^{+}$y $a_{i}^{-}$, las cuales no son independientes, si no que cuando $a_{i}^{+}=2 \rightarrow a_{i}^{-}=0$ y viceversa. Estos dos casos se dan con una probabilidad igual a 0.5. De aquí se desprende que el término $\left\{\left(a_{i}^{-}\right)^{2}-\left(a_{i}^{+}\right)^{2}\right\}$ varíe entre -4 y 4 con probabilidad igual a 0.5 . Por otra parte cabe recordar que la contribución de MAI viene dada por las fluctuaciones de potencia de las señales interferentes $P_{i}$ las cuales en general son una variable aleatoria, que al igual que en el caso de OOK podemos definir como $\left\langle P_{i}\right\rangle=P_{d} \xi$. Rescatando el carácter aleatorio de $P_{i}$ podemos reordenar la expresión 2.48 en su forma más general como

$$
I(M A I)=\frac{1}{4} \sum_{k=-(N-1)}^{N-1} \Gamma\left(-k T_{c}\right) \sum_{i=1}^{m} P_{i, k}\left\{\left(a_{i}^{-}\right)^{2}-\left(a_{i}^{+}\right)^{2}\right\}
$$

Teniendo en cuenta que $P_{i}$ y $\left\{\left(a_{i}^{-}\right)^{2}-\left(a_{i}^{+}\right)^{2}\right\}$ son procesos independientes, encontramos que

$$
\begin{gathered}
\overline{I(M A I)}=0 \\
\sigma_{M A I}^{2}=\overline{I_{M A I}^{2}}=m \frac{1}{16}\left(\sum_{k=-(N-1)}^{N-1} \Gamma^{2}\left(-k T_{c}\right)\right) \overline{P_{i}^{2}}\left\{\overline{\left(\left(a_{i}^{-}\right)^{2}-\left(a_{i}^{+}\right)^{2}\right)^{2}}\right\} \\
=m \frac{1}{16}\left(\sum_{k=-(N-1)}^{N-1} \Gamma^{2}\left(-k T_{c}\right)\right)\left(\sigma_{M A I-0}^{2}+\left\langle P_{i}\right\rangle^{2}\right) 16 \\
=m\left(\sum_{k=-(N-1)}^{N-1} \Gamma^{2}\left(-k T_{c}\right)\right)\left(\sigma_{M A I-0}^{2}+\left(\xi P_{d}\right)^{2}\right)
\end{gathered}
$$

Para el ruido de batido primario procedemos de forma similar

$$
\begin{aligned}
I_{P B N}=\frac{1}{2} P_{d} \sqrt{\xi} \sum_{i=1}^{m} \Gamma(0) \cos \left(\Delta \Phi_{i}\right)\left\{a_{i}^{-}-a_{i}^{+}\right\} & \overline{I(P B N)}=0 \\
\sigma_{P B N}^{2}=\overline{I_{P B N}^{2}} & =m \frac{1}{4} P_{d}^{2} \xi \Gamma^{2}(0) \overline{\cos ^{2}\left(\Delta \Phi_{i}\right)} \overline{\left\{a_{i}^{-}-a_{i}^{+}\right\}^{2}} \\
& =m \frac{1}{4} P_{d}^{2} \xi \Gamma^{2}(0) \cdot \frac{1}{2} \cdot 4 \\
& =\frac{1}{2} m P_{d}^{2} \xi \Gamma^{2}(0)
\end{aligned}
$$


finalmente para el ruido de batido secundario tenemos que

$$
\begin{aligned}
I_{S B N}= & \frac{1}{2} P_{d} \xi \sum_{k=-(N-1)}^{N-1} \Gamma\left(-k T_{c}\right) \sum_{i=1}^{m-1} \sum_{j=i+1}^{m} \cos \left(\Delta \Phi_{i j k}\right)\left\{a_{i}^{-} a_{k}^{-}-a_{i}^{+} a_{k}^{+}\right\} \\
\sigma_{S B N}^{2}= & \frac{m(m-1)}{2} \frac{1}{4} P_{d}^{2} \xi^{2} \sum_{k=-(N-1)}^{N-1} \Gamma^{2}\left(-k T_{c}\right) \overline{\cos ^{2}\left(\Delta \Phi_{i j k}\right)} \overline{\left\{a_{i}^{-} a_{k}^{-}-a_{i}^{+} a_{k}^{+}\right\}^{2}} \\
= & \frac{m(m-1)}{2} \cdot \frac{1}{4} \cdot P_{d}^{2} \xi^{2} \sum_{k=-(N-1)}^{N-1} \Gamma^{2}\left(-k T_{c}\right) \cdot \frac{1}{2} \cdot 8 \\
= & \frac{1}{2} m(m-1) P_{d}^{2} \xi^{2} \sum_{k=-(N-1)}^{N-1} \Gamma^{2}\left(-k T_{c}\right)
\end{aligned}
$$

Nuestro objetivo ahora, es encontrar las expresiones para las corrientes medias de los símbolos 1 y 0 , para poder hallar el valor del factor Q. Para encontrar dichos valores partimos de la expresión 2.47. Como ya hemos visto anteriormente los valores medios de los tres últimos términos de esa ecuación son iguales a cero, por lo tanto

$$
\begin{aligned}
I & =\frac{1}{4} P_{d} \Gamma(0)\left(\left|\exp \left(j \phi_{d}\right)-\exp \left(j \phi_{d_{-} D}\right)\right|^{2}-\left|\exp \left(j \phi_{d}\right)+\exp \left(j \phi_{d_{-} D}\right)\right|^{2}\right) \\
& =\frac{1}{4} P_{d} \Gamma(0)\left(\left|\exp \left(j \phi_{d}\right)\right|^{2}\left(\left|1-\exp \left(j \phi_{d_{-} D}-\phi_{d}\right)\right|^{2}-\left|1+\exp \left(j \phi_{d_{-} D}-\phi_{d}\right)\right|^{2}\right)\right)
\end{aligned}
$$

aplicando las expresiones 2.37 y 2.38 obtenemos que para el símbolo 1

$$
\begin{aligned}
I_{1} & =\frac{1}{4} P_{d} \Gamma(0)(4-0) \\
& =P_{d} \Gamma(0)
\end{aligned}
$$

y para el símbolo 0

$$
\begin{aligned}
I_{0} & =\frac{1}{4} P_{d} \Gamma(0)(0-4) \\
& =-P_{d} \Gamma(0)
\end{aligned}
$$

El factor de calidad Q bajo la aproximación de p.d.f gausianas de todas las fuentes de ruido y con umbral de detección óptimo es

$$
Q=\frac{I_{1}-I_{0}}{\sigma_{0}+\sigma_{1}}
$$




\subsection{MODELO DEL RUIDO EN SISTEMAS OCDMA CON \\ MODULACIÓN DPSK}

en el caso de DPSK las contribuciones de ruido de los símbolos " 1 " y "0" son iguales, porque en ambos casos se codifica un pulso óptico, por tal razón

$$
\begin{gathered}
Q=\frac{I_{1}-I_{0}}{2 \sigma} \\
\sigma^{2}=\sigma_{M A I}^{2}+\sigma_{S B N}^{2}+\sigma_{P B N}^{2}+\sigma_{s h}^{2}+\sigma_{t h}^{2}
\end{gathered}
$$

quedando finalmente el factor de calidad $\mathrm{Q}$ como

$$
\begin{aligned}
Q_{D P S K} & =\frac{1}{\sqrt{m\left(\frac{\sigma_{M A I-0}^{2}}{P_{d}^{2}}+(\xi)^{2}\right) \bar{\Gamma}+\frac{1}{2} m(m-1) \xi^{2} \bar{\Gamma}+\frac{1}{2} m \xi+\frac{\sigma_{s h}^{2}+\sigma_{t h}^{2}}{\Gamma^{2}(0) P_{d}^{2}}}} \\
& =\frac{1}{\sqrt{m\left(\frac{1}{S N R_{M A I-0}}+(\xi)^{2}\right) \bar{\Gamma}+\frac{1}{2} m(m-1) \xi^{2} \bar{\Gamma}+\frac{1}{2} m \xi+\frac{1}{S N R_{R}}}}
\end{aligned}
$$

los términos $\bar{\Gamma}, S N R_{R}$ y $S N R_{M A I-0}$ están definido de la misma forma que en el análisis para OOK.

Habiendo obtenido la expresión del factor Q para los sistemas que usan DPSK, es conveniente realizar un paralelo con la obtenida en los sistemas que usan OOK. Para facilitar la comparación desdoblamos la raíz de $Q_{D P S K}$ de forma que aparezcan las contribuciones de " 0 " y " 1 ". Estas contribuciones son exactamente iguales por lo que en el denominador de la expresión 2.60 hemos puesto un factor 2.

$$
Q_{D P S K}=\frac{1}{2 \sqrt{\frac{m}{4}\left(\frac{1}{S N R_{M A I-0}}+(\xi)^{2}\right) \bar{\Gamma}+\frac{m(m-1) \xi^{2} \bar{\Gamma}}{8}+\frac{m \xi}{8}+\frac{1}{4} \frac{1}{S N R_{R}}}}
$$

comparando la ecuación 2.60 con la ecuación 2.35 podemos ver que la potencia del ruido MAI disminuye tras la estructura de detección diferencial, de forma que pasamos de un término determinado por $\frac{1}{S N R_{M A I-0}}$ a $\frac{1}{4}\left(\frac{1}{S N R_{M A I-0}}+\xi^{2}\right)$. Por ejemplo, para un código Gold de $\mathrm{N}=127$ chips $\frac{1}{S N R_{M A I-0}} \approx 6,5 \times 10^{-5}$ y recordando que $\xi \approx \frac{1}{N}$ tendríamos que para un sistema DPSK $\frac{1}{S N R_{M A I-0}}+\xi^{2} \approx 3,17 \times 10^{-5}$. Esta ligera reducción en la potencia de ruido MAI dependerá del comportamiento de las señales interferentes, que a su vez son consecuencia de las características del código usado.

Por otra parte comparando el término de ruido de batido secundario de los sistemas DS-OCDMA con modulación DPSK se reduce en un octavo $\left(\frac{1}{8}\right)$ respecto del que se verifica en OOK.

El ruido de batido primario también se ve reducido, pero esta vez en un factor de un cuarto $\left(\frac{1}{4}\right)$ respecto de la que se presenta en OOK. A pesar de la evidente mejora, cabe aclarar que en OOK el término de ruido primario PBN solo se da en la contribución del término del símbolo "1". No existe para el símbolo "0" al no transportar potencia. En DPSK el batido primario entre "señal" e "interferencia" se produce tanto para el símbolo "1" como para el "0". 
Finalmente decir, que el ruido debido al receptor, es decir, el ruido térmico y el ruido shot se reduce en un factor de un cuarto $\frac{1}{4}$.

La comparación a nivel global del factor Q, entre los sistemas que usan DPSK y los que usan OOK, la podemos hacer a partir de los posibles escenarios. El primer escenario seria aquel en el que el ruido dominante sea el ruido de batido primario, es decir, $\xi \ll 1$ y ruido térmico y shot por debajo de los ruidos de interferencia, así los valores de $\mathrm{Q}$ los podemos simplificar a

$$
\begin{aligned}
Q_{D P S K} & =\frac{1}{\sqrt{\frac{m \xi}{2}}}=\frac{2}{\sqrt{2 m \xi}} \\
Q_{O O K} & =\frac{1}{\sqrt{2 m \xi}}
\end{aligned}
$$

En este caso la mejora en términos de Q es 2 . Si fijamos el valor de Q, es decir el valor de BER, la mejora en términos de $m$ será justamente 4 . Es decir las mejoras en $\mathrm{Q}$ al cuadrado. Esto supone un incremento sustancial en el número de usuarios activos al utilizar DPSK.

Si ahora el escenario que se nos presenta es donde el ruido dominante es el de batido secundario, entonces se considera que $m \gg 1$ y $\bar{\Gamma} \gg 1$ y en ese caso

$$
\begin{aligned}
Q_{D P S K} & =\frac{1}{\sqrt{\frac{m(m-1) \xi^{2} \overline{\bar{\Gamma}}}{2}}} \\
Q_{O O K} & =\frac{1}{2 \sqrt{m(m-1) \xi^{2} \bar{\Gamma}}} \\
\frac{Q_{D P S K}}{Q_{O O K}} & =2 \sqrt{2}
\end{aligned}
$$

La comparación completa entre los sistemas OCDMA DPSK y OOK se debe evaluar por medio de la BER que se realiza en un apartado posterior Por ahora diremos solo que la BER para sistemas OOK depende únicamente de los usuarios activos $(0<m<K-1)$ que interfieran sobre el bit de datos, mientras que para el caso de la BER en sistemas DPSK depende de todos los usuarios del sistema en ese momento $(K-1)$, ya que en DPSK se transmite señal tanto para el símbolo "1" como para el símbolo "0".

\subsection{Modelo del Ruido Bajo Hipótesis Asíncrona}

El modelo anterior parte de una hipótesis simplificadora en la que la totalidad de los $m$ chips interferentes se solapan perfectamente en la posición temporal del chip de datos recuperado tras la decodificación (peor caso de ruido de batido). Aunque esta suposición simplifica notablemente el modelo, no representa una situación real, en la que los distintos usuarios del sistema están totalmente incorrelados no sólo en fase óptica sino en retardo temporal. Es lo que se conoce como sistema asíncrono. En 


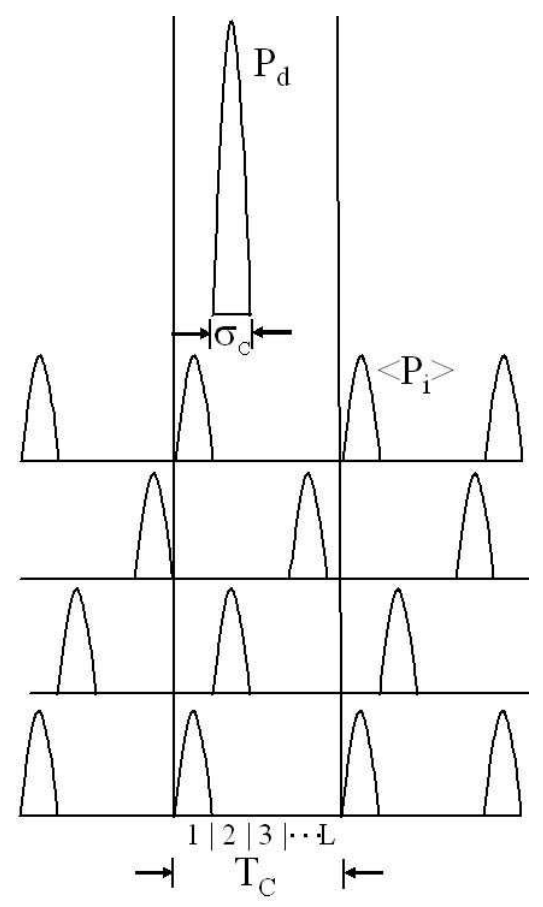

Figura 2.6: Sistema DS-OCDMA Asíncrono

la figura 2.6 muestra una situación arbitraria en la disposición temporal de los chips interferentes respecto del chip de datos.

La situación representada en la figura 2.6 introduce una nueva hipótesis en el modelo y es que la duración temporal de los chips puede ser en general menor que la separación entre los mismos. Esta hipótesis es valida ya que las fuentes láser pulsadas, generalmente de tipo Mode-Locked Laser Diode (MLLD), proporcionan anchuras de pulso en el rango de 0.5 a 10 ps con tasas de repetición entre $2.5,5$ y $10 \mathrm{GHz}$. En esta situación podemos imaginar un ejemplo de sistema DS-OCDMA con una tasa binaria de $1.25 \mathrm{~Gb} / \mathrm{s}$ (tiempo de bit de $800 \mathrm{ps}$ ), con una codificación de 63 o 127 chips por bit, en el que el tiempo de chip por lo tanto es de aproximadamente 12.7 y 6.3 ps respectivamente. En estos casos, si la anchura del pulso codificador es de $2 \mathrm{ps}, \mathrm{y}$ el dispositivo codificador no introduce ensanchamiento adicional sobre el mismo, la relación entre tiempo de chip y anchura de los pulsos codificados es de 6.35 y 3.15.

En los sistemas DS-OCDMA de tipo coherente, el cual en nuestro concepto es el que ha demostrado tener mayores ventajas, el ruido de batido primario es la mayor fuente de degradación del sistema. El ruido de batido primario es directamente proporcional al nivel de crosstalk $\xi$, mientras que el ruido de batido secundario es proporcional a $\xi^{2}$. De acuerdo a las expresiones obtenidas en los apartados anteriores es fácil deducir que en la medida que el número de usuarios se incrementa, el nivel de crosstalk necesario para mantener una determinada BER debe ser disminuido. Con la hipótesis de sistema asíncrono se reduce la contribución de ruido de batido pri- 
mario ya que no inciden sobre el chip de datos todos los usuarios interferentes. Esto se cumple tanto para sistemas con OOK como para sistemas con DPSK.

Para cuantificar la reducción del ruido de batido primario bajo la hipótesis de un sistema asíncrono asumiremos las siguientes simplificaciones:

- Definimos L posiciones discretas a lo largo del tiempo de chip $\left(T_{c}\right)$, donde los $m$ chips interferentes pueden estar localizados aleatoriamente. Nos referiremos a estas posiciones discretas como slots. Asumimos que la probabilidad de ocupación de cada slot de tiempo por un usuario interferente esta uniformemente distribuida para todos los slots y que esa probabilidad es $\alpha=\frac{1}{L}$. Además que la interferencia producida por los usuarios son procesos incorrelados con el mismo comportamiento.

- El ancho del tiempo de chip $\left(\sigma_{c}\right)$ es igual para todos los usuarios y esta dado por $\sigma_{c}=\frac{T_{c}}{L}$. Y se considera despreciable el solapamiento entre chips adyacentes.

- Definimos $M_{B 1}$ como el número de usuarios interferentes del total de $m$, que en un instante determinado ocupan el mismo slot que el de la señal que se desea decodificar $\left(P_{d}\right)$. Los chips $M_{B 1}$ son los que contribuirán al ruido de batido primario.

- $M_{B 2}$ se define como el número de usuarios interferentes remanente del conjunto $m-M_{B 1}$. Los chips interferentes de estos usuarios caen con igual probabilidad en cualquiera de los $l \in[1 \rightarrow(L-1)]$ slots disponibles dentro del tiempo de chip. El ruido de batido secundario es consecuencia de $M_{B 2}$. En resumen $M_{B 1}$ y $M_{B 2}$ constituyen el número total de usuarios interferentes en el sistemas distribuido de la siguiente manera

$$
m=M_{B 1}+\sum M_{B 2}(l)
$$

Bajo esta extensión del modelo del sistema, las posibles combinaciones de $M_{B 1}$ y $M_{B 2}$ producirán diferentes valores de potencia de ruido de batido primario y secundario, y por lo tanto diferentes valores de BER. La probabilidad de ocurrencia de cada una de estas combinaciones se expande sobre un amplio espectro de valores cada uno con un peso particular que incide sobre la BER del sistema de la siguiente manera

$$
\operatorname{BER}(m)=\sum P\left(M_{B 1}, M_{B 2}(l)\right) \cdot \operatorname{BER}\left(M_{B 1}, M_{B 2}\right)
$$

donde $P\left(M_{B 1}, M_{B 2}(l)\right)$ es la probabilidad de una combinación en particular.

La expresión de la fotocorriente en el instante central, que hemos escrito anteriormente podemos re-escribirla para incluir los términos $M_{B 1}$ y $M_{B 2}(l)$ dividiendo los $m$ posibles usuarios interferentes como 


$$
\begin{aligned}
i(t)= & \Re\left(P_{d} \Gamma(0)+P_{i} \sum_{k=-N}^{N} \sum_{i=1}^{m} \Gamma\left(-k T_{c}\right)\right)+2 \Re \sqrt{P_{d} P_{i}} \sum_{i=1}^{M_{B 1}} \Gamma(0) \cos \left(\triangle \Phi_{i}\right) \\
& +2 \Re P_{i} \sum_{k=-(N-1)}^{N-1} \Gamma\left(-k T_{c}\right) \sum_{i=1}^{M_{B 1}-1} \sum_{j=i+1}^{M_{B 1}} \cos \left(\triangle \Phi_{i j k}\right) \\
& +2 \Re P_{i} \sum_{k=-(N-1)}^{N-1} \Gamma\left(-k T_{c}\right) \sum_{l=1}^{L-1}\left\{\sum_{i=1}^{M_{B 2}(l)-1} \sum_{j=i+1}^{M_{B 2}(l)} \cos \left(\triangle \Phi_{i j k}\right)\right\}
\end{aligned}
$$

La diferencia con las expresiones de fotocorriente halladas en los apartados anteriores, se nota a partir del tercer término, el cual corresponde al ruido de batido primario. En este término la sumatoria ya no cubre los $m$ usuarios interferentes si no apenas a los que influyen al chip de datos. El cuarto término corresponde al batido secundario producido por el batido en campo de las componentes de usuarios que caen sobre el chip de datos. El último término es el ruido de batido secundario de los usuarios que caen dentro del tiempo de chip, pero que no influyen directamente sobre el chip de datos.

Tomando en cuenta las mismas consideraciones que para las ecuaciones 2.20, 2.21, 2.22 y 2.23 con respecto a la aleatoriedad de las variables de fase relativas, los términos de potencia para el ruido de batido primario y secundario quedan como

$$
\begin{aligned}
\sigma_{P B N}^{2} & =2 M_{B 1} \xi P_{d}^{2} \Gamma^{2}(0) \\
\sigma_{S B N}^{2} & =\xi^{2} P_{d}^{2} \sum_{k=-N}^{N-1} \Gamma^{2}\left(-k T_{c}\right)\left[M_{B 1}\left(M_{B 1}-1\right)+\sum_{l=1}^{L-1} M_{B 2}(l)\left(M_{B 2}(l)-1\right)\right]
\end{aligned}
$$

las ecuaciones 2.63 y 2.64 toman en cuenta el caso general con el conjunto completo de posibles combinaciones del vector $M_{B 2}(l)$. Para reducir la complejidad y el tiempo de procesamiento de la expresión 2.64 podemos asumir que los $m-M_{B 1}$ usuarios interferentes que causan el ruido de batido secundario están uniformemente distribuidos a lo largo de $l \in[1 \rightarrow(L-1)]$ posiciones. De acuerdo a esto el número de usuarios interferentes a lo largo de los $l$ slots puede ser tomado como una constante $M_{B 2}(l)=M_{B 2}=\left(m-M_{B 1}\right)(L-1)$. Si aplicamos esta simplificación a la ecuación 2.64 , la potencia de ruido de batido secundario queda como

$$
\sigma_{S B N}^{2}=\xi^{2} P_{d}^{2} \sum_{k=-N}^{N-1} \Gamma^{2}\left(-k T_{c}\right)\left[M_{B 1}\left(M_{B 1}-1\right)+(L-1) M_{B 2}\left(M_{B 2}-1\right)\right]
$$

y bajo esta simplificación la $B E R(m)$ de la ecuación 2.61 se reduce a

$$
\begin{aligned}
\operatorname{BER}(m) & =\sum_{M_{B 1}=0}^{m} P\left(M_{B 1}\right) \cdot \operatorname{BER}\left(M_{B 1}\right) \\
P\left(M_{B 1}\right) & =\left(\begin{array}{c}
m \\
M_{B 1}
\end{array}\right)\left(\frac{1}{L}\right)^{M_{B 1}}\left(1-\left(\frac{1}{L}\right)\right)^{m-M_{B 1}}
\end{aligned}
$$




$$
P\left(M_{B 1}\right)=\left(\begin{array}{c}
m \\
M_{B 1}
\end{array}\right)\left(\frac{1}{L}\right)^{M_{B 1}}\left(1-\frac{1}{L}\right)^{m-M_{B 1}}
$$

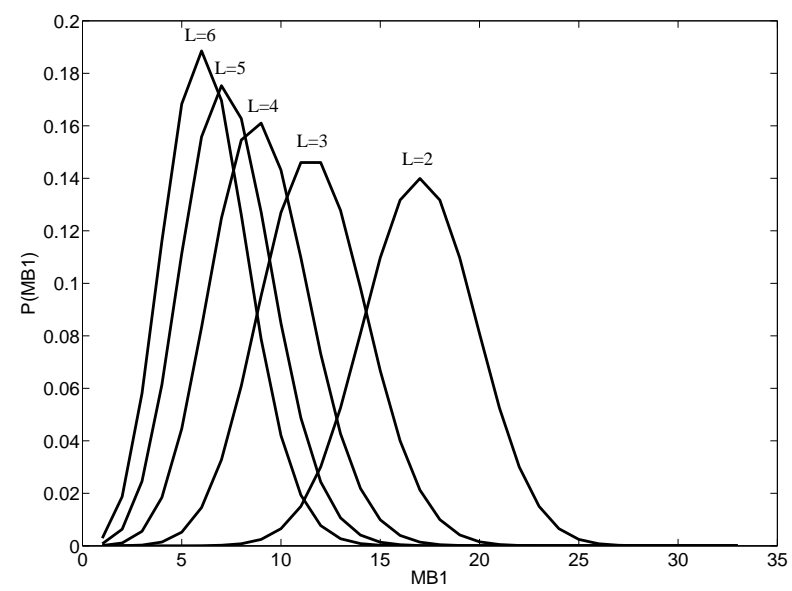

Figura 2.7: Función de Distribución de Probabilidad de que $M_{B 1}$ chips interferentes sobrelapen el chip de datos

donde $P\left(M_{B 1}\right)$ es la probabilidad de que $M_{B 1}$ usuarios interferentes del conjunto de $m$ se encuentren en la misma posición de slot del dato decodificado.

La figura 2.7 muestra un ejemplo de la función de distribución de probabilidad para $m=32$ (usuarios activos) y $l$ entre 2 y 6 slots dentro del tiempo de chip. El pico de la función de probabilidad se localiza aproximadamente en $\frac{m}{L}$, y los valores de probabilidad $P\left(M_{B 1}\right)$ se reducen drásticamente para valores de $M_{B 1}$ mayores que el promedio.

Para hallar el factor de calidad Q y así poder calcular la $B E R\left(M_{B 1}\right)$, asumimos que tenemos una aproximación gausiana, al igual que se hizo para los apartados anteriores. Tomando las nuevas expresiones halladas para las potencias de ruido primario y secundario, y reemplazando primero para el caso de modulación OOK (ecuación 2.35) obtenemos

$$
\begin{gathered}
Q_{O O K}=\frac{1}{\sqrt{\frac{m \bar{\Gamma}}{S N R_{M A I}}+\Psi \xi^{2} \bar{\Gamma}+\frac{1}{S N R}}+\sqrt{\frac{m \bar{\Gamma}}{S N R_{M A I}}+\Psi \xi^{2} \bar{\Gamma}+2 M_{B 1} \xi+\frac{1}{S N R}}} \\
\Psi=M_{B 1}\left(M_{B 1}-1\right)+(L-1) M_{B 2}\left(M_{B 2}-1\right) \\
M_{B 2}=\frac{m-M_{B 1}}{L-1}
\end{gathered}
$$


Se tienen las mismas consideraciones para el tipo de modulación DPSK sin cambios conceptuales. Substituyendo en la ecuación $2.59 \mathrm{~m}$ por $M_{B 1}$ en el término de potencia de ruido de batido primario, y $m(m-1)$ por $\Psi$ en el término de potencia de ruido de batido secundario, obtenemos

$$
Q_{D P S K}=\frac{1}{\sqrt{m\left(\frac{1}{S N R_{M A I-0}}+(\xi)^{2}\right) \bar{\Gamma}+\frac{1}{2} \Psi \xi^{2} \bar{\Gamma}+\frac{1}{2} M_{B 1} \xi+\frac{1}{S N R_{R}}}}
$$

\subsection{Efecto del Uso de Técnicas de Thresholding en Sistemas DS-OCDMA}

En los sistemas OCDMA es fundamental la habilidad que tiene el receptor para discriminar entre la señal deseada y las señales interferentes. Cuando se realiza el proceso de decodificación de la señal, la amplitud de los pulsos decodificados correctamente puede llegar a ser muy similar a la suma de los pulsos decodificados incorrectamente de los múltiples usuarios. Los receptores ópticos, dado su limitada respuesta temporal, no pueden diferenciar entre el pulso objetivo y los interferentes [10, 11]. De tal manera que en los sistemas OCDMA se requiere utilizar alguna técnica de "thresholding" en el dominio óptico que permita discriminar correctamente las señales.

El thresholding óptico consiste en encontrar un punto de umbral a partir del cual la señal pueda ser detectada correctamente por el fotodetector, de tal forma que los valores que estén por debajo de ese umbral sean despreciados. Mediante el uso de estas técnicas es posible reducir, y en el mejor de los casos eliminar, el ruido incoherente MAI y el ruido de batido de segundo orden. No obstante el ruido de batido primario es irreducible usando este tipo de técnicas.

Existen múltiples técnicas de thresholding que han sido propuestas por diferentes autores [39, 41, 42, 9, 43]. Aunque podemos decir que en términos generales las técnicas típicas de thresholding óptico se basan fundamentalmente en la inducción de efectos no lineales en fibras ópticas u otros materiales no lineales. Gracias a estos elementos se pueden generar componentes espectrales que contengan la información deseada y que luego podrán ser seleccionadas mediante un filtro. El hecho de que las componentes espectrales generadas lleven la información deseada, ocurre porque solamente el pulso decodificado correctamente tiene la energía de pico necesaria para inducir los efectos no lineales.

En la figura 2.8 podemos ver como el pulso decodificado correctamente sufre un desplazamiento en su espectro, tanto hacia longitudes de onda más bajas como hacia longitudes de onda más altas, mientras que el pulso decodificado incorrectamente no sufre ningún desplazamiento. Finalmente un filtro óptico sintonizado para dejar pasar las longitudes de onda deseadas filtra el espectro antes de la detección. Un thresholder ideal puede eliminar completamente el ruido de batido de segundo orden y la interferencia de múltiple acceso; $\sigma_{M A I}^{2}=\sigma_{S B N}^{2}=0$ [44].

Normalmente para llevar a acabo el thresholding se usa el esquema de la figura 2.9, básicamente consiste de un amplificador de fibra dopada con Erbio (EDFA), el elemento no lineal y un filtro óptico. Se han demostrado diversas tecnologías según el 


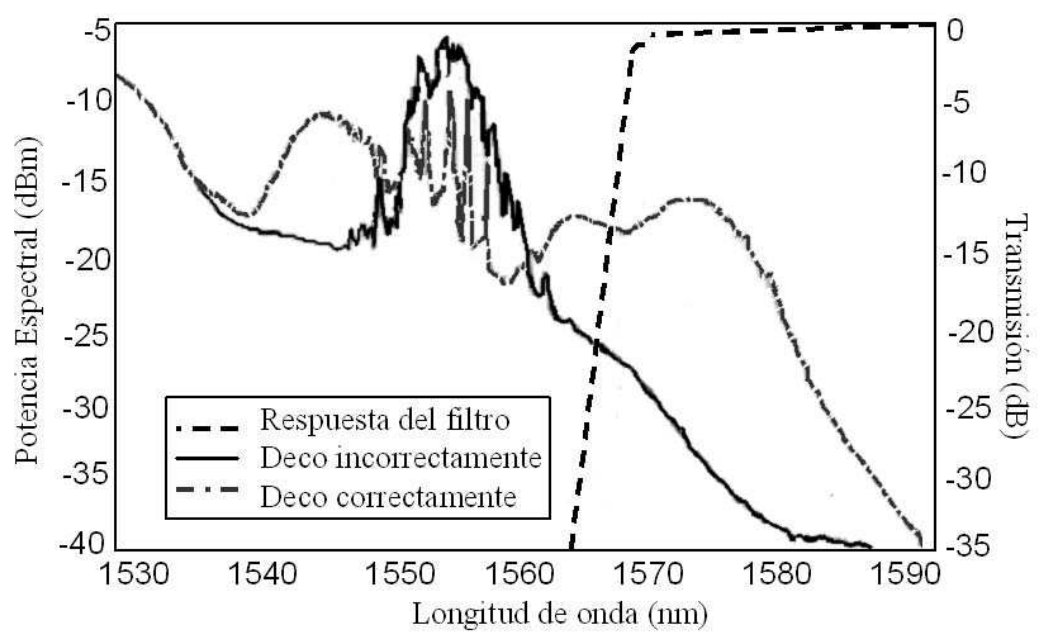

Figura 2.8: Resultados espectrales para un thresholder basado en HNLF de un pulso decodificado incorrectamente (línea negra) y uno decodificado correctamente (línea gris) y la respuesta del filtro (línea a trazos)[11].

dispositivo que se use para implementar el efecto no lineal, entre ellos podemos citar; la HNFL (High NonLinear Fiber) [42, 45], que puede ser una fibra de cristal fotónico de la cual se usan algunas decenas o centenas de metros, fibras de dispersión desplazada de alta no-linealidad [46, 47]. Otras tecnologías como las guías PPLN (PeriodicallyPoled Lithium Niobate) han demostrado muy altas eficiencias con relativamente baja potencia de pulsos [10,48], o las estructuras de tipo Sagnac de fibra no lineal como los NOLM (Non-linear Optical Loop Mirror) [49, 50].

Aunque los procedimientos de implementación de los thresholders son muy heterogéneos en función de los dispositivos no-lineales utilizados, en todos ellos se produce una discriminación según la potencia óptica instantánea de la señal, que se traduce en

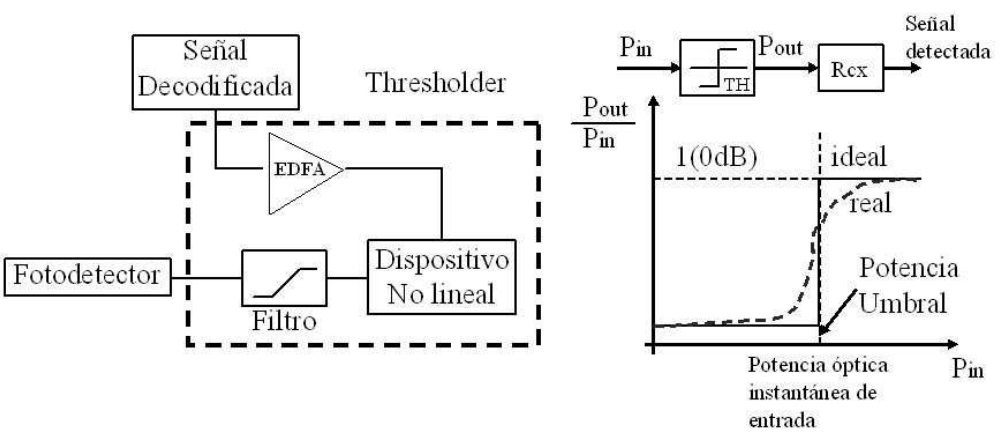

Figura 2.9: Thresholder óptico 
un desplazamiento de frecuencia y un posterior filtrado óptico. Este proceso se puede ver como una función de transferencia de potencia de entrada instantánea a potencia de salida instantánea no lineal como el representado en la parte derecha de la figura 2.9 .

Como podemos ver en dicha figura, el thresholder ideal queda definido mediante dos únicos parámetros, 1) la potencia instantánea a la que se produce el escalón de discriminación no lineal, y 2) la relación entre la atenuación de las potencias más bajas (por debajo del umbral) respecto de las que están por encima del mismo, o lo que se puede denominar "relación de thresholding" (TH en el esquema de la figura 2.9).

Para la aplicación del thresholder al modelo de cálculo de la BER del sistema OCDMA es necesario suponer que el valor umbral de potencia óptica instantánea, y por lo tanto de fotocorriente equivalente, se encuentra ajustado dentro del rango que forma la apertura del diagrama de ojos sin thresholder. Con esto aseguramos que realiza su función correctamente. Adicionalmente para poder incluirlo en el modelo, el thresholding óptico debe tener una respuesta paso ideal. De esta manera, definimos una ganancia óptica debida al thresholding $\left(G_{t h}=-10 \log _{10}\left(g_{t h}\right)\right)$, como la relación entre la señal antes y después del thresholder.

Para incluir el efecto del Thresholding partiremos de las expresiones para el sistema con modulación OOK. Los primeros términos que se afectan, son los de las expresiones $2.21,2.22$ y 2.23, y por lo tanto el factor Q en la ecuación 2.35. El efecto se incluye fácilmente substituyendo el $\bar{\Gamma}$ original y teniendo en cuenta que afecta de forma diferente al símbolo " 0 " que al símbolo " 1 ".

$$
\begin{aligned}
& B i t^{\prime} 0^{\prime} \rightarrow \overline{\Gamma_{0}^{\prime}}=\bar{\Gamma} g_{t h}^{2} \\
& {\operatorname{Bit} 1^{\prime} 1^{\prime}}^{\rightarrow} \overline{\Gamma_{1}^{\prime}}=\left((\bar{\Gamma}-1) g_{t h}^{2}\right)+1
\end{aligned}
$$

Nótese que para el símbolo "0", los ruidos SBN y MAI son reducidos para la totalidad del número equivalente de chips $\bar{\Gamma}$, pero para el símbolo "1" los beneficios de la ganancia por el thresholding solo afecta si $\bar{\Gamma}>1$. La apertura del ojo dada por $I_{1}-I_{0}$ dentro de la definición del factor $\mathrm{Q}$ también se vera afectada por la ganancia de thresholding. En este caso la señal multiusuario promedio de los símbolos "1" y " 0 " no puede ser eliminada, como se hizo en las ecuaciones 2.26 y 2.27 debido a la discriminación en potencia. Aun así podemos incluir el efecto con un nivel de crosstalk modificado como $\xi^{\prime}=\xi g_{t h}$ para todos los valores de $k$ dentro de $I_{0}$ definido en 2.27 y aplicándolo para todo $k \neq 0$ dentro de $I_{1}$. La apertura de ojo resultante es

$$
I_{1}-I_{0}=P_{d} \Gamma(0)[1+\xi m]+P_{d} \xi m g_{t h}\left(\sum_{k \neq 0} \Gamma\left(-k T_{c}\right)-\sum_{\forall k} \Gamma\left(-k T_{c}\right)\right)
$$

La expresión 2.74 se puede simplificar fácilmente porque la resta de las sumatorias se hace igual a $\Gamma(0)$ y rescribiéndola tenemos

$$
I_{1}-I_{0}=P_{d} \Gamma(0)\left[1+\xi m\left(1-g_{t h}\right)\right]
$$


es importante ver que esta ecuación es independiente de la forma de la función $\Gamma(t)$ y por lo tanto independiente de $\bar{\Gamma}$.

En el mejor de los casos, cuando $g_{t h} \ll 1$, la apertura del diagrama de ojos se incrementa en un factor de $(1+\xi m)$ y sin ganancia de thresholding $\left(g_{t h}=1\right)$ las expresiones halladas en los apartados anteriores no sufren modificaciones.

La expresión del factor Q en el modelo del sistema con modulación OOK, incluyendo el efecto de thresholding queda definitivamente como

$$
\text { QOOK }_{t h}=\frac{1+\xi m\left(1-g_{t h}\right)}{\sqrt{\frac{m \overline{\Gamma_{0}}}{S N R_{M A I}}+m(m-1) \xi^{2} \overline{\Gamma_{0}}+\frac{1}{S N R}}+\sqrt{\frac{m \overline{\Gamma_{1}}}{S N R_{M A I}}+m(m-1) \xi^{2} \overline{\Gamma_{1}}+2 m \xi+\frac{1}{S N R}}}
$$

Para el sistema con modulación DPSK el efecto del thresholding óptico, se aplica antes del receptor DPSK. De tal forma que $\bar{\Gamma}$ debe ser modificado, pero solamente atendiendo la consideración de los símbolos 1, es decir, según la expresión 2.73.

No se realiza ninguna modificación en la apertura del diagrama de ojo, ya que en la deducción del factor $\mathrm{Q}$ no se realizó ponderación alguna. Por lo tanto el factor $\mathrm{Q}$ en sistemas con modulación DPSK queda como

$$
Q_{D P S K_{t h}}=\frac{1}{\sqrt{m\left(\frac{1}{S N R_{M A I-0}}-(\xi)^{2}\right) \overline{\Gamma_{1}}+\frac{1}{2} m(m-1) \xi^{2} \overline{\Gamma_{1}}+\frac{1}{2} m \xi+\frac{1}{S N R_{R}}}}(2.77)
$$

Los cambios en las ecuaciones bajo hipótesis de sistema asíncrono son análogos.

\subsection{Efecto de la Polarización de las Señales Interferentes}

El modelo planteado por [37] consideraba que la polarización entre la señal de datos y la señal interferente era la misma, lo cual significa que se realizó el estudio para el peor caso. A continuación se realiza el análisis para encontrar cual es efectivamente el efecto cuando se modela el sistema con estados de polarización aleatorios para cada una de las señales.

Partimos de que el campo eléctrico lo podemos definir como:

$$
\bar{E}(t)=\left[\begin{array}{l}
e_{1}(t) \\
e_{2}(t)
\end{array}\right] e^{j 2 \pi f t}
$$

En donde $e_{1}(t)$ y $e_{2}(t)$ son componentes complejas transversales del campo respecto a vectores ortogonales de referencia

Estos vectores pueden modificar su posición a medida que el campo avanza por el material sobre el que se propaga, de tal manera que se debe definir una matriz de Jones de birrefringencia que representa el cambio de polarización que causa determinado material o componente cuando el campo se propaga

$$
\left[\begin{array}{l}
e_{1}^{\prime}(t) \\
e_{2}^{\prime}(t)
\end{array}\right]=Q^{\prime}\left[\begin{array}{l}
e_{1}(t) \\
e_{2}(t)
\end{array}\right]
$$


En la representación de stokes, cada estado posible de polarización o SOP (State of Polarization), se representa en un punto del espacio 3 D con coordenadas S1, S2, $\mathrm{S} 3$, respecto de las coordenadas unitarias $\hat{s_{1}}, \hat{s_{2}}, \hat{s_{3}}$.

Una característica de la representación de stokes es que todos los SOP están contenidos en la esfera de Poincare y se dice que puntos diametralmente opuestos en la esfera son o corresponden a polarizaciones ortogonales.

Si consideramos un vector de referencia $\overrightarrow{S_{d}}$ (señal de datos) en el espacio de stokes alineado con $\hat{s_{1}}$ (por conveniencia) se puede expresar la relación SOP entre las señales interferentes y $\overrightarrow{S_{d}}$ en términos de las coordenadas esféricas $\theta$ y $\phi$ (figura 2.10a.).

$$
\underbrace{\left[\begin{array}{c}
e_{1}^{\prime} \\
e_{2}^{\prime}
\end{array}\right]}_{V J i}=Q_{1}(\phi) Q_{2}(\theta) \underbrace{\left[\begin{array}{c}
e_{1} \\
0
\end{array}\right]}_{V J d}
$$

donde $V J i$ es el vector de Jones de la señal interferente arbitraria $\vec{S}_{i}$ y $V J d$ es el vector de Jones de la señal de datos correspondiente a $\overrightarrow{S_{d}}$.

Las matrices $Q_{1}(\phi)$ y $Q_{2}(\theta)$ las podemos definir como

$$
\begin{aligned}
Q_{1}(\phi) & =\left[\begin{array}{cc}
e^{j \frac{\phi}{2}} & 0 \\
0 & e^{-j \frac{\phi}{2}}
\end{array}\right] \\
Q_{2}(\theta) & =\left[\begin{array}{cc}
\cos \frac{\theta}{2} & j \sin \frac{\theta}{2} \\
j \sin \frac{\theta}{2} & \cos \frac{\theta}{2}
\end{array}\right]
\end{aligned}
$$

El producto $Q_{1}(\phi) Q_{2}(\theta)$ nos proporciona la relación entre las polarizaciones

$$
Q_{1}(\phi)=\left[\begin{array}{cc}
e^{j \frac{\phi}{2}} \cdot \cos \frac{\theta}{2} & e^{j \frac{\phi}{2}} \cdot j \sin \frac{\theta}{2} \\
e^{-j \frac{\phi}{2}} \cdot j \sin \frac{\theta}{2} & e^{-j \frac{\phi}{2}} \cdot \cos \frac{\theta}{2}
\end{array}\right]\left[\begin{array}{c}
e_{1} \\
0
\end{array}\right]
$$

De tal forma que nuestras nuevas componentes complejas de campo serán

$$
\begin{aligned}
& e_{1}^{\prime}=e^{j \frac{\phi}{2}} \cdot \cos \frac{\theta}{2} e_{1} \\
& e_{2}^{\prime}=e^{-j \frac{\phi}{2}} \cdot j \sin \frac{\theta}{2}
\end{aligned}
$$

La relación de potencias asociadas a las componentes "heterodina" (paralela) y total será:

$$
\begin{gathered}
\gamma=\frac{\left|e_{1}^{\prime}\right|^{2}}{\left|e_{1}^{\prime}\right|^{2}+\left|e_{2}^{\prime}\right|^{2}}=\frac{\cos ^{2} \frac{\theta}{2}\left|e_{1}^{\prime}\right|^{2}}{\left|e_{1}^{\prime}\right|^{2}}=\cos ^{2} \frac{\theta}{2}=\frac{1}{2}(1+\cos \theta) \\
\gamma_{i}=\frac{1}{2}(1+\cos \theta) \\
\left\{\begin{array}{lll}
\text { si } & \theta=0 & \text { Peor caso, batido perfecto } \\
\text { si } & \theta=\pi & \text { No hay batido }
\end{array}\right.
\end{gathered}
$$



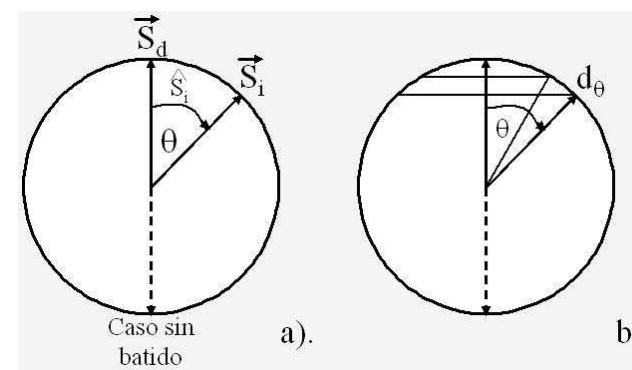

b).

Figura 2.10: a). Representación de la esfera de Poincare, b).Descripción del área que cubre la variación del ángulo de la señal interferente

Podemos suponer que $\overrightarrow{S_{i}}$ estarán distribuidos uniformemente en la superficie de la esfera. Esta suposición ha sido generalmente aceptada.

El área correspondiente a este $d \theta$ es $2 \pi \sin \theta d \theta$ (figura 2.10b.)

$$
\begin{aligned}
\int_{0}^{\pi} 2 \pi \sin \theta d \theta & =4 \pi \\
\int_{0}^{\pi} P_{\theta}(\theta) d \theta & =1 \\
P_{\theta}(\theta) & =\frac{1}{2} \sin \theta
\end{aligned}
$$

En donde $P_{\theta}(\theta)$ es la función de densidad de probabilidad para el ángulo $\theta$ extendida entre $\theta=[0, \pi]$.

La aleatoriedad de la SOP afecta los términos de batido, de forma que cada uno de los términos $\cos \left(\Delta \phi_{i}\right)$ ó $\cos \left(\Delta \phi_{i j}\right)$ se deben afectar por un término $\sqrt{\gamma_{i}}$ al ser $\gamma_{i}$ una fracción de la potencia total. Además podemos suponer que $\cos \left(\Delta \phi_{i}\right)$ y $\sqrt{\gamma_{i}}$ son funciones aleatorias independientes. De esta forma la media y la varianza quedan como

$$
\begin{gathered}
E\left\langle\cos \left(\Delta \phi_{i}\right) \cdot \sqrt{\gamma_{i}}\right\rangle=E \underbrace{\left\langle\cos \left(\Delta \phi_{i}\right)\right\rangle}_{=0} E\left[\sqrt{\gamma_{i}}\right]=0 \\
\sigma^{2}=E\left\langle\cos ^{2}\left(\Delta \phi_{i}\right) \cdot \gamma_{i}\right\rangle-\underbrace{E\left\langle\cos \left(\Delta \phi_{i}\right) \cdot \sqrt{\gamma_{i}}\right\rangle^{2}}_{=0} \\
\sigma^{2}=\underbrace{\int_{-\pi}^{-\pi} \cos ^{2}\left(\Delta \phi_{i}\right) \cdot P_{\Delta \phi_{i}}\left(\Delta \phi_{i}\right) \cdot d \Delta \phi_{i}}_{A} \cdot \underbrace{\int_{0}^{\pi} \frac{1}{2}(1+\cos \theta) \cdot \frac{\sin \theta}{2} \cdot d \theta}_{B}
\end{gathered}
$$

En el primer término de esta varianza, al que hemos llamado A tiene a un valor de $\frac{1}{2}$ y el segundo, B, tiene un valor de $\left(\frac{1}{2}+\frac{\pi}{8}\right)$ que es un valor muy cercano a 1 , 
luego podemos concluir que la inclusión del efecto de la polarización aleatoria entre señales interferentes y de datos no supone una variación significativa respecto de la suposición del peor caso. En cualquier caso, la aplicación de esta suposición de polarización aleatoria es inmediata sobre los términos de ruido quedando el ruido de batido primario por ejemplo:

$$
\begin{aligned}
\sigma_{P B N}^{2} & =\left\langle i_{P B N}^{2}\right\rangle-\underbrace{\left\langle i_{P B N}\right\rangle^{2}}_{\rightarrow 0}=4 \xi P_{d}^{2} \sum_{i=1}^{m} \underbrace{\left\langle\cos ^{2}\left(\Delta \Phi_{i}\right) \gamma_{i}\right\rangle}_{\rightarrow A B} \\
& =2 \xi P_{d}^{2} m
\end{aligned}
$$

\subsection{Resultados de la Simulación y Discusión}

En este capítulo hemos planteado 3 modelos que contemplan los sistemas OCDMA con modulación OOK, los sistemas con modulación DPSK y el modelo bajo hipótesis asíncrona que es valido para ambos tipos de modulaciones. Se ha considerado dentro del modelado el efecto del aumento o reducción del ancho de banda del receptor, suponiéndolo en el mejor de los casos para un time gating ideal y también para el peor de los casos con ancho de banda comparable al inverso del tiempo de bit. Se ha incluido el efecto del uso ó no, de las técnicas de thresholding. Y por último se ha descartado la consideración de polarización aleatoria de las señales interferentes, ya que se ha concluido que su efecto no es relevante.

\subsubsection{Sistemas OCDMA con Modulación OOK vs. Sistemas OCDMA con Modulación DPSK}

En esta primera evaluación de los modelos descritos comparamos los sistemas con modulación OOK vs. los sistemas con modulación DPSK. Para ellos hemos fijado el valor de BER en 1e-9. El objetivo aquí será encontrar cual es el máximo de usuarios permitidos según el nivel de crosstalk presente en el sistema.

Como era previsible, los resultados para los sistemas DPSK mostrados en la figura 2.11 son mucho mejores que los obtenidos para sistemas OCDMA con modulación OOK. La figura 2.11(a) representa el caso de time gating perfecto $\bar{\Gamma}=1$, es decir, $B_{R}=\frac{1}{2 T_{c}}$, allí los sistemas DPSK presentan una mejora con respecto a los sistemas con modulación OOK de casi 4 veces, corroborando lo dicho en [39]. Cabe resaltar que a medida que el crosstalk aumenta el número de usuarios en el sistema que garantiza una $B E R=10^{-9}$ disminuye y también disminuye la mejora de un sistema con respecto al otro. Para la simulación mostrada en la figura 2.11(b), se ha empleado un sistema con time gating no ideal, donde se considera que el $5 \%$ de los posibles chips dentro de un tiempo de bit esta interfiriendo sobre el pulso deseado. Esto quiere decir que $B_{R}=\frac{1}{2 T_{c}} \bar{\Gamma}=\frac{1}{2 T_{c}}(2 N-1) \frac{5}{100}$. Nótese que esta pequeña disminución en el rendimiento del time gating causa un decremento, en un factor aproximadamente igual a 2, del número de usuarios que puede acceder al sistema. Además se puede ver que los sistemas con modulación DPSK se ven más afectados que los OOK, lo cual es lógico bajo la perspectiva de que en estos sistemas se considera transmisión 


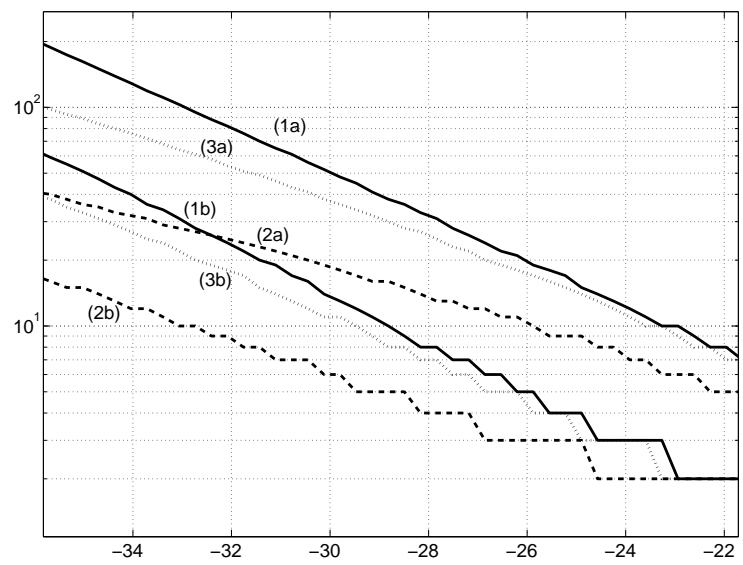

Figura 2.11: Comparación del rendimiento entre los sistemas OCDMA con modulación a) DPSK y b) OOK. BER $=1 \times 10^{-9}$. 1) Time gating ideal, solo un tiempo de chip $(\bar{\Gamma}=1)$. 2) Time gating no ideal, $5 \%$ del total de chips interferentes dentro de un tiempo de bit. 3) Time gating no ideal, pero empleando thresholding óptico con $G_{t h}=5 d B$.

de energía tanto para el símbolo "1" como para el símbolo "0". Finalmente la figura 2.11(c) muestra la mejora conseguida al emplear técnicas de thresholding sobre un sistema que ha usado un time gating imperfecto como el simulado en 2.11(b). La ganancia de thresholding dada en este caso fue de $5 \mathrm{~dB}$ como la empleada en [43, 39], y con ella se consigue una mejora del sistema de casi el $30 \%$. Esto es consecuencia de la disminución tanto del ruido de batido secundario como del MAI. Si la ganancia de thresholding aumenta las curvas 1 y 3 de la figura 2.11 tenderían a converger.

\subsubsection{Evaluación del Modelo Generalizado de los Sistemas OCDMA.}

Para la evaluación del modelo generalizado del sistema DS-OCDMA, se empleara como parámetro de calidad, la penalización por interferencia multiusuario (MUI). Nosotros la definimos como el incremento requerido de potencia óptica promedio a la entrada del receptor, respecto del caso limitado por ruido térmico, para compensar la degradación del conjunto de ruidos de interferencia multiusuario y por lo tanto mantener una $B E R=1 \times 10^{-9}$.

Esta aproximación permite claramente estudiar las relaciones entre los principales parámetros del sistema: Número de usuarios (K), nivel de crosstalk de las señales interferentes $(\xi)$ y el número de slots de tiempo $(\mathrm{L})$ para el modelo asíncrono. Para este primer análisis se ha resuelto la ecuación 2.35 para una $B E R=1 \times 10^{-9}$ fija y una densidad espectral de ruido térmico de $N_{t h}=1 \frac{p A^{2}}{H z}$.

La figura 2.12 muestra la penalización en potencia MUI vs. el nivel de crosstalk. 


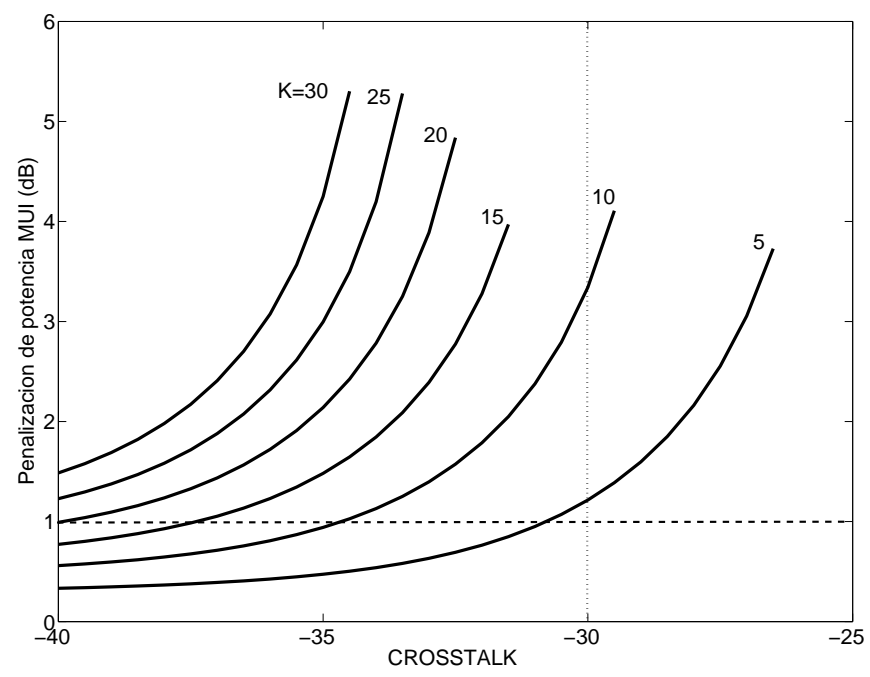

Figura 2.12: Penalización de potencia MUI (dB) vs. relación de crosstalk $10 \log _{10}(\xi)$ para diferente número de usuarios totales $(K)$. Solapamiento perfecto entre señales de datos y señales interferentes.

Aquí el parámetro $\bar{\Gamma}=1$ ha sido fijado para una condición de time gating perfecto, no se usa ninguna técnica de thresholding $\left(g_{t h}=1\right)$ y el número de slots de tiempos es $\mathrm{L}=1$. Esto equivale al modelo simplificado síncrono de [37]. Las diferentes curvas corresponden con un número total de usuarios $(\mathrm{K})$.

La máxima penalización admisible que se toma normalmente es de $1 \mathrm{~dB}$. En la tabla 2.1 se muestra el crosstalk mínimo aceptado según el número de usuarios para obtener dicha penalización.

El grado de crosstalk en sistemas DS-OCDMA de tipo coherente se puede aproximar a la inversa del número de chips o longitud del código $\left(\xi=\frac{1}{N_{\text {chips }}}\right)$ [37]. Y como se puede ver en la tabla 2.1 el nivel $\xi$ máximo admisible incluso para 5 usuarios es de

\begin{tabular}{|c|c|c|}
\hline Usuarios & Crosstalk & Longitud de código mínima \\
\hline \hline 5 & -30.0191 & 1024 chips \\
\hline 10 & -34.6591 & 4096 chips \\
\hline 15 & -37.3944 & 8192 chips \\
\hline 20 & -39.9174 & 16384 chips \\
\hline 25 & $<-40$ & \\
\hline 30 & $<-40$ & \\
\hline
\end{tabular}

Cuadro 2.1: Crosstalk para obtener una penalización máxima de $1 \mathrm{~dB}$, para diferentes números de usuarios y sistema síncrono. 


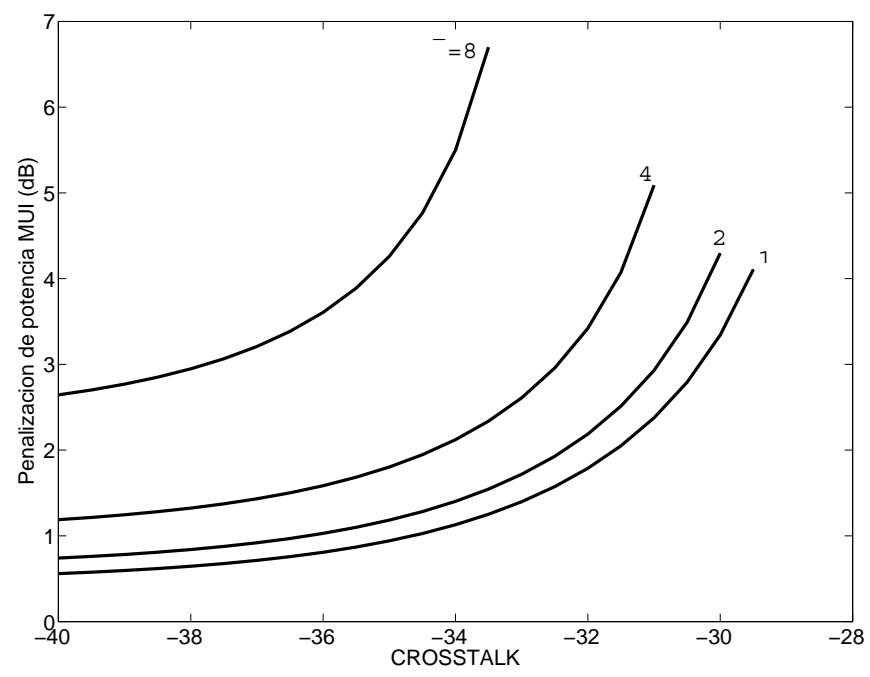

Figura 2.13: Penalización de potencia MUI $(\mathrm{dB})$ frente a la relación de crosstalk $1_{10 \log _{10}}(\xi)$. Para 10 usuarios. Modelos síncrono, para diferentes valores de $\bar{\Gamma}$.

-30dB (requiere códigos de 1000 chips) o de -34.6dB para 10 usuarios (requiere códigos de 4000 chips), lo que es una importante limitación tecnológica. Con los resultados anteriores podemos decir que un sistema que requiera trabajar con los parámetros indicados al principio, es inviable bajo el criterio de 1 dB máximo de penalización, debido a la dificultad de implementar códigos con más de 500 chips.

Anteriormente vimos como el sistema se degradaba al considerar un time gating no ideal. Para verlo aun más claramente podemos realizar una simulación que nos muestre la penalización en potencia MUI necesaria para conservar una $B E R=1 \times$ $10^{-9}$ modificando en este caso la cantidad de tiempos de chip considerados como interferentes. De esta manera el valor de $\bar{\Gamma}$ dado en la figura 2.13 , indicara el número de tiempos de chip considerados en la integral.

La figura 2.13 muestra como a medida que el ancho de banda disminuye, el sistema decrementa notoriamente su rendimiento. Para los mismos 10 usuarios el valor de crosstalk se hace más exigente. Para un incremento del tiempo de integración de 8 veces, el valor del crosstalk aumenta en más de $3 \mathrm{~dB}$, por fuera del rango de penalización máxima de $1 \mathrm{~dB}$.

Los resultados obtenidos eran los esperados, y demuestran el impacto del ruido de batido secundario (SBN) y MAI cuando el time gating no es el ideal.

\subsubsection{Evaluación del Modelo Bajo Hipótesis Asíncrona}

En la sección 2.5 se reformuló el modelo de [37] bajo la hipótesis de asincronía en el sistema. La asincronía implica, que no necesariamente los chips que caen dentro del período del chip de dato interferirán directamente sobre él, reduciendo por tanto el 


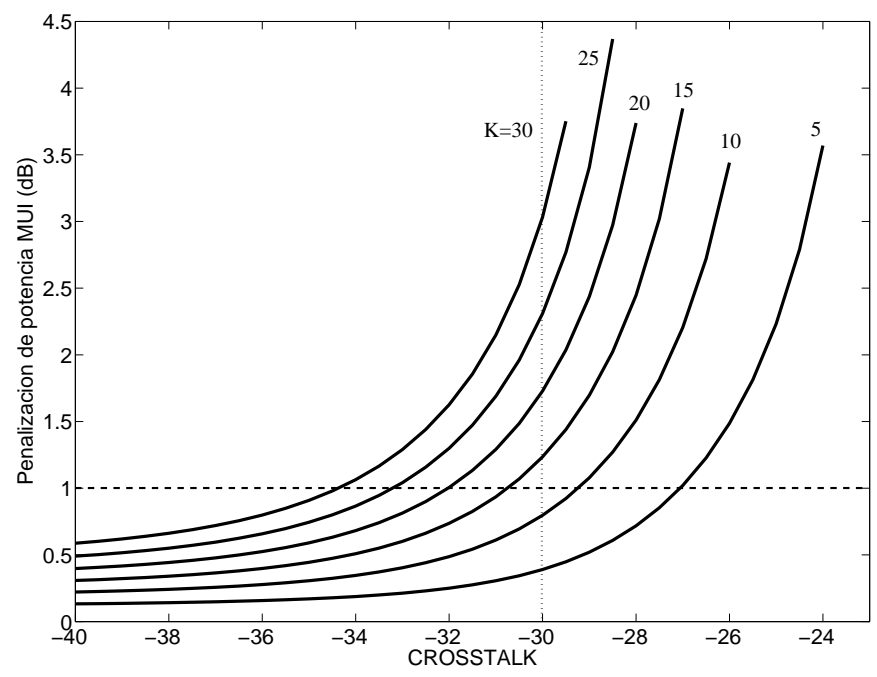

Figura 2.14: Penalización de potencia MUI $(\mathrm{dB})$ frente a la relación de crosstalk

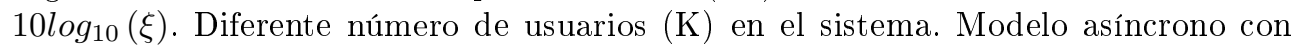
$\mathrm{L}=6$.

\section{MAI y el SBN.}

La evaluación del modelo para $\mathrm{L}=6$ (figura 2.14), muestra una reducción sustancial del impacto del ruido de batido dominante (PBN), suavizando los estrictos requisitos de crosstalk máximo a $-26 \mathrm{~dB}$ para $\mathrm{K}=5$ y $-34 \mathrm{~dB}$ para $\mathrm{K}=30$ (tabla 2.2). En la medida que $\mathrm{L}$ se incrementa el valor de crosstalk necesario para obtener una $B E R=1 \times 10^{-9}$ disminuye.

Los beneficios del modelo asíncrono $(\mathrm{L}>1)$ se resumen en las figuras 2.15 y 2.16 , donde se representa las relaciones entre $\mathrm{K}$, L y crosstalk, fijados para conseguir una penalización máxima de $1 \mathrm{~dB}$. Los resultados mostrados en la figura 2.15 muestran que el crosstalk requerido para mantener un número determinado de usuarios en el sistema disminuye a medida que se considera un número de slots (L) mayor. Esto sin

\begin{tabular}{|c|c|c|}
\hline Usuarios & Crosstalk & Longitud de código mínima \\
\hline \hline 5 & -27.0606 & 512 chips \\
\hline 10 & -29.2518 & 1024 chips \\
\hline 15 & -30.07603 & 1024 chips \\
\hline 20 & -32.0257 & 2048 chips \\
\hline 25 & -33.2174 & 2048 chips \\
\hline 30 & -34.3787 & 4096 chips \\
\hline
\end{tabular}

Cuadro 2.2: Crosstalk según número de usuarios para obtener una penalización máxima de $1 \mathrm{~dB}$ con $\mathrm{L}=6$. 


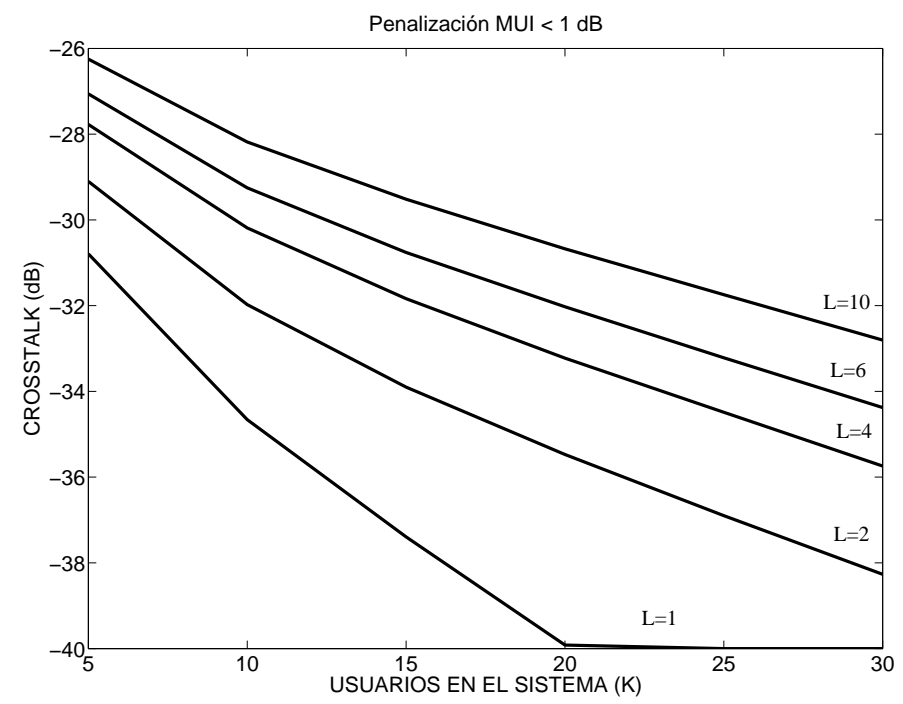

Figura 2.15: Máximo Crosstalk permitido vs. número de usuarios (K). Las curvas corresponden con diferentes valores de razón de $\mathrm{L}\left(L=\frac{T_{c}}{\sigma_{c}}\right)$ para el modelo asíncrono.

aumentar la penalización de potencia MUI. El incremento de L desde 1 a un valor de 2 o 4 aumenta el número de usuarios posibles dentro del sistema. También se observa que la mejora en el número de usuarios $\mathrm{K}$ cuando se aumenta el número de slots, aumenta cuando el nivel de crosstalk disminuye. Si el crosstalk es $\sim-29 \mathrm{~dB}, \mathrm{~L}=2$ permite $\mathrm{K}=5$ usuarios, $\mathrm{L}=4$ permite $\mathrm{K}=8$ y $\mathrm{L}=10$ tolerara hasta un $\mathrm{K}=13$, pero si el crosstalk es de $-33 \mathrm{~dB}$ el número posible de usuarios para $\mathrm{L}=1,2,4$ y 10 llega a $\mathrm{K}=7$, 14, 21 y 30 respectivamente.

Estos resultados se observan más claramente en la figura 2.16, en donde se han puesto valores de crosstalk iguales a $-25,-30$ y $-35 \mathrm{~dB}$.

El hecho de que no sea perfecto el solapamiento entre los chips que interfieren sobre el chip objetivo cuando se asume asincronía, presenta un claro beneficio para los sistemas OCDMA en general. Pero esta suposición requiere pagar un precio en otros aspectos del sistema. Si queremos incrementar la razón L manteniendo la longitud del código $\mathrm{N}$, tenemos dos alternativas

- Reducir el ancho del pulso $\sigma_{c}$ si el tiempo de chip es fijo. Para ello es posible usar los láser pulsados MLLD basados en anillos de fibra disponibles comercialmente y que entregan pulsos con un ancho entre 0.1 y 1 ps. Lo cual produciría un incremento del espectro óptico ocupado en un factor L, y adicionalmente estas fuentes pueden ser costosas, siendo esto incompatible con los bajos costos esperados por los usuarios.

- Incrementar el tiempo de chip manteniendo el ancho del pulso. Si buscamos mantener el nivel de crosstalk, se debe mantener el número de chips $\mathrm{N}$ y por lo 


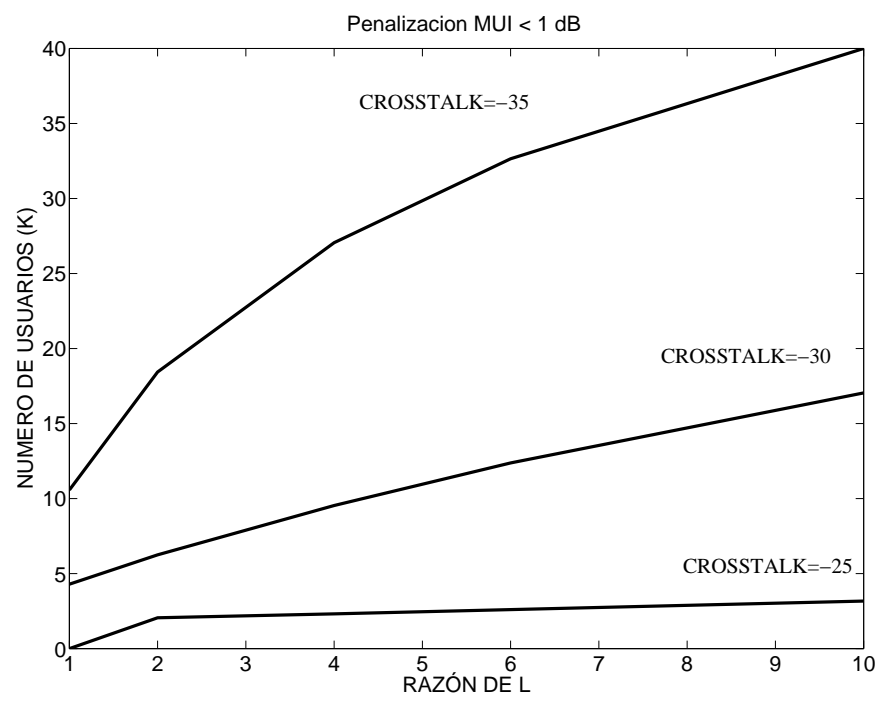

Figura 2.16: Máximo número de usuarios posibles $(\mathrm{K})$ vs. Razón de $\mathrm{L}\left(L=\frac{T_{c}}{\sigma_{c}}\right)$ para el modelo asíncrono. Se usa el Crosstalk $\left(10 \log _{10}(\xi)\right)$ como parámetro.

tanto la razón de bit de usuario debe ser reducida en un factor L. Consideremos por ejemplo: $\sigma_{c}=0,5 \mathrm{ps}(\sim 16 \mathrm{~nm}$ de ancho de banda espectral), longitud de código $\mathrm{N}=511$ chips $(\xi(d B)=-27)$. El máximo tiempo de bit esta dado por $T_{c} \approx \frac{T_{B}}{2 N n}$, por lo que a $622 \mathrm{Mb} / \mathrm{s}$ por usuario tendremos $\mathrm{L} \sim 3$ y para $155 \mathrm{Mb} / \mathrm{s}$ $\mathrm{L} \sim 12$.

Además de la reducción de la razón de bit también existe la limitación tecnológica debida al incremento de la longitud del camino óptico requerido para los codificadores y decodificadores y por lo tanto los inconvenientes en las tolerancias de fabricación y las inestabilidades en temperatura [51].

\subsubsection{Efecto del Uso de Técnicas de Thresholding.}

Para concluir el análisis de resultados incluiremos el efecto de thresholding, que como ya habíamos dicho reduce el ruido de batido secundario y el MAI. En la figura 2.17 tenemos las curvas de penalización de potencia para un sistema síncrono que usa un receptor de ancho de banda $B=\frac{1}{2 T_{c}}$ o lo que es lo mismo $(\bar{\Gamma}=1)$, al cual le hemos aplicado las técnicas de thresholding con diferentes parámetros de $G_{t h}$. La mínima mejora que se obtiene al usar técnicas de thresholding combinado con un $(\bar{\Gamma}=1)$, se debe a que solo se reduce el nivel de potencia de ruido cuando se transmite un cero.

En la gráfica 2.18 se muestra lo que sucede al disminuir el ancho de banda del sistema $(\bar{\Gamma}=8)$ y usar técnicas de thresholding. La penalización en potencia disminuye significativamente al usar técnicas de thresholding antes del fotodetector, emulando el uso de time gating, lo que significa que las técnicas son compatibles. 


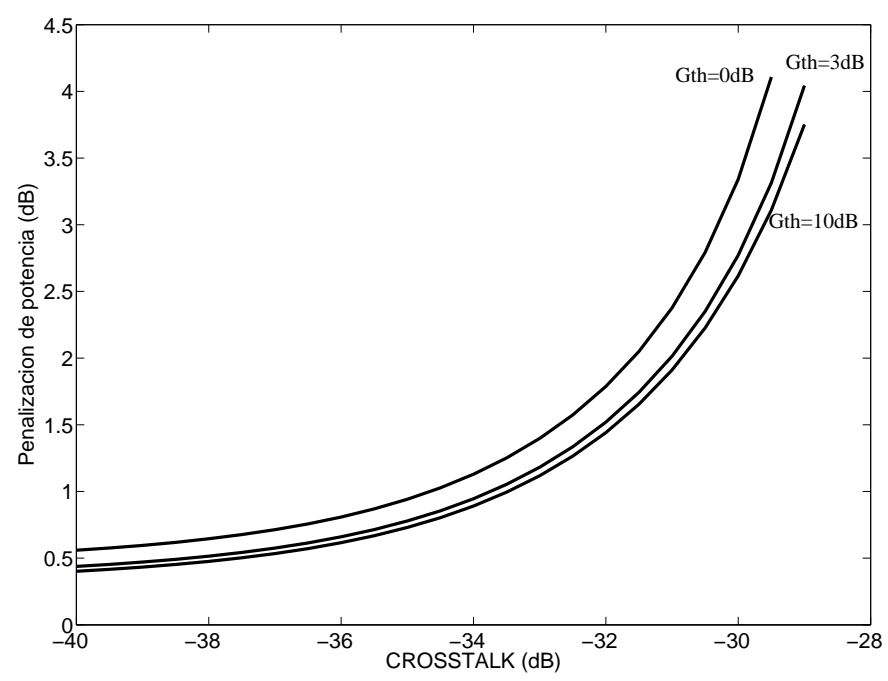

Figura 2.17: Penalización de potencia MUI (dB) vs. relación de crosstalk $10 \log _{10}(\xi)$. 10 usuarios. Modelo síncrono para diferentes valores de ganancia de thresholding $\left(G_{t h}\right)$.

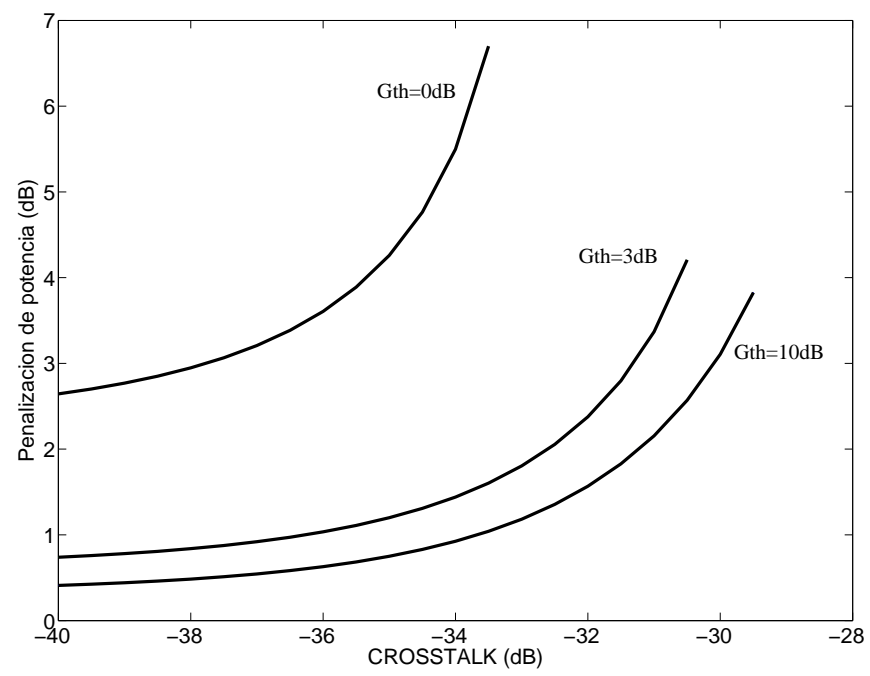

Figura 2.18: Penalización de potencia MUI (dB) vs. relación de crosstalk $10 \log _{10}(\xi)$. 10 usuarios. Modelo síncrono para diferentes valores de $G_{t h}$ con un $\bar{\Gamma}=8$. 


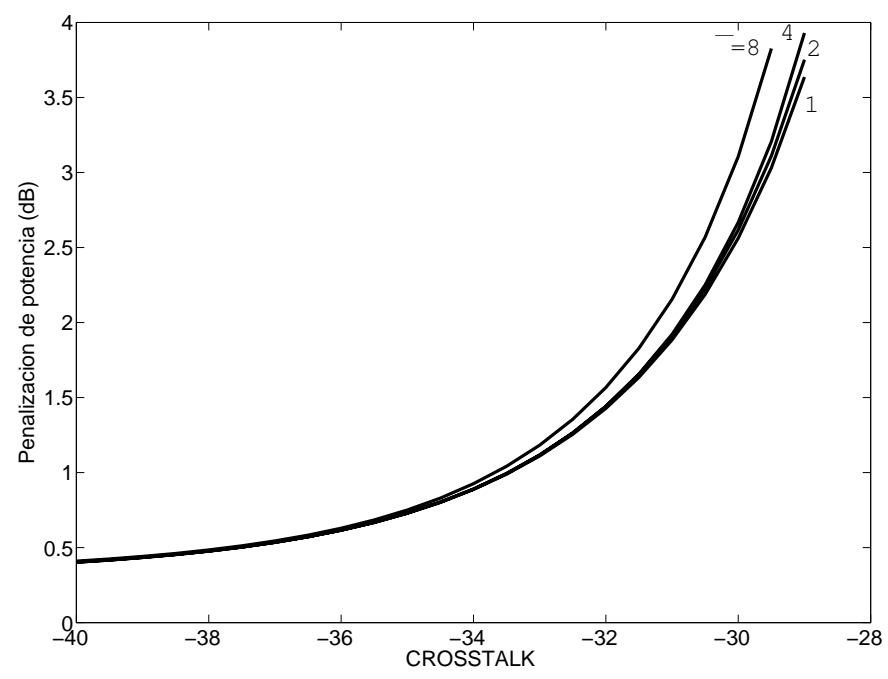

Figura 2.19: Penalización de potencia $(\mathrm{dB})$ frente a relación de crosstalk $10 \log _{10}(\xi)$. 10 usuarios. Modelo síncrono para diferentes valores de $\bar{\Gamma}$, con $G_{t h}=10 \mathrm{~dB}$.

Aunque la figura 2.17 nos pueda inducir a pensar que usar las técnicas de time gating y thresholding simultáneamente podría ser redundante, la verdad es que conseguir un receptor con un ancho de banda que permita obtener un time gating ideal puede ser muy difícil. Por tal motivo el uso de técnicas de thresholding es complementario y necesario para un rendimiento óptimo del sistema.

En la figura 2.19 se describe, como a pesar de que el ancho de banda del receptor pueda variar, si se usa una técnica de thresholding el sistema no se vera afectado. Para este caso el sistema se ha simulado con un factor de thresholding $G_{t h}=10 \mathrm{~dB}$ y se ha variado el valor de $\bar{\Gamma}$. La mejora es evidente si se compara esta figura con la figura 2.13 en donde también se variaba el ancho de banda pero no se usaban técnicas de thresholding. 



\section{Capítulo 3}

\section{SISTEMA OCDMA BASADO EN REDES DE DIFRACCIÓN DE BRAGG SUPERESTRUCTURADAS UNIFORMES}

\subsection{Introducción}

En DS-OCDMA se han propuesto diferentes dispositivos para ser implementados como codificadores y decodificadores. Entre ellos se cuentan, arrays de fibras ópticas de múltiples longitudes [12, 52], redes de difracción de Bragg superestructuradas (SSFBG) [53, 32], Planar Lightwave Circuits (PLC)[54, 55], resonadores en anillo [56], etc. Pero entre todos ellos destacan las SSFBG, gracias a las características propias de su estructura basada en fibra, como son: compatibilidad total con la misma, facilidad de fabricación y bajo coste.

En este capítulo se describirá la teoría básica de las redes de difracción, desglosando detalladamente las ecuaciones que modelan las FBGs e indicando los diferentes parámetros a tener en cuenta para su construcción. Como las redes de difracción escogidas para ser implementadas en sistemas OCDMA son las del tipo SSFBG (SuperStructured Fiber Bragg Grating) se hará especial énfasis en este tipo de redes.

Cada SSFBG lleva grabado un código que ha sido seleccionado por tener un destacado pico de autocorrelación y una baja correlación cruzada. Existen diferentes tipos de códigos de acuerdo al sistema OCDMA en donde vaya a ser implementado. Hay códigos de 1 dimensión que funcionan en sistemas coherentes [1] y también en sistemas incoherentes [2,3] o de 2 dimensiones para sistemas incoherentes [57, 58]. Para sistemas de tipo coherente los más óptimos son los códigos de 1 dimensión que a su vez pueden ser bipolares [32] ó multipolares [59]. Nosotros nos hemos centrado 
en los códigos de 1 dimensión de tipo bipolar, y por lo cual en el presente capítulo describimos la forma de obtenerlos.

Siguiendo esta misma línea, resumimos la forma como se fabrican las SSFBGs gracias a la técnica de máscara de fase y las ventajas y limitaciones que presenta nuestro sistema de fabricación.

Después de la descripción de las SSFBGs y de su fabricación con los códigos bipolares, se presentan los parámetros de la señal de entrada con la cual se trabajará, los equipos de medida y las características de la señal recuperada que nos permitirá evaluar la calidad del sistema.

Finalmente, y después de realizar múltiples pruebas se observó que el pico de autocorrelación obtenido no se mantenía constante con el tiempo. El motivo de esta inestabilidad es la alta sensibilidad a la temperatura que tienen las SSFBGs. Describiremos detalladamente el problema de estabilidad en temperatura, cuales son las tolerancias y como se puede aprovechar la desintonía producida por la temperatura como un elemento adicional para la multiplexación de las señales.

\subsection{Teoría de las FBGs}

Una red de difracción de Bragg sobre fibra óptica (FBG), es una fibra óptica a la cual se le ha introducido una variación periódica del índice de refracción $(\Delta n)$ en la dirección longitudinal. Las FBGs pueden ser clasificadas en dos tipos: aquellas que acoplan ondas en contra-propagación (típicamente se emplean en reflexión) y son referidas como FBGs de período corto, y aquellas que acoplan ondas en copropagación hacia modos radiados en la cubierta de la fibra y son conocidas como gratings de período largo. Si consideramos que la FBG ha sido hecha sobre una fibra monomodo, la luz estará contenida dentro del modo fundamental $L P_{01}$, el cual será reflejado y dispersado por la perturbación del índice de refracción. Si la longitud de onda de la luz incidente satisface la condición de Bragg $\lambda_{B}=2 n_{e f f} \Lambda$ donde $n_{\text {eff }}$ es el índice efectivo de la fibra y $\Lambda$ es el período espacial de la perturbación del grating, las ondas reflejadas de manera distribuida serán sumadas coherentemente formando la banda de reflexión del dispositivo. Por otra parte las ondas que no cumplan dicha condición eventualmente se irán cancelando. La figura 3.1 ilustra el principio de operación de una FBG.

Una FBG es una perturbación periódica del índice de refracción en el núcleo de una fibra óptica. El índice de refracción a lo largo de la FBG $(0 \leq z \leq L)$ puede ser escrito como

$$
\delta n_{e f f}(z)=\overline{\delta n}_{e f f}(z)\left\{1+v(z) \cos \left(\frac{2 \pi z}{\Lambda_{0}}+\phi(z)\right)\right\}
$$

donde $\overline{\delta n}_{e f f}(z)$ es el índice promedio efectivo (más conocido como índice DC); $v(z)$ es la visibilidad de franjas; $\Lambda_{0}$ es el período espacial central del grating; $\phi(z)$ describe la variación espacial de fase (chirp) del grating y L es la longitud del grating. La expresión 3.1 asume que la distribución del grating es uniforme en la dirección transversal de la fibra.

Asumimos una onda electromagnética de frecuencia $\omega$ descrita por 


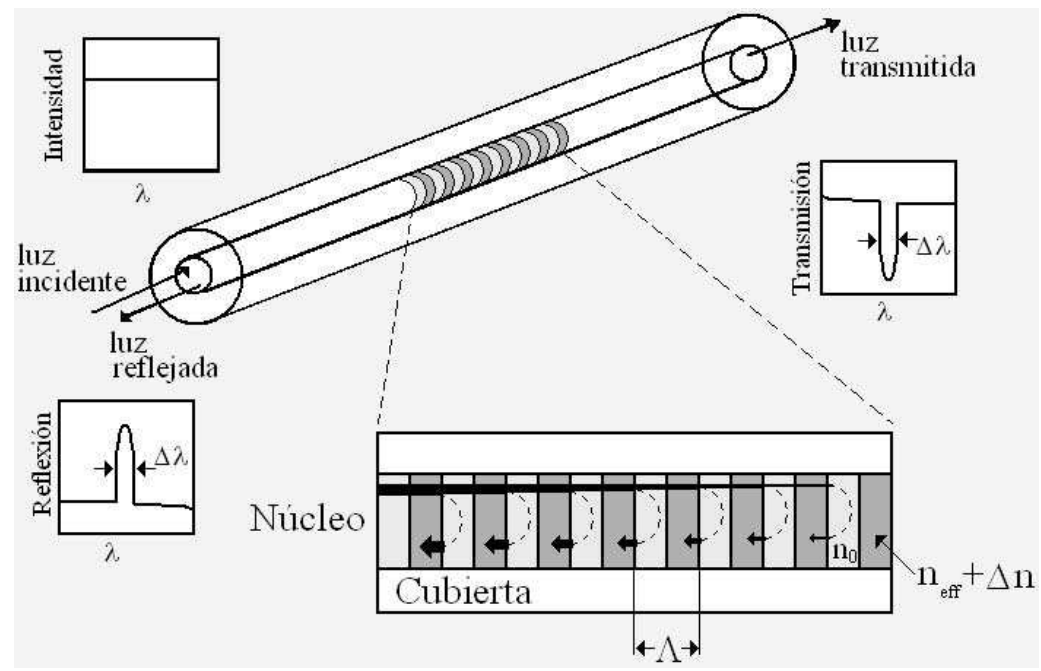

Figura 3.1: Representación esquemática del principio de operación de una FBG

$$
E(z, t)=\hat{x} E(z) e^{-j \omega t}+c . c
$$

se propaga en el medio periódico con dependencia espacial

$$
E(z)=A(z) e^{j \beta z}+B(z) e^{-j \beta z}
$$

donde $A(z)$ y $B(z)$ son las envolventes complejas de las ondas que se transmiten y se reflejan, respectivamente, y $\beta$ es la constante de propagación. El grating causa un acoplamiento entre las ondas que se transmiten y las ondas que se propagan y su interacción puede ser descrita en términos de las siguientes ecuaciones de acoplamiento de modos [60].

$$
\begin{aligned}
& \frac{d R}{d z}=j \widehat{\sigma} R(z)+j \kappa S(z) \\
& \frac{d S}{d z}=-j \widehat{\sigma} S(z)-j \kappa^{*} R(z)
\end{aligned}
$$

donde $R(z)=A(z) \exp \left(j \delta z-\frac{\phi}{2}\right), S(z)=B(z) \exp \left(-j \delta z-\frac{\phi}{2}\right), \delta$ es el parámetro de desintonía definido por

$$
\delta=\beta-\frac{\pi}{\Lambda_{0}}=2 \pi n_{e f f}\left(\frac{1}{\lambda}-\frac{1}{2 n_{e f f} \Lambda_{0}}\right)
$$

$\mathrm{y}$

$$
\hat{\sigma}=2 \pi n_{e f f}\left(\frac{1}{\lambda}-\frac{1}{2 n_{e f f} \Lambda_{0}}\right)+\frac{2 \pi}{\lambda} \overline{\delta n_{e f f}(z)}-\frac{1}{2} \frac{d \phi}{d z}
$$


La ecuación 3.7 representa el coeficiente de auto-acoplamiento DC y $\kappa$ es el coeficiente de acoplamiento AC, el cual para una fibra monomodo, esta dado por

$$
\kappa(z)=\kappa^{*}(z)=\frac{\pi}{\lambda} v \overline{\delta n_{e f f}}(z)
$$

Para una FBG uniforme, $\overline{\delta n}_{\text {eff }}$ y todos los otros parámetros del grating son independientes de $z$ y la solución a las ecuaciones de acoplo de modos puede ser obtenida en forma cerrada cuando se usan las condiciones de contorno adecuadas. La condición de contorno esta basada en la suposición de que existe una onda transmitiéndose desde $z=-\infty[R(0)=1]$ y no hay ondas reflejándose para $z \geq L[S(L)=0]$. Las ecuaciones 3.4 y 3.5 , conforman las condiciones de contorno que constituyen el valor de frontera del problema. La propagación de ondas a través de un grating uniforme puede ser descrita por la matriz fundamental de $2 \times 2, T M$.

$$
\left(\begin{array}{c}
R(L) \\
S(L)
\end{array}\right)=T M\left(\begin{array}{c}
R(0) \\
S(0)
\end{array}\right)
$$

donde

$$
T M=\left(\begin{array}{cc}
\cosh (\gamma L)-j \frac{\hat{\sigma}}{\gamma} \sinh (\gamma L) & -j \frac{\kappa}{\gamma} \sinh (\gamma L) \\
j \frac{\kappa}{\gamma} \sinh (\gamma L) & \cosh (\gamma L)+j \frac{\hat{\sigma}}{\gamma} \sinh (\gamma L)
\end{array}\right)
$$

y $\gamma=\sqrt{\kappa^{2}-\widehat{\sigma}^{2}}$. Los coeficientes de reflexión $(r)$ y de transmisión $(t)$ pueden ser calculados como sigue

$$
\begin{aligned}
& r(\lambda)=\frac{S(0)}{R(0)} \\
& t(\lambda)=\frac{R(L)}{R(0)}
\end{aligned}
$$

finalmente, la reflectividad $R(\lambda)$ y la transmitividad $T(\lambda)$ vienen dadas por $R(\lambda)=$ $|r|^{2}$ y $T(\lambda)=|t|^{2}$. Nótese que si asumimos un grating de bajas pérdidas y que sólo acopla los modos fundamentales de la onda que se transmite y la onda que se refleja, entonces $R(\lambda)+T(\lambda)=1$. Usando las ecuaciones $3.9,3.10$ y 3.11 , encontramos la expresión analítica de la reflectividad:

$$
R(\lambda)=\frac{\kappa^{2} \sinh (\gamma L)}{\kappa^{2} \cosh (\gamma L)-\hat{\sigma}^{2}}
$$

a la longitud de onda de Bragg, $\hat{\sigma}=0$, y el valor pico obtenido para la reflectividad del grating es

$$
R_{\max }\left(\lambda=\lambda_{B}\right)=\tanh ^{2}(\kappa L)
$$

Para el caso de gratings no uniformes, todos los parámetros $\overline{\delta n}_{e f f}, v, \mathrm{y} \phi$ pueden ser dependientes de la posición. En este caso, podemos determinar la respuesta espectral del grating numéricamente. Primero dividimos el grating en $p$ segmentos discretos de longitud $\Delta z_{p}$, cada uno de los cuales puede ser tratado como un segmento uniforme, 


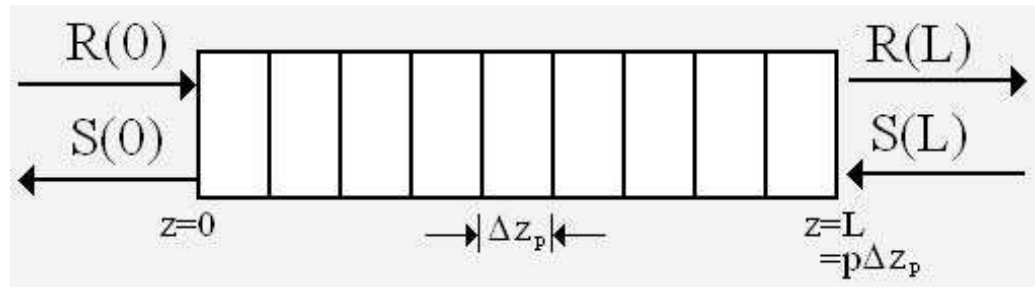

Figura 3.2: Descomposición de una FBG en términos de múltiples matrices fundamentales [61].

figura 3.2. La matriz $T M$ definida en la ecuación 3.10 relaciona los campos de entrada y salida de un segmento de grating individual y una vez que estos son conocidos, se obtiene el total de la estructura del grating mediante la cascada de los $p$ segmentos discretos. Los campos de entrada y salida se relacionan por una expresión similar a la ecuación 3.9:

$$
\left(\begin{array}{c}
R(L) \\
S(L)
\end{array}\right)=T M_{p} T M_{p-1} \ldots T M_{2} T M_{1}\left(\begin{array}{c}
R(0) \\
S(0)
\end{array}\right)=T M^{N U}\left(\begin{array}{c}
R(0) \\
S(0)
\end{array}\right)
$$

La reflectividad y la transmitividad se pueden encontrar siguiendo el procedimiento anteriormente descrito.

Las respuestas en reflexión y transmisión (amplitud y fase) dependen del perfil del grating, descrito en la ecuación 3.1. Entre los perfiles de grating más comúnmente utilizados en comunicaciones encontramos los siguientes:

- Grating uniforme en el cual $\overline{\delta n}_{e f f}(z), v(z)$ y $\phi(z)$ son constantes

- Grating con chirp en el cual $\phi(z)$ no es cero y por lo tanto el período del grating varía con la posición.

- Grating apodizado en el cual varía $\overline{\delta n}_{e f f}(z)$

- Grating apodizado sin índice DC en el cual $\overline{\delta n}_{e f f}(z)$ es constante y varía $v(z)$.

- Grating desplazado en fase en el cual se introducen desplazamientos discretos en fase.

- Grating superestructurado en el que $\overline{\delta n}_{e f f}(z)$ es constante y lo típico es que varía periódicamente $v(z)$.

Los perfiles antes mencionados son descritos en la figura 3.3.

Del análisis anterior, podemos concluir que la respuesta de una red de difracción dependerán del perfil del índice de refracción, que a su vez depende de las variables $\delta n_{e f f}, v$, y $\phi$. Modificando dichas variables podremos llegar a diseñar la red de difracción requerida para realizar los procesos de codificación y decodificación. En otras palabras podremos llegar a grabar un código sobre una fibra óptica mediante la construcción de una FBG. 


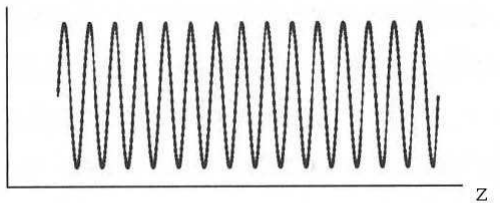

(a)

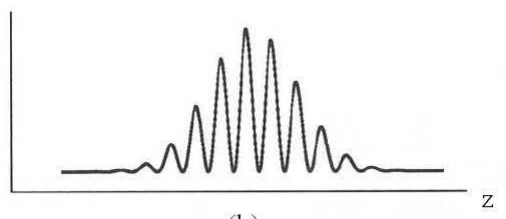

(b)

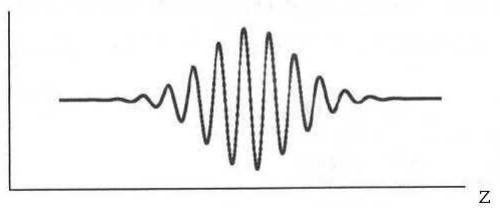

(c)

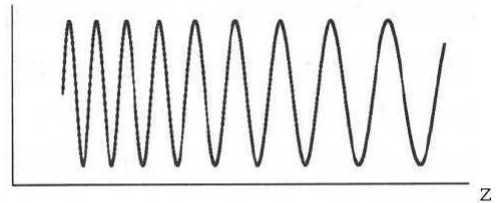

(d)

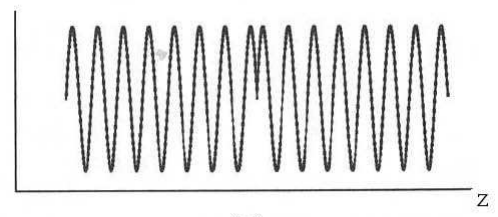

(e)

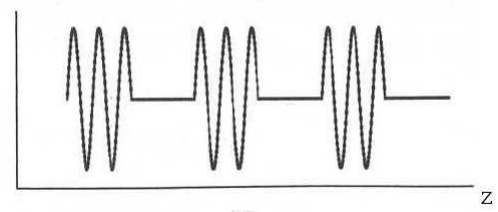

(f)

Figura 3.3: Perfiles típicos de FBGs para diferentes índices de refracción: a) uniforme, b) apodizada con variación del índice DC, c) apodizada sin variación del índice DC, d) Con chirp, e) Desplazada en fase, y f) Superestructurada [61]. 


\subsubsection{Redes de Difracción de Bragg Superestructuradas}

Una SSFBG esta definida como una FBG estándar, sobre la que se ha realizado adicionalmente una modulación lenta de amplitud y fase de la perturbación del índice de refracción, figura 3.3(f). Gracias a esta modulación adicional es posible mediante las SSFBGs implementar códigos que permitan utilizarlos como dispositivos codificadores y decodificadores en sistemas OCDMA.

En los sistemas OCDMA que usan SSFBGs como elementos codificadores, la señal de entrada consiste en una serie de pulsos ultracortos, donde cada uno de ellos, en el modelo más sencillo representa un bit de información. El diagrama de la figura muestra el proceso de codificación y decodificación cuando se usan SSFBGs. La señal se aplica a la SSFBG codificador, por medio de un circulador. La señal reflejada por la SSFBG es la señal codificada que será transmitida. La señal codificada viaja por la fibra óptica hasta llegar al receptor, donde se realizara el proceso inverso. Para que la señal original pueda ser reconstruida correctamente la SSFBG decodificadora deberá tener grabado el código conjugado de la SSFBG codificador. Si no es así la señal recuperada será interpretada como ruido.

Como se vio en la figura 3.3(f), la SSFBG es realmente la unión de múltiples FBGs dentro de una misma fibra óptica, y cada una de ellas tiene sus propias características de amplitud y fase. En nuestro caso podemos decir que cada una de ellas representara un "chip" del código (término que se utiliza habitualmente en OCDMA para identificar cada uno de los elementos de una palabra código). En el caso de códigos bipolares la amplitud de cada chip es la misma y la fase será la asignada según el código.

Para que la señal sea correctamente codificada, el pulso de luz debe recorrer toda la SSFBG. Por tal motivo las SSFBG que se usan en esta tecnología son conocidas como SSFBGs débiles, es decir que su coeficiente de reflexión es bajo y además constante. De esta forma cada chip contribuye de manera uniforme a la respuesta total de la red de difracción.

Cuando un pulso ultracorto es reflejado por una SSFBG, se transforma en un pulso con una forma temporal dada por la convolución entre la señal de entrada y la respuesta impulsiva del grating

$$
y(t)=x(t) \otimes h(t)
$$

El proceso se describe en el dominio de la frecuencia por el producto de la transformada de Fourier de la señal incidente $X(\omega)$ con la respuesta en frecuencia del grating $H(\omega)$.

$$
Y(\omega)=X(\omega) \cdot H(\omega)
$$

De esta manera es posible grabar sobre las SSFBGs diferentes tipos de códigos, desde unipolares, donde la fase es constante y variaría la amplitud, hasta multipolares donde puede existir variación de amplitud y fase.

Para realizar el reconocimiento óptico de la secuencia de código temporal, la señal codificada es reflejada por una segunda SSFBG (el decodificador) con una respuesta en frecuencia $G(\omega)$, asociada a una respuesta impulsiva $g(t)$. En el dominio de la frecuencia la respuesta total del sistema estará dada por 


$$
R(\omega)=Y(\omega) \cdot G(\omega)
$$

De donde podemos decir que si usamos la respuesta al impulso del grating codificador y el conjunto $G(\omega)=Y^{*}(\omega)=H^{*}(\omega), r(t)$ es la función de autocorrelación entre el perfil de la superestructura usado para escribir el codificador con la respuesta impulso del grating decodificador, $g(t)=h(-t)$. Físicamente significa que la función de la superestructura del grating decodificador esta espacialmente invertida con respecto de la usada en el codificador. Por lo tanto el principio para reconocer el patrón no es otro que el de un filtro adaptado. Se ve fácilmente que si $G(\omega) \neq H^{*}(\omega)$ la forma de onda resultante será la función de correlación cruzada de dos perfiles de gratings diferentes (códigos). Nótese que $r(t)$ tiene una longitud temporal igual a dos veces la longitud del código.

Para lograr un alto contraste en el reconocimiento de los códigos, necesitamos restringir el uso de los códigos a sólo aquellos que presenten un alto pico de autocorrelación y un bajo nivel de correlación cruzada. Estos requerimientos son los mismos que en los sistemas que usan CDMA en el entorno inalámbrico.

\subsection{Diseño de Códigos}

En los sistemas OCDMA múltiples usuarios comparten el medio de transmisión y son identificados gracias a la asignación de un código en particular, con el cual codifican la información que envían a la red. La correcta discriminación de la información destinada a un usuario dependerá, entre otras cosas, de la calidad de los códigos utilizados. En general podemos decir que para que una familia de códigos puedas ser usada en un sistema OCDMA deberá cumplir las siguientes características

- Tener un pico de autocorrelación destacado. Gracias al cual se podrá distinguir la información correctamente decodificada.

- La función de correlación cruzada entre códigos diferentes debe ser lo más baja posible. De esta manera se reduce el ruido por MAI (Multiple Access Interference).

- La cardinalidad del código debe ser lo mayor posible. La cardinalidad del código equivale al número de códigos disponibles, es decir, el número máximo de usuarios en el sistema.

Estas características se cumplen por diferentes clases de códigos, los cuales se implementan de acuerdo al tipo de sistema con el que estemos trabajando. Como ya hemos indicado anteriormente los sistemas OCDMA se pueden clasificar en coherentes e incoherentes. Los sistemas de tipo incoherente usan códigos OOC (Optics Orthogonal Codes), códigos primos y códigos 2D (Tiempo-Longitud de onda). Aunque estos códigos cumplen las características descritas, su función de correlación cruzada no es la ideal y por ello estos sistemas tienen un bajo rendimiento. Por otra parte los sistemas OCDMA coherentes usan códigos bipolares o multipolares entre los que destacan las 


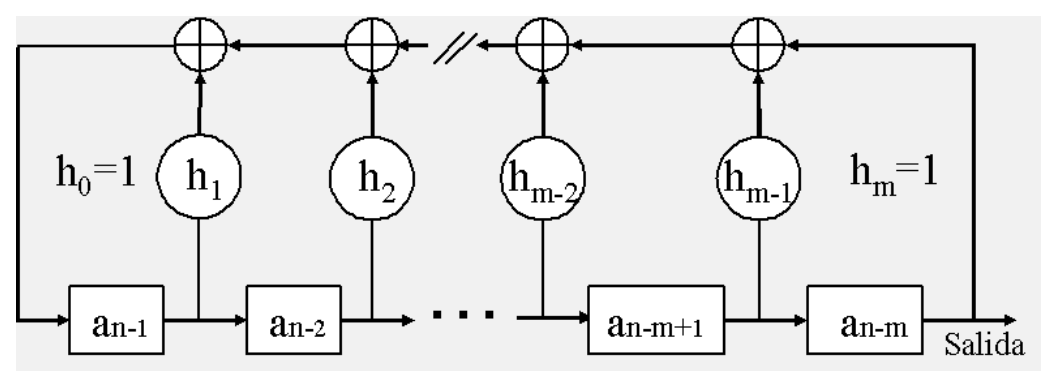

Figura 3.4: Feedback Shift Register correspondiente al polinomio primitivo $h(x)$ de la expresión 3.16 .

secuencias pseudoaleatoria (de máxima longitud [62, 63] y códigos Gold) y los códigos de Walsh [64], los cuales tienen funciones de correlación cruzada cercanas a cero, reduciendo el efecto de MAI y por lo tanto dando un mejor rendimiento.

Entre los códigos de tipo coherente los más usados son los códigos bipolares los cuales surgieron de la tecnología de radio de espectro ensanchado durante la década de los años 40's. Fundamentalmente surgen para prevenir los "espías" y la interferencia en sistemas de comunicaciones militares. Posteriormente este tipo de códigos fue adoptado por los sistemas de comunicaciones móviles CDMA y en la actualidad son usados en una gran variedad de redes inalámbricas y sistemas de comunicaciones móviles digitales. Por ejemplo, el estándar para redes celulares digitales CDMA esta basado en IS-95 de la segunda generación y el estándar para la tercera generación de CDMA de banda ancha usa códigos Walsh y secuencias pseudoaleatorias o también conocidas como secuencias de dispersión [61].

\subsubsection{M-sequences}

Los códigos que hemos utilizado para nuestros experimentos están basados en códigos Gold que son derivados de una secuencia pseudoaleatoria conocida como Msequence, por lo que a continuación daremos una breve explicación de las mismas

Las M-sequences son secuencias pseudoaleatorias que cumplen las tres propiedades de la aleatoriedad enunciadas por S. W. Golomb en 1967. Para construir una Msequence de longitud $N=2^{m}-1$, se necesita como base un polinomio primitivo $h(x)$ de grado $m$, que presente la siguiente expresión [65]:

$$
h(x)=h_{0} x^{m}+h_{1} x^{m-1} h_{2} x^{m-2}+\cdots+h_{m-1} x+h_{m}=\sum h_{i} x^{m-i}, \quad i=0 \ldots m
$$

donde $h_{0}=h_{m}=1$.

Este polinomio se corresponde con un linear feedback shift register (LFSR), el cual se muestra en la figura 3.4.

Este registro de desplazamiento con realimentación lineal consiste en $m$ cajas, cada una de las cuales representa elementos de memoria o "flip-flops", cuyo contenido o estado puede ser un " 0 " o un " 1 ". En cada instante de tiempo, el contenido de las 
cajas es desplazado una posición hacia la derecha y las cajas correspondientes a los términos de la expresión $\mathrm{h}(\mathrm{x})$ son sumados y realimentan a la caja de la izquierda del todo, la cual contiene al término $a_{n-1}$. La suma se calcula en módulo 2 , lo que significa que:

$$
0+0=1+1=0 \quad 0+1=1+0=1
$$

De esto, se deduce que dado un polinomio [66], una secuencia puede ser generada por un LFSR binario de $n$ estados, el cual realimenta a su entrada con una combinación lógica de los estados o contenidos de las diferentes cajas o etapas. La salida de un generador de secuencia y los contenidos de sus $n$ etapas en cada instante de tiempo, son una función de las salidas de las etapas que les preceden y que fueron realimentadas en el instante anterior.

Si el registro contiene los valores $a_{m-1}, a_{m-2}, \cdots, a_{1}, a_{0}$, en el instante $n=m-1$, entonces en el instante $n=m$, su salida será la siguiente:

$$
\begin{aligned}
a_{n} & =-h_{1 a_{n-1}}-h_{2 a_{n-2}}-\cdots-h_{m-1 a_{n-(m-1)}}-h_{m a_{n-m}} \\
& =h_{1 a_{n-1}}+h_{2 a_{n-2}}+\cdots+h_{m-1 a_{n-(m-1)}}+h_{m a_{n-m}} \\
& =\sum_{i=1}^{m} h_{i} \cdot a_{n-1}, \quad n \geq m, \quad h_{i} \in\{0,1\}
\end{aligned}
$$

En otras palabras, el LFSR de la figura anterior genera una secuencia infinita $a_{0} a_{1} a_{2} \cdots a_{i} \cdots a_{m-1}$, la cual satisface la ecuación recurrente anterior. Para ello, es necesario especificar una secuencia inicial $a_{0} a_{1} a_{2} \cdots a_{i} \cdots a_{m-1}$ en el registro de desplazamiento. De este modo, en cada instante de tiempo saldrá un valor del LFSR que formará parte de la M-sequence final.

En la Figura 3.4 que representa un LFSR genérico, ya que cada caja o etapa contiene un " 0 " o un " 1 ", existen entonces $2^{m}$ estados posibles del registro de desplazamiento. De este modo, la secuencia $a_{0} a_{1} a_{2} \cdots a_{i} \cdots a_{m-1}$ será periódica. Sin embargo, el estado $00 \cdots 0$ no puede darse porque generaría una secuencia de todo ceros. Por este motivo, el período máximo posible es $2^{m-1}$.

Ya ha sido probado que si un polinomio primitivo $h(x)$ tiene un grado $m$, el registro de desplazamiento pasa a través de los $2^{m-1}$ estados distintos antes de repetir un estado, y produce una secuencia de salida $a_{0} a_{1} a_{2} \cdots a_{i} \cdots a_{m-1}$ de período $2^{m-1}$, para un estado inicial distinto al de todo ceros. De este modo, llamamos M-sequence a cualquier segmento $a_{i} a_{i}+1+\cdots a_{i}+2^{m}-2$ de longitud $2^{m-1}$ generada a partir de un LFSR que represente a un polinomio primitivo. Es preciso aclarar que se obtendrá el mismo conjunto de secuencias pseudoaleatorias inicializando el registro de desplazamiento con los valores iniciales que deseemos, menos el estado inicial de todo ceros.

A nosotros lo que nos interesa es encontrar parejas de M-sequences que tengan un valor bajo en la función de correlación cruzada. De este modo, sean $a$ y $b$ dos M-sequences de período $N=2^{m}-1$, siendo $b$ una secuencia obtenida a partir de $a$ mediante un muestreador " $f$ " que puede tomar los siguientes valores:

$$
f=2^{k}+1 \quad f=2^{2 k}-2^{k}-1
$$


en donde $k$ puede tomar los valores de 1 ó 2 . Si ahora definimos a $e=M C D(m, k)$ como el máximo común divisor de $m$ y $k$, tal que $\frac{m}{e}$ es impar, entonces la correlación cruzada $R_{a b}(\tau)$ presenta tres valores posibles:

$$
R_{a b}(\tau)=\left\{\begin{array}{llll}
-1+2^{\frac{m+e}{2}} & \text { ocurre } & 2^{m-e-1}+2^{\frac{m-e-2}{2}} & \text { veces } \\
-1 & \text { ocurre } & 2^{m}-2^{m-e}-1 & \text { veces } \\
-1-2^{\frac{m+e}{2}} & \text { ocurre } & 2^{m-e-1}-2^{\frac{m-e-2}{2}} & \text { veces }
\end{array}\right.
$$

como se puede ver, esto se cumple para todo $m \neq 0(\bmod 4)$. Una función de correlación cruzada que tome esos tres valores se denomina "preferente" y el par correspondiente de M-sequences que cumple dicha función se denomina "par preferente de M-sequences".

En nuestro caso hemos decidido tomar un grado del polinomio primitivo $m=6$, lo que implica un período $N=2^{6}-1=63$. De este modo, y utilizando un LFSR, hemos generado la siguiente M-sequence:

$a=\left\{a_{n}\right\}=(000001000011000101001111010001110010010110111011001101010111111)$

Ya que el grado del polinomio primitivo utilizado para generar esta M-sequence es $m=6 \equiv 2(\bmod 4), \mathrm{y}$ tomando $k=2$, entonces obtenemos una $e=M C D(6,2)=2 \mathrm{y}$ por lo tanto $\frac{m}{e}=\frac{6}{2}=3$, que es impar y cumple que la función de correlación cruzada tiene los tres valores ya comentados.

De este modo, conseguimos una $f=2^{k}+1=2^{2}+1=5$, y la M-sequence muestreada $b$, denominada "preferente" es:

$b=\left\{b_{n}\right\}=(011111101011100011001110110000011110010010101001101000010001011)$

Y su función de correlación cruzada correspondiente es:

$$
\begin{aligned}
R_{a b}(\tau)= & (15,-1,-1,-1,-1,-1,-1,-1,-1,-1,-1,15,-1,-1,-1,-1,-1, \\
& -1,-1,-1,-1,-1,15,-1,-1,15,-1,15,-1,-1,-1,-17,-1,-1, \\
& -1,-1,-1,15,-1,-1,-1,-1,-1,-1,15,15,-1,-17,-1,-1,15 \\
& -1,-1,-1,15,-17,-1,-1,-1,-17,-1,-17,-17)
\end{aligned}
$$

De forma similar, un conjunto conexo o relacionado de M-sequences, en donde cada uno de ellos cumple la propiedad de que cada par del conjunto es un par "preferente", obtendrá funciones de correlación similares. Al conjunto relacionado más grande posible se le denomina "maximal connected set" y su tamaño se denota mediante la variable $M_{m}$.

En la siguiente lista vamos a incluir los valores de $M_{m}$, hasta el valor que nos interesa que es el grado $m=6$, y las magnitudes del pico de la correlación cruzada periódica $R_{\max }$. 


\begin{tabular}{|c|c|c|c|c|c|}
\hline $\mathrm{m}$ & $\begin{array}{c}\text { período } \\
N=2^{m}-1\end{array}$ & $\begin{array}{c}\text { número de } \\
\text { M-sequences }\end{array}$ & $\begin{array}{c}R_{\max } \text { para } \\
\text { todas las } \\
\text { M-sequences }\end{array}$ & $M_{m}$ & $\begin{array}{c}R_{\max } \text { para el } \\
\text { conjunto }\end{array}$ \\
\hline \hline 3 & 7 & 2 & 5 & 2 & 5 \\
\hline 4 & 15 & 2 & 9 & 0 & 9 \\
\hline 5 & 31 & 6 & 11 & 3 & 9 \\
\hline 6 & 63 & 6 & 23 & 2 & 17 \\
\hline
\end{tabular}

Cuadro 3.1: Tabla de valores de $M_{m}$ y $R_{\max }$.

Notar en la tabla 3.1 que si $M_{m}=0$, esto significa que no existen pares de Msequences preferentes para ése grado de polinomio primitivo.

De todo lo comentado hasta el momento, es obvio pensar que únicamente los conjuntos pequeños de M-sequences pueden tener buenas propiedades de correlación cruzada periódica; mientras que los conjuntos grandes de M-sequences tendrán unas propiedades de correlación cruzada bastante malas. Por lo tanto, los "maximal connected sets" de M-sequences serán muy útiles en aquellas aplicaciones que requieran un número relativamente pequeño de M-sequences, las cuales posean unas propiedades de correlación cruzada bajas y unas propiedades de autocorrelación óptimas.

Como el objetivo en un sistema OCDMA es tener un gran número de usuarios, queda claro que las M-sequences no son una solución viable. No obstante las familias de códigos Gold, presentan buenas características de "ortogonalidad" y pueden ser generadas partiendo de un par de M-sequences preferentes.

\subsubsection{Generación de una Familia de Códigos Gold.}

Recordemos que los objetivos al diseñar una familia de códigos que sea útil para un sistema OCDMA, son; un pico de autocorrelación destacado, una función de correlación cruzada lo más baja posible y una alta cardinalidad del código. De esta manera garantizamos que un buen número de usuarios pueda ingresar al sistema.

Los códigos Gold destacan de sus similares en sistemas coherentes, por poder ser utilizados en sistemas asíncronos, tal como ha sido hecho en los sistemas inalámbricos CDMA. Además las secuencias de Gold no solamente permiten una alta cardinalidad si no que además tienen unas propiedades de correlación cruzada muy buenas para operaciones asíncronas [67], [66].

Un conjunto de secuencias Gold puede ser construido a partir de cualquier par preferente de M-sequences [65]. De este modo, sean $a=\left\{a_{n}\right\}$ y $b=\left\{b_{n}\right\}$ un par "preferente" de M-sequences de período $N=2^{m}-1$, generadas mediante el proceso que describimos detalladamente en el apartado anterior, entonces, tenemos el siguiente conjunto:

$$
G(a, b)=\left\{a, b, a+b, a+T b, a+T b, a+T^{2} b, \cdots, a+T^{N-1} b\right\}
$$

Donde el operador + se refiere a una suma en módulo 2 y $T^{n}$ denota el operador desplazamiento, el cual desplaza un vector cíclicamente $n$ veces hacia la izquierda. 


\begin{tabular}{|c|c|c|}
\hline No $^{\mathbf{0}}$ & $G(a, b)$ & Secuencia Gold \\
\hline \hline 1 & $\mathrm{a}$ & 000001000011000101001111010001110010010110111011001101010111111 \\
\hline 2 & $\mathrm{~b}$ & 011111101011100011001110110000011110010010101001101000010001011 \\
\hline 3 & $\mathrm{a}+\mathrm{b}$ & 011110101000100110000001100001101100000100010010100101000110100 \\
\hline 4 & $a+T_{b}$ & 111110010100000011010010110001001110110011101000011101110101001 \\
\hline 5 & $a+T_{b}^{2}$ & 111111101101001001110100010000001011011100011101101100010010010 \\
\hline
\end{tabular}

Cuadro 3.2: 5 primeros valores de un familia de secuencias Gold para $N=63$.

De este modo, si $a=\left\{a_{n}\right\}=\left(a_{0}, a_{1}, a_{2}, a_{N-1}\right)$, entonces $T_{a}=\left(a_{1}, a_{2},, a_{N-1}, a_{o}\right)$, $T_{a}^{2}=\left(a_{2}, a_{N-1}, a_{0}, a_{1}\right)$, y así sucesivamente.

De este modo, obtenemos un conjunto $G(a, b)$ que contiene $N+2=2^{m}+1$ secuencias de período $N=2^{m}-1$.

En nuestro caso, hemos generado primero una M-sequence mediante un LFSR que implementaba el polinomio primitivo $h(x)=1+x^{6}$, el cual aparece como referencia en [65] y, a continuación, hemos realizado un diezmado de la misma siguiendo los pasos descritos en el apartado anterior. El resultado de este proceso ha sido la obtención de un par "preferente" de M-sequences, las cuales ya mostramos en el apartado 3.3.1.

Por otro lado, para generar la familia de secuencias Gold simplemente hemos realizado las operaciones de desplazamiento y suma que se muestran en el conjunto $G(a, b)$. El resultado es la familia de 65 códigos Gold con período $N=63$. En la tabla 3.2 se muestran los 5 primeros resultados para esta familia.

Gold comprobó que las funciones de correlación cruzada y de autocorrelación, para cualquier par de secuencias $\left\{a_{n}^{\prime}\right\},\left\{b_{n}^{\prime}\right\}$ que pertenezcan al conjunto $G(a, b)$, toman como valor de su función de correlación cruzada los siguientes tres valores preferentes únicamente, dependiendo del grado del polinomio primitivo $(m)$ :

$$
R_{a^{\prime} b^{\prime}}(\tau)= \begin{cases}-1,-1-2^{\frac{m+1}{2}},-1+2^{\frac{m+1}{2}} & \text { para m impar } \\ -1,-1-2^{\frac{m+2}{2}},-1+2^{\frac{m+2}{2}} & \text { para } m \text { par }\end{cases}
$$

por otro lado queda claro que:

$$
R_{\max }= \begin{cases}1+2^{\frac{m+1}{2}} & \text { para } m \text { impar } \\ 1+2^{\frac{m+2}{2}} & \text { para } m \equiv 2(\bmod 4)\end{cases}
$$

Cabe darse cuenta, aunque ya lo hemos recalcado en varias ocasiones, que tenemos un período de $N=2^{m}-1$ y un tamaño del conjunto de secuencias Gold de $M=2^{m}+1$. Por lo que tenemos $N \approx M$.

\subsection{Fabricación de las Redes de Difracción SSFBGs para OCDMA}

Para fabricar una perturbación periódica en el índice de refracción de una fibra óptica, por medio del efecto de fotosensitividad, se requiere un marco de interferencia de ultravioleta (UV). El método más efectivo para realizarlo es mediante el uso de 


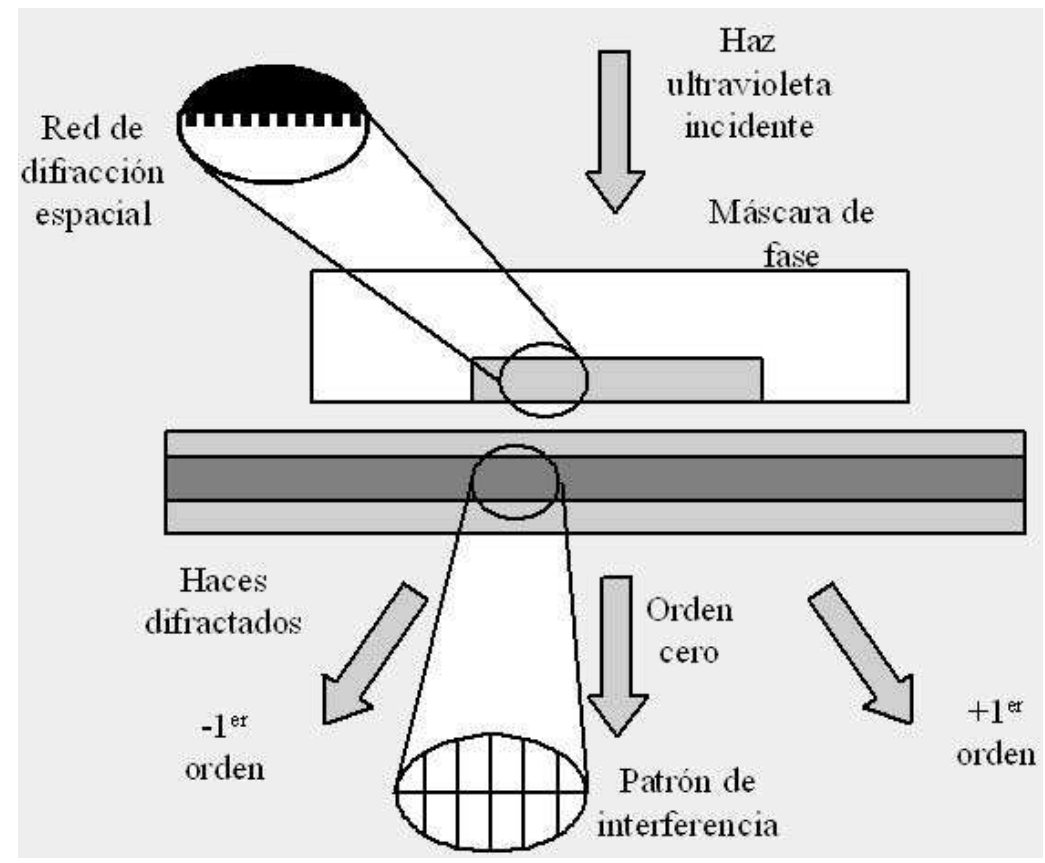

Figura 3.5: Tecnología de fabricación basada en máscara de Fase, [70].

la técnica de máscara de fase [68][69]. Con este método, la luz incidente es dividida por medio de la máscara de fase en dos rayos de diferente orden, que luego se solapan para crear el patrón de interferencia deseado (figura 3.5). La máscara de fase es una pieza de material transparente a la cual se le ha grabado equi-espacialmente ranuras mediante un proceso de litografía electrónica.

La elaboración de las redes SSFBG que se describirán en esta tesis se realizó en el sistema de fabricación de FBGs del Grupo de Comunicaciones Ópticas y Cuánticas (GCOC) inscrito en el Instituto de Telecomunicaciones y Aplicaciones Multimedia (iTEAM) de la Universidad Politécnica de Valencia (UPV). Dicho sistema es capaz de fabricar redes de difracción con distintos apodizados y chirps utilizando tan solo una máscara de fase de período uniforme [71]. La máscara de fase ha sido diseñada para optimizar la potencia difractada en los órdenes \pm 1 y minimizar el resto, especialmente el orden 0 , de modo que en la región del espacio donde estos órdenes se superponen se crea una zona de franjas interferométricas de alto contraste.

El funcionamiento del sistema está basado en la creación y superposición de pequeñas redes sobre la fibra fotosensible. La superposición de forma adecuada de muchas de estas redes produce la red final. El aspecto más interesante de esta técnica es que, con un control adecuado y preciso del desfase entre exposiciones sucesivas, es posible fabricar redes con prácticamente cualquier tipo de apodización y de chirp. Esto hace que este sistema de fabricación sea extremadamente versátil.

En nuestro sistema de fabricación, el factor limitante para construir las SSFBGs, es el tamaño del haz UV, que define la anchura de las redes individuales que conformaran 


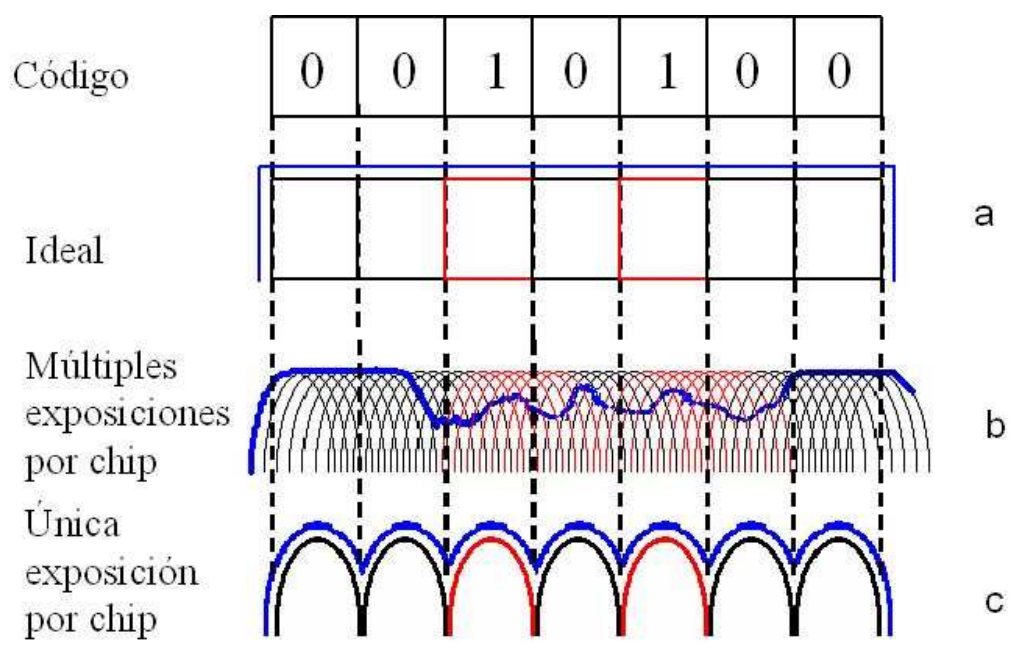

Figura 3.6: Perfiles del índice de refracción de las SSFBGs.

por superposición la red final. En el momento de fabricar las SSFBGs para OCDMA, la anchura mínima del haz UV era de 500 micras. Esto afecta directamente al diseño de la SSFBG, ya que limita el tamaño mínimo del chip. Pese a escoger este tamaño de haz, surge otro problema debido a la técnica de fabricación y al tipo de red. Una SSFBG básicamente es una red uniforme con saltos de fase equiespaciados una determinada distancia (tamaño de chip). Debido a la técnica de fabricación empleada, cuando el sistema introduce un salto de fase entre dos exposiciones se produce una cancelación entre las exposiciones sucesivas, lo que provoca que el índice de refracción no aumente como debería, distorsionando el perfil de la red. A este método le hemos llamado, método de múltiples exposiciones. En las figuras 3.6a. y b. se muestra un ejemplo del perfil de índice de refracción ideal y el que se consigue mediante el método de múltiples exposiciones, descrito anteriormente.

Para solucionar este problema, se decidió modificar el diseño de las SSFBGs. En el diseño original se considera que cada chip debe tener un perfil uniforme, pero realmente esta condición no es necesaria. Tan solo es necesario que la luz se refleje principalmente en el punto central del chip, y en una FBG débil esa condición la cumple cualquier perfil simétrico centrado en la posición del chip. Es posible por lo tanto, cambiar el perfil uniforme por uno gausiano (el perfil del haz UV) sin perder las funcionalidades de la red como sistema cod/decodificador OCDMA. Esto se traduciría en una modificación de la técnica de fabricación. En el caso de las SSFBG para OCDMA, en lugar de superponer múltiples redes individuales, lo que hicimos fue hacer una única red individual por cada chip, en la posición central de este. Debido a la anchura del haz UV (500 micras), se estimó que la anchura mínima posible del chip era de 600 micras, lo que tiene implicaciones sobre la tasa máxima de funcionamiento del sistema. El perfil obtenido mediante este nuevo método se muestra en la figura 3.6c.

En la figura 3.7 se observa la respuesta espectral teórica de la SSFBG con per- 


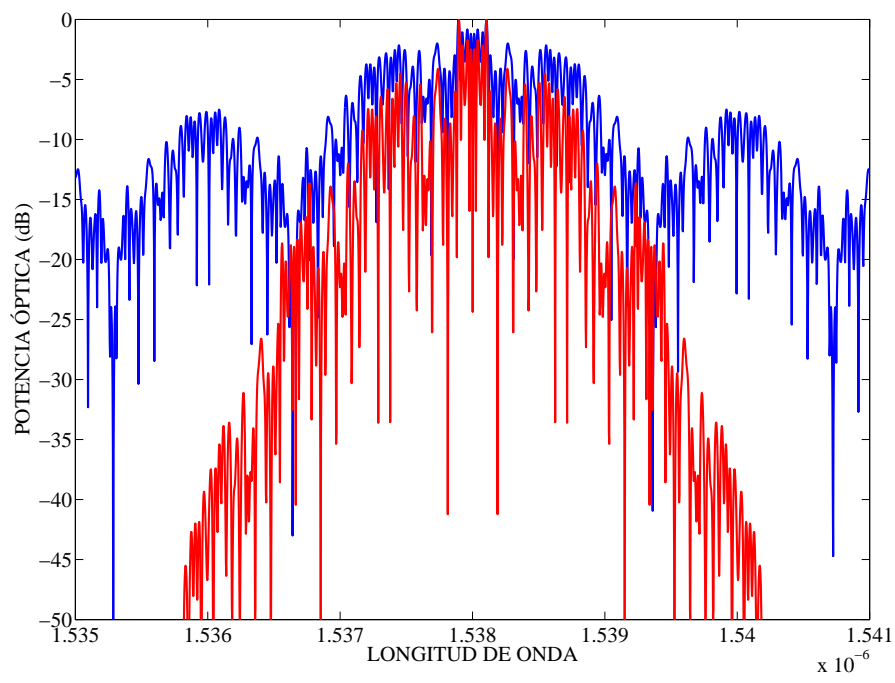

Figura 3.7: Espectros de la SSFBG para un diseño con perfil uniforme (azul) y perfil gausiano (rojo)

fil de índice de refracción uniforme (azul) y con el perfil gausiano (rojo). De allí se puede concluir que las respuestas espectrales en su lóbulo principal son prácticamente idénticas. No obstante si vemos los lóbulos secundarios podemos observar que los correspondientes al perfil gausiano son inferiores a los que aparecen con el perfil uniforme. La razón de esta diferencia es que el espectro de las redes de difracción no es otra cosa que la transformada de Fourier del perfil de cada red bajo suposición de reflectividad baja. De esta manera si la forma de los chips es uniforme, la envolvente del espectro será de tipo sinc, de allí los múltiples lóbulos secundarios, mientras que para un perfil gausiano de cada chip la envolvente es gausiana. La diferencia entre los lóbulos secundarios, de la red uniforme y de la red gausiana, no tiene ninguna influencia relevante en su capacidad para realizar los procesos de codificación y decodificación, debido a que la potencia esta contenida en el lóbulo principal.

\subsection{Codificación y Decodificación Óptica Mediante SSFBG Bipolares Uniformes}

El diagrama de la figura 3.8 muestra un sistema OCDMA que consta básicamente de 5 bloques principales; La fuente de pulsos estrechos modulada con la información que se desea enviar, el codificador, la fibra óptica por la que enviaremos la señal codificada, el decodificador y el receptor óptico. Para nuestro trabajo se ha utilizado como fuente de pulsos estrechos una fuente Mode Locked Laser Diode (MLLD). Esta fuente emite pulsos de aproximadamente 3 ps de duración a una tasa que puede 


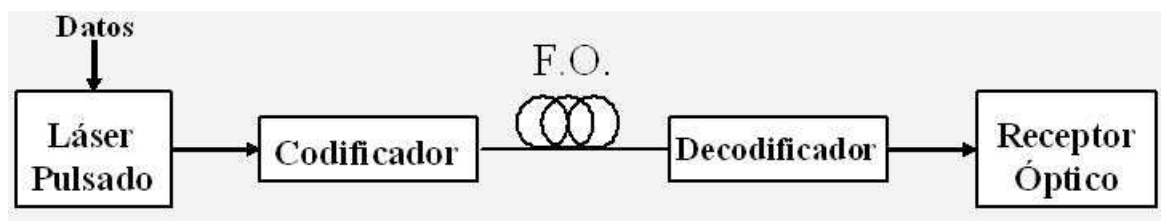

Figura 3.8: Diagrama de bloques básico del sistema OCDMA.

estar entre 5 y $10 \mathrm{GHz}$ y con una potencia media cercana a los $10 \mathrm{dBm}$. Como dispositivos codificador y decodificador se han usado SSFBGs con codificación en fase óptica bipolar y con amplitud uniforme. En este apartado se presenta únicamente el caso back-to-back, aunque en un capítulo posterior se mostrarán los resultados considerando fibra real y por lo tanto el efecto de la dispersión cromática. Finalmente en el receptor se ha utilizado un detector óptico con un ancho de banda máximo de $30 \mathrm{GHz}$ y un osciloscopio de muestreo para la recuperación de las señales en el dominio temporal.

A cada una de las SSFBGs utilizadas se les grabó un código de 63 chips, obtenido de la familia descrita en el apartado 3.3.2. En el proceso de fabricación existe la limitación en cuanto al tamaño o longitud del chip $l_{c}$ mínima que podemos obtener. Con nuestro sistema de fabricación dicha longitud mínima es de $0.6 \mathrm{~mm}$. Si además conocemos que el tiempo de chip esta dado por la ecuación 3.23, podemos encontrar que la señal codificada tendrá una duración aproximada de 365 ps.

$$
T_{c}=2 \frac{l_{c}}{c} n
$$

También se fabricaron SSFBGs con longitud de chip de $1 \mathrm{~mm}$ para poder tener puntos de comparación. Para el caso de una SSFBG con tamaño de chip de $1 \mathrm{~mm}$ la señal codificada dura aproximadamente 610 ps. Con estos datos definimos que la tasa de transmisión a la que deberíamos enviar la información, garantizando que no existiese interferencia intersimbólica (ISI), tenía que ser de $1.25 \mathrm{Gbps}$. Por lo tanto esta frecuencia debía ser la de trabajo de la fuente MLLD.

La MLLD proporciona dos valores de frecuencia de oscilación, 5 ó $10 \mathrm{GHz}$. En la figura 3.9 podemos ver el espectro cuando la fuente oscila a $10 \mathrm{GHz}$ y centrada a $1550 \mathrm{~nm}$. Como la frecuencia de oscilación es demasiado alta para nuestro propósito, se resolvió realizar un diezmado de pulsos. Para ello se hizo oscilar la fuente a $5 \mathrm{GHz}$ y se tomo un pulso de cada 4, obteniendo de esta manera una señal a $1.25 \mathrm{GHz}$.

El diagrama de bloques de la figura 3.10 corresponde con el esquema del diezmador implementado. Básicamente consta de un generador eléctrico oscilando a $1.25 \mathrm{GHz}$ cuya salida dividimos en dos. Una de estas salidas pasa por un multiplicador $\mathrm{x} 2 \mathrm{de}$ frecuencia, lo que indica que tendremos una señal a $2.5 \mathrm{GHz}$ y una a $1.25 \mathrm{GHz}$ con una relación de fase constante. Con la salida de $2.5 \mathrm{GHz}$ realizamos un primer diezmado del láser pulsado mediante el modulador Mach-Zehnder(MZ) 1. La salida resultante, pasa por el modulador MZ 2 el cual termina reduciendo la frecuencia de la señal del láser al valor deseado por nosotros, es decir, $1.25 \mathrm{GHz}$. Es muy importante en la estructura del diezmador al ajuste apropiado entre los retardos de propagación óptica 


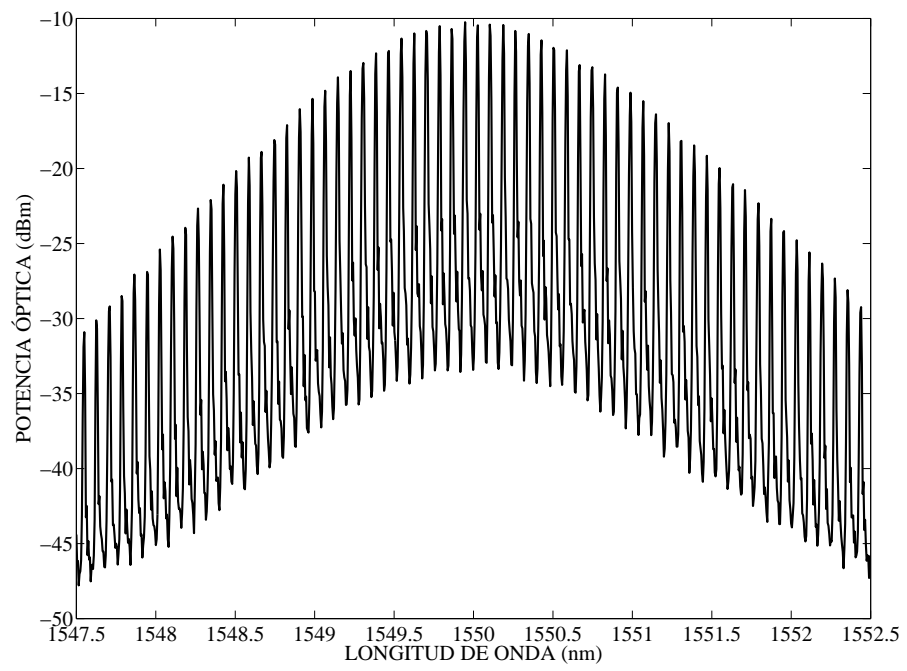

Figura 3.9: Espectro de la fuente pulsada.

y eléctrica así como el ajuste y mantenimiento estable del estado de polarización a la entrada de los dos moduladores electroópticos.

Como ya hemos indicado todas las medidas han sido hechas con un osciloscopio de muestreo (CSA8000 Tektroniks), cuyo ancho de banda máximo es de $30 \mathrm{GHz}$. En la figura 3.11 podemos ver la señal de salida de la fuente MLLD después de ser diezmada a $1.25 \mathrm{GHz}$. En esta figura podemos ver que el pulso que se mide en el osciloscopio tiene una anchura aproximada de 20 ps, lo cual no es real, ya que la anchura del pulso es cercana a los 3 ps. Así mismo sucede con la amplitud del pulso, que se ve reducida con respecto a la real. El error en la lectura es precisamente consecuencia del efecto de la limitación del ancho de banda del receptor empleado y del osciloscopio.

Para describir más detalladamente el procesamiento de señal que se hace dentro de un sistema OCDMA, utilizaremos el diagrama básico mostrado en la figura 3.12. El primer bloque, que corresponde a la fuente pulsada, encierra los elementos necesarios para su diezmado, de tal forma que a la salida de dicho bloque tendremos una señal a $1.25 \mathrm{GHz}$. La fuente se ha centrado a una longitud de onda de $1538.5 \mathrm{~nm}$, porque a esa misma longitud se han fabricado las SSFBG. La señal resultante es aplicada a la SSFBG 1, cuya señal reflejada, corresponderá con la señal codificada. Vale la pena recordar que la señal codificada no es otra cosa que la respuesta impulsiva $h(t)$ de la SSFBG convolucionada con la forma de los pulsos ópticos. Para verla en detalle podemos ver el resultado de su simulación, (figura 3.13) y compararlo con el obtenido a partir de la medida con el osciloscopio, (figura 3.14).

En la simulación, podemos ver que la respuesta impulsiva de la SSFBG consiste de un tren de pulsos. El ancho de cada uno de estos pulsos estará dado por la convolución entre la anchura del pulso y el ancho del chip. Además cada pulso tendrá una fase 


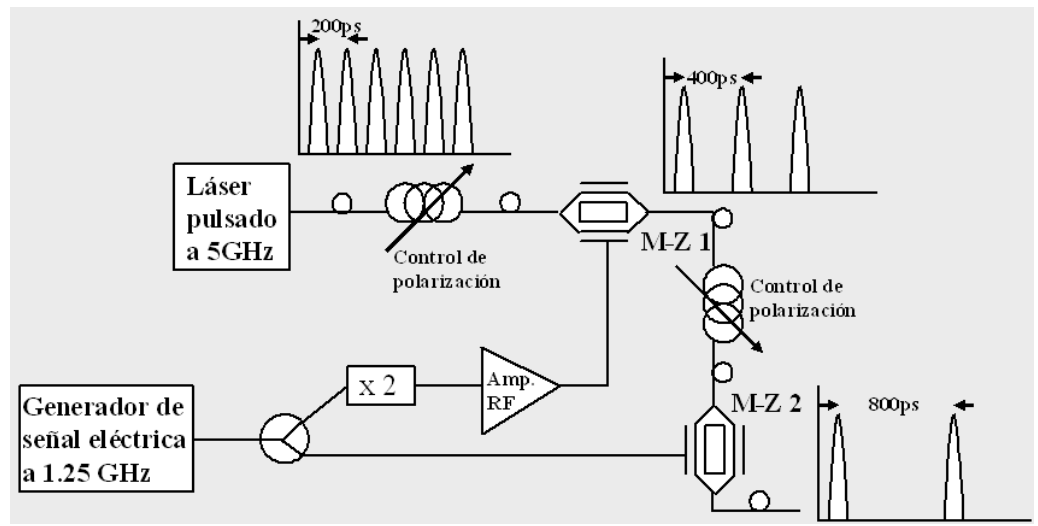

Figura 3.10: Diezmador óptico

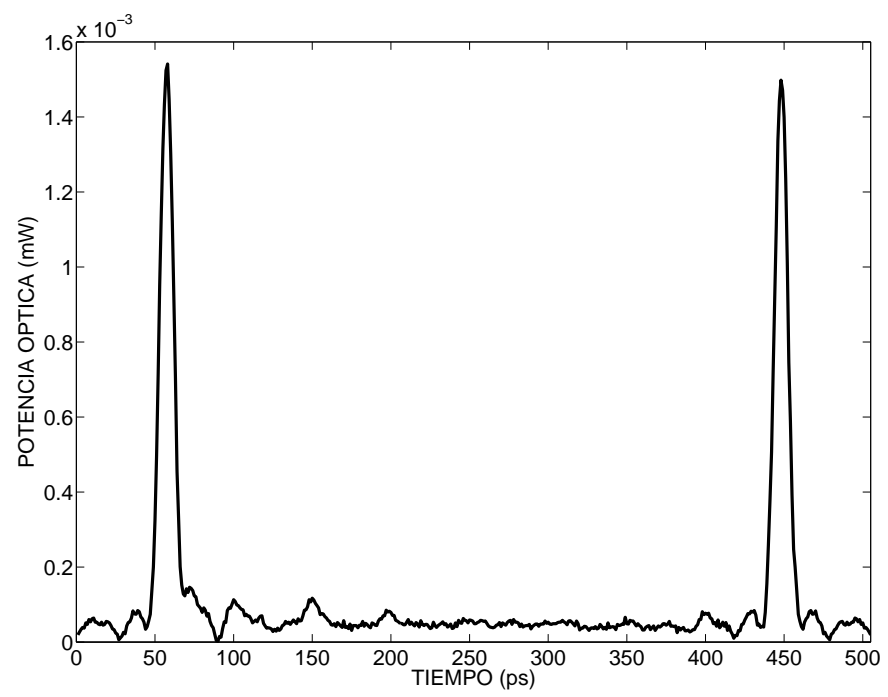

Figura 3.11: Señal de la fuente MLLD a $1.25 \mathrm{GHz}$

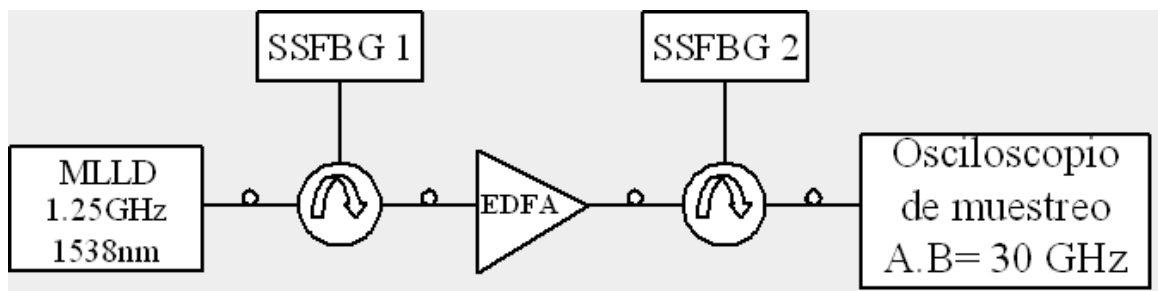

Figura 3.12: Sistema OCDMA básico con SSFBG 


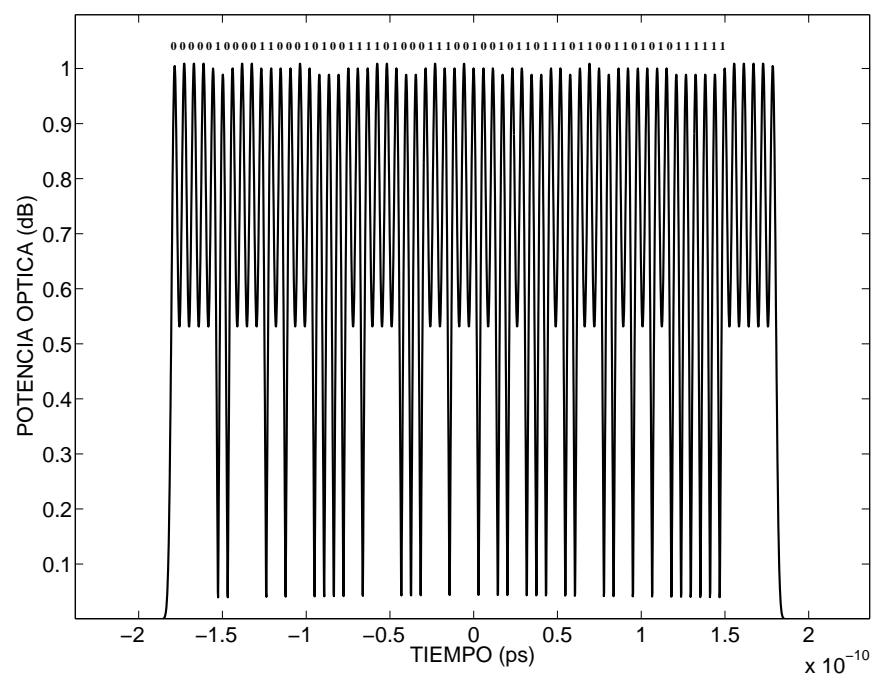

Figura 3.13: Simulación de la respuesta impulsiva de la SSFBG codificadora.

asignada de acuerdo a una palabra código de la familia descrita en el apartado anterior. Más exactamente, para la figura 3.13 se simuló la secuencia $a$, en donde los valores de 0 indican un fase igual a cero y los valores de 1 indican una fase igual a $\pi$ o 180 grados. Sobre la curva de simulación se ha puesto la secuencia a para mostrar el efecto de borrado en la zona de solapamiento entre chips adyacentes, cuando existe un cambio de 1's a 0's o viceversa. Dos aspectos importantes que se observan en la simulación, son; 1) el tiempo de duración del pulso codificado es $t_{p c}=N \cdot T_{c}=63 \cdot 5,8 p s \approx 365 p s$. $\mathrm{Y} 2$ ) todos los pulsos tienen la misma altura, lo que nos indica que el coeficiente de acoplamiento $\kappa$ es el mismo para toda la SSFBG.

En la medida de laboratorio no se puede observar los distintos pulsos discriminados, como consecuencia del ensanchamiento que sufren los mismos por las limitaciones de ancho de banda del osciloscopio, tal y como se mostró para pulsos aislados en la figura 3.14. No obstante si que se puede confirmar como la SSFBG ha sido diseñada con un coeficiente de acoplo bajo y constante a lo largo de toda la SSFBG, y por lo tanto la distribución de amplitud de los 63 chips reflejados es aproximadamente plana.

El problema del uso de SSFBG de baja reflectividad en sistemas OCDMA son las altas pérdidas de inserción del dispositivo. Aunque el empleo de SSFBGs de baja reflectividad y las posibles soluciones al problema se desarrollan en profundidad en el capítulo siguiente, se muestran las medidas para el caso práctico de las SSFBGs que nos ocupan en este apartado. Las pérdidas de inserción las podemos obtener mediante la figura 3.15, donde hemos representado el espectro de la SSFBG codificadora (línea continua), cuando la alimentamos con una fuente de luz blanca (línea a trazos ). Podemos ver que la diferencia de potencia entre la fuente de luz blanca y el pico 


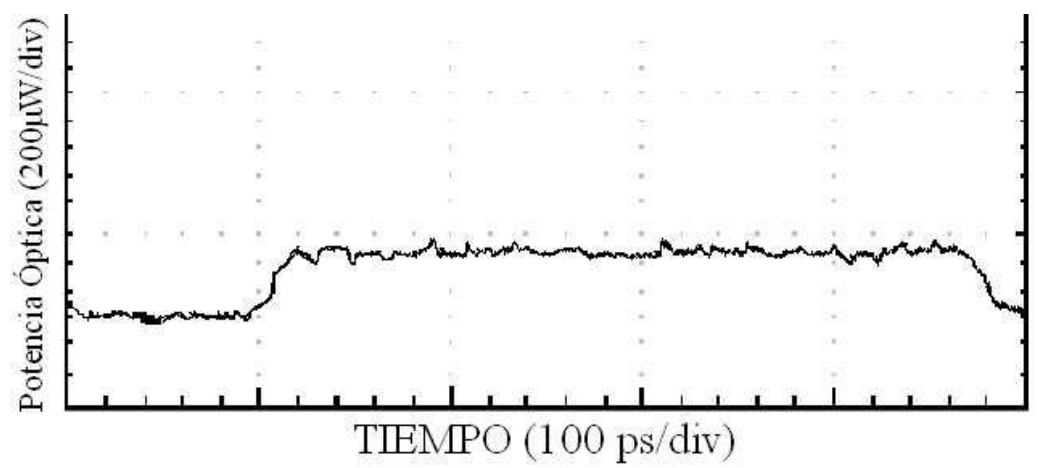

Figura 3.14: Medida de la respuesta impulsiva con el CSA.

máximo del espectro de la SSFBG es cercana a los $8 \mathrm{~dB}$. Aunque como es bien sabido, la medida exacta de reflectividad de una FBG se debe determinar empleando el espectro en transmisión, en nuestro caso para reflectividades tan bajas resulta más ilustrativo el espectro en reflexión compensando las pérdidas en el circulador óptico y en los conectores.

Con pérdidas de $8 \mathrm{~dB}$ en el codificador es necesario amplificar la señal, razón por la cual usamos después del codificador un EDFA (Erbium Doped Fiber Amplifier). El EDFA proporciona una ganancia de aproximadamente $20 \mathrm{~dB}$, con lo que nuestra señal vuelve a tener un nivel adecuado para el proceso de decodificación.

En el decodificador se tiene la SSFBG 2, a la que se le ha grabado el código conjugado de la SSFBG 1. En realidad lo que se hace es fabricar dos SSFBG exactamente iguales, pero cada una se conectoriza por un extremo diferente. Esta simplificación a nivel práctico se puede realizar únicamente en el caso de SSFBGs con codificación de fase bipolar (cambios de fase 0 o $\pi$ alternativos). En el caso de que la codificación de fase de cada chip fuera Multipolar, es decir con múltiples niveles de fase repartidos entre 0 y $\pi$ (por ejemplo cuadripolar [9]), sería necesaria la fabricación de una red decodificadora especifica mediante el procedimiento general consistente en $1^{\mathrm{O}}$ ) inversión en la posición de los chips y $2^{\underline{O}}$ ) conjugación de fase de los mismos. Hay que indicar que desde un punto de vista de fabricación esto no supone ninguna modificación de los procedimientos antes descritos resultando en una extensión inmediata del caso bipolar.

La figura 3.16 muestra el resultado de la simulación de la decodificación del pulso. La traza azul corresponde al pulso decodificado con el código correcto y la traza roja con el decodificador incorrecto. En la gráfica también se especifican dos términos muy importantes para la evaluación del sistema, el primero se refiere a los wings $(W)$, que son los niveles de señal espuria que surgen durante el proceso de autocorrelación, y el valor de la función de correlación cruzada $(C)$ que se observa cuando se decodifica con la palabra código incorrecta. El valor aproximado teórico (valor medio para una familia de códigos de Gold) de la relación entre el pico de potencia $(P)$ y la potencia de los wings es $\eta=\frac{1}{2 N}$ [72] y el valor de crosstalk $\xi=\frac{C}{P}=\frac{1}{N}$ [37], en donde $N$ es el número de chips. 


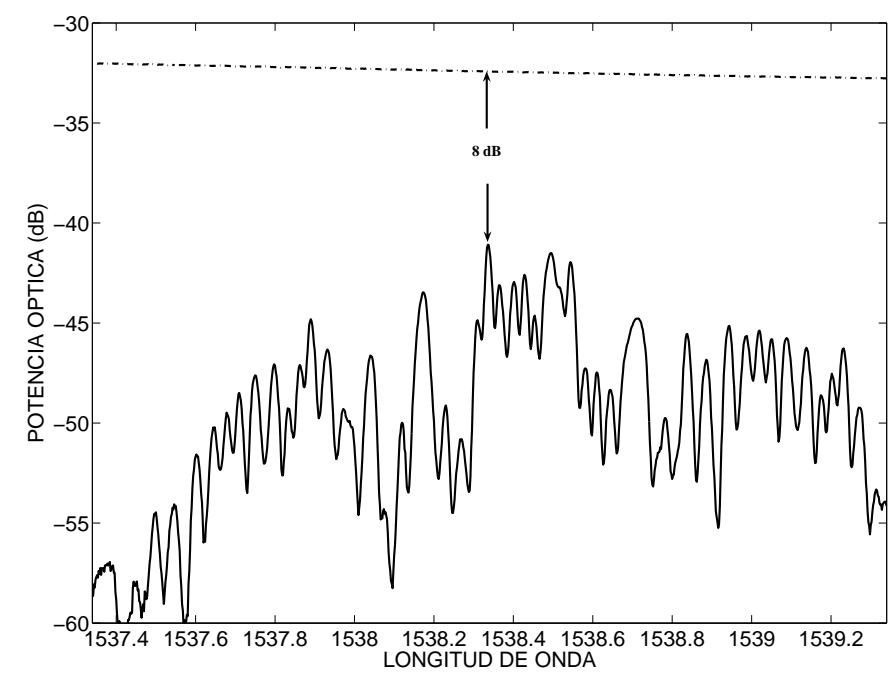

Figura 3.15: Pérdidas de inserción introducidas por una SSFBG codificadora.

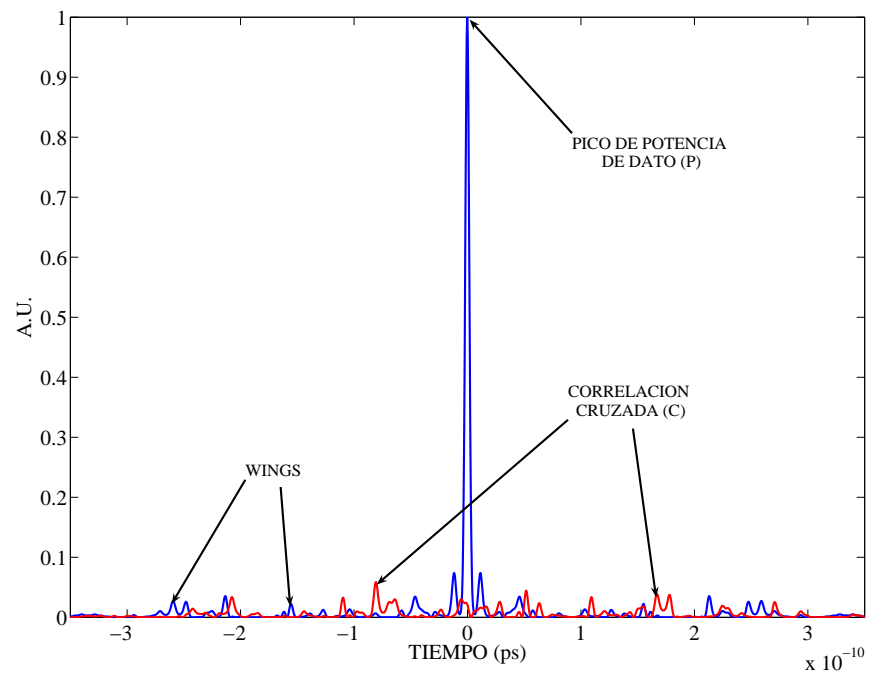

Figura 3.16: Salida del decodificador. (azul) Decodificada con código correcto, (rojo) con código incorrecto. 


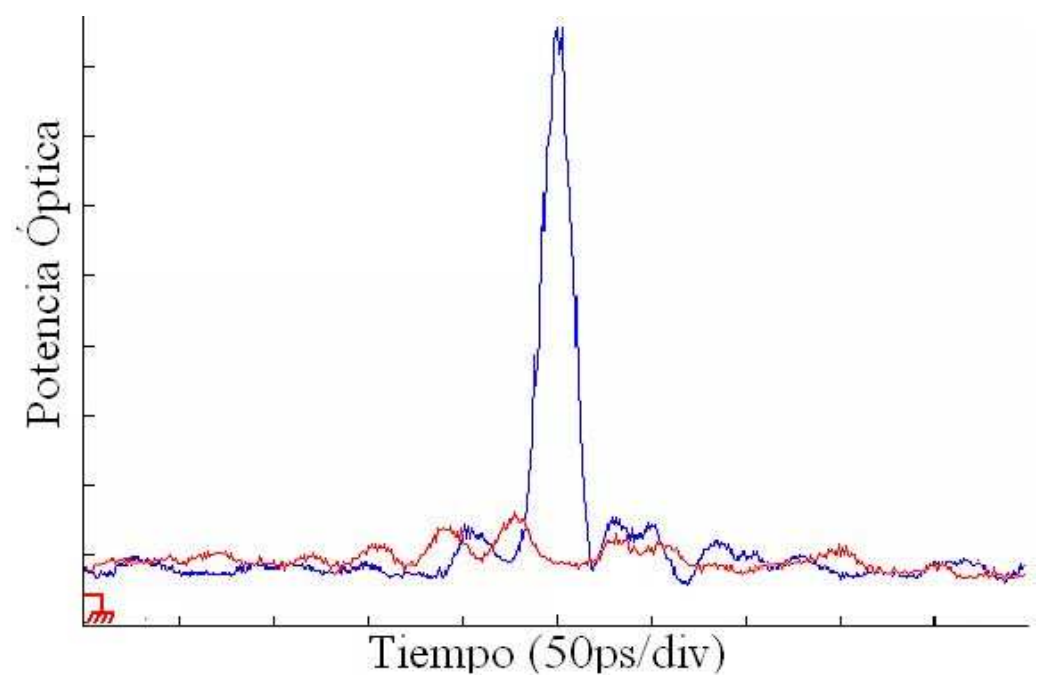

Figura 3.17: Señal decodificada, medida con el CSA. (azul) Decodificada correctamente, (rojo) Con el decodificador incorrecto.

Los resultados de esta primera simulación corroboran la correcta selección de la familia de códigos, ya que se obtiene un pico de autocorrelación destacado y el nivel de la correlación cruzada es bajo. Si ahora vemos los resultados medidos con el osciloscopio, obtenemos resultados similares, eso si, afectados por los limitantes de ancho de banda y ruido del detector y de la instrumentación.

A primera vista, las medidas tomadas con el CSA, podrían llevar a pensar que los wings tienen un valor similar al de la función de correlación cruzada. No obstante, al comparar este gráfico con el de la señal original mostrado en la figura 3.11 se puede ver que los picos adyacentes al pico de potencia principal son realmente una imperfección de la señal original emitida por la fuente.

Este sencillo experimento permite: realizar un primera prueba de la calidad de los códigos usados, verificar que las relaciones de $\eta$ y $\xi$ tengan valores aproximados a los ideales y por último medir el efecto de las limitaciones en ancho de banda del receptor. Para nuestro caso, las limitaciones en ancho de banda están determinadas por el osciloscopio, el cual tenía tres posibles valores de ancho de banda que podían ser seleccionados, $30 \mathrm{GHz}, 12.5 \mathrm{GHz}$ y $2.5 \mathrm{GHz}$. En la figura 3.18 , podemos ver este efecto, el hecho de recibir la señal con un dispositivo limitado en banda ocasiona que los pulsos se ensanchen y se atenúen. Para nuestro caso, el máximo ancho de banda disponible en el receptor es de $30 \mathrm{GHz}$ con él, lográbamos la mejor recepción de la señal. Ahora si comparamos la recepción con el filtro de $12.5 \mathrm{GHz}$ con el de $30 \mathrm{GHz}$ podemos ver que la disminución del ancho de banda del receptor en un $60 \%$, ocasiona una caída en la potencia del pulso recuperado cercana al $50 \%$ y un ensanchamiento de $100 \%$. Por otra parte si recepcionamos con el de $2.5 \mathrm{GHz}$ la caída en la amplitud del pulso será del $70 \%$ y el ensanchamiento de $500 \%$. Afortunadamente esta atenuación la recibe toda la señal y no solamente el pulso correctamente codificado. 


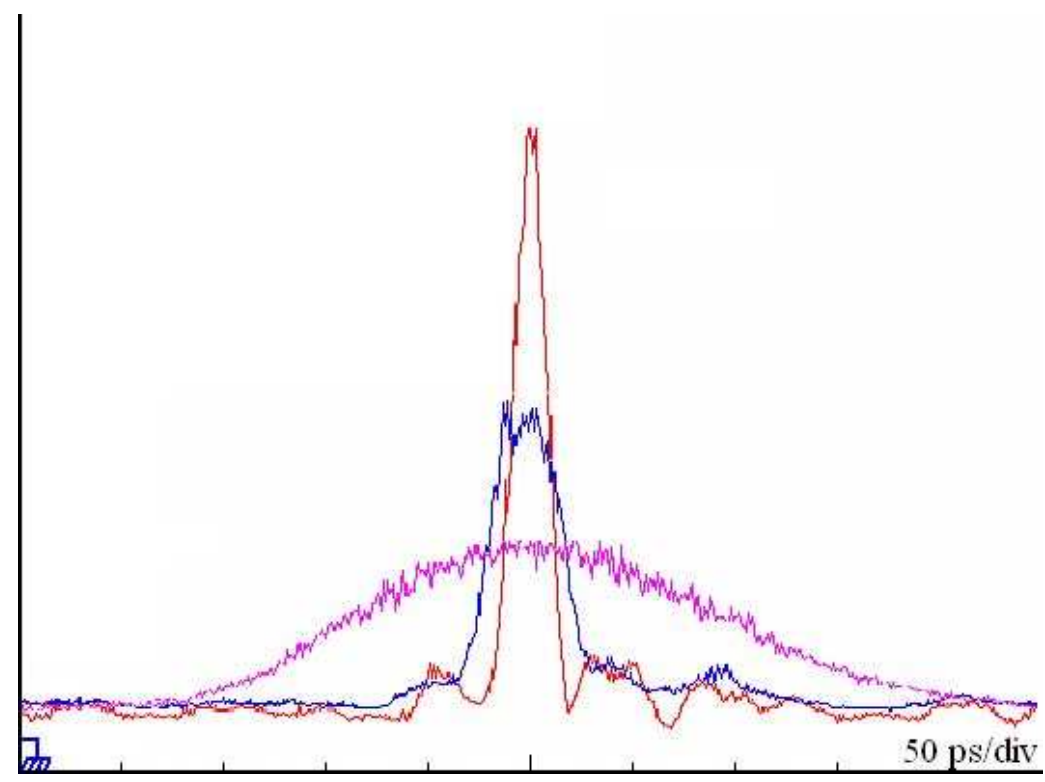

Figura 3.18: Efecto del filtrado sobre la señal decodificada. $30 \mathrm{GHz}$ (traza roja), 12.5 $\mathrm{GHz}$ (traza azul) y $2.5 \mathrm{GHz}$ (traza violeta)

En este punto, vale la pena recordar lo visto en el capítulo anterior en el apartado 2.3 , en donde se describían la influencia sobre el sistema de las variaciones en ancho de banda del receptor. Tener un receptor con un ancho de banda muy grande equivale al uso de técnicas de time gating, las cuales me permiten eliminar el ruido producido por la interferencia multiusuario. Sin embargo en la medida que el ancho de banda se incrementa el costo de los receptores también lo hace. Existen algunas aplicaciones donde puede ser conveniente trabajar con dispositivos con un ancho de banda menor y que resulten a su vez más económicos. Además un dispositivo con un ancho de banda menor puede ser combinado con alguna técnica de thresholding que permita compensar los efectos negativos, tal como se demostró en 2.8.4. En general, la restricción por ancho de banda del receptor, estará dada por la aplicación en donde vaya a ser implementado. Por ejemplo, en sistemas OCDMA multiusuario las opciones están en el uso de dispositivos con gran ancho de banda ó con bajo ancho de banda en combinación con técnicas de thresholding. Y en sistemas OCDMA usados para detección de etiquetas serán útiles dispositivos con bajo ancho de banda que permitan discriminar la señal correcta, a un coste relativamente económico.

\subsection{Técnicas de Estabilidad en Temperatura}

Como hemos visto, los sistemas DS-OCDMA pueden ser implementados con redes de difracción de Bragg como dispositivos codificadores y decodificadores. Usar SSFBGs tienen múltiples ventajas, entre ellas; su completa compatibilidad con la fi- 
bra óptica, posibilidad de implementación de diferentes tipos de códigos, facilidad de fabricación, bajo costo cuando se producen en grandes cantidades, posibilidad de ser sintonizada a longitudes de onda determinadas, etc. No obstante las SSFBGs también tienen 2 inconvenientes importantes; uno, sus altas pérdidas de inserción y dos un exigente grado de sintonía en longitud de onda. Del primer problema nos ocuparemos en un capítulo posterior, por ahora caracterizaremos el segundo.

Para comprender el problema tenemos que recordar que una SSFBG es una fibra óptica a la que se le ha introducido una variación periódica de su índice de refracción. En nuestro caso la variación de índice de refracción introducida, sigue un patrón determinado por un código bipolar de una familia de Gold. Para que el sistema funcione correctamente la SSFBG del receptor deberá tener grabado el código conjugado de la SSFBG codificadora. Las SSFBGs deberán ser fabricadas bajo los mismos parámetros de tamaño de chip, variación del índice de refracción y longitud de onda central. Estos tres parámetros se controlan en el momento de fabricación de la SSFBG, sin embargo es muy difícil lograr que la longitud de onda central sea exactamente igual en los diferentes dispositivos que se construyan. El hecho de que no exista una coincidencia perfecta en la longitud de onda de las SSFBGs usadas implica que la señal no pueda ser decodificada correctamente. Por lo tanto es necesario buscar un método que permita sintonizar las SSFBGs a la misma longitud de onda. Una forma de lograrlo es mediante la tensión mecánica. Se toma una de las fibras y se somete a un proceso de tensión, a medida que esta tensión aumenta, la longitud de onda se desplaza hacia longitudes mayores. Usando este método es posible lograr una sintonía entre las SSFBGs codificadora y decodificadora. Sin embargo, después de varias pruebas, se observaba que la estabilidad conseguida no duraba más de 30 segundos, al cabo de los cuales se tenían considerables reducciones en el pico de autocorrelación, cuando no su completa desaparición. La razón es que las SSFBGs tienen una dependencia con respecto a la temperatura demasiado alta. Cualquier variación en la temperatura afecta la SSFBG, inclusive si está siendo sometida a tensión mecánica. Esto significa que la mejor forma de lograr la sintonía entre SSFBGs es variando la temperatura hasta lograr la coincidencia exacta en longitud de onda.

Nosotros realizamos diferentes pruebas, buscando la forma óptima de sintonización con temperatura, primero realizamos la variación en temperatura con la SSFBG tensionada y después con la SSFBG libre de tensión mecánica.

En la figura 3.19 vemos dos curvas que muestran la variación de la longitud de onda en una SSFBG cuando sobre ella se varía la temperatura. Para hallar la gráfica de la SSFBG tensionada, lo que hicimos fue tomar la SSFBG y ponerla sobre una lamina de aluminio, tensionarla y mantener dicha tensión mediante el pegado de los extremos de la SSFBG. Posteriormente se varía la temperatura y se toman los datos. La variación en longitud de onda cuando la SSFBG esta tensionada es cercana a los $24 \mathrm{pm} / \mathrm{C}$. Por otra parte, para dibujar la otra curva lo que se hace es tomar la SSFBG sin tensionar y variar su temperatura. En este caso, por cada grado centígrado de cambio en la temperatura obtenemos una variación de aproximadamente $11 \mathrm{pm}$ en la longitud de onda. El segundo caso corresponde con el coeficiente de variación de longitud de onda frente a temperatura, típico de una FBG aislada y debido al coeficiente de expansión de la fibra y al coeficiente de variación termo-óptico del sílice dopado [73]. En el primer caso se añade a los dos mencionados el coeficiente de expansión del aluminio. 


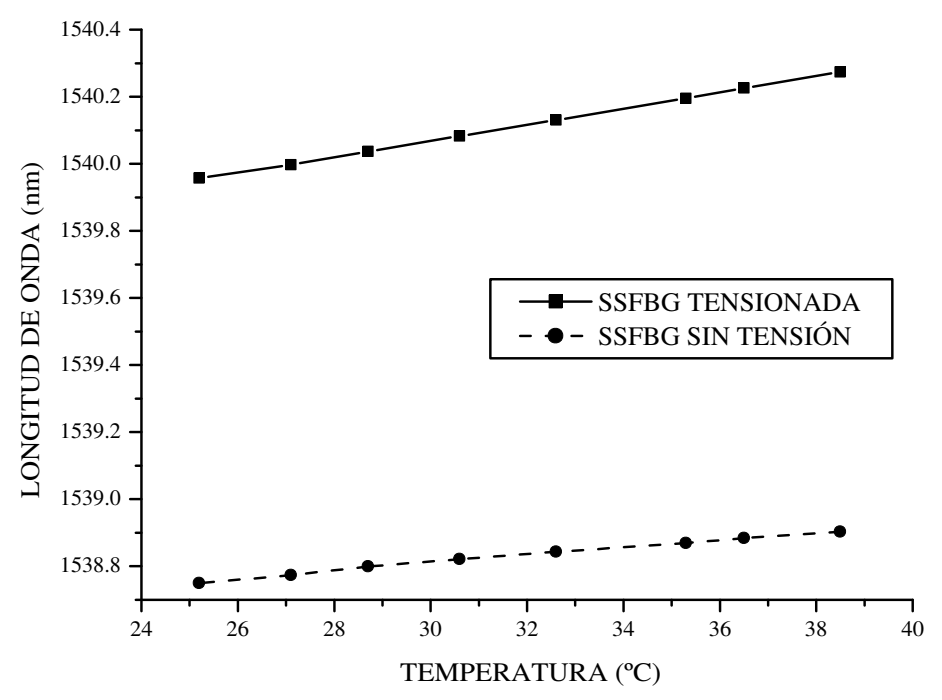

Figura 3.19: Variación de la longitud de onda con la temperatura en una SSFBG tensionada.

Como se puede observar en ambos casos el comportamiento es lineal. Por lo tanto se podría escoger indiferentemente uno u otro en función de las necesidades de rango de sintonización gruesa que se requiera. No obstante después de diversas tentativas y por cuestión de precisión y facilidad de control, es más aconsejable tener una variación pequeña en longitud de onda. Por esta razón se decidió realizar la sintonía sin tensionar las SSFBGs.

Con el objeto de tener un control preciso de la temperatura, además de una estabilidad de la misma, se fabricó por cada SSFBG una caja controladora de temperatura (CCT). Cada CCT tiene la arquitectura típica de un servo sistema de una entrada y una salida, con el controlador en cascada con el elemento calentador (figura 3.20).

Una desventaja de utilizar un sistema térmico es su dinámica lenta y por lo tanto el tiempo empleado en la caracterización y ajuste del controlador. Aunque después de realizado no tenía mayor complicación y se alcanza una alto grado de precisión. El sistema térmico está constituido por dos pares de resistencias de potencia de $47 \Omega$ a $15 \mathrm{~W}$ montada sobre una placa metálica. Sobre la placa metálica se depositan las SSFBGs. La etapa de potencia, está constituida por una fuente de voltaje alterno de $220 v$ que se conecta a través de un relé a las resistencias. El sensor de temperatura (Pt100/RTD2), en contacto con la placa metálica, mide la magnitud a controlar, y este valor es realimentado. Dicho valor se compara con la señal de referencia introducida y de esta manera se logra el control de temperatura.

Alcanzar el valor de temperatura deseado es una de las características importantes de las CCT, pero también lograr mantener esta temperatura con una deriva muy 


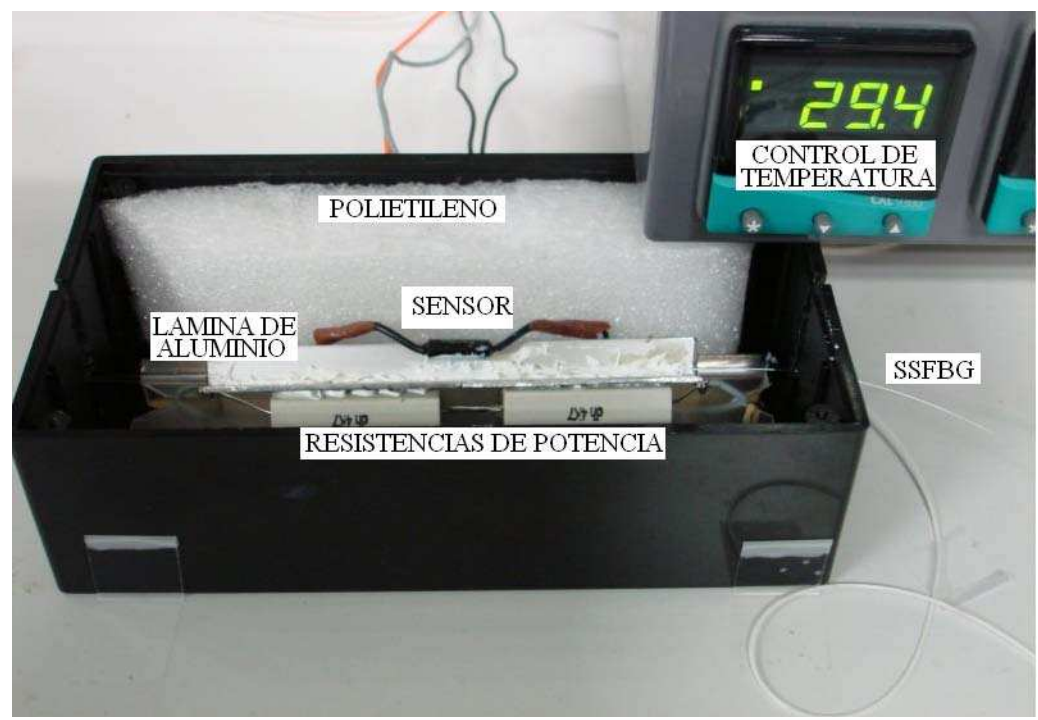

Figura 3.20: Diagrama de la Caja Controladora de Temperatura.

baja durante el mayor tiempo posible. Para conseguir el mayor grado de precisión cada caja fue rellenada de polietileno que conserva mejor la temperatura. Al final, el sistema implementado consigue alcanzar la temperatura deseada en aproximadamente 20 minutos, con un grado de precisión de $\pm 0,1$ grado.

Como hemos indicado anteriormente nuestro sistema de fabricación de SSFBGs carece de un control preciso de longitud de onda a la que se centra cada dispositivo. Por tal motivo la diferencia en longitudes de onda entre una SSFBG y otra es aleatoria, pudiendo ser un valor cercano a cero hasta valores de $400 \mathrm{pm}$. Teniendo en cuenta esto, las CCT fueron fabricadas para poder tener una variación de temperatura desde los $25 C$ hasta los $60 C$ cubriendo con ello todo el rango de longitudes de onda posibles. La estabilidad también fue comprobada y podemos asegurar que las CCT pueden soportar encendidas sin modificar sus parámetros de diseño durante días.

\subsection{Determinación de la Desintonía Máxima y su Relación con la Longitud de la SSFBG}

Las SSFBGs usadas en sistemas OCDMA requieren ser sintonizadas para poder realizar su función de codificación y decodificación de manera óptima. Si existe algún grado de desintonía, esto se vera reflejado en el desvanecimiento del pico de autocorrelación de la señal recuperada. Por este motivo es muy importante determinar en que porcentaje se puede permitir la desintonía entre los dispositivos codificadores y decodificadores para que al final la señal pueda seguir siendo discriminada del ruido.

Para realizar este estudio se considera una SSFBG como la mostrada en la figura 3.21 , recordando que $N$ es el número de chips del código y $l_{c h}$ es el espacio que existe 


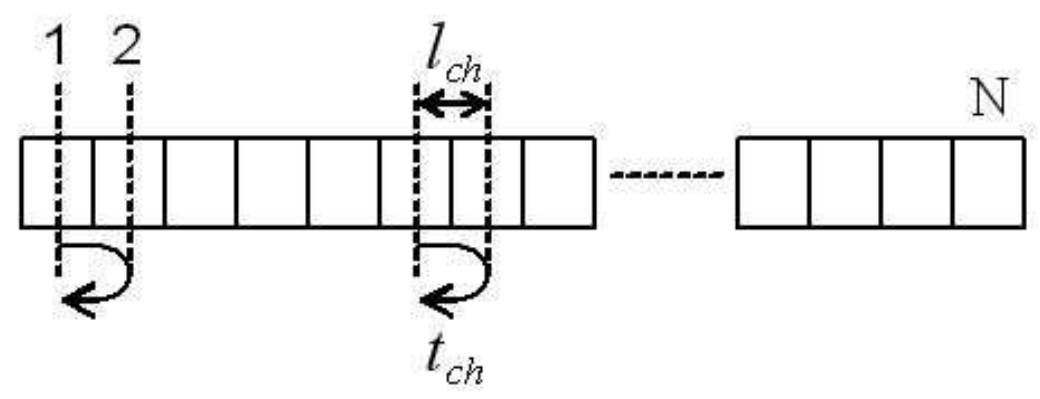

Figura 3.21: SSFBG simplificada

entre chips a lo largo de la fibra.

Para nuestro caso el sistema esta realizando una codificación en fase óptica y por lo tanto la respuesta impulsiva de la SSFBG es:

$$
h_{c o}(t)=\sum_{i=1}^{N} C_{i} h_{c h}\left(t-(i-1) T_{c}\right) \exp \left[j(i-1) l_{c h} \beta(\lambda)\right]
$$

donde $C_{i}$ representa la amplitud y la fase asociada a la reflectividad total de cada sección de chip. $h_{c h}(t)$ es la respuesta impulsiva normalizada de un solo chip. $T_{c}=\frac{2 l_{c h}}{v_{g}}$ es el tiempo de chip, y $\beta(\lambda)=\frac{2 \pi n_{e f f}}{\lambda}$ es la constante de propagación dentro de la SSFBG a la longitud de onda aplicada. Se puede observar de la ecuación 3.24 que la condición óptima de diseño de la longitud del chip individual la obtenemos del argumento de la función exponencial. Debido a que un recorrido óptico de ida y vuelta $\left(2 l_{c h}\right)$ entre un par de chips debe producir saltos enteros de $2 \pi$ de fase para asegurar un proceso de codificación y decodificación apropiado, la regla de diseño es:

$$
l_{c h}=\frac{\lambda_{B}}{2 n_{e f f}} q
$$

Siendo $q$ un entero, $\lambda_{B}$ la longitud de onda de Bragg de la SSFBG y $n_{e f f}$ el índice de refracción efectivo del modo. Esta condición asegura una fase óptica incremental entre chips igual a cero cuando $\lambda_{B}$ es aplicada al dispositivo. Si se aplica cualquier otra longitud de onda $\lambda=\lambda_{B}+\Delta \lambda$ la respuesta impulsiva será:

$$
h_{c o}(t)=\sum_{i=1}^{N} C_{i} h_{c h}\left(t-(i-1) T_{c}\right) \exp \left[j(i-1) 2 \pi q\left(\frac{\lambda_{B}}{\lambda_{B}+\Delta \lambda}\right)\right]
$$

Es importante observar que el incremento relativo de fase óptica de un chip al chip adyacente debido a la desintonía de la longitud de onda es:

$$
\Delta \phi=2 \pi q\left(\frac{\Delta \lambda}{\lambda_{B}+\Delta \lambda}\right) \approx-2 \pi q\left(\frac{\Delta \lambda}{\lambda_{B}}\right)
$$


En la expresión 3.27 podemos ver que el cambio incremental de fase es consecuencia del cambio relativo de la longitud de onda multiplicado por $q$ o lo que es igual, al número entero de longitudes de onda contenidas en la extensión del chip (camino de ida y vuelta). Sustituyendo la ecuación 3.27 en 3.26 podemos encontrar las respuestas impulsivas del codificador y decodificador.

$$
\begin{aligned}
h_{c o}(t) & \left.=\sum_{i=1}^{N} C_{i} h_{c h}\left(t-(i-1) T_{c}\right) \exp \left[j(i-1)\left(2 \pi q+\Delta \phi_{c o}\right)\right)\right] \\
h_{\text {deco }}(t) & \left.=\sum_{k=1}^{N} C_{N-k+1}^{*} h_{c h}\left(t-(k-1) T_{c}\right) \exp \left[j(k-1)\left(2 \pi q^{\prime}+\Delta \phi_{\text {deco }}\right)\right)\right]
\end{aligned}
$$

Para el decodificador se ha empleado la misma palabra código que en el codificador pero conjugada e invertida en el tiempo $C_{\text {deco }}(k)=C_{c o}^{*}(N-k+1)$, como es normal para cada par codificador-decodificador. Después del decodificador la señal se obtiene mediante la convolución en el tiempo de las respuestas impulsivas descritas en 3.28 y 3.29. Como sabemos que el diseño de la pareja codificador-decodificador implica que $C_{i} C_{N-i+1}^{*}=1$, tenemos que el pico de autocorrelación se puede expresar como:

$$
\left(h_{c o} \otimes h_{\text {deco }}\right)_{t=(N+1) T_{c}}=h_{c h}(0) \exp \left(j N \Delta \phi_{\text {deco }}\right) \sum_{i=1}^{N} \exp \left\{j(i-1)\left(\Delta \phi_{c o}-\Delta \phi_{\text {deco }}\right)\right\}
$$

De esta ecuación se deduce, que en el caso de no existir desintonía entre las longitudes de onda, es decir, que $\Delta \phi_{c o}-\Delta \phi_{\text {deco }}=0$, la autocorrelación alcanzará su valor máximo $N$. Para que no exista desintonía las longitudes de onda del codificador y del decodificador deben ser iguales, aunque puedan no ser iguales a longitud de onda central de la señal óptica utilizada. Para cualquier otro caso $\Delta \phi_{c o}-\Delta \phi_{\text {deco }} \neq 0$ representa una diferencia real de la longitud de onda de operación entre los dispositivos.

Con el objetivo de evaluar el efecto de esta desintonía, hemos definido la eficiencia de autocorrelación en términos de potencia, así:

$$
\begin{aligned}
\eta= & \left|\frac{\sum_{i=1}^{N} \exp \left\{j(i-1)\left(\Delta \phi_{c o}-\Delta \phi_{\text {deco }}\right)\right\}}{N}\right|^{2} \\
& \left(\frac{\sin \left(\frac{N \Delta \phi_{\text {co } / \text { deco }}}{2}\right)}{\left(\frac{N \Delta \phi_{\text {co/deco }}}{2}\right)}\right)^{2}
\end{aligned}
$$

donde la diferencia incremental de fase entre el codificador y el decodificador es referida como:

$$
\begin{aligned}
\Delta \phi_{c o / d e c o} & =\Delta \phi_{c o}-\Delta \phi_{\text {deco }} \\
& \approx 2 \pi q\left(\frac{\lambda_{B_{c o}}-\lambda_{B_{\text {deco }}}}{\lambda}\right)
\end{aligned}
$$




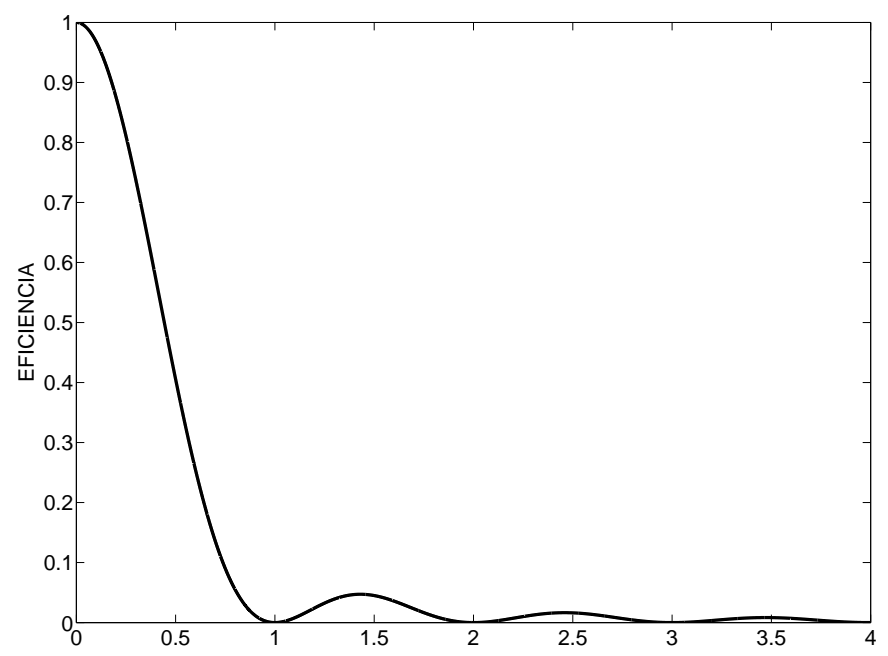

Figura 3.22: Curva de eficiencia vs. $N \Delta \phi_{c o / d e c o}$.

La eficiencia dada en 3.31 aumenta notablemente a medida que el argumento $\left(N \Delta \phi_{c o / d e c o}\right)$ tiende a cero, y es cero cuando $N \Delta \phi_{c o / d e c o}=2 \pi$ (figura 3.22$)$.

Conociendo que la penalización de potencia se puede hallar mediante $\delta=-10 \log _{10}(\eta)$ y usando como criterio que la máxima penalización permisible es de $1 \mathrm{~dB}$, se encuentra que la eficiencia debe ser como mínimo de $\eta=0,8$. Este caso se alcanza cuando el producto $N \Delta \phi_{c o / \text { deco }}=1,62$. Aplicando este criterio de penalización límite se obtiene que la condición de máxima desintonía permitida es:

$$
\left(\frac{\Delta \lambda_{B}}{\lambda}\right) \leq 1,62 \frac{\lambda_{B}}{4 \pi n_{e f f}} \frac{1}{N l_{c h}}
$$

Obsérvese que la máxima desintonía permitida es inversamente proporcional al producto entre el número de chips y la longitud del chip. Por lo tanto si se desea implementar un código más largo es necesario optimizar el proceso de fabricación de las SSFBGs para lograr un tamaño de chip lo más pequeño posible.

\subsubsection{Modelo Experimental}

De acuerdo a los resultados teóricos podemos concluir, que se requiere de un exigente control de temperatura de los dispositivos codificadores y decodificadores en un sistema OCDMA que utilice SSFBGs. Para verificar experimentalmente la máxima desintonía permitida entre los dispositivos codificador y decodificador se fabricaron un par de SSFBGs basadas en la misma palabra código de una familia de Gold de 63 chips con codificación en fase binaria como en [1] y centradas a $1538 \mathrm{~nm}$. Los dos pares difieren solamente en la separación entre los chips, la cual es de $1 \mathrm{~mm}$ para uno y 0,6 

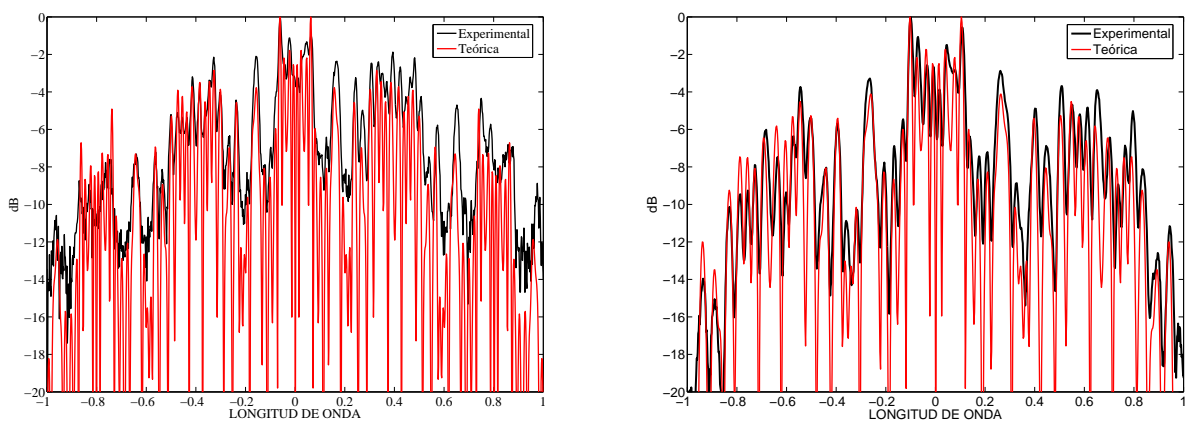

Figura 3.23: Espectros de las SSFBGs. 1mm (izq), 0,6 mm (der)

mm para el otro, lo que corresponde a 104 Gchips/s y 174 Gchips/s respectivamente. Cada una las SSFBGs fue colocada en una CCT, asegurando una estabilidad térmica con una precisión de $0.1^{\circ} \mathrm{C}$ y por lo tanto una estabilidad en longitud de onda entre los dispositivos de $\pm 1 \mathrm{pm}$.

El montaje utilizado para la verificación experimental es el mismo que el usado en el apartado 3.5 y mostrado en la figura 3.12. Los pulsos codificados se extendían a lo largo de 604 ps ( $1 \mathrm{~mm}$ chip) y $361 \mathrm{ps}$ (0,6 mm chip). En la figura 3.23 se muestran los espectros ópticos para los dispositivos con longitud de chip igual a $1 \mathrm{~mm}$ y $0,6 \mathrm{~mm}$. El dispositivo receptor es el CSA de $30 \mathrm{GHz}$ de ancho de banda.

A partir de este setup y usando las ecuaciones explicadas en el apartado anterior podríamos encontrar que teóricamente la máxima desintonía permitida, para una penalización de $1 \mathrm{~dB}$, para las parejas de SSFBGs de $1 \mathrm{~mm}$ y de $0.6 \mathrm{~mm}$ era de $3.4 \mathrm{pm}$ y $5.6 \mathrm{pm}$ respectivamente. Lo cual traducido en términos de temperatura, significa que no pueden existir variaciones superiores a los $0.31^{\circ} \mathrm{C}$ para el caso de la SSFBG con longitud de chip de $1 \mathrm{~mm}$ ó de $0.51^{\circ} \mathrm{C}$ para la de $0.6 \mathrm{~mm}$.

Para realizar la verificación experimental de los datos anteriores, se calibraron inicialmente las dos CCT para tener una temperatura de $25^{\mathrm{o}} \mathrm{C}$, independizándolas así de la posible influencia de las condiciones ambientales de laboratorio, el cual esta acondicionado a $20^{\circ} \mathrm{C}$. Partiendo de una temperatura igual, podíamos encontrar la diferencia exacta que existe entre SSFBGs de un mismo par. Después de determinar la diferencia entre las SSFBGs y conociendo que por grado centígrado se producía un desplazamiento en longitud de onda de $11 \mathrm{pm}$, procedimos a igualar los espectros. El pico máximo de autocorrelación de la señal decodificada, se obtiene cuando se ha conseguido la sintonía en longitud de onda. En la medida que dicha sintonía se pierde el pico de autocorrelación se desvanece, bastando pocos picómetros para su completa eliminación. Por esta razón partiendo de las condiciones de máxima amplitud de pico de autocorrelación empezamos primero a aumentar la temperatura muy lentamente, hasta conseguir que el pico desapareciera. Posteriormente se realizó la misma tarea pero esta vez bajando la temperatura. Mediante este procedimiento se consiguieron las curvas de la figura 3.24, que comparadas con las teóricas muestran una buena concordancia tanto para el caso del par SSFBG de 0,6 mm como para el par de 


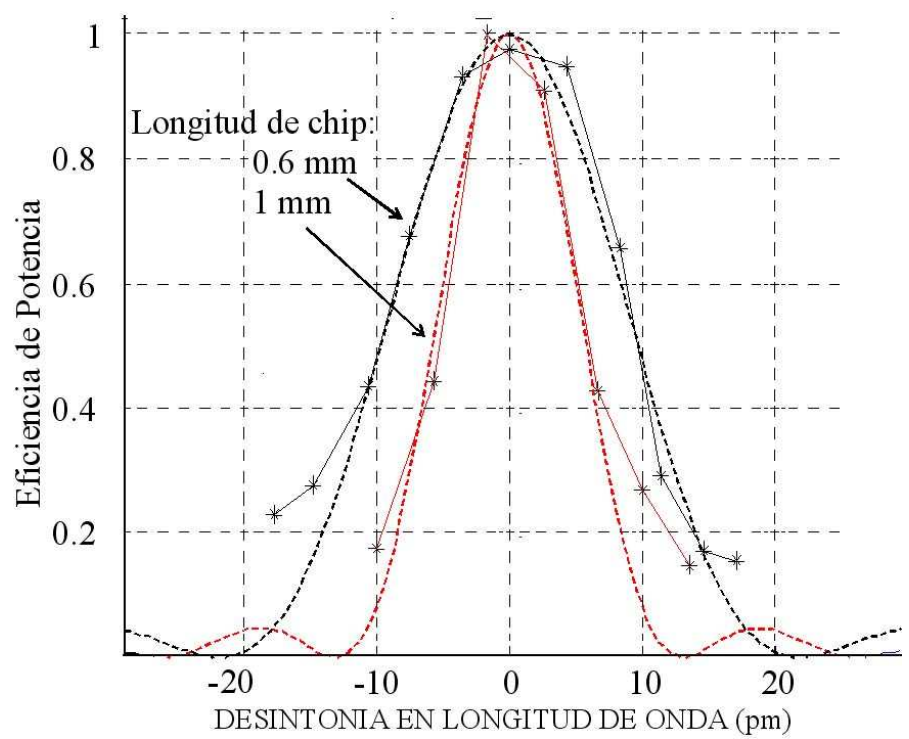

Figura 3.24: Curvas de eficiencia vs. Desintonía en longitud de onda. SSFBGs de $1 \mathrm{~mm}$ (rojo), de $0.6 \mathrm{~mm}$ (negro)

SSFBG de $1 \mathrm{~mm}$.

El eje horizontal representa la desintonía en longitud de onda causada por la variación en temperatura entre las cajas que contienen al codificador y al decodificador. Para el caso en que la separación entre chips es de $1 \mathrm{~mm}$ de longitud $\left(N l_{c h}=63 \mathrm{~mm}\right)$, la eficiencia se reduce al $50 \%$ para $\pm 6 \mathrm{pm}\left( \pm 0,54{ }^{\mathrm{o}} \mathrm{C}\right.$ para fibra al aire sin aislamiento térmico). Para el caso de $0.6 \mathrm{~mm}\left(N l_{c h}=37,8 \mathrm{~mm}\right)$ la eficiencia se reduce al $50 \%$ a $\pm 10 \mathrm{pm}\left( \pm 0,9{ }^{\circ} \mathrm{C}\right)$.

\subsection{Propuesta de Técnica de Desintonía para la Reutilización de Códigos .}

Los resultados obtenidos a partir de las variaciones en temperatura realizados sobre la SSFBG, nos han mostrado que los dispositivos codificadores y decodificadores son altamente sensible a los cambios en temperatura, lo cual supone un punto negativo del sistema. Sin embargo como hemos observado, después de que se consigue la sintonía entre dispositivos y mediante el correcto uso de las CCT los codificadores y decodificadores logran una estabilidad adecuada.

Esto nos ha llevado a pensar que es posible dar un uso adicional al desvanecimiento del pico de autocorrelación ocasionado por la desintonía en longitud de onda causada por temperatura. Lo que proponemos es emplearlo como un grado adicional de multiplexación, modificando la posición relativa de la longitud de onda entre los codificadores y decodificadores.

Para verificar esta posibilidad se ha realizado el montaje de la figura 3.25 , en donde 


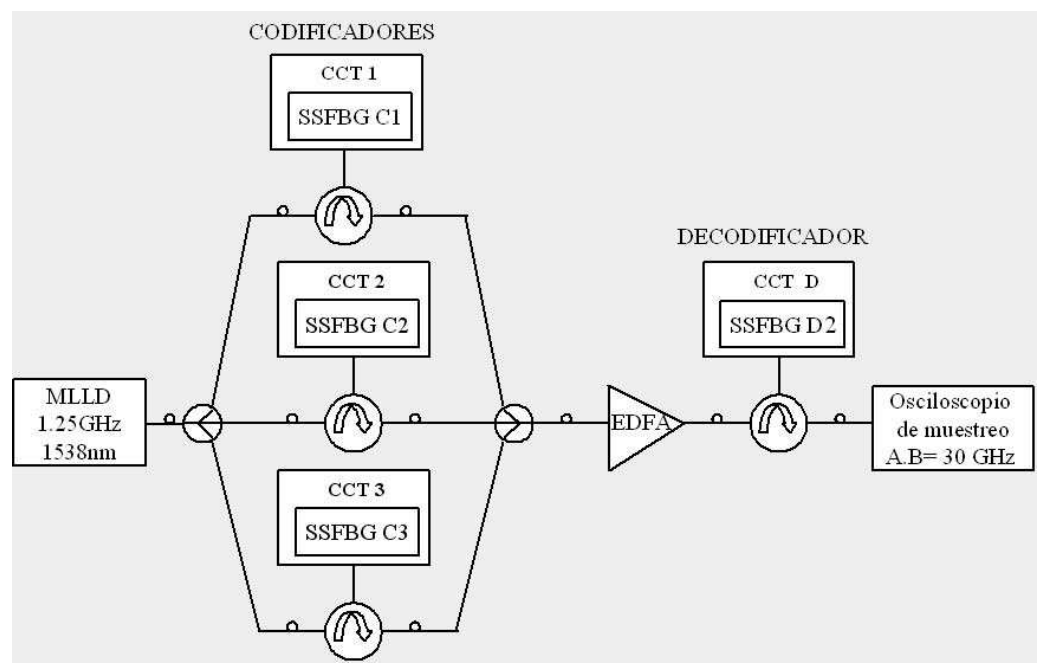

Figura 3.25: Multiplexación por variación en temperatura.

se han combinado tres codificadores idénticos con la misma palabra código basada en la secuencia Gold de 63 chips (a 174 Gchips/s) a tres temperaturas diferentes empleando las CCTs. Los codificadores están espaciados 50 pm en longitud de onda. El decodificador también esta colocado dentro de una CCT y gracias a ello se puede desplazar su longitud de onda para hacerla coincidir con cada uno de los codificadores.

El decodificador parte de una posición inicial a $50 \mathrm{pm}$ del primer codificador. Los incrementos de temperatura se hicieron en pasos de 1 grado con intervalos de espera de 2 minutos por grado hasta obtener la primera sintonía. Posteriormente los intervalos de espera aumentaron a 5 minutos para evitar los fenómenos de histéresis propios del control de temperatura. La figura 4 muestra los picos de autocorrelación obtenidos cuando el decodificador es sintonizado a la longitud de onda de cada codificador, y también la señal sin pico obtenido cuando las otras dos longitudes de onda no están sintonizadas.

De la figura 3.26 se puede concluir que es posible hacer un reuso de los códigos si se realiza una multiplexación por medio de la temperatura. Se puede observar que existe una perfecta diferenciación de las señales enviadas con los diferentes codificadores. Para comprobar que esto se cumple para los tres casos se realizó el mismo procedimiento, recuperando la señal enviada por cada uno de los codificadores.

La figura 3.27 muestra la máxima potencia pico a pico decodificada a lo largo de un período completo de 800 ps (peor caso) para los tres codificadores (Transmisores) conectados consecutivamente. La interferencia mutua esta limitada entre 20 y $25 \%$ a lo largo del eje de desintonía de longitud de onda. Es importante resaltar que esta interferencia es la misma que la que se consigue decodificando en el receptor con un dispositivo perfectamente sintonizado, pero basado en otra palabra código ortogonal de la misma secuencia Gold de 63 chips (véase la palabra código 2 de [1]).

Demostramos así, que la desintonía en longitud de onda permite obtener niveles equivalentes de MUI a los que se obtienen cuando se realiza un procedimiento 


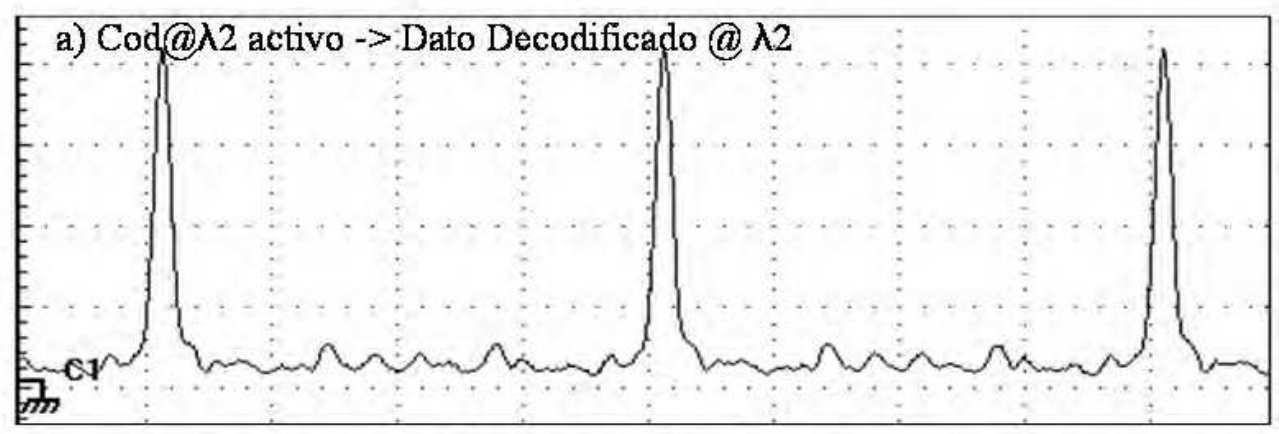

b)Cod@ $\lambda 1$ activo $\rightarrow$ Interferencia después de deco@ $@ 2$

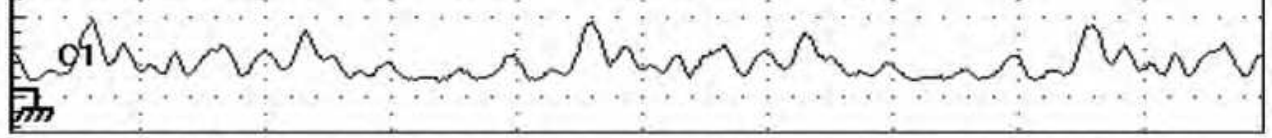

c)Cod@ $\lambda 3$ activo $\rightarrow$ Interferencia después de deco@ $@ 2$

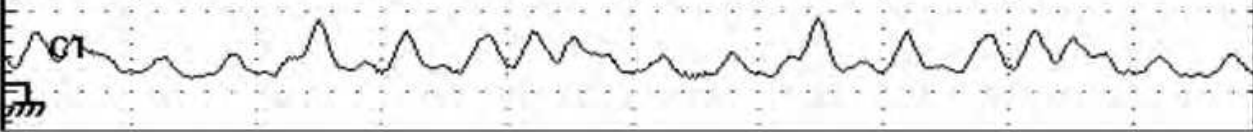

Figura 3.26: Señal decodificada por el receptor con el decodificador sintonizado a $\lambda_{2}$ desde los tres diferentes transmisores. a) Transmisor @ $\lambda_{2}$ activo. b) Transmisor @ $\lambda_{1}$ activo. c) Transmisor @ $\lambda_{3}$ activo. 


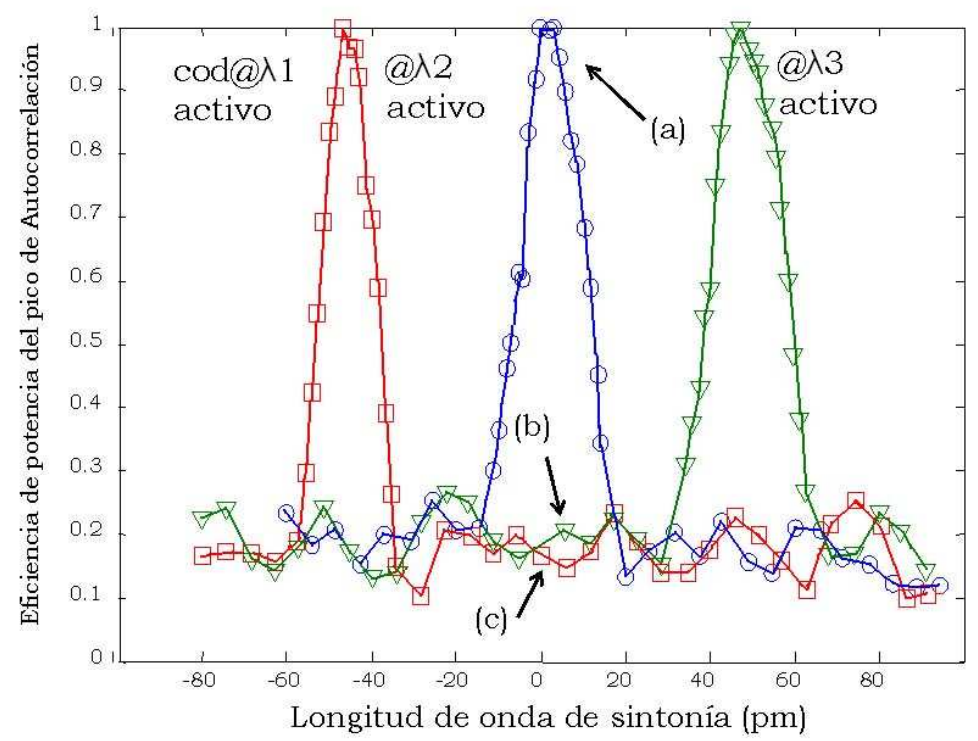

Figura 3.27: Potencia pico-pico máxima normalizada detectada después de decodificar barriendo en longitud de onda. Transmisores a $\lambda_{1}, \lambda_{2} y \lambda_{3}$ (espaciado de $\sim 50 \mathrm{pm}$ ) fueron activados consecutivamente. (a), (b) y (c) corresponden a las ventanas de la figura 3.26 .

estándar de codificación y decodificación. Es importante remarcar que la desintonía requerida para completar un total desvanecimiento no supera los 10 a 20 pm (para los dispositivos reportados en el experimento) esto es una pequeña fracción del espectro total ocupado que es cercano a los $2 \mathrm{~nm}$ como se puede ver en la figura 3.23. De esta manera la desintonía se puede emplear para expandir el número de palabras código disponibles o para seleccionar activamente distintos pares codificador/decodificador sin requerir ancho de banda óptico adicional. 



\section{Capítulo 4}

\section{DISPOSITIVOS SSFBG DE ALTA REFLECTIVIDAD PARA SISTEMAS OCDMA.}

\subsection{Introducción}

Las redes de difracción de Bragg superestructuradas son uno de los dispositivos más versátiles para ser utilizados como codificadores en los sistemas DS-OCDMA. En los sistemas que usan redes de difracción, un pulso estrecho es aplicado a una SSFBG obteniendo como señal reflejada una serie de pulsos coherentes cuya fase estará determinada por el patrón grabado sobre la SSFBG. Si la longitud de cada chip $l_{c}$ es la misma y la amplitud de modulación del índice de refracción a lo largo de la SSFBG es de valor bajo, la luz penetrara la totalidad de la longitud de la SSFBG y cada segmento individual del grating contribuirá más o menos igual a la señal reflejada. En este caso las SSFBGs actúan como un filtro transversal para codificar en fase óptica la respuesta impulsiva y de la misma manera decodificarla. Como ya hemos dicho las SSFBGs pueden ser fabricadas mediante la técnica de máscara de fase o mediante técnicas holográficas [7], consiguiendo una gran flexibilidad para fabricar códigos ultra largos. Las SSFBGs han sido probadas por diferentes autores demostrando sistemas que usan códigos de 551 [32, 7], 255 [17], 127 [74] y 63 chips [1].

Para que las SSFBGs funcionen correctamente la respuesta impulsiva debe corresponder con un patrón de pulsos codificados en fase lo más uniforme posible y por supuesto manteniendo fiel la información de fase óptica relativa entre ellos. Esta característica debe mantenerse tanto en los procesos de codificación como decodificación. Una forma de garantizar esto es construyendo las SSFBGs con constantes de acoplo relativamente bajas, que dan lugar también, a una reflectividad de valor bajo por cada uno de los chips. Normalmente en estos casos se obtienen picos de reflectividad total del codificador/decodificador inferiores al $20 \%$ [17]. La baja reflectividad ocasiona altas pérdidas de inserción, tanto en el momento de codificar como durante el proceso de decodificación. En una red PON (Pasive Optical Network) donde los niveles de 


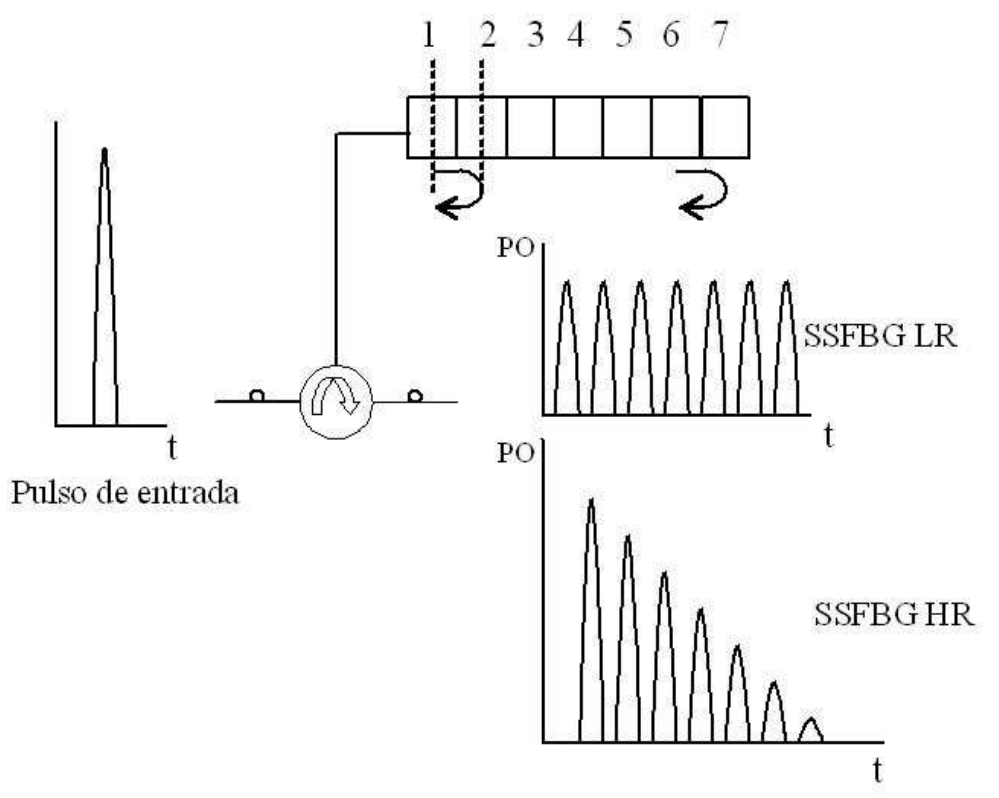

Figura 4.1: Degradación de potencia en SSFBGs de alta reflectividad

potencia son muy ajustados, el factor de las pérdidas de inserción es crítico [75].

Para reducir las pérdidas, se podría pensar en principio, en elevar el valor de la reflectividad, pero esto implica dos problemas, el primero es la excesiva degradación de potencia del pulso a medida que se propaga a través de la SSFBG y el segundo, las múltiples reflexiones dentro del mismo. Estos problemas ocasionan una deformación de la respuesta impulsiva y por tanto un fuerte deterioro de la capacidad para realizar los procesos de codificación y decodificación. En las figuras 4.1 y 4.2 se ilustran estos dos problemas. En el caso de la respuesta impulsiva de una SSFBG de alta reflectividad la mayor parte de la potencia del pulso de entrada se refleja al principio de la SSFBG, disminuyendo la potencia a medida que avanza y por lo tanto presentando una respuesta impulsiva que se decrementa a medida que atraviesa la SSFBG.

Por otra parte, cuando la reflectividad local de cada chip aumenta, el pulso de entrada puede sufrir múltiples reflexiones esta vez ya no de valor despreciable. Las múltiples reflexiones pueden recaer nuevamente sobre las contribuciones directas de los chips, aumentando o disminuyendo su amplitud y modificando también su fase óptica total y por lo tanto introduciendo errores en la señal codificada

Durante el desarrollo del presente capítulo mostraremos los posibles regímenes en los que puede trabajar una SSFBG con sus respectivas simulaciones que permitirán observar el comportamiento de la señal en cada caso. Posteriormente se revisará brevemente la solución propuesta por otros autores a los inconvenientes del uso de SSFBGs de alta reflectividad, y finalmente se presenta una propuesta desarrollada en esta tesis, que aborda el problema de las altas pérdidas de inserción y la distorsión de la señal codificada en SSFBG HR mediante técnicas de síntesis de FBG. 


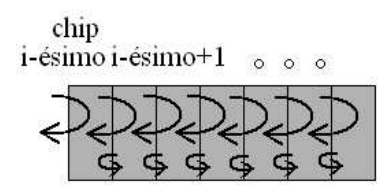

SSFBG LR

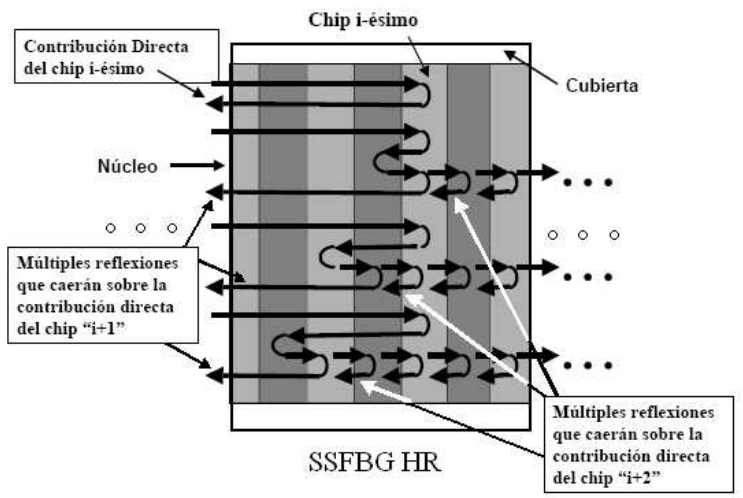

Figura 4.2: Efecto de múltiples reflexiones en SSFBGs de alta reflectividad

\subsection{Simulaciones de las SSFBGs en Diferentes Regímenes de Trabajo.}

El compromiso entre las pérdidas de inserción y la capacidad de realizar correctamente los procesos de decodificación, ha sido ya estudiado en [75, 76]. De acuerdo a estos estudios se ha podido concluir lo siguiente:

- Existen 3 regímenes de trabajo: 1) Régimen I: SSFBG con baja reflectividad $\left(\Delta n_{e f f} \leq 10^{-5}\right)($ SSFBG LR), 2) Régimen II: SSFBG de media reflectividad $\left(\Delta n_{e f f}=10^{-5} \sim 7 \times 10^{-5}\right)$ (SSFBG MR), y 3) Régimen III: SSFBG de alta reflectividad $\left(\Delta n_{\text {eff }} \geq 7 \times 10^{-5}\right)(\mathrm{SSFBG} \mathrm{HR})$.

- En el Régimen I se tiene el mejor rendimiento pero una baja eficiencia de potencia. En este régimen el pico de autocorrelación $(P)$ es relativamente bajo, no obstante el contraste entre $P$ y los wings $(W)$, así como entre $P$ y pico de correlación cruzada $(C)$, es muy bueno. Por ello la mejor aplicación de SSFBGs con baja reflectividad, es en sistemas OCDMA de múltiples usuarios.

- En el Régimen II las relaciones entre $P, W$, y $C$ alcanzan el valor medio de los otros regímenes. Sin embargo en este régimen no se consigue un valor óptimo para ninguna aplicación, ni para sistemas multiusuarios ni tampoco para el reconocimiento de etiquetas.

- En el Régimen III las relaciones $\frac{W}{P}$ y $\frac{C}{P}$ son bajas, no obstante el $P$ es relativamente alto. El uso de las SSFBGs en este caso podría servir como reconocimiento de etiquetas en redes de conmutación de paquetes o de ráfagas. En este tipo de aplicaciones no se tiene el problema de interferencia, pero se requiere una correcta detección del código enviado.

Para observar el efecto, que tiene sobre el espectro y la respuesta impulsiva, el incrementar el valor del índice de refracción en las SSFBGs, hemos simulado tres de ellas, 
cada una en un régimen. Se ha empleado un código de 63 chips y los parámetros de la simulación fueron los siguientes:

Tamaño de chip $=0.6 \mathrm{~mm}$

$T_{c}=5,74 \mathrm{ps}$

Período de Bragg $=5,3034 \times 10^{-7}$

$n_{\text {eff }}=1.45$

$\triangle n_{S S F B G-L R}=1 \times 10^{-5}$

$\triangle n_{S S F B G-M R}=4 \times 10^{-5}$

$\triangle n_{S S F B G-H R}=10 \times 10^{-5}$

En la figura 4.3 se muestra la reflectividad frente a la longitud de onda (espectro en reflexión) y la respuesta impulsiva correspondiente en unidades de potencia óptica. Podemos ver que a medida que el índice de refracción aumenta, la reflectividad de la SSFBG también lo hace. Por lo tanto las pérdidas por inserción se reducen, siendo 8 $\mathrm{dB}$ para las SSFBG LR, $2.5 \mathrm{~dB}$ para las SSFBG MR y apenas $0.4 \mathrm{~dB}$ para las SSFBG HR.

No obstante aunque las pérdidas por inserción se reducen, la respuesta impulsiva se degrada de igual manera. En una SSFBG LR la respuesta impulsiva tiende a ser constante en valor medio, siendo los picos que surgen el resultado del truncamiento espectral en el cálculo numérico del dispositivo. Por el contrario cuando vemos la respuesta impulsiva de la SSFBG HR, podemos observar los dos problemas descritos: la reducción de potencia y las múltiples reflexiones que distorsionan el nivel promedio. La duración de la respuesta impulsiva es la misma en su parte fundamental, y se extienda a $N \times T_{c}$, aunque por encima de este rango temporal, para el caso HR, se pueden observar picos de potencia debidos a las múltiples reflexiones. Estos picos de potencia indeseada, pueden llegar a interferir sobre la misma señal en forma de ISI o como MAI en el resto de usuarios.

\subsection{SSFBG con Apodización del Índice de Refracción}

El ámbito de aplicación más cercano para los sistemas OCDMA es el de las redes PON, en donde como ya hemos dicho, las limitaciones en potencia son significativas. Por tal motivo, algunos autores han propuesto soluciones para disminuir el problema de las pérdidas de inserción ocasionadas por las SSFBGs LR.

Una de las soluciones propuestas, es la de diseñar redes con el índice de refracción apodizado. Esta propuesta ha sido planteada en [76], en donde se proponen dos funciones de apodización, una primera con un incremento constante del índice de refracción y otra con una función de apodización que ha sido hallada mediante experimentación, básicamente a prueba y error [75]. Para realizar la apodización del índice de refracción, primero se busca un valor inicial que garantice un valor mínimo deseado de la señal reflejada. Así se consigue disminuir las pérdidas de inserción, y a partir de ese primer valor se empieza a aumentar el índice de refracción procurando con cada incremento compensar las pérdidas de potencia que se tienen con respecto al primer pulso reflejado. De esta manera se consigue evitar las pérdidas de potencia 

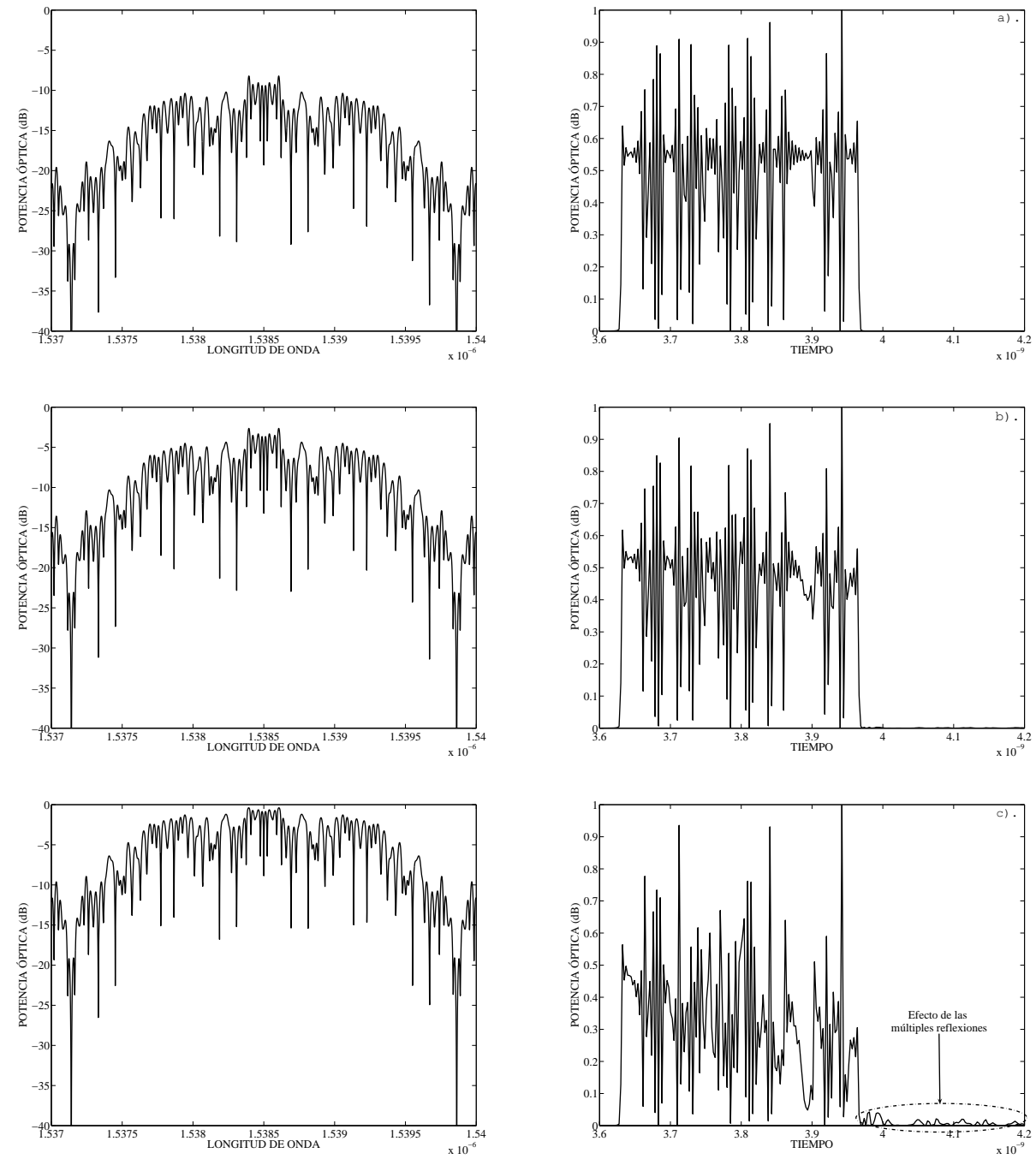

Figura 4.3: Espectros de SSFBG para tres valores diferentes de reflectividad y sus respectivas respuestas impulsivas normalizadas. a). SSFBG-LR, b) SSFBG-MR, c) SSFBG-HR 


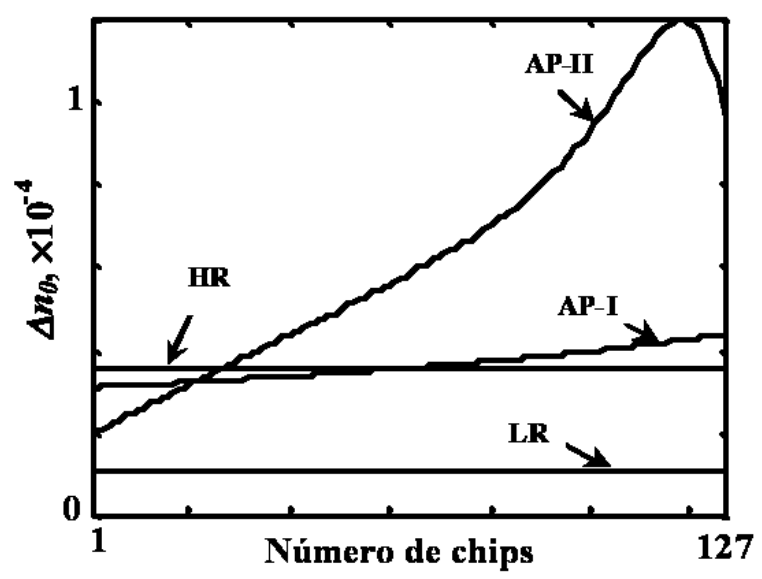

Figura 4.4: Diferentes perfiles del Índice de Refracción usados en [76].

que se sufre al recorrer la SSFBG, como consecuencia de la alta reflectividad de la misma.

Para demostrar su planteamiento ellos construyeron 4 SSFBGs con cada uno de los perfiles mostrados en la figura 4.4. Los resultados obtenidos cuando se usaron las redes SSFBG con LR y HR fueron los esperados; los más óptimos con la SSFBG LR y una mala recuperación de la señal deseada cuando se usa la SSFBG de alta reflectividad. Por otra parte con la función de apodización AP-I los resultados obtenidos no fueron los más alentadores, llegando apenas a una leve mejoría con respecto a cuando se usa la SSFBG LR. Finalmente cuando emplean la segunda función de apodización se consigue mejorar notablemente la magnitud del pico de autocorrelación y la relación $\frac{P}{W}$, no obstante la relación $\frac{P}{C}$ se mantiene igual que cuando se usa una red uniforme.

Los resultados de dichos experimentos se resumen en la gráfica 4.5 , en donde se corrobora lo anteriormente comentado. Las flechas muestran la optimización conseguida con cada una de las funciones de apodización, para cada una de las relaciones allí descritas.

Como podemos observar, las mejoras obtenidas pueden ser calificadas de positivas, sin embargo existen un par de inconvenientes con este método: el primer problema que presenta la apodización del índice de refracción es que aunque reduce el decremento de potencia, no soluciona el problema de las múltiples reflexiones, razón por la cual la respuesta impulsiva de estas SSFBGs no es óptima. Por otra parte el hecho de que el perfil del índice se obtenga por medio de experimentación resta fiabilidad y también disminuye la versatilidad de las mismas. Esto nos ha llevado a hacer una propuesta que represente una solución integral a los problemas de pérdidas de inserción, desvanecimiento de la señal a medida que recorre la SSFBG y las múltiples reflexiones cuando se trabaja con redes de alta reflectividad 


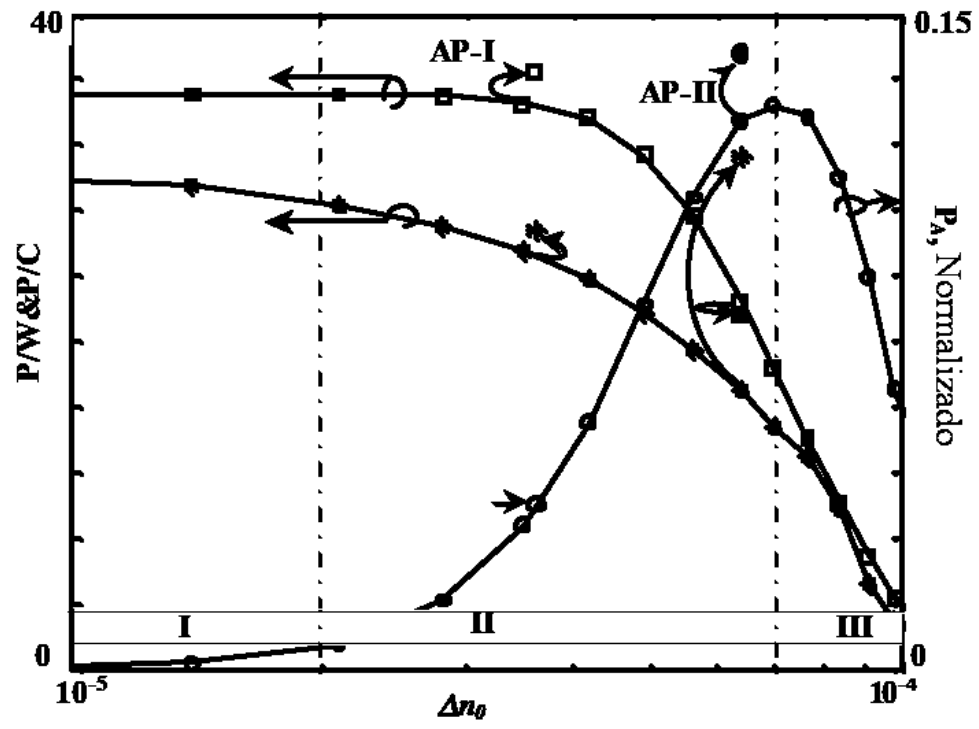

Figura 4.5: Pico de autocorrelación, $\frac{P}{W}$ y $\frac{P}{C}$ Vs, índice de refracción [76].

\subsection{Diseño de SSFBG-HR Empleando Métodos de Síntesis}

El diseño de SSFBGs mediante los métodos de análisis deja muy poco margen de maniobrabilidad, ya que los parámetros que podemos cambiar para obtener la respuesta deseada, son limitados. Por otra parte hemos visto que si queremos reducir las pérdidas de inserción producidas por las SSFBGs, es necesario aumentar el índice de refracción. Pero aumentar el índice de refracción, a su vez genera problemas de distorsión en la respuesta impulsiva que deteriora el rendimiento del sistema en general.

Las características a considerar cuando se diseñan SSFBGs que puedan ser usadas en sistemas OCDMA son: 1) Bajas pérdidas de inserción y 2) una respuesta impulsiva constante y sin picos adyacentes ocasionados por las múltiples reflexiones. Estas características permiten tener una idea clara de lo que queremos que sea la respuesta impulsiva, por lo tanto conoceremos su forma y valores ideales. Con base en ello proponemos que el diseño de los codificadores basados en SSFBG, parta de la respuesta impulsiva que conocemos y que deseamos obtener. Para conseguir este objetivo debemos sintetizar a partir de la respuesta impulsiva ideal, el perfil del coeficiente complejo de acoplo $(q(z))$, necesario para obtener dicha respuesta impulsiva.

Los métodos de síntesis para el diseño de redes de difracción de Bragg son bien conocidos y han sido descritos por diferentes autores [77, 78, 79, 80]. Nosotros en particular hemos usado el descrito en [77], por estar basado en el método de síntesis DLP (Discrete Layer Peeling), el cual tiene un óptimo tiempo de procesamiento.

El método de síntesis DLP parte de la conocida matriz de transferencia $T M$ de- 


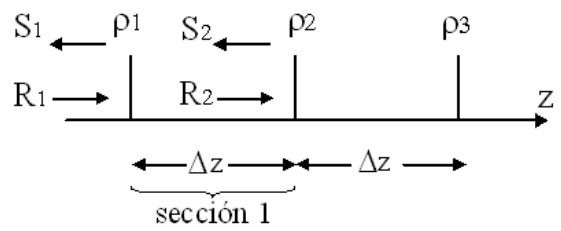

Figura 4.6: Modelo discreto de una FBG, Propagación de campos hacia adelante $\left(R_{j}\right)$ y en reflexión $\left(S_{j}\right)$ asociados con cada una de las franjas del dibujo.

scrita en la sección 3.2. Esta matriz conecta los campos en un punto $z+\Delta z$ con los campos en $z$. Para poder realizar el proceso de discretización hay que reemplazar la matriz $T M$ por el producto de dos matrices de transferencia $T M_{\Delta} T M_{\rho} . T M_{\rho}$ describe un reflector discreto y $T M_{\Delta}$ describe la propagación del campo, las cuales podemos escribir como:

$$
\begin{aligned}
T M_{\rho} & =\left(1-|\rho|^{2}\right)^{-\frac{1}{2}}\left[\begin{array}{cc}
1 & -\rho^{*} \\
-\rho & 1
\end{array}\right] \\
T M_{\Delta} & =\left[\begin{array}{cc}
\exp (i \delta \Delta z) & 0 \\
0 & \exp (-i \delta \Delta z)
\end{array}\right]
\end{aligned}
$$

donde el coeficiente complejo de reflexión esta dado por

$$
\rho=-\tanh (\kappa \Delta z) \frac{q^{*}}{\kappa}
$$

vale la pena aclarar que $\kappa=|q|$ y $\delta$ es la desintonía existente entre la constante de fase con respecto a la constante de fase de Bragg.

La matriz de transferencia $T M_{\rho}$ puede ser obtenida de $T M$ permitiendo que todo el acoplamiento tenga lugar en un punto. El modelo completo de la red de difracción es, por lo tanto, una serie de $\mathrm{N}$ reflectores complejos discretos con una distancia $\Delta z$ entre ellos (figura 4.6).

Partiendo del espectro de reflexión complejo $r_{1}(\delta)$ se desea conocer las amplitudes del coeficiente de reflexión complejo $\rho_{j}, j=1,2 \ldots, N$. Se definen los campos de propagación y contrapropagación antes de la j-ésima sección como $R_{j}(\delta)$ y $S_{j}(\delta)$.

Los campos antes de la primera sección están dados por:

$$
\left[\begin{array}{c}
R_{1}(\delta) \\
S_{1}(\delta)
\end{array}\right]=\left[\begin{array}{c}
1 \\
r_{1}(\delta)
\end{array}\right]
$$

Gracias al principio de causalidad podemos encontrar la amplitud compleja del primer reflector. Nótese que la respuesta impulsiva del reflector colocado para el tiempo $\mathrm{t}=0,\left(\rho_{1}\right)$, es independiente de los demás reflectores $\rho_{j} \forall j \geq 2$ porque la luz no tiene suficiente tiempo de propagarse hacia el segundo reflector y mucho menos hacia los siguientes. De esta manera, cuando encontramos la respuesta impulsiva para este primer reflector, obtenemos lo mismo, que si solo estuviese presente ese reflector. Por lo tanto, podemos calcular $\rho_{1}$ a partir de la transformada inversa de Fourier de 
$r_{1}(\delta)=\frac{S_{1}(\delta)}{R_{1}(\delta)}$ evaluada en $\mathrm{t}=0$. Conociendo los resultados de la primera sección y usando nuevamente el producto matricial $T M_{\Delta} T M_{\rho}$ podemos transferir los campos a las secciones siguientes. De esta manera es como esa primera sección fuese retirada de la FBG. Siguiendo este procedimiento podemos determinar toda la serie de reflectores. La función del coeficiente de acoplamiento complejo $q(z)$ puede ser determinada de la ecuación 4.3.

Usando 4.1 y 4.2 podemos hallar que la transferencia del campo usando $T M_{\Delta} T M_{\rho}$ puede ser descrita en términos de la reflectividad local como

$$
r_{2}(\delta)=\exp (-i 2 \delta \Delta z) \frac{r_{1}(\delta)-\rho_{1}}{1-\rho_{1}^{*} r_{1}(\delta)}
$$

donde $r_{j}(\delta)=\frac{S_{j}}{R_{j}}$.

Para determinar el valor de $\rho_{1}$ por medio de la transformada inversa de Fourier, nótese que el espectro $r_{1}(\sigma)$ puede ser escrito como la transformada discreta de Fourier de la respuesta impulsiva $h(t)$,

$$
r_{1}(\delta)=\sum_{\tau=0}^{\infty} h_{1}(t) \exp (i \delta \tau 2 \Delta z)
$$

porque la respuesta impulsiva es discreta en muestras de $2 \Delta z$, lo cual equivale a la longitud de propagación de ida y vuelta de una sección. Se ha definido $\tau=\frac{t}{2 \Delta z}$ como la variable de tiempo discreto con $t$ como tiempo normalizado. Así la respuesta impulsiva para $\tau=0$ es la misma que se encontraría si solo el primer reflector estuviese presente. De esta manera $\rho_{1}$ es simplemente el coeficiente 0 de la serie de Fourier descrita por 4.6, o

$$
\rho_{1}=h_{1}(0)=\frac{\Delta z}{\pi} \int_{-\frac{\pi}{2}}^{\frac{\pi}{2}} r_{1}(\delta) d \delta
$$

tenemos entonces que el modelo esta basado inherentemente en las funciones discretas que describen el grating. Para su implementación numérica, la dependencia espectral debe ser también discreta, y por tanto, el cálculo de $\rho_{1}$ por la transformada inversa de Fourier de $r_{1}(\sigma)$ puede ser obtenida por la transformada discreta de Fourier

$$
\rho_{1}=\frac{1}{M} \sum_{m=1}^{M} r_{1}(m)
$$

donde $r_{1}(m)$ representa la versión discreta del espectro $r_{1}(\delta)$ en el rango $|\delta| \leq \frac{\pi}{2 \Delta z}$, y $M \geq N$ es el número de longitudes de onda del espectro.

Resumiendo podemos decir que el método de síntesis DLP consiste en:

1. Se parte de un coeficiente de reflexión realizable $r_{1}(\delta)$.

2. Se calcula $\rho_{1}$ de 4.8 .

3. Se propagan los campos usando las matrices de transferencia 4.1, 4.2, 4.3 o su expresión equivalente 4.5 .

4. repetir desde el paso 2 hasta completar la estructura completa del grating. 


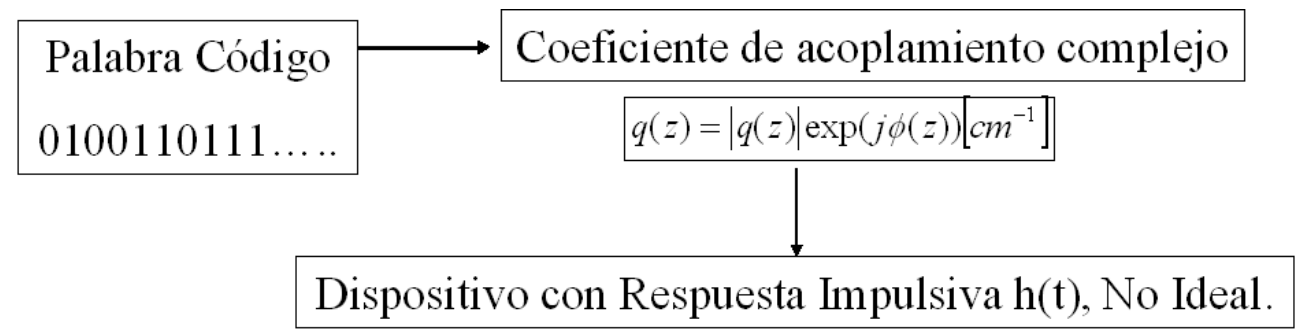

Figura 4.7: Diagrama de flujo del método estándar de diseño

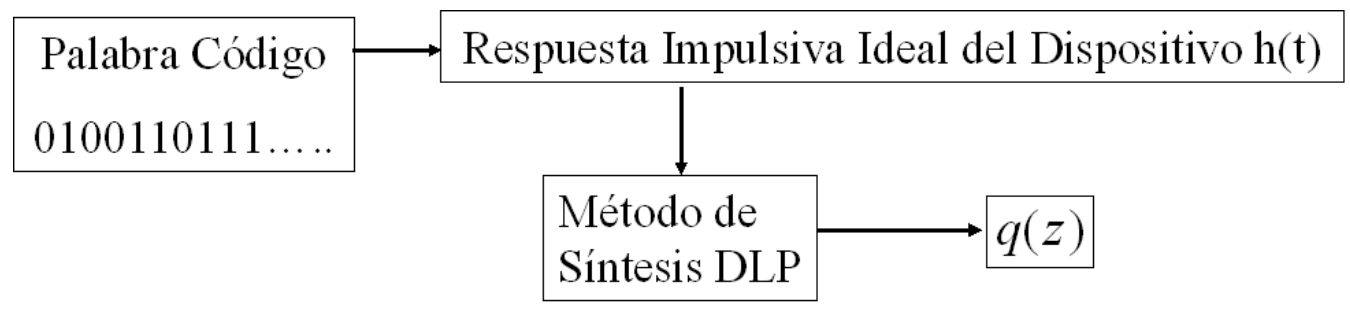

Figura 4.8: Diagrama de flujo usando para el diseño el método de síntesis.

\subsubsection{Procedimiento de Síntesis Empleado}

El método de síntesis DLP que ha sido descrito en el apartado anterior es el que utilizaremos para nuestro diseño. Es fácil ver que el proceso de diseño propuesto es inverso al proceso estándar empleado en SSFBG de reflectividad débil. En el proceso estándar, la palabra código seleccionada que contiene los chips modulados en fase binaria, es mapeada sobre el coeficiente de acoplamiento complejo descrito por:

$$
q(z)=|q(z)| \exp (j \phi(z))\left[\mathrm{cm}^{-1}\right]
$$

$q(z)$ es proporcional al perfil de la perturbación del índice de refracción $\Delta n(z)$, $|q(z)|$ es una constante y $\phi(z)$ contiene los cambios de fase dictados por la palabra código en las posiciones adecuadas de los chips. La secuencia puede ser resumida como se ve en la figura 4.7 .

La propuesta que se presenta es precisamente el proceso inverso, fijando la respuesta impulsiva $h(t)$ que se desea del dispositivo, se busca mediante un método de síntesis, el perfil de coeficiente complejo especifico que proporcione dicha $h(t)$. En este caso, la secuencia es: partiendo de la palabra código, construimos la $h(t)$ deseada con el pico de reflectividad requerido, aplicamos la transformada de Fourier y hallamos el espectro en reflexión de la SSFBG y empleando el método de síntesis obtenemos $q(z)$. El diagrama de flujo mediante este método se ve en la figura 4.8 .

\subsubsection{Diseño y Resultados de la Simulación}

Siguiendo la metodología propuesta para este diseño se partió del código de 63 chips, que recordamos a continuación: 


\subsection{DISEÑO DE SSFBG-HR EMPLEANDO MÉTODOS DE SÍNTESIS}
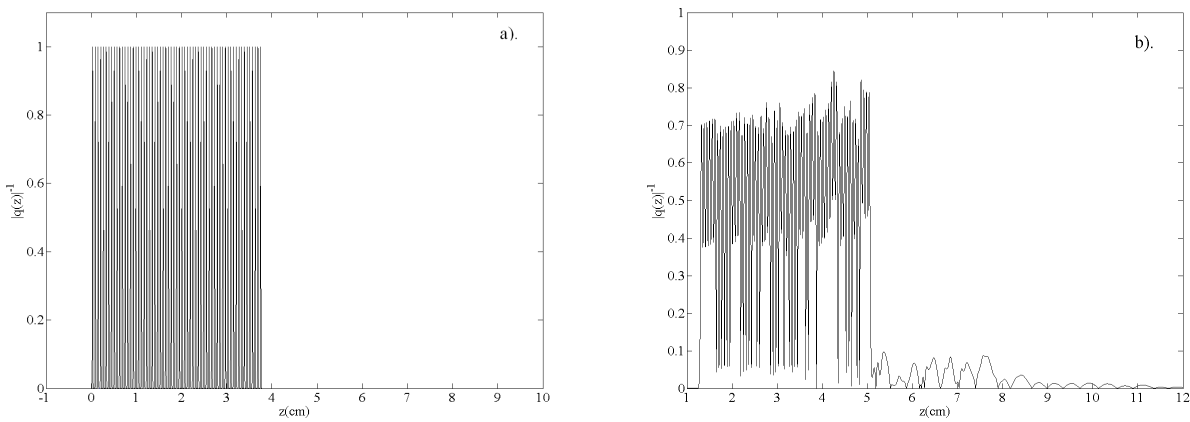

Figura 4.9: Coeficiente de Acoplamiento Complejo $(\mathrm{q}(\mathrm{z}))$. a) método estándar, y b) obtenida mediante el método de síntesis DLP.

codigo1 $=[000000101010000101011011110101100101000100011111111000101101111]$

a partir de este código se construyó la respuesta impulsiva ideal, es decir, con la forma y el valor de reflectividad deseado. Con la respuesta impulsiva y usando la transformada de Fourier hallamos el espectro en reflexión, el cual nos servirá de punto de partida para hallar mediante el método de síntesis DLP el coeficiente complejo de acoplamiento.

En la figura 4.9 podemos observar una comparativa entre el perfil del coeficiente de acoplamiento complejo que hallamos mediante el método estándar y el obtenido con el método de síntesis DLP. La función $q(z)$ obtenida con el método estándar mide exactamente $N \times l_{c}=63 x 0,6 \mathrm{~mm}=37,8 \mathrm{~mm}$ mientras que la obtenida mediante el método de síntesis DLP supera dicha longitud. La gráfica también nos muestra como el perfil sintetizado integra en cada paso (cada chip discreto) la amplitud requerida y la fase para compensar la pérdida de potencia sufrida en cada punto y las causadas por el efecto de las múltiples reflexiones en el resto de la estructura de la SSFBG. El perfil sintetizado de $q(z)$ sobrepasa el tamaño o duración del código original compensando incluso las múltiples reflexiones que recaen fuera de dicho rango.

Como se puede ver el método de síntesis permite hacer del diseño de SSFBG de alta reflectividad un proceso repetitivo, es decir, implementable para cualquier forma, tamaño o duración de chip, y por supuesto para cualquier otro código. No obstante, cabe aclarar que para su implementación es necesario encontrar el valor óptimo de la amplitud de la respuesta impulsional de tal forma que el método de síntesis converja. Si introducimos un valor menor del óptimo las pérdidas por inserción introducidas por la SSFBG fruto del $q(z)$ obtenido serán mayores, si por el contrario el valor ingresado es mayor al óptimo cabe la posibilidad de que la función no converja numéricamente dando lugar a soluciones irrealizables. Esto se debe a que si exigimos reflectividades altas, las múltiples reflexiones también serán cada vez más altas y más numerosas, no permitiendo compensar la convergencia y por lo tanto una solución estable. En nuestro caso el valor óptimo de amplitud para la respuesta impulsional fue 4 veces superior al que se conseguía con una SSFBG débil. Para conseguir estos valores de amplitud se requiere trabajar en alta reflectividad (régimen ), que llevado a valores 


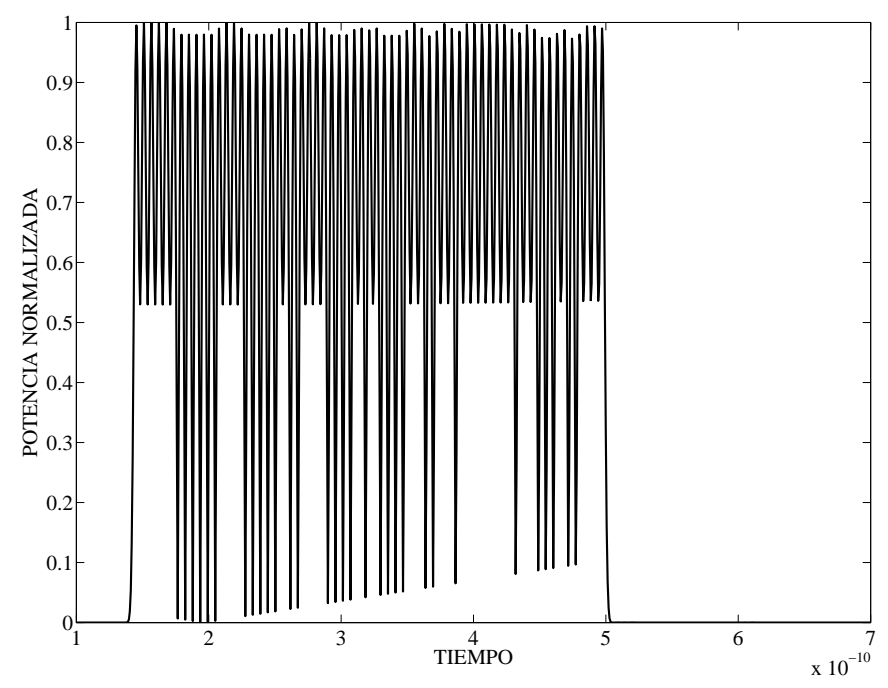

Figura 4.10: Respuesta impulsiva obtenida a partir de la función q(z) sintetizada.

de índice de refracción significa que trabajamos con un $\Delta n \approx 11 \times 10^{-5}$.

Para comprobar que efectivamente el nuevo método de diseño cumple con los objetivos propuestos, se emplea un método de análisis estándar como la solución numérica de la ecuación de acoplo de modo sobre el coeficiente $q(z)$ sintetizado y finalmente realizando la transformada inversa del coeficiente de reflexión se obtiene la respuesta impulsiva $h(t)$. La respuesta impulsiva ideal obtenida mediante la función $q(z)$ sintetizada, mostrada en la figura 4.10, no tiene problemas de pérdidas de potencia ni tampoco presenta los efectos negativos de las múltiples reflexiones, corroborando que el método utilizado es correcto.

Las SSFBGs estándar tienen la ventaja de poder ser utilizadas por cualquier extremo, respetando eso si, que la SSFBG en decodificación sea empleada por el lado complementario. En el caso de las SSFBGs sintetizadas, se pierde esta ambivalencia, dado que en el diseño mediante síntesis se obtiene una solución específica en función de la información del código y del extremo por el que se inicia el procedimiento, por lo que el dispositivo codificador tiene un perfil del coeficiente de acoplamiento complejo diferente al del decodificador, aunque pueden ser usados indistintamente como codificador o decodificador. En la figura 4.11 se ven los dos perfiles, que aunque muy similares pueden ser fácilmente diferenciados.

El perfil $q(z)$ es la información de partida que se requiere para fabricar las SSFBGs. Con esta función se determina la cantidad de iluminaciones o exposiciones del haz UV que se deben hacer a la fibra para el grabado del código. Como en este caso la función $q(z)$ no es uniforme, se requiere hacer un muestreo de la misma, que nos permita discretizar las iluminaciones necesarias para fabricar el perfil. La longitud total de la $q(z)$ sintetizada es $119,1 \mathrm{~mm}$, de tal forma que para realizar la discretización se dividió 


\subsection{DISEÑO DE SSFBG-HR EMPLEANDO MÉTODOS DE SÍNTESIS}

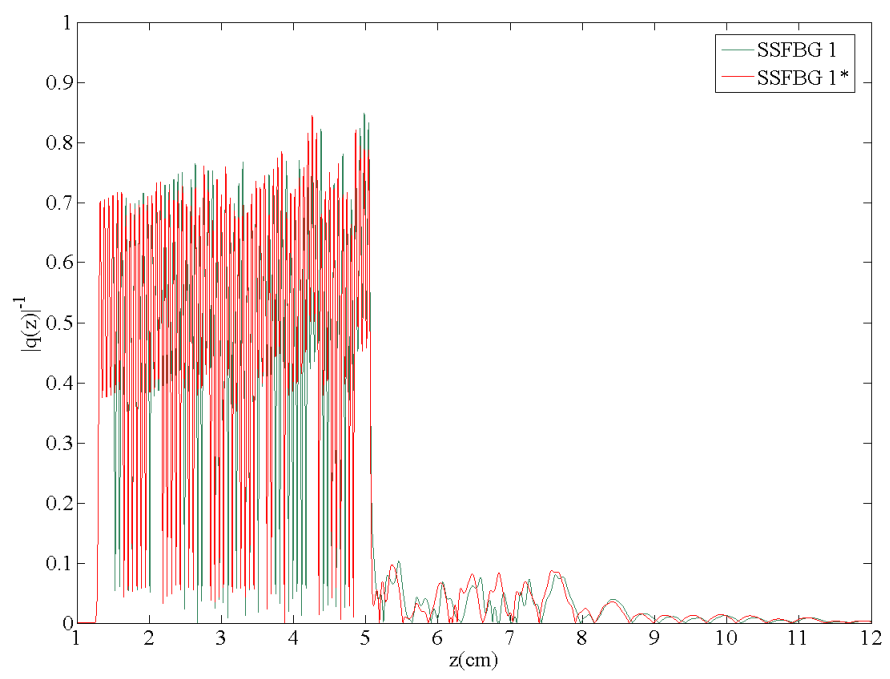

Figura 4.11: Perfiles del coeficiente de acoplamiento complejo para una pareja codificador/decodificador basados en SSFBGs sintetizadas

en dos partes, la primera consta de los primeros $37,8 \mathrm{~mm}(63 x 0,6 \mathrm{~mm})$ y la segunda de $81,3 \mathrm{~mm}$. En la figura 4.12 podemos ver como se realizó dicha división, la primera parte corresponde a la longitud estándar de la función $q(z)$ y contiene la información de los chips del código y la información para la compensación en amplitud y por múltiples reflexiones. La segunda parte es la que compensa las múltiples reflexiones que se suceden fuera del rango original de la SSFBG. Además se puede ver que el resultado del muestreo de $q(z)$ no la modifica significativamente. La razón para realizar esta división es porque la parte A de la figura 4.12 se fabricará mediante el método explicado en el apartado 3.4, es decir, con una exposición doble de rayos UV de 0,6 $\mathrm{mm}$, mientras que la segunda se realizaría con iluminaciones separadas cada $0,3 \mathrm{~mm}$. De esta manera para construir la primera parte requeriremos 63 iluminaciones y para la segunda 271, para un total de 334 que cubrirían los 119,1 $\mathrm{mm}$ de la SSFBG.

\subsubsection{Resultados Experimentales}

Las simulaciones mostraron que a medida que aumenta la reflectividad en las SSFBGs la respuesta impulsiva se deteriora, debido al decremento de la potencia que recorre la SSFBG. Para ilustrar este efecto, se fabricaron 4 redes de difracción con diferentes valores de reflectividad, $\Delta n=3 \times 10^{-5}(S S F B G-L R), \Delta n=5 \times$ $10^{-5}(S S F B G-M R 1), \Delta n=7 \times 10^{-5}(S S F B G-M R 2), \Delta n=9 \times 10^{-5}(S S F B G-$ $H R$ ). Cada SSFBG tiene grabado un código de 63 chips de una familia de códigos de Gold como en [1]. Para construir la respuesta objetivo $h(t)$ los parámetros del sistema son: $T_{c}=5,74 p s$ que corresponde con una tasa de $\sim 174 \mathrm{Gchip} / \mathrm{s}$, ancho de chip $\sim 3 p s$ para evitar el borrado entre chips y se supone una forma de chip gausiano. 


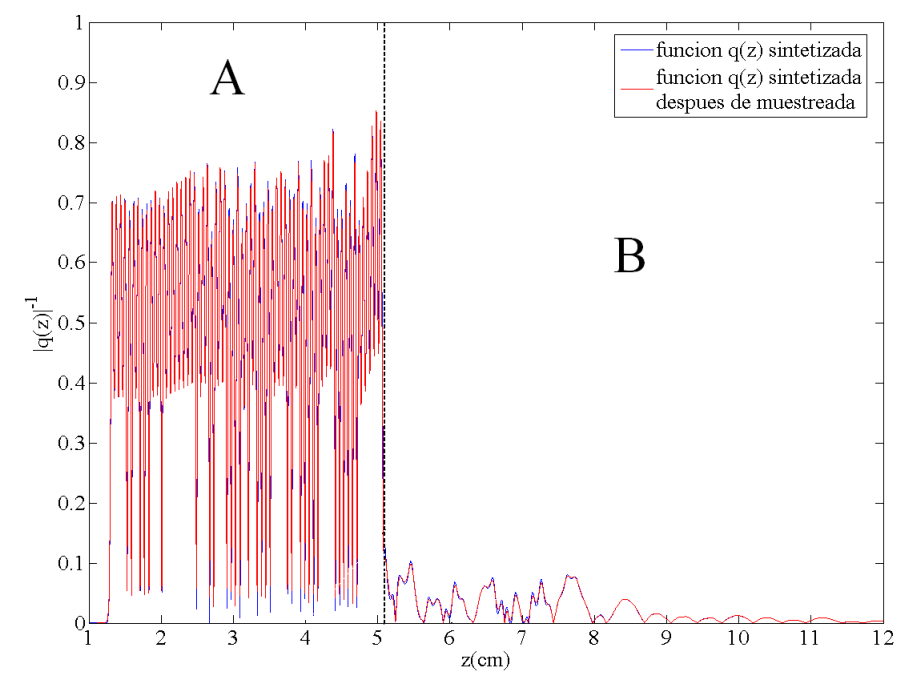

Figura 4.12: función $q(z)$ sintetizada antes y después de discretizar.

En la figura 4.13 se muestran los resultados de la respuesta impulsiva de cada dispositivo. Estas gráficas se consiguen mediante un analizador vectorial óptico (OVA - LUNA Technologies) que emplea un interferómetro para obtener la amplitud y la fase, y realizando la transformada de Fourier calcula la respuesta impulsiva de cada SSFBG. En las gráficas podemos ver como aumenta el nivel de la respuesta impulsiva, lo cual disminuye las perdidas de inserción del dispositivo, pero también vemos como se deteriora.

Posteriormente se fabrico 1 par adicional diseñado mediante el proceso de síntesis DLP descrito. La amplitud del chip en la respuesta impulsiva de la SSFBG sintetizada fue ajustada de forma que se obtenga la reflectividad de pico deseada. Todas fueron fabricadas empleando el proceso de iluminación chip a chip con un preciso control de la fase de Bragg. El haz UV gausiano fue enfocado aproximadamente a $350 \mu \mathrm{m}$ y el espaciamiento entre chips fue de $0,6 \mathrm{~mm}$ y $0,3 \mathrm{~mm}$ como se indicó en el apartado anterior. Todo el proceso se realizó con potencia UV y tiempo constante para evitar inducir chirp residual en la SSFBG, y la amplitud del chip y su fase se obtuvo únicamente por medio del control de fase de una doble exposición.

En la figura 4.14 se puede ver que el espectro correspondiente a la SSFBG HR supera en apenas $1 \mathrm{~dB}$ de potencia al espectro de la SSFBG sintetizada, y que ambos superan en más de $6 \mathrm{~dB}$ al espectro de la SSFBG LR.

La forma del espectro en los tres casos es la misma y por lo tanto la medida espectral no nos permite sacar muchas conclusiones, excepto que la SSFBG sintetizada tiene unas pérdidas de inserción similares a las de la SSFBG HR. Lo que realmente nos dará una idea del comportamiento de la SSFBG sintetizada como dispositivo codificador y decodificador será su respuesta impulsiva y para hallarla se procedió a 

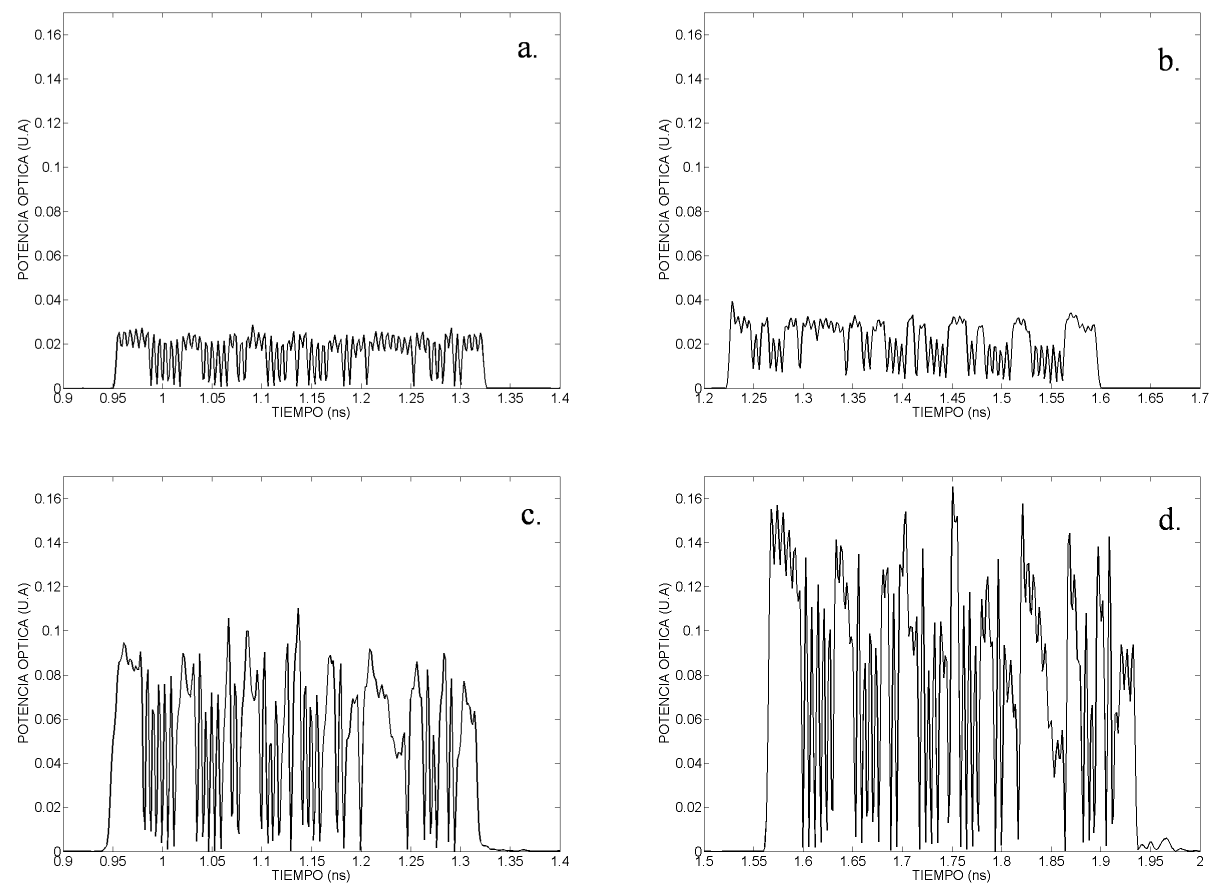

Figura 4.13: Efecto del incremento de la reflectividad sobre la respuesta impulsiva. a). $\left.\left.\Delta n=3 \times 10^{-5}(S S F B G-L R), b\right) . \Delta n=5 \times 10^{-5}(S S F B G-M R 1), c\right) . \Delta n=$ $\left.7 \times 10^{-5}(S S F B G-M R 2), d\right) . \Delta n=9 \times 10^{-5}(S S F B G-H R)$ 


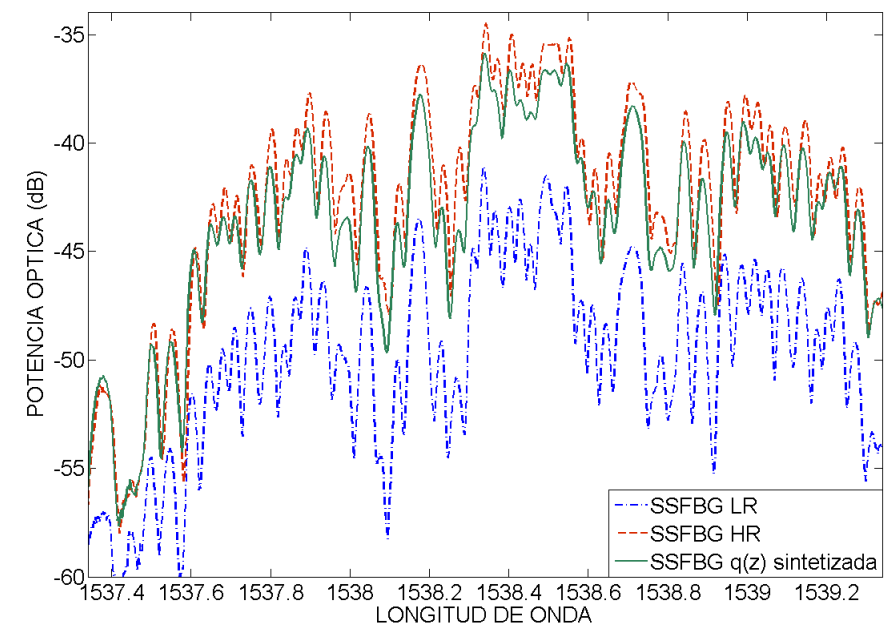

Figura 4.14: Espectros de las SSFBGs fabricadas, alta y baja reflectividad y con la función q sintetizada.

realizar el montaje indicado en la figura 4.15 .

En el bloque codificador tenemos una fuente de pulsos estrechos a una tasa de $1.25 \mathrm{GHz}$ y centrada a una longitud de onda de $1538 \mathrm{~nm}$. La longitud de onda es la misma a la cual están sintonizadas las diferentes SSFBGs y estabilizadas gracias a las CCT. En primera instancia se tomaron las mediciones de la señal codificada, con la SSFBG LR, posteriormente con la SSFBG HR y finalmente con la SSFBG sintetizada. Después de obtener las respuestas impulsivas de las fibras codificadoras se procedieron a conectarse ambos bloques para poder medir la señal decodificada.

En la figura 4.16 vemos las repuestas impulsivas correspondientes a las 3 SSFBGs obtenidas con el osciloscopio de muestreo $(\mathrm{AB}=30 \mathrm{GHz})$. La SSFBG LR presenta una señal codificada (respuesta impulsiva) plana sin pérdidas de potencia (figura 4.16a.). Este es el mejor caso para realizar los procesos de codificación y decodificación, no obstante las pérdidas de inserción son muy altas, alrededor de los $8 \mathrm{~dB}$. La figura 4.16b. muestra la respuesta para una SSFBG HR, en donde el pico de reflectividad aumenta en $6 \mathrm{~dB}$ comparado con el de la SSFBG LR, pero a cambio se observa la fuerte distorsión causada por las pérdidas de potencia y las múltiples reflexiones. En la figura 4.16c. tenemos la señal codificada con la SSFBG sintetizada, allí la respuesta es casi plana y con una reflectividad $1 \mathrm{~dB}$ por debajo de la SSFBG HR. De esta manera se disminuyen las pérdidas de inserción sin decrementar sus capacidades codificadores y decodificadoras.

Estos mismos resultados los podemos obtener con mayor claridad si empleamos nuevamente el OVA. En la figura 4.17 se muestra la respuesta impulsiva del dispositivo codificador diseñado mediante el método de síntesis DLP. Comparando la figura 4.17 con 4.13 podemos ver que el dispositivo compensado tiene una respuesta de amplitud 


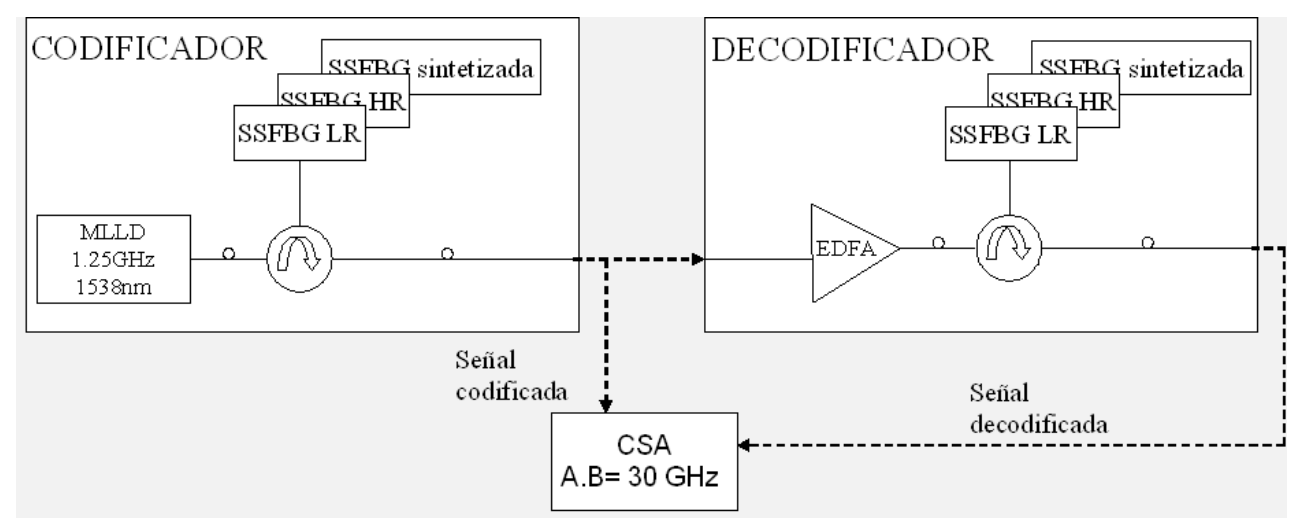

Figura 4.15: Montaje para medir la respuesta impulsiva de las SSFBGs.

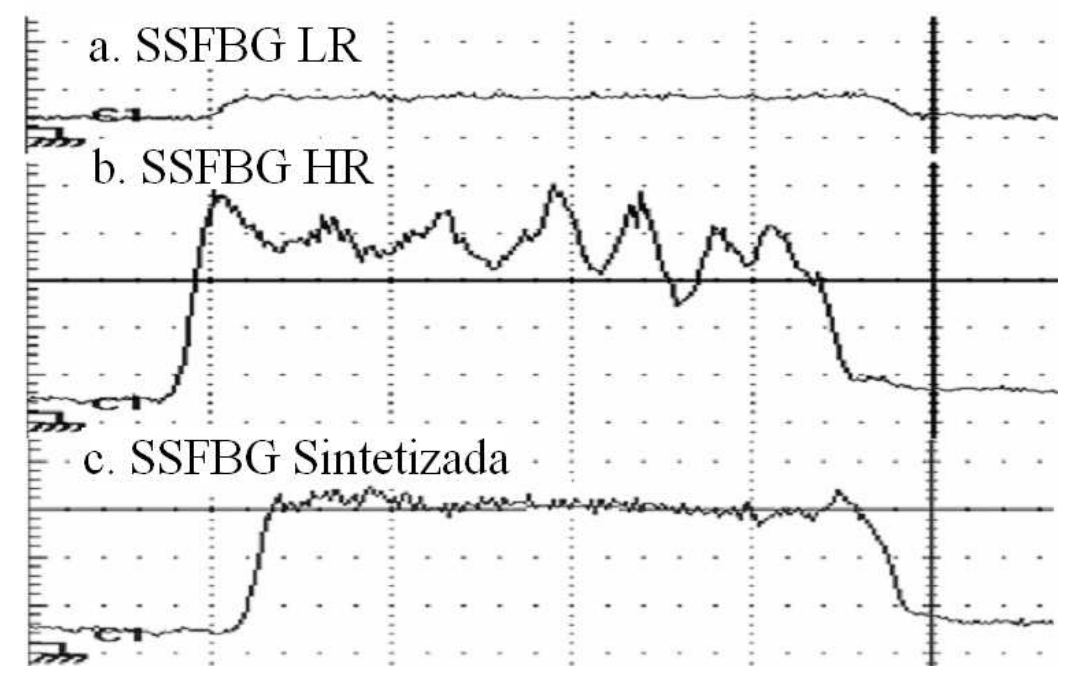

Figura 4.16: Señales codificada con cada una de las SSFBGs construidas 


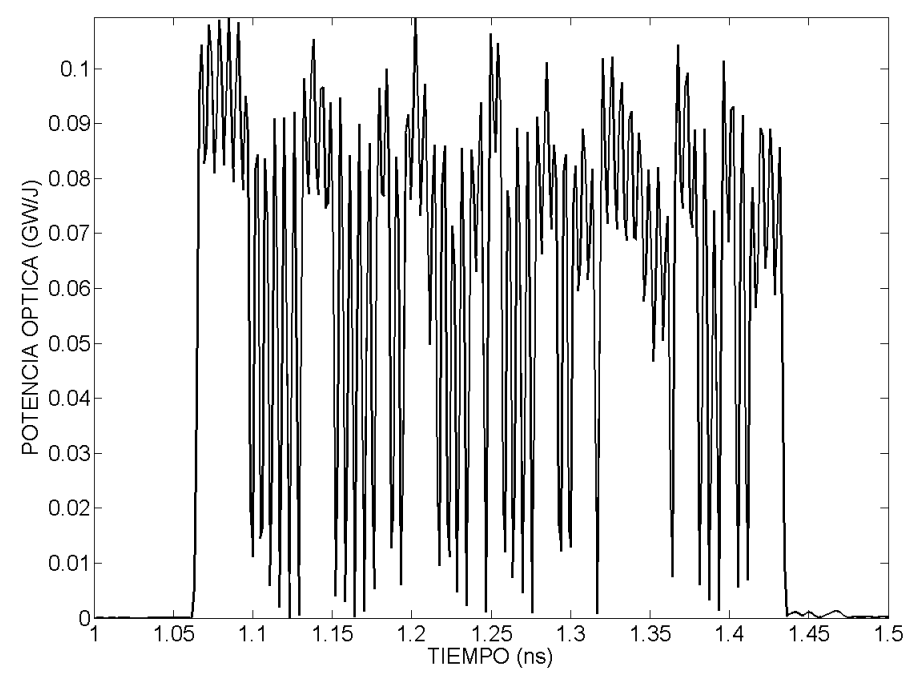

Figura 4.17: Respuesta impulsiva de la SSFBG codificadora diseñada mediante síntesis, obtenida con el OVA

superior y más plana que sus similares de alta y media reflectividad.

La respuesta impulsiva nos permite intuir que efectivamente la SSFBG sintetizada presentara mejores prestaciones que las otras redes de difracción, sin embargo para realizar un juicio más objetivo es necesario verificar el comportamiento de la respuesta decodificada. La figura 4.16 nos muestra los resultados obtenidos al decodificar la señal con el decodificador correcto (izquierda) y con un decodificador que no corresponde al mismo código (derecha). Para el caso en que el decodificador tenía la palabra código conjugada usada en el codificador, el pico de correlación fue máximo y con aproximadamente la misma amplitud para los tres casos. Se observa un ligero incremento en el valor de los wings cuando se usan las SSFBGs HR, lo cual es un factor negativo.

Para hallar la correlación cruzada se construyeron 3 SSFBGs cada una con uno de los perfiles anteriores, pero con un código diferente al de las parejas originales. A simple vista podemos ver que el pico de correlación cruzada aumenta cuando se usan SSFBG HR. La mejor forma de comparar las tres SSFBGs es mediante la razón Pico de autocorrelación (P) vs. pico de correlación cruzada (C). Cuando se usan SSFBGs la relación $\frac{P}{C}$ es aproximadamente 10, mientras que cuando se usa la pareja SSFBG HR esta relación disminuye a la mitad. El hecho de que la relación decaiga en $50 \%$ significa que el nivel de potencia interferente se ha incrementado en $3 \mathrm{~dB}$. Finalmente cuando se usa, la pareja SSFBG sintetizada la relación $\frac{P}{C}$ retorna a su valor de 10 , con la ventaja de que las pérdidas de inserción se han reducido significativamente. 


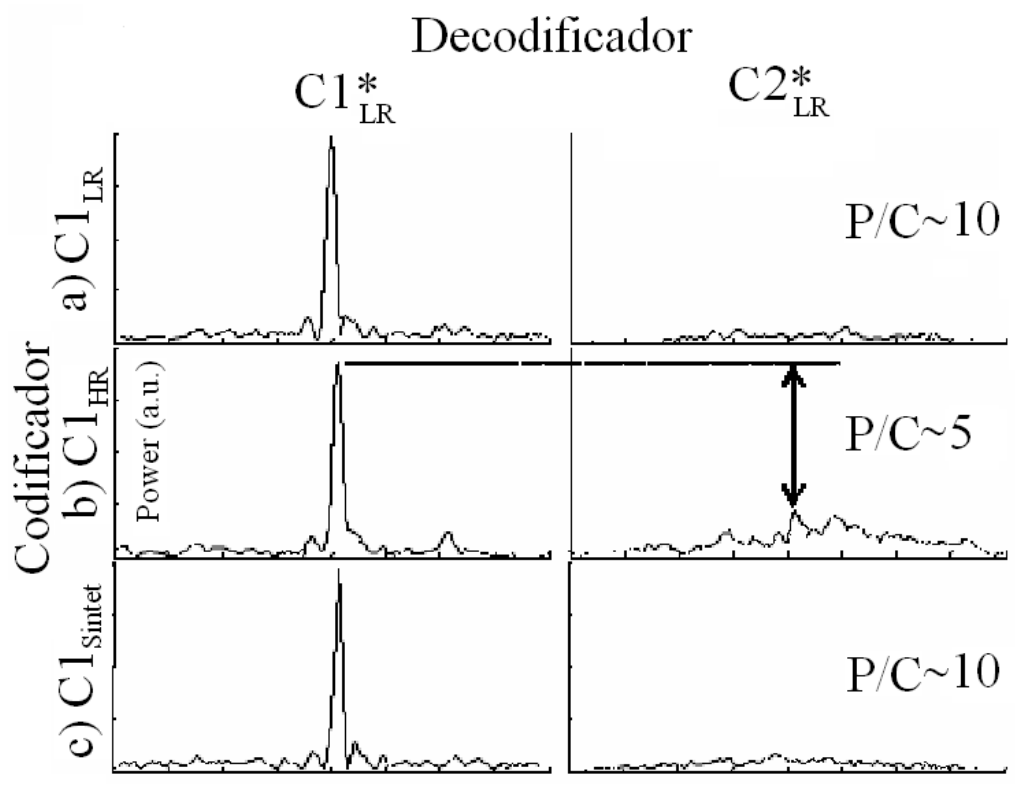

Figura 4.18: Señales Decodificadas con el código correcto y con un decodificador incorrecto para cada tipo de SSFBG 



\section{Capítulo 5}

\section{CODIFICACIÓN Y DECODIFICACIÓN TODO ÓPTICA DE ETIQUETAS EN REDES DE CONMUTACIÓN DE PAQUETES.}

\subsection{Introducción}

Las aplicaciones de los procesos de codificación y decodificación ópticos vistos hasta ahora, han estado orientadas al acceso múltiple en redes PON. El objetivo es que las redes PON tengan una capacidad y flexibilidad adicional a las obtenidas cuando se trabaja con técnicas de acceso múltiple por división en longitud de onda (WDMA) o multiplexación electrónica por división en tiempo (ETDMA), o en combinación con las mismas [17, 32, 9]. Las investigaciones realizadas por diferentes autores dentro de este campo han llevado a enunciar múltiples propuestas para la codificación y decodificación óptica con óptimas propiedades y gran fiabilidad, no obstante este no es el único campo de acción. En paralelo y debido a los logros tecnológicos, la capacidad de codificación y decodificación óptica en tiempo real también se ha propuesto como una alternativa para el tradicional procesamiento eléctrico de las cabeceras en redes de paquetes ópticos y en redes de ráfagas. Esto es lo que se ha dado en llamar PLS (Photonic Label Switching) y en donde se emplean etiquetas basadas en códigos ópticos.

PLS emplea códigos ópticos como etiquetas, generadas y procesadas directamente en el dominio óptico. Existen arquitecturas para enrutadores basados en códigos ópticos que pueden conmutar paquetes a una tasa de 160 Gbps [25, 81]. La única limitación de hardware de esta tecnología es el conjunto de parejas codificadores/decodificadores (E/Ds), una por cada etiqueta, que se requieren para procesar simultáneamente todas 


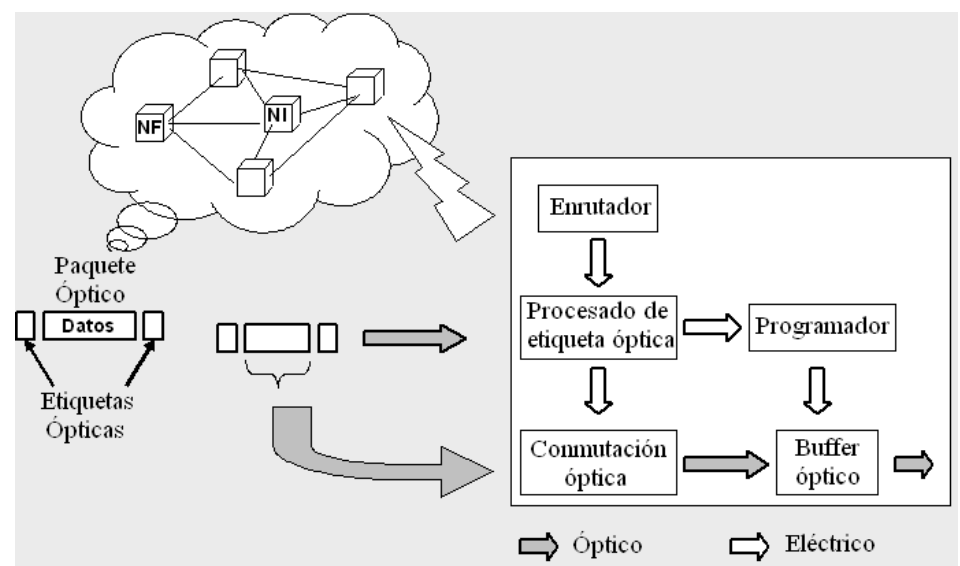

Figura 5.1: Nodo basado en etiquetas ópticas

las entradas de código de la tabla de búsqueda.

En un enrutador basado en codificación óptica como el mostrado en la figura 5.1, el controlador del nodo LSR (Label-Switch-Routing) determina la nueva etiqueta desde una tabla de enrutamiento, de acuerdo al puerto utilizado y a la etiqueta que ha llegado. En un nodo de frontera (NF) de la red óptica, el LSR asignara una etiqueta al paquete o ráfaga de salida, determinando así la ruta a seguir. En un nodo intermedio (NI) la función de reenvío involucra el cambio de la etiqueta anterior por la nueva. En la entrada del nodo, el procesamiento de la etiqueta es realizado por un primer bloque que realiza de manera simultánea la correlación óptica entre la señal codificada de entrada (etiqueta) y todos los decodificadores existentes en el nodo. El pico de autocorrelación (ACP) emerge solamente por una de las salidas, por el resto solo se obtienen señales de correlación cruzada. La señal ACP se detecta, y con ella, primero se determina hacia donde se debe conmutar el paquete óptico, asignando el nuevo puerto de salida y segundo se asigna la nueva etiqueta. El intercambio de etiquetas se realiza quitando la etiqueta entrante e insertando la nueva, de acuerdo al protocolo de distribución de etiquetas (LDP). La etiqueta de salida es generada por un láser de pulsos ultracortos aplicada a la salida del banco de codificadores, en donde el codificador apropiado deberá ser conmutado y alineado en tiempo con el paquete de datos.

La técnica de tiempo ensanchado (TS) coherente o también conocida como de secuencia directa (DS), ha sido la más utilizada en los nodos PLS, para realizar los procesos de codificación y decodificación. En esta técnica, el pulso óptico inicial es mapeado en N posiciones de tiempo (llamadas "chips") a lo largo de la señal codificada total. Cada chip es modulado en fase de acuerdo con un código de cambio de fase, binario o multinivel. La señal resultante, se vera por tanto, como ruido con un nivel igual a $\frac{1}{N}$ de la potencia del pulso original. La señal original podrá ser recuperada con el decodificador apropiado, el cual contendrá los cambios de fase conjugados y los retardos de tiempos adecuado para reconstruir la señal codificada.

Las primeras implementaciones prácticas, emplearon principalmente tecnologías 
de circuitos planares ópticos (PLC), los cuales permiten realizar retardos y cambios de fase ópticos estables. Además, los PLC pueden incorporar elementos sintonizables que permiten reconfigurar la fase óptica, lo que a su vez, da la posibilidad de obtener códigos reconfigurables [25, 22, 82]. También se ha demostrado el uso de redes de difracción de Bragg superestructuradas (SSFBG) para sistemas DS-OCDMA coherentes con un gran número de chips $(\mathrm{N}=511)$, y proporcionando los beneficios intrínsecos de la fibra óptica [17, 32, 9]. En [83] se usan SSFBGs para generar una secuencia de pulsos codificados en fase cuaternaria de 255 chips (320Gchip/s). Estos códigos tienen un destacado pico de autocorrelación y una muy baja correlación cruzada, permitiendo tener hasta 257 cabeceras distintas para el número de chips dado. La combinación de PLC y SSFBGs fue demostrada en [84], donde se utilizó un codificador de etiquetas de 16 chips (código Gold binario PSK (Phase-Shift-Keyed)), basado en un PLC programable, para generar diferentes patrones de etiquetas. Al final de la unidad OPS (Optical Packet Switching), una SSFBG de 16 chips con un patrón inverso de fase fue usado para el reconocimiento de las etiquetas. En [85]-[81] se demuestra un sistema codificador/decodificador que genera y procesa un conjunto de códigos PSK simultáneamente. El dispositivo usado, esta basado en un PLC pasivo con una estructura muy similar a la de un filtro AWG (Arrayed Waveguide Gratings), con $\mathrm{N}$ entradas y $\mathrm{N}$ salidas.

En todos los casos, los ACP del encabezado o la etiqueta son electrónicamente procesados por un generador de patrones de pulso (PPG) que maneja un conmutador electro-óptico para separar los datos de la etiqueta. De la misma manera, la señal del PPG debe ser usada para activar la selección de la nueva etiqueta de acuerdo al protocolo de distribución de etiquetas y conmutar al nuevo codificador óptico.

En todas las demostraciones anteriormente citadas, las etiquetas codificadas se generaron empleando una fuente láser de pulsos ultracortos, normalmente MLL (Mode Locked Laser) y se centran en los procesos de codificación y decodificación de la etiqueta. Sin embargo en estas demostraciones, la generación de la nueva etiqueta y su sincronización con los datos de salida pueden presentar algunas dificultades. Primero, si consideramos una red de paquetes ópticos asíncrona con tiempos de llegada aleatorios, tendremos que cada nodo PLS deberá estar equipado como mínimo, con el mismo número de fuentes MLL que puertos de entrada. Además cada fuente pulsada MLL debe estar en cierta forma sincronizada con cada uno de los paquetes, empleando por seguridad tiempos de guarda. Estas circunstancias dificultan la viabilidad de una red de este tipo, ya que entre los objetivos buscados con la utilización de etiquetas ópticas está la reducción de los tiempos de procesado o latencia del nodo.

En este capítulo se estudia la viabilidad de un escenario alternativo en el que se tratará de reutilizar los ACP generados cuando se reconoce la etiqueta entrante, para la generación de una nueva etiqueta. Este escenario ya ha sido planteado con anterioridad por algunos autores entre ellos [83]. En dicho artículo se demuestra el reuso de un solo ACP, es decir, el equivalente a un salto entre nodos. También se describe como mediante NOLM (Non-Linear Optical Loop Mirror) se mejora la razón de extinción en el reconocimiento de la cabecera. Nuestra contribución con respecto a estas propuestas previas es el reuso de señales ACP en múltiples saltos, sin intermediación de procesos no lineales, obteniendo una reducción de la complejidad del sistema.

Presentamos en primera instancia una descripción completa de nuestra propuesta, 
el soporte teórico en el que esta basada y su verificación mediante simulación. Posteriormente se desglosa el setup utilizado para la verificación experimental con sus respectivos resultados.

Por otra parte sabemos que el deterioro de los ACP después de múltiples saltos no depende únicamente de los defectos o inconvenientes presentados en los E/D's, sino también de la dispersión ocasionada durante su propagación a través de la fibra que interconecta los nodos. Razón por la cual en este capítulo también describimos los efectos de la dispersión sobre los sistemas OCDMA obteniendo primero resultados mediante simulaciones y posteriormente realizamos la comparación con los resultados obtenidos de la verificación experimental.

\subsection{Principios de la Recodificación de Pulsos}

Se han planteado en capítulos anteriores los inconvenientes que presentan los sistemas OCDMA, entre los que destacan el ruido de batido y la interferencia multiacceso. Ambos, responsables de las posibles incertidumbres en el momento de detectar la señal deseada en los equipos receptores. Esto podría llevar a pensar en la incompatibilidad de su uso en aplicaciones de reconocimiento de etiquetas en redes de paquetes ópticos. No obstante, la utilización de las técnicas de multiplexación por división en código, es decir el hecho de utilizar procesos de codificación y decodificación como mecanismos para crear etiquetas ópticas que permitan identificar paquetes o ráfagas, se encuentra sustentada en dos principios básicos:

1. Durante el reconocimiento de las etiquetas ópticas no se tiene en cuenta el ruido de interferencia multiusuario (MUI) como en los sistemas OCDMA tradicionales para red de acceso. $\mathrm{Y}$ en consecuencia el ruido de batido no esta tampoco presente. Por lo tanto no se requiere en principio, el uso de técnicas de time gating, ó de thresholding usadas para reducir el ruido de interferencia. Un simple thresholding electrónico puede ser empleado después de la detección directa.

2. Los principios fundamentales de codificación y decodificación óptica coherente son de naturaleza lineal, se mantienen inalterados aunque la señal inicial para el proceso de codificación/decodificación no proceda de una fuente pulsada si no de reutilizar la señal ACP de una etapa anterior. Es decir, la capacidad de distinguir unos códigos de otros no sufre ningún detrimento.

Eliminando los problemas de interferencia y garantizando que los procesos de codificación y decodificación permanecen inalterados es posible plantear la recodificación de un pulso que ha sido recuperado previamente.

Matemáticamente el proceso de codificación consiste en tomar un pulso gausiano $x(t)$ y convolucionarlo por la respuesta impulsiva del dispositivo codificador $h(t)$, para nuestro caso un SSFBG. Tendríamos entonces que el proceso de codificar la señal original estaría dado por la ecuación

$$
y(t)=x(t) \otimes h(t)
$$

lo que en el dominio de la frecuencia equivale a: 


$$
Y(w)=X(w) H(w)
$$

Ahora si en el receptor tenemos el decodificador correcto, es decir, $H^{*}(w)$, podremos recuperar el pulso original, y la señal recibida será:

$$
R(w)=Y(w) H^{*}(w)
$$

$r(t)$ es nuestro pulso recuperado, el cual corresponde al pulso original más un número de picos satélites que surgen durante los procesos de cod/decodificación. Estos picos son conocidos como wings y son inevitables en este tipo de procedimientos. Los wings son un factor determinante, porque en el segundo salto o procedimiento de cod/decodificación el pulso a codificar ya no es gausiano puro. Para el segundo salto la señal de entrada será el pulso más los wings originados en el primer proceso. En el caso contrario cuando la señal codificada no es recibida con el decodificador correcto, la señal que se obtiene es interpretada como ruido. Del conjunto total de decodificadores ópticos en el banco de entrada se debe obtener la información de control para la etapa de enrutamiento del paquete.

En nuestro caso, además de la detección de la de señal de ACP, lo que proponemos es su reutilización para la codificación de la nueva etiqueta a la salida del nodo, aliviando en la medida de lo posible la necesidad de una nueva fuente pulsada.

Vemos por tanto que $r(t)=x(t)+W$ donde $W$ son los wings de la señal recuperada. $r(t)$ o $A C P_{1}$ será ahora la señal de entrada al siguiente codificador. Con ello es fácil deducir que el $A C P_{2}$ será fruto de la convolución matemática del pulso $A C P_{1}$ consigo mismo y que $A C P_{3}$ será la convolución entre $A C P_{1}$ y $A C P_{2}$ y así sucesivamente. La cascada reparte la energía del pulso original en el tiempo y después de 4-5 saltos la señal ACP se va aproximando a una forma gausiana.

Cabe destacar que no solo la forma de la señal va cambiando a medida que se da cada salto entre nodos de la red, si no que también se modifica la duración del tiempo durante el que hay señal presente. Esto se da porque en cada proceso de correlación el eje temporal de la señal resultante es el eje temporal de la señal de entrada multiplicado por dos. La extensión en el tiempo del pulso no debería ser un problema en una aplicación que use etiquetas ópticas, donde el tamaño de dichas etiquetas puede llegara a ser un $10 \%$ de los bits destinados a datos.

\subsection{Simulación en Matlab y VPI}

Para describir mejor lo que sucede en los repetidos procesos de codificación y decodificación podemos ver los resultados de las simulaciones realizadas para un sistema que usa códigos de 63 chips pertenecientes a una familia de Gold, construidos sobre redes de difracción de Bragg. Las simulaciones se realizaron usando inicialmente Matlab, partiendo del modelo usado en las simulaciones de la sección 3.5. Los cambios realizados a dicho modelo, consistieron simplemente en realizar un bucle que representa un salto entre nodos, o lo que es lo mismo, un proceso de codificación y decodificación. A la entrada del bucle estará, para el primer salto, la señal original, y su salida será reinyectada a la entrada obteniendo así los ACP para cada caso. Adicionalmente se agregó el efecto de un filtro electrónico tras la detección de cada 


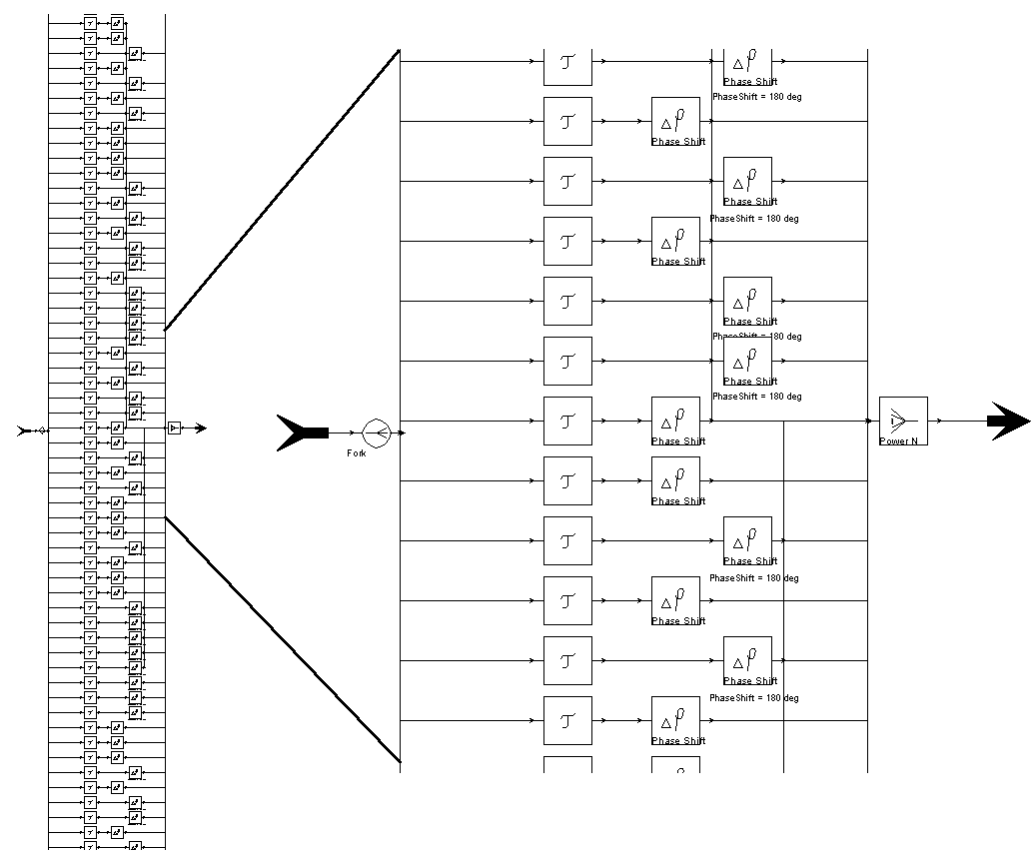

Figura 5.2: Diagrama del modelo de codificador/decodificador basado en SSFBG realizado en VPI.

etapa con diferentes anchos de banda para poder obtener resultados realistas y poder establecer comparaciones con las medidas experimentales .

Por otra parte, con el objetivo de poder aplicar parámetros adicionales al sistema, se uso la herramienta de simulación VPI versión 7.6. Para ello se modelaron los codificadores y decodificadores basados en redes de difracción de Bragg, la fuente MLLD y se uso como receptor un osciloscopio con un filtro electrónico para diferentes valores de ancho de banda. La fuente MLLD fue modelada para obtener una secuencia aleatoria de pulsos estrechos de 2.5 ps de duración a una tasa de $1.25 \mathrm{Gbps}$, constituyéndose así en nuestra señal de entrada. Los E/D's, elementos fundamentales del sistema, se modelaron empleando N (número de chips del código) bloques de retardo, que representan los retardos introducidos en el pulso a medida que este se propaga por la red de difracción. Como para nuestro caso consideramos que cada chip tiene una longitud de $0.6 \mathrm{~mm}$, podemos inferir que el retardo introducido por cada uno de ellos es de aproximadamente 6 ps (tiempo de ida y vuelta). Para introducir los cambios de fase que realiza cada chip, y que caracteriza cada palabra código, se usaron $\mathrm{N}$ bloques de cambio de fase. El código usado es un código bipolar por lo que cada bloque introducía en los chips correspondientes un desfase de 180 grados. El diagrama del codificador lo podemos ver en la figura 5.2.

Cabe anotar que el diagrama del decodificador es idéntico externamente y que la única diferencia se encuentra en que los bloques de retardo han sido invertidos de posición de tal forma que se configure el código conjugado del que se ha puesto en el 

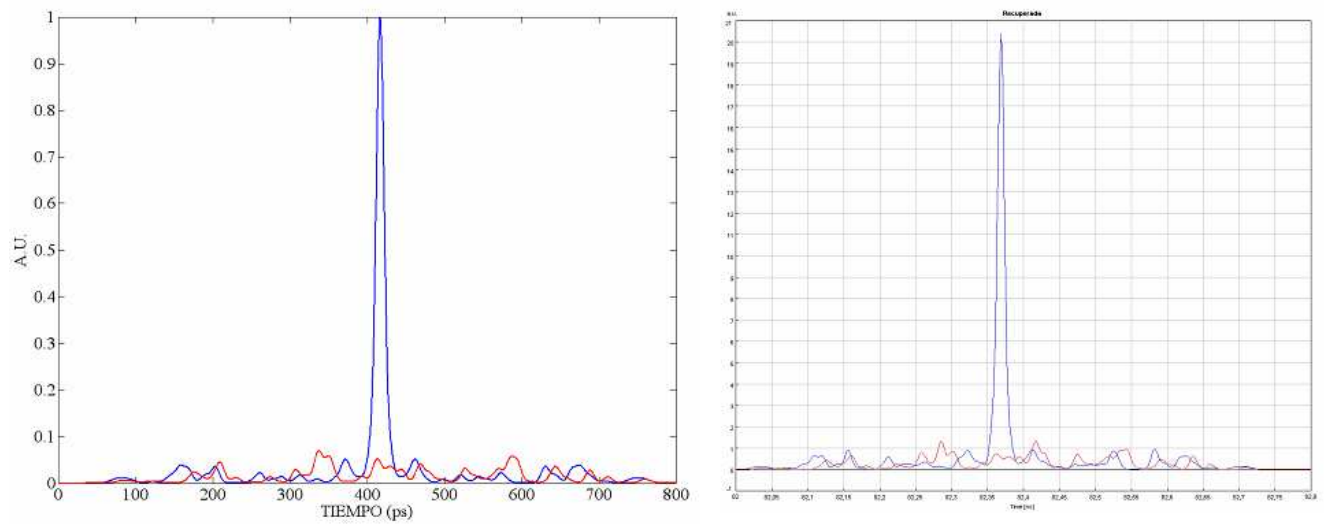

Figura 5.3: Resultados del primer salto. 1 pareja cod/decodificador. $A B=30 \mathrm{GHz}$. Matlab (izq), VPI (der).

codificador.

Las simulaciones se realizaron para un sistema de cuatro parejas de E/Ds en cascada, que representan 4 saltos entre nodos. Los resultados de la simulación del primer proceso de cod/decodificación se pueden ver en la figura 5.3 y son similares a los obtenidos en la sección 3.5, en donde se observa una clara recuperación de la señal, y la aparición de pequeños picos satélites a cada lado del pico principal. La señal obtenida a partir de la correlación cruzada es muy inferior al pico de autocorrelación, siendo la relación $\frac{c}{p}=0,07$. Por otra parte estos resultados también nos sirven para demostrar que el modelado hecho en VPI es correcto. Las señales no son perfectamente idénticas porque el software VPI introduce algunos aspectos en el sistema que no quisimos obviar, como por ejemplo ruido térmico, algunas pequeñas imperfecciones de los dispositivos y en el momento de visualizar la señal se usa una tasa de muestreo diferente.

Para el segundo salto, la señal de entrada es el ACP del primer proceso, es decir, el pulso principal más los pulsos satélites. En la figura 5.4 se observa como las impurezas en la señal de entrada para este nuevo proceso de cod/decodificación hacen que se incremente el número de picos satélites en la señal de salida y que cada uno de ellos tenga una mayor amplitud. La señal de correlación cruzada también se incrementa ligeramente siendo ahora la relación $\frac{C}{P}=0,08$. Nótese, no obstante, que la mayoría de wings están por encima de la señal de correlación cruzada.

En la figura 5.5 tenemos los resultados para el tercer salto, en los cuales podemos observar un incremento importante de los wings y una disminución en la amplitud de la señal de correlación cruzada, obteniendo una relación $\frac{C}{P}=0,063$. En este punto, es importante recordar que cuando se usan los procesos de cod/decodificación como generadores e identificadores de etiquetas, no es importante la interferencia multiacceso y que solo se requiere una clara diferenciación entre la señal de autocorrelación y la señal de correlación cruzada. Por esta razón es posible el uso de receptores con un ancho de banda inferior, como se puede ver en las figuras 5.5 b y $5.5 \mathrm{c}$, donde se usaron 

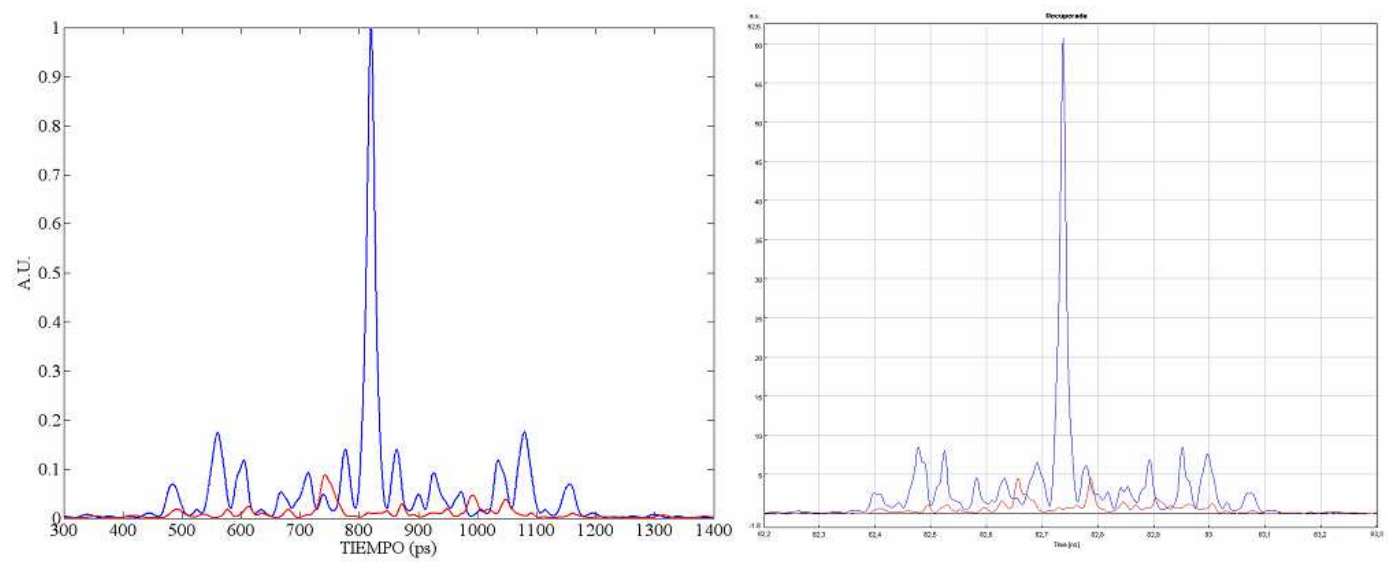

Figura 5.4: Resultados del segundo salto. 2 parejas cod/decodificador. $\mathrm{AB}=30 \mathrm{GHz}$. Matlab (izq), VPI (der).

anchos de banda de filtrado de 12.5 y $2.5 \mathrm{GHz}$ respectivamente. En estas gráficas es clara la diferencia entre la señal del ACP y la obtenida a partir de la correlación cruzada. Nótese que la relación $\frac{C}{P}$ se mantiene dentro del mismo rango de valores, siendo de 0.07 para el filtro de $12.5 \mathrm{GHz}$ y de 0.05 para el de $2.5 \mathrm{GHz}$.

Para el cuarto salto, la señal de entrada esta conformada por múltiples pulsos de diferente tamaño, cuya envolvente podríamos llegar a aproximar a una forma gausiana. Por esta razón el aspecto de la señal de salida cuando decodificamos con el dispositivo correcto es también de la misma forma (figura 5.6). Por otra parte la señal de correlación cruzada se decrementa en un $50 \%$ adicional con respecto al salto anterior, obteniéndose así una relación $\frac{C}{P}=0,03$. Esta relación se mantiene cuando se realiza un filtrado de la señal a 12.5 y $2.5 \mathrm{GHz}$ tal y como se puede ver en las figuras $5.6 \mathrm{~b}$ y $5.6 \mathrm{c}$ respectivamente.

Podemos concluir a partir de estas simulaciones que la capacidad de reconocimiento de etiquetas ópticas puede ser explotada aun después de múltiples cascadas. Además, conociendo que en esta aplicación lo principal es la diferenciación entre el ACP y la señal de correlación cruzada, es posible usar receptores con una ancho de banda inferior al óptimo, ya que como se pudo observar con poder detectar la envolvente de la señal es suficiente.

\subsection{Demostración Experimental}

Para demostrar experimentalmente la posibilidad de identificación de señales después de múltiples procesos de codificación y decodificación se realizó el montaje que se muestra en la figura 5.7 con su respectivo diagrama de bloques mostrado en la figura 5.8 .

Como señal de entrada inicial se uso una fuente pulsada MLLD que proporciona una secuencia de pulsos de 5 ps de duración a una tasa de bit de 1.25 Gbps, centrada 

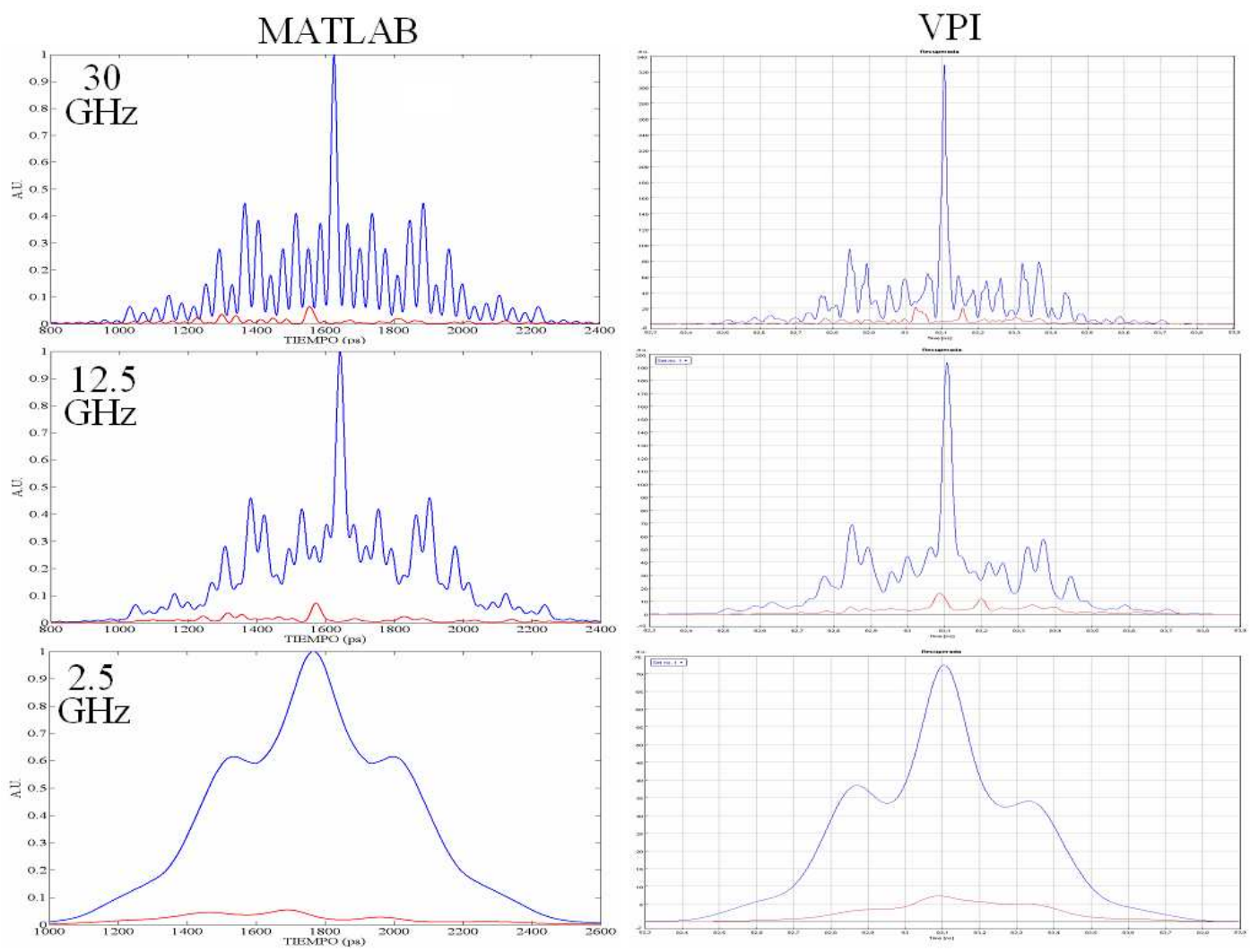

Figura 5.5: Resultados del tercer salto. 3 parejas cod/decodificador. . 


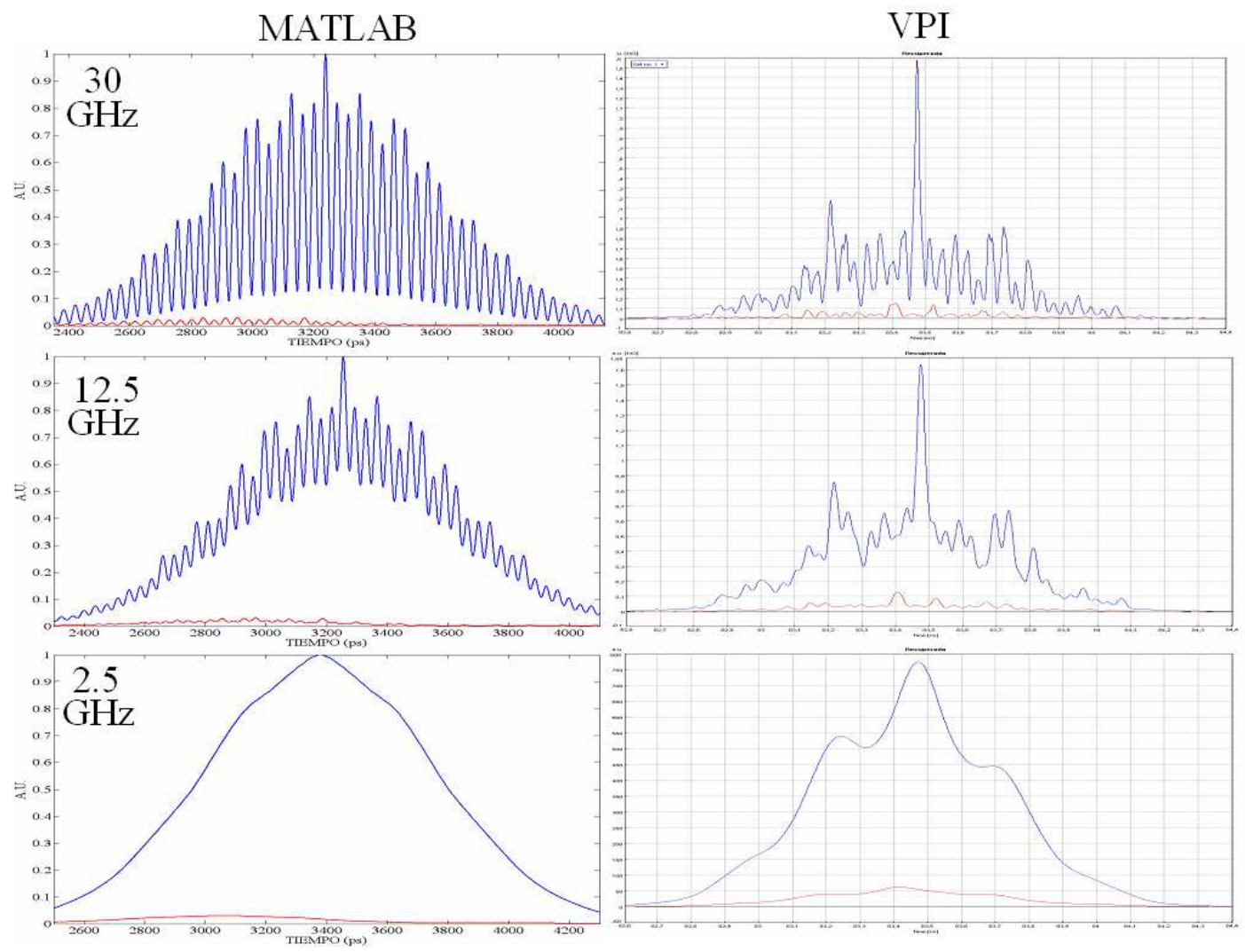

Figura 5.6: Resultados del cuarto salto. 4 parejas cod/decodificador. 


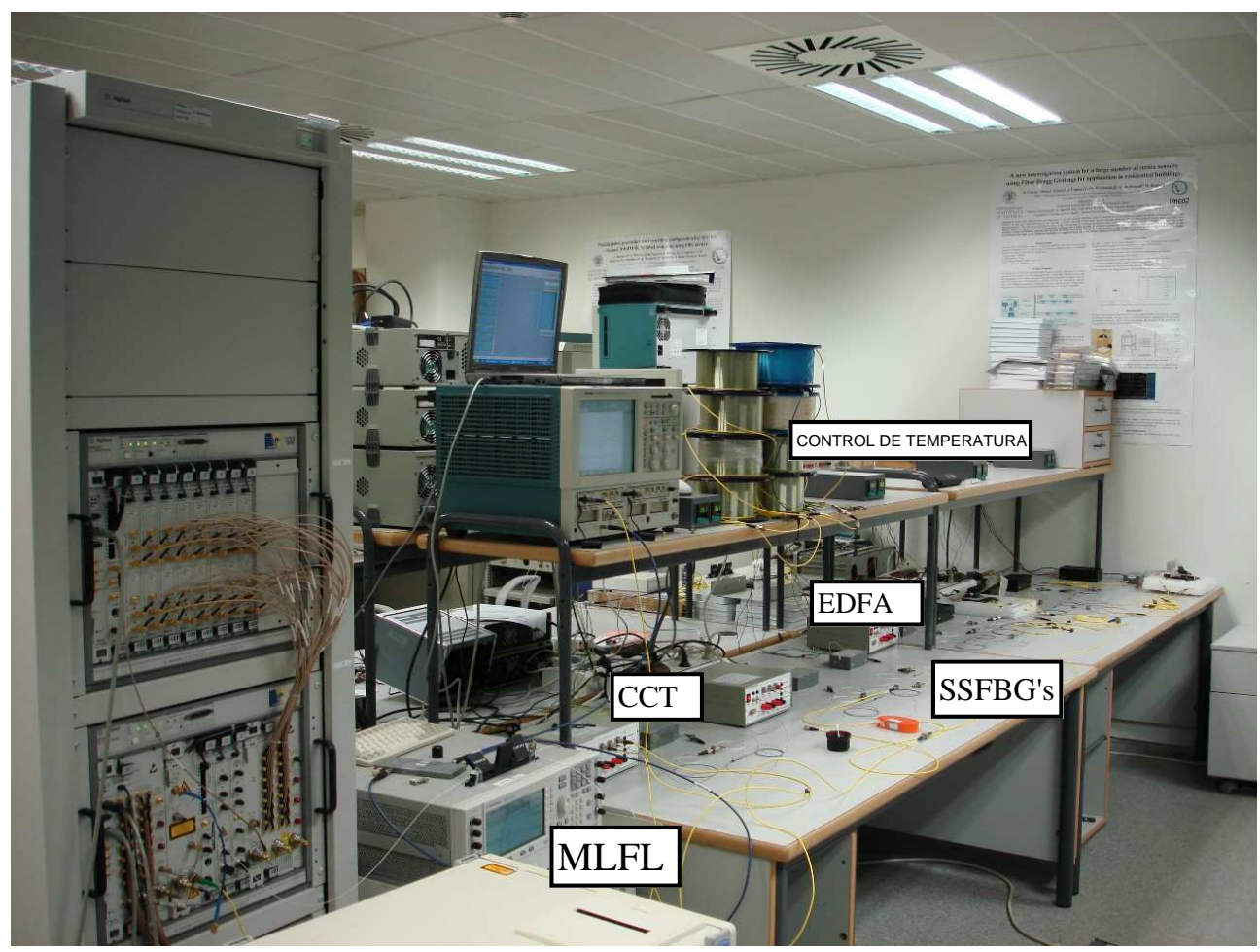

Figura 5.7: Montaje en laboratorio de la cascada de 8 SSFBGs

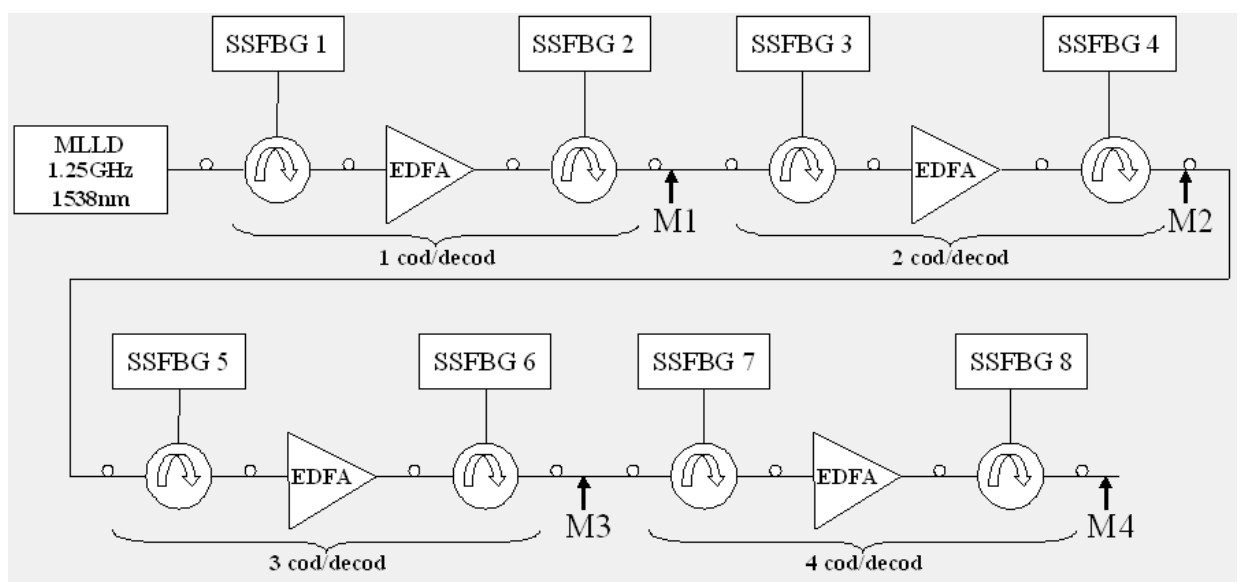

Figura 5.8: Diagrama del experimento. 4 procesos de codificación y decodificación en cascada, basados en dispositivos SSFBG. 
CAPÍTULO 5. CODIFICACIÓN Y DECODIFICACIÓN TODO ÓPTICA DE ETIQUETAS EN REDES DE CONMUTACIÓN DE PAQUETES.

\begin{tabular}{|c|c|c|}
\hline & ACP & Xcorr \\
\hline \hline M1 & $C 1 \cdot C 1 *$ & $C 1 \cdot C 2 *$ \\
\hline M2 & $C 1 \cdot C 1 * \cdot C 1 \cdot C 1 *$ & $C 1 \cdot C 1 * \cdot C 1 \cdot C 2 *$ \\
\hline M3 & $C 1 \cdot C 1 * \cdot C 1 \cdot C 1 * \cdot C 1 \cdot C 1 *$ & $C 1 \cdot C 1 * \cdot C 1 \cdot C 1 * \cdot C 1 \cdot C 2 *$ \\
\hline M4 & $C 1 \cdot C 1 * \cdot C 1 \cdot C 1 * \cdot C 1 \cdot C 1 * \cdot C 1 \cdot C 1 *$ & $C 1 \cdot C 1 * \cdot C 1 \cdot C 1 * \cdot C 1 \cdot C 1 * \cdot C 1 \cdot C 2 *$ \\
\hline
\end{tabular}

Cuadro 5.1: Funciones de transferencia para las mediciones usando la misma palabra código.

a una longitud de onda de $1538 \mathrm{~nm}$. Esta señal es aplicada a una primera pareja de E/D's, cuya señal de salida es posteriormente aplicada a la siguiente pareja de E/D's y así sucesivamente.

En el diagrama de la figura 5.8, las referencias M1 a M4 indican los puntos en donde se realizaron las mediciones de la señal ACP y de las señales de correlación cruzada.

Como dispositivos E/D's se utilizaron 4 parejas de dispositivos basados en redes de difracción de Bragg superestructuradas. Para la primera parte del experimento todos los dispositivos tenían grabada la misma palabra código de 63 chips obtenida a partir de una familia de códigos Gold, para realizar una codificación en fase binaria. La longitud de cada chip es de $0.6 \mathrm{~mm}$ lo cual corresponde a una tasa de chip de 174 Gchip/s. Los cod/decodificadores están sintonizados a una longitud de onda de $1538 \mathrm{~nm}$ y la palabra código fue impresa mediante una iluminación chip a chip como se ha descrito en el capítulo 3.4. La reflectividad estimada por chip esta por debajo de los $0.5 \%$ para evitar desvanecimientos a lo largo de la SSFBG y degradación por múltiples reflexiones. Después de fabricar cada pareja cod/decodificador fueron colocadas en sus respectivas cajas con control electrónico de temperatura. Con este control se obtiene una estabilidad térmica de $0.1^{\mathrm{O}}$ de precisión y la posibilidad de realizar una sintonización en longitud de onda que permitirá el perfecto acople entre los dispositivos. Como receptor se uso un osciloscopio de muestreo con un ancho de banda ajustable entre 2.5 y $30 \mathrm{GHz}$.

La secuencia de funciones de transferencia de los dispositivos SSFBG utilizados para realizar las diferentes medidas fueron las dadas en la tabla 5.1. La figura 5.9 muestra las señales ACP (izquierda) y de correlación cruzada (derecha) recibidas con el osciloscopio ajustado a $30 \mathrm{GHz}$ de ancho de banda.

Como habían predicho las simulaciones teóricas, la energía del pico original es esparcida después de las sucesivas cascadas y se incrementa el número de picos satélites que aparecen en la señal ACP. En la demostración experimental se observa que la señal de correlación cruzada no incrementa su nivel tal y como lo predice la simulación aunque la relación $\left(\frac{P}{C}\right)$ si disminuye, lo cual se debe a la dificultad del ajuste en longitud de onda (temperatura) entre parejas codificadoras que redunda en una pérdida de eficiencia del pico ACP.

La Figura 5.10 muestra los resultados para el cuarto paso en la cascada cod/ decodificador donde la función de transferencia incluye una cadena de 8 SSFBGs. El promediado del osciloscopio fue apagado para preservar tanto como sea posible la forma de la señal real aunque también de esta manera se observa la fuerte contribución 


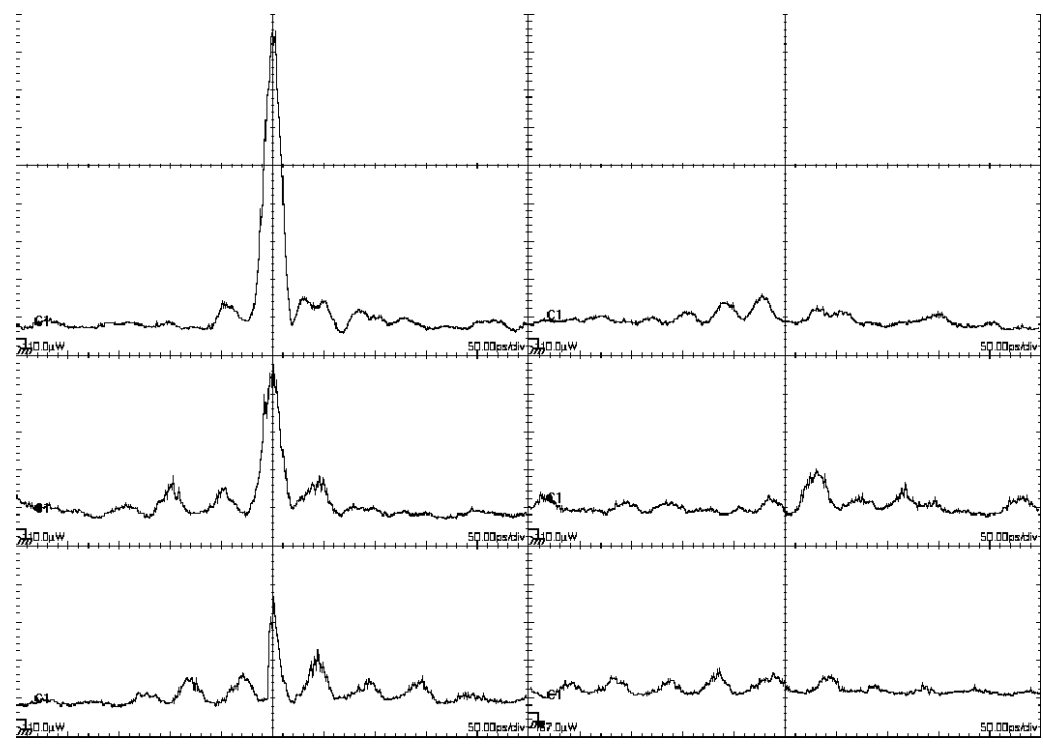

Figura 5.9: Señal ACP y de correlación cruzada medida en los puntos M1, M2 y M3.

de ruido ASE.

A pesar de las dificultades para realizar la medida, como consecuencia del ruido ASE y las inestabilidades térmicas de la cascada de 8 SSFBG, los resultados muestran que es factible explotar la capacidad de reconocimiento de códigos ópticos aun después de múltiples saltos entre nodos (El caso aquí presentado es equivalente a 4 saltos entre nodos de red). Las señales de ACP y correlación cruzada se ensancharon más de 1 ns pero aun así es posible distinguirlas electrónicamente mediante el adecuado filtro paso bajo y la detección de un valor umbral.

Los resultados mostrados en las figuras 5.9 y 5.10 (30 GHz de ancho de banda) y en general en las simulaciones, sugieren que una apropiada recuperación de la señal ACP no depende de un gran ancho de banda eléctrico (o su equivalente concepto de Time Gating) para ser distinguido de la señal de correlación cruzada. La figura 5.11 ilustra los resultados empleando un filtro estándar SDH $2.5 \mathrm{GHz}$ en el receptor, reduciendo 10 veces el ancho de banda eléctrico.

Como era de esperarse, el ACP detectado es filtrado perdiendo energía y el ruido presente como correlación cruzada después de filtrado a $2.5 \mathrm{GHz}$ permanece cercano al ACP. La relación $\frac{P}{C}$ decrece si el ancho de banda eléctrico disminuye. Este decrecimiento es más acentuado cuando se refiere al proceso de una sola pareja cod/decodificador, no obstante a medida que consideramos el segundo y tercer salto, el efecto de reducir el ancho de banda se desvanece progresivamente. Lo cual es consecuencia de que a partir del segundo proceso de cod/decodificación la señal de entrada este compuesta de múltiples pulsos del estado previo.

Cuando se realiza el enrutamiento de los paquetes ó ráfagas ópticas, la decisión de la ruta depende de la congestión existente en ese instante en la red y de los caminos disponibles, por eso lo más normal es que la etiqueta sea cambiada en cada salto, 


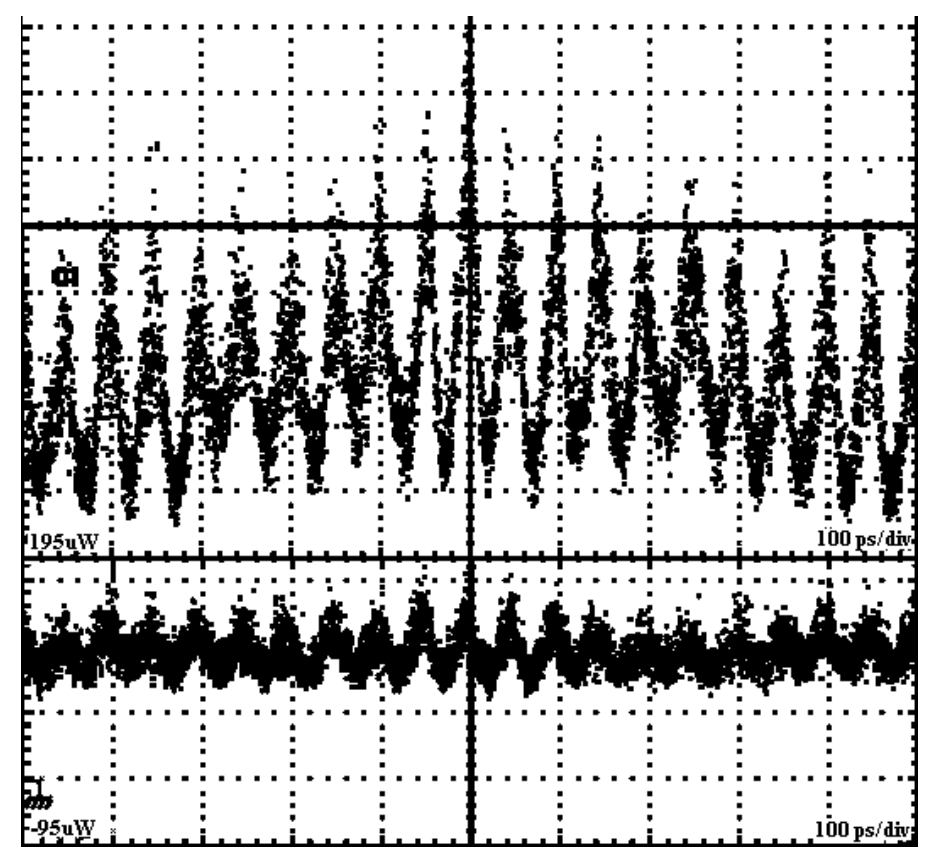

Figura 5.10: Señal ACP y de correlación cruzada medida en el punto M4.

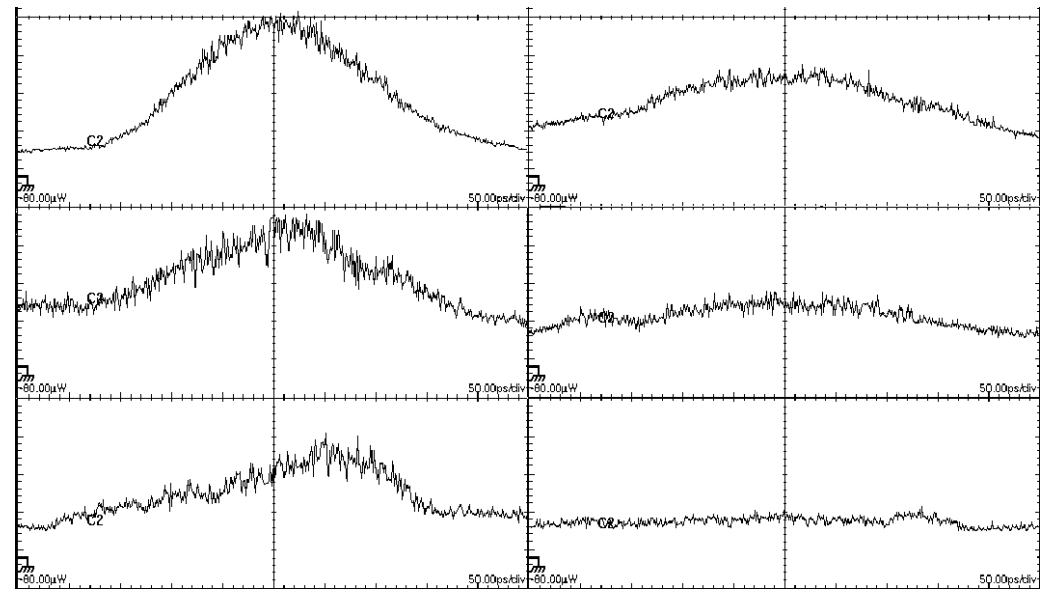

Figura 5.11: Señal ACP y de correlación cruzada medidas en los puntos M1 ,M2 y $\mathrm{M} 3$, empleando un detector con ancho de banda de $2.5 \mathrm{GHz}$ 


\begin{tabular}{|c|c|}
\hline CÓDIGO1 & 000000101010000101011011110101100101000100011111111000101101111 \\
\hline \hline CÓDIGO2 & 000011101011001111111001111010111000011110000100111100001100001 \\
\hline CÓDIGO3 & 011110101000100110000001100001101100000100010010100101000110100 \\
\hline CÓDIGO4 & 110000100100011101000000011000100110100010110011100000101001010 \\
\hline
\end{tabular}

Cuadro 5.2: códigos Gold usados para construir las 4 nuevas parejas de SSFBG
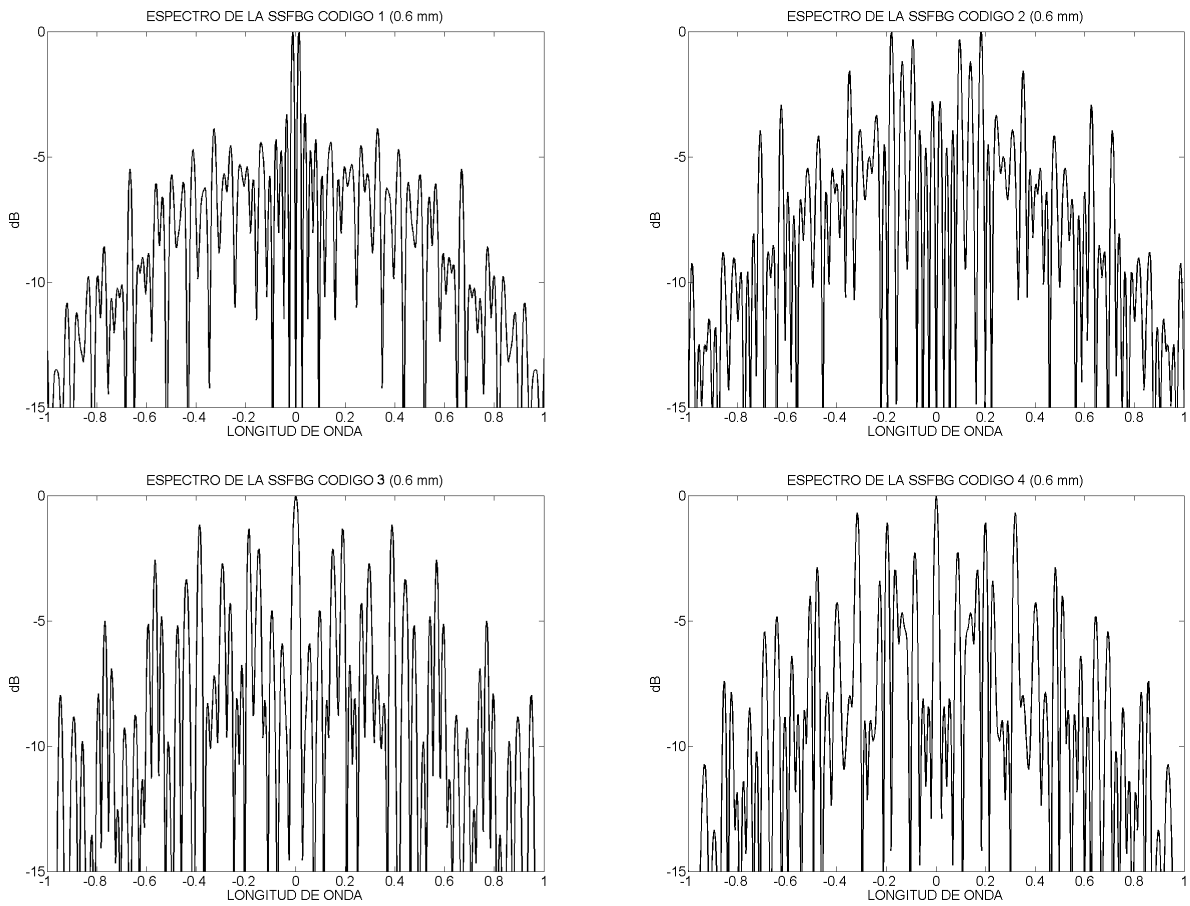

Figura 5.12: Espectros de los 4 códigos de las 4 nuevas parejas de E/D's.

asignando la nueva ruta. Esto implica que en cada salto entre nodos de la red, según el modelo de direccionamiento que proponemos, exista un cambio en el código asignado a la etiqueta. Para verificar que esta opción también era posible se seleccionaron 4 códigos más en donde cada uno de ellos representa la nueva etiqueta asignada a cada nodo.

Cada uno de los códigos seleccionados (ver tabla 5.2) pertenece a la misma familia a la que pertenece el código usado en el anterior experimento y por lo tanto tienen las mismas propiedades, es decir, una óptima relación de autocorrelación y correlación cruzada. Los espectros de los nuevos códigos utilizados se muestran en la figura 5.12.

Antes de realizar la comprobación experimental se simuló todo el sistema usando los nuevos códigos y se obtuvieron resultados muy similares a los conseguidos en el primer experimento. Los cambios en los valores del pico de autocorrelación como de correlación cruzada varían ligeramente como era de esperarse al variar los códigos, 


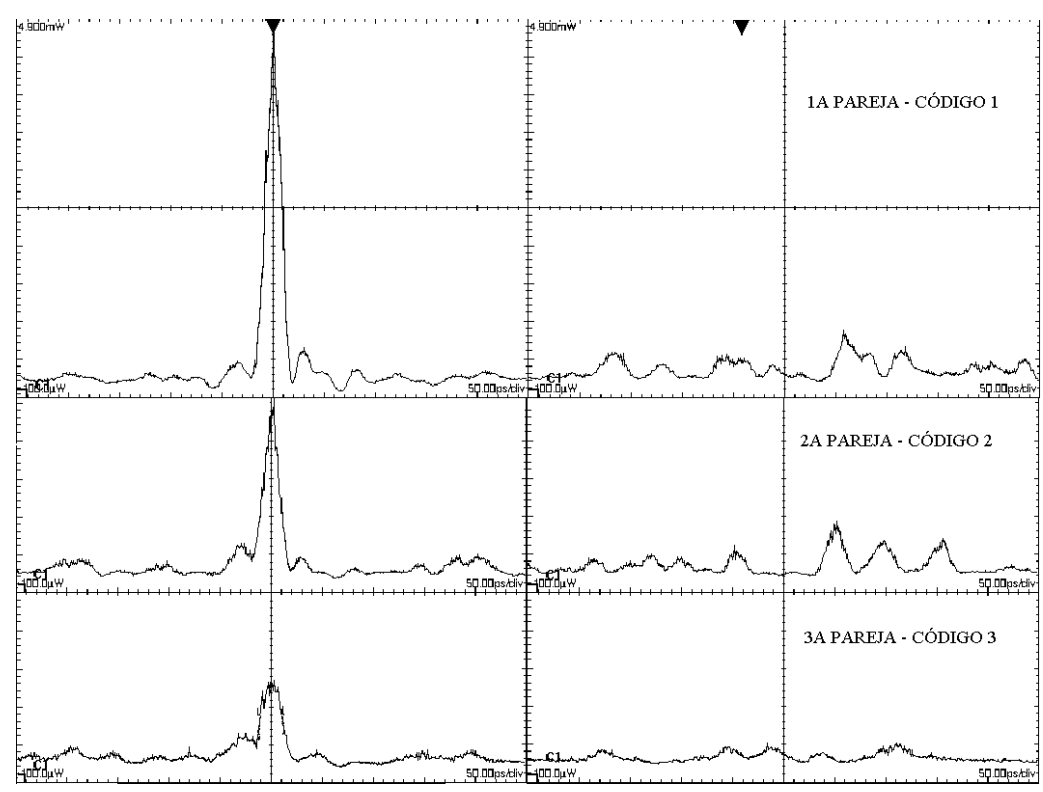

Figura 5.13: Señal ACP y de correlación cruzada medida en los puntos M1, M2 y M3 cuando se usan códigos diferentes en cada salto.

pero las relaciones $\frac{C}{P}$ y $\frac{W}{P}$ se mantienen inalteradas.

Para verificar experimentalmente las simulaciones, se fabricaron 4 nuevas parejas de redes de difracción, conservando los mismos parámetros de construcción, es decir, tamaño de chip de $0.6 \mathrm{~mm}$, reflectividad de $0.5 \%$ y centrados a una longitud de onda de $1538 \mathrm{~nm}$. Con ello conseguimos realizar una comparación objetiva de los dos experimentos. La figura 5.13 muestra los resultados para el pico de autocorrelación así como también la señal de correlación cruzada. Si comparamos la figura 5.13 con la figura 5.9 vemos que las señales obtenidas son muy similares entre si y que la diferencia entre una y otra es solo la consecuencia de las diferencias entre los códigos. Dichas diferencias no se manifiestan en las relaciones $\frac{C}{P}$ y $\frac{W}{P}$ que se mantienen iguales a las observadas cuando el experimento se realiza usando el mismo código para todos los saltos.

El hecho de que sea posible usar diferentes códigos manteniendo la capacidad de reconocimiento de la señal aun después de cambiar el código múltiples veces, demuestra la posibilidad de usar las tecnologías de codificación y decodificación óptica como una alternativa viable en la asignación de etiquetas ópticas y también la posibilidad de su reuso a medida que se propagan entre nodos de redes completamente ópticas. Las bondades de esta aplicación subsanan las desventajas que había tenido la propuesta de direccionamiento mediante etiquetas ópticas. Dichas desventajas, como por ejemplo la necesidad de sincronismo, o de una fuente pulsada en cada nodo quedan solucionadas en gran medida, otorgando a la red en general una mayor versatilidad al momento de realizar el direccionamiento y por ende a su rendimiento. 


\subsection{Efecto de la Dispersión en la Transmisión de Señales Codificadas}

Los sistemas OCDMA han sido propuestos como una posible solución de acceso en redes ópticas de última generación tales como FTTH (Fiber to the Home) o FTTC (Fiber To The Curb) [86, 20]. Su aplicación en este tipo de redes es bastante acertada ya que con esta técnica se permite a múltiples usuarios el acceso a la red de forma asíncrona y simultánea [2, 3]. En estas aplicaciones las distancias recorridas por la señal no superan los $2 \mathrm{~km}$., y la dispersión podría no ser tenida en cuenta, si no fuera porque los pulsos que se utilizan en los sistemas DS-OCDMA de tipo coherente son pulsos ultracortos, y por lo tanto la influencia sobre ellos llega a ser notable. Las señales de entrada, normalmente pulsos gausianos, tienen una duración entre 2 y 10 ps. Por otra parte en esta misma sección veíamos la posible aplicación de los sistemas de codificación todo óptica a la etiqueta en redes ópticas de paquetes o ráfagas de paquetes, situación en la que la señal podría viajar incluso varias decenas de kilómetros.

Los sistemas DS-OCDMA también son conocidos como sistemas de codificación temporal o de espectro ensanchado [61]. La codificación es temporal porque la señal codificada es realmente una expansión temporal de la señal de entrada, y esta conformada por un tren de pulsos de baja intensidad a los cuales se les ha manipulado la fase de acuerdo a un código bipolar o multipolar. Cada pulso de la señal codificada es fruto de la convolución en tiempo de la respuesta impulsiva del dispositivo codificador con el pulso de entrada y por lo tanto guarda proporcionalidad con la señal de entrada en términos de duración, fase y forma.

Como ya hemos mencionado en apartados anteriores uno de los dispositivos más usados en DS-OCDMA para realizar los procesos de codificación y decodificación son las redes de difracción de Bragg superestructuradas. Estos dispositivos son fibras a las que por medio de un proceso de iluminación mediante rayos ultravioleta se les ha grabado un código de N chips (N FBGs individuales). Cada uno de estos chips es una red de difracción en si misma cuyo índice refracción tiene un perfil de tipo gausiano, tal como se explicaba en la sección 3.4. Para el proceso de codificación, la señal de entrada es aplicada sobre la SSFBG, en donde se refleja en cada una de las FBG's que conforma cada chip, de tal manera que la señal reflejada total, fruto de la suma de cada una de las reflexiones, es la señal codificada. Sabiendo que $t_{p}$ es la duración del tiempo del pulso de entrada y que $\sigma_{c}$ es la duración de la gausiana del chip, podemos encontrar que la duración de cada uno de los $\mathrm{N}$ pulsos que conforman la señal codificada esta determinado por la relación cuadrática $\sqrt{t_{p}^{2}+\sigma_{c}^{2}}$, ya que cada uno ha surgido de la convolución entre el pulso de entrada y el chip de la SSFBG codificadora. No obstante el tiempo total de señal codificada esta limitado por el tiempo de chip al que hemos llamado $T_{c}$, y por tanto la señal codificada tiene una duración $N \times T_{c}$. Nótese que necesariamente $t_{p}$ deberá ser inferior a $T_{c}$, para evitar que el pulso de entrada englobe más de un chip en el momento de ser codificado, lo que llevaría a perder resolución en la codificación. Por esta razón si se desea tener una óptima relación entre la longitud del código y la estabilidad en temperatura de la SSFBG será necesario trabajar con pulsos ultracortos. Recordemos que cuanto 

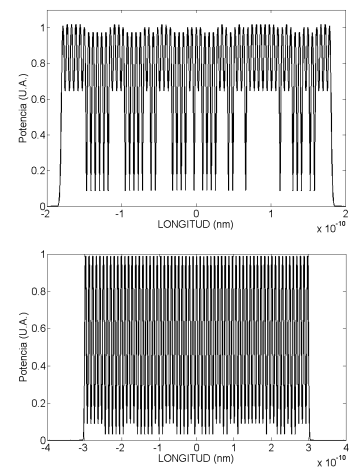
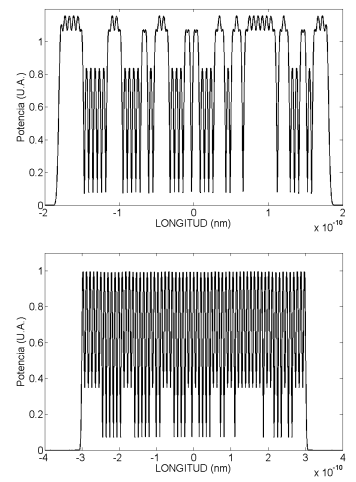
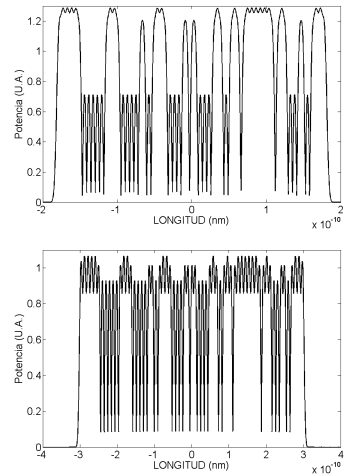

Figura 5.14: Señales codificadas. Arriba SSFBGs con chip de $0.6 \mathrm{~mm}\left(T_{c} \approx 6 p s\right)$ y pulsos de 3, 5 y 6 ps. Abajo SSFBGs con chip de $1 \mathrm{~mm}\left(T_{c}=9,6 p s\right)$ y pulsos de 3,5 y $8 \mathrm{ps}$.

mayor sea la longitud del código, mejores serán sus propiedades de autocorrelación y correlación cruzada, y cuanto más corta sea la SSFBG total, mayor es su estabilidad en temperatura [51].

En un sistema DS-OCDMA cada usuario tiene un código propio con el cual realiza la codificación de la señal que desea transmitir y la señal codificada es la que se envía a través de la fibra óptica. En la figura 5.14 podemos ver la señal codificada con SSFBGs que tienen grabados chips de $0.6 \mathrm{~mm}$ y $1 \mathrm{~mm}$, y para pulsos de entrada con diferente duración. Como era de esperarse, en dicha figura se puede ver como el tamaño del pulso entrante y la palabra código influyen directamente sobre la respuesta impulsiva. Para ver mejor la influencia de los cambios de fase del código sobre la respuesta impulsiva, vale la pena recordar la palabra código que se esta utilizando, la cual escribimos a continuación.

código1 $=[000000101010000101011011110101100101000100011111111000101101111]$

Observando el código se puede ver que allí donde los cambios de fase están más cercanos, los pulsos son borrados entre si. Por otra parte cuando aparece una serie continua de chips sin cambios de fase, terminan fundiéndose como consecuencia del solapamiento entre ellos. Si los pulsos fuesen lo suficientemente estrechos se vería cada uno de ellos independientemente.

Partiendo que la figura 5.14 muestra la señal codificada en potencia óptica, podemos encontrar que cualquier ensanchamiento de los pulsos causará una deformación de la respuesta impulsiva de la señal codificada, que al final ocasionará una deficiente recuperación del pulso original en el extremo decodificador y una pérdida de relación $\frac{P}{C}$. Este mismo razonamiento se puede aplicar a los "chips" individuales una vez codificados y formando parte de la palabra código, que se propagan por un medio dispersivo. La distorsión o ensanchamiento derivados de la dispersión cromática impactarán en el ACP y en la relación $\frac{P}{C}$. Estas fueron las razones que motivaron el estudio de la dispersión sobre los sistemas DS-OCDMA.

En un sistema de comunicaciones cuyo medio de transmisión es la fibra óptica, pueden llegar a afectar dos tipos de dispersión. La primera de ellas conocida como 
dispersión modal que solo es relevante cuando se trabaja con fibras multimodo y la segunda, es la dispersión cromática, dominante en sistemas que utilizan fibras monomodo. La dispersión cromática es consecuencia de la dependencia de $\beta$ con respecto $\omega$, dicha dependencia es más fácil de expresar en términos de una serie de Taylor como

$$
\beta(\omega)=\beta_{0}\left(\omega_{0}\right)+\frac{d \beta_{1}}{d \omega}\left(\omega-\omega_{0}\right)+\frac{1}{2} \frac{d^{2} \beta_{2}}{d \omega^{2}}\left(\omega-\omega_{0}\right)^{2}+\frac{1}{6} \frac{d^{3} \beta_{3}}{d \omega^{3}}\left(\omega-\omega_{0}\right)^{3}+\ldots
$$

de la expresión anterior nos interesa el tercer término, que es el correspondiente a la dispersión cromática de primer orden y cuya influencia en el sistema vamos a analizar. De esta manera y considerando que la fuente óptica que utilizamos es monocromática, podemos decir que la función de transferencia de una fibra óptica es

$$
H(w)=e^{j \frac{1}{2} \beta_{2} \omega^{2} L}
$$

en donde L es la longitud de la fibra óptica existente entre el transmisor y el receptor. En la función de transferencia hemos omitido intencionalmente el término de atenuación ya que nos interesa conocer la magnitud en la que se reduce el pico de autocorrelación por efecto de la dispersión. De esta manera los resultados de las simulaciones que mostraremos a continuación se basan en un esquema que ha sido modelado usando la anterior función de transferencia.

\subsection{Resultados de las Simulaciones}

De acuerdo a las ecuaciones descritas anteriormente, se realizó la programación en Matlab para las respectivas simulaciones de un sistema OCDMA, consistente en una pareja de E/D's basados en redes de difracción de Bragg y entre los cuales se ha instalado fibra óptica. Cada E/D tiene grabado una palabra código de 63 chips de una familia de Gold. Para realizar las simulaciones partimos del hecho de que el fenómeno de dispersión es de naturaleza lineal, razón por la cual la variable que la modela puede ser incluida a la entrada o salida del sistema, o donde realmente afecta, que es sobre la señal codificada viajando por la fibra óptica.

El modelado que se realizo para evaluar el efecto de la dispersión, consistió en construir primero la respuesta impulsiva de la red de difracción de Bragg codificadora. Como ya se ha visto en apartados anteriores, la respuesta impulsiva de la SSFBG es para nuestro caso una secuencia de pulsos gausianos, cada uno con una fase determinada por el código bipolar utilizado. De tal forma que se procedió a generar un tren de pulsos gausianos, con una separación $T_{c}$ entre cada pulso. El ancho de cada pulso de la señal codificada estará determinado por la relación cuadrática que mencionamos en el apartado anterior.

Posteriormente, hallamos la transformada de Fourier a la respuesta impulsiva y la multiplicamos por la función de transferencia de la fibra descrita en la ecuación 5.1, aplicando de esta manera el efecto de dispersión sobre la señal. En seguida hacemos la transformada inversa, la cual finalmente convolucionamos con la respuesta impulsiva del decodificador recuperando así el pulso original. 

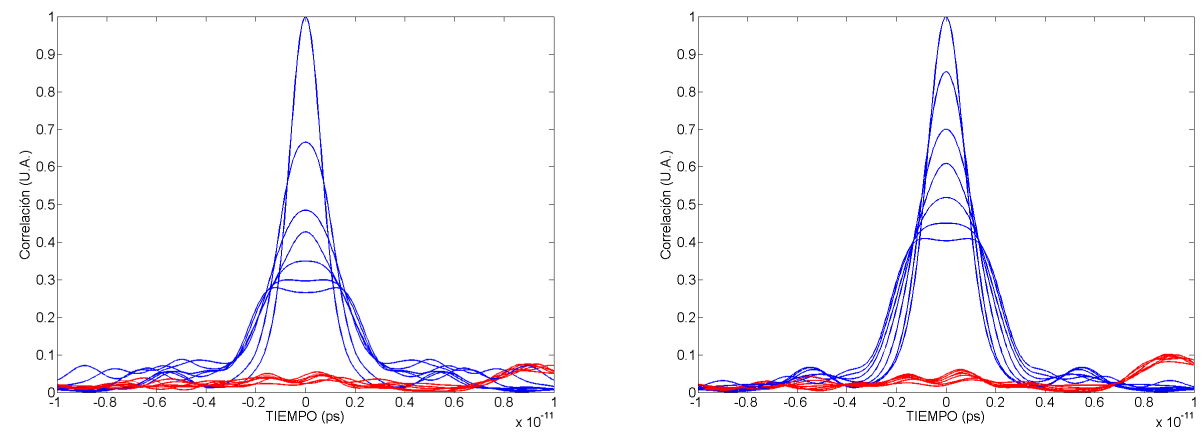

Figura 5.15: Señal de autocorrelación (azul) y correlación cruzada (rojo) para un sistema DS-OCDMA basado en SSFBGs con $L_{c}=0,6 m m$ y pulsos de entrada con $t_{p}=3 p s$ (Izq) y $t_{p}=6 p s$ (Der). Las distancias entre TX y $\mathrm{RX}$ van desde 0 hasta 8.4 $\mathrm{km}$.

La primera simulación se realizó para una SSFBG cuya longitud de chip mide $0.6 \mathrm{~mm}$, lo que corresponde a un $T_{c} \approx 6 p s$ y aplicando una señal de entrada con forma gausiana. Se asignó a la señal de entrada dos posibles valores de duración, 3 y 6 ps.

Los resultados mostrados en la figura 5.15 corresponden con la señal decodificada de un pulso que originalmente mide $t_{p}=3 p s$ (izq) y $t_{p}=6 p s$ (der). Cada una de las curvas describe el comportamiento de la señal después de que ha viajado entre 0 y $8.4 \mathrm{~km}$ de distancia a través de una fibra monomodo con un parámetro de dispersión de $16 \mathrm{ps} / \mathrm{nm} \cdot \mathrm{km}$.

Como se puede ver en la figura 5.15 el pulso de menor duración tiene un factor de ensanchamiento y de atenuación superior que su similar de mayor duración. Adicionalmente, después de $5 \mathrm{~km}$, los pulsos además de ensancharse se empiezan a deformar llegando a ser casi un pulso con doble pico . La señal de correlación cruzada no se ve afectada en la misma magnitud, y solo se observa una ligera reducción en su amplitud a medida que aumenta la longitud que recorre la señal.

En la tabla 5.3 se han tabulado los factores de ensanchamiento y de atenuación encontrando que ambos factores se incrementan a medida que la distancia aumenta. Por otra parte se han colocado las relaciones $\frac{P}{C}$ y $\frac{P}{W}$ que permiten deducir que el pulso de autocorrelación obtenido se ve afectado en mayor medida que la señal de correlación cruzada. Y por lo tanto dichas relaciones disminuyen con la distancia, lo que se traduce en un claro detrimento del sistema en general.

La segunda simulación se realizó para un pareja de E/Ds basados en SSFBGs con un tamaño de chip de $1 \mathrm{~mm}$, que corresponde a un tiempo de chip de $9.6 \mathrm{ps}$. La señal aplicada, también fue de tipo gausiano solo que en esta oportunidad se asignaron valores de duración de pulso de 3 y 8 ps. Aquí vale la pena aclarar que el tiempo de duración del chip $\sigma_{c}$ es el mismo tanto para la SSFBG con $L_{c}=0,6 \mathrm{~mm}$ como la para la que tiene un $L_{c}=1 \mathrm{~mm}$. Por lo tanto, para el caso del pulso de entrada de $3 \mathrm{ps}$ el ensanchamiento inicial, producto de la convolución entre el pulso de entrada y el chip de la red es el mismo y la única diferencia entre ambos experimentos es $T_{c}$, no 


\begin{tabular}{|c|c|c|c|c|c|c|c|c|}
\hline & \multicolumn{3}{|c|}{ Pulso de entrada de 3ps } & \multicolumn{4}{c|}{ Pulso de entrada de 6 ps } \\
\hline \hline Longitud $(\mathrm{Km})$ & FE & $\mathrm{D}(\mathrm{dB})$ & $\frac{P}{C}$ & $\frac{P}{W}$ & FE & D $(\mathrm{dB})$ & $\frac{P}{C}$ & $\frac{P}{W}$ \\
\hline 1.4 & 1.7 & 1.77 & 9.6 & 21.7 & 1.2 & 0.7 & 10.2 & 23 \\
\hline 2.8 & 2.27 & 3.15 & 7.1 & 16.5 & 1.52 & 1.55 & 8.4 & 19 \\
\hline 4.2 & 2.35 & 3.7 & 7 & 16 & 1.82 & 2.16 & 8.2 & 17.4 \\
\hline 5.6 & 2.85 & 4.57 & 6 & 13.8 & 2.4 & 2.85 & 7.5 & 15.5 \\
\hline 7 & 3.34 & $\sim 5,22$ & 5.4 & 12.5 & 2.6 & 3.47 & 6.7 & 14 \\
\hline \hline 8.4 & 3.66 & $\sim 5,68$ & 5 & 12.5 & 2.8 & 3.9 & 6.35 & 13.5 \\
\hline
\end{tabular}

Cuadro 5.3: Resumen del Factor de Ensanchamiento (FE) del pulso y del decremento de la amplitud del pico de potencia (D) causado por efecto de la dispersión, para señales de entrada de 3 y 6 ps. $l_{c}=0,6 \mathrm{~mm}$

obstante, lo resultados obtenidos son muy diferentes.

Analicemos primero lo que pasa con los pulsos de 3 y 8 ps en su recorrido por la SSFBG con $L_{c}=1 \mathrm{~mm}$. Por una parte vemos que el pulso de $3 \mathrm{ps}$ se deforma recorriendo tan solo $3 \mathrm{~km}$ de longitud mientras que el de 8 ps se deforma a los $4.2 \mathrm{~km}$, lo cual se debe a la diferencia de duración entre pulsos, entre más ancho sean, menores son los efectos de la dispersión. Si ahora comparamos lo que sucede con el pulso de $3 \mathrm{ps}$ en la SSFBG con $L_{c}=0,6 \mathrm{~mm}$ con respecto a la SSFBG con $L_{c}=1 \mathrm{~mm}$ vemos que el pulso se deforma primero en la SSFBG con $L_{c}$ mayor. Con base en lo anterior se puede ver que el efecto de la dispersión sobre la señal decodificada, además de depender de la longitud recorrida por la señal y de la anchura del pulso inicial también depende de la longitud de chip. No obstante, la dependencia con respecto a la longitud de chip no sigue un patrón establecido si no que a su vez dependerá también del código que estemos usando. Para ilustrarlo podemos ver en la figura 5.16 las simulaciones realizadas para dos códigos adicionales en donde vemos que el pulso se deforma en cada caso de manera diferente. Para explicar la deformación que sufre el pulso basta con recordar que al decodificar la señal no obtenemos exactamente el pulso original, si no un pulso más wings. Dichos wings también sufren el ensanchamiento producido por la dispersión, y terminan solapándose en tiempo y sumándose en campo constructiva o destructivamente, generando los picos y valles que deforman el pulso y que podemos ver en las simulaciones.

El respectivo resumen de los resultados de la simulación se encuentran consignados en la tabla 5.4. Es importante resaltar que los datos tomados pretenden ilustrar el fenómeno de ensanchamiento que sufre el pulso debido a la dispersión. Sin embargo por las deformaciones particulares que se tienen en cada caso no es posible realizar una extrapolación general. Aun así podemos ver que la dispersión afecta de peor manera a los pulsos de entrada más estrechos y que el efecto sobre la correlación cruzada es insignificante, por lo que la relación $\frac{P}{C}$ disminuye con la distancia. Los wings que hasta el momento no habíamos mencionado tampoco sufren una reducción significativa y por lo tanto ocasionan que la relación $\frac{P}{W}$ también decrezca.

En la figura 5.18se muestra las curvas de ensanchamiento y decremento de la amplitud del pico de potencia para cada una de las simulaciones realizadas.

La simulación con pulsos más anchos y por lo tanto menos afectados por la dis- 

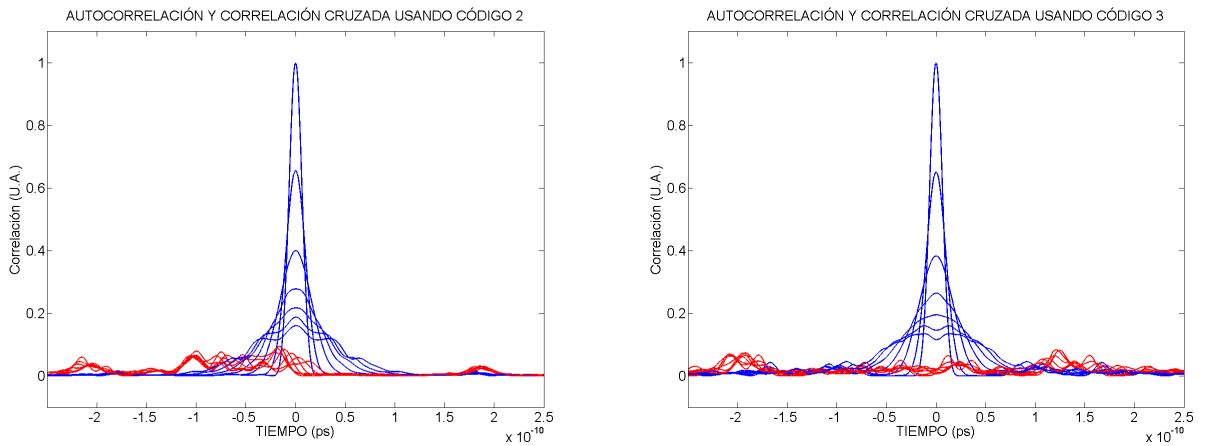

Figura 5.16: Picos de Autocorrelación y correlación cruzada para los códigos 2 (Izq) y 3 (Der) después de recorrer desde 0 hasta $8.4 \mathrm{Km} . L_{c}=1 \mathrm{~mm}$
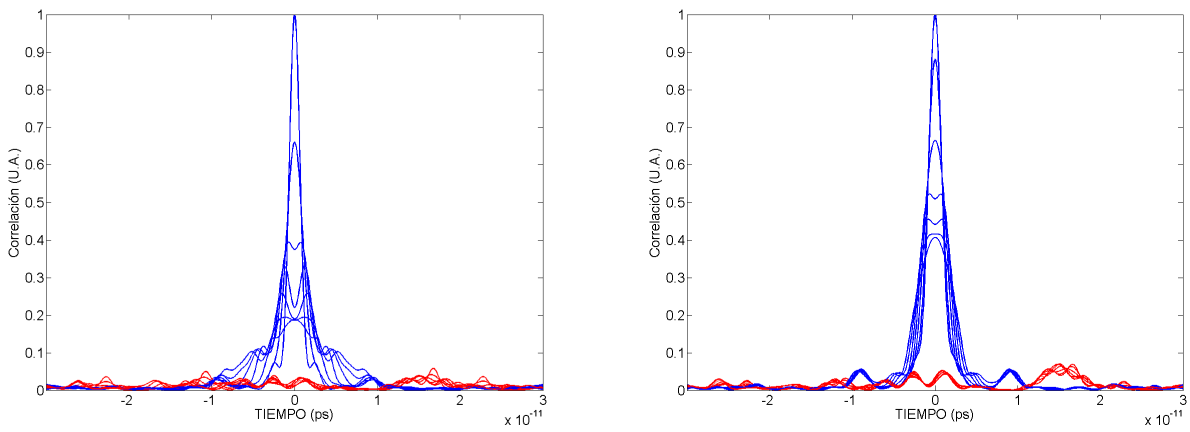

Figura 5.17: Señal decodificada en un sistema DS-OCDMA basado en SSFBGs de $1 \mathrm{~mm}$ de chip con pulsos de entrada de $t_{p}=3 p s$ (izq) y $t_{p}=8 p s$ (der). Las distancias entre TX y RX van desde 0 hasta $8.4 \mathrm{~km}$.

\begin{tabular}{|c|c|c|c|c|c|c|c|c|}
\hline & \multicolumn{3}{|c|}{ Pulso de entrada de 3ps } & \multicolumn{5}{|c|}{ Pulso de entrada de 8 ps } \\
\hline \hline Longitud (Km) & FE & D (dB) & $\frac{P}{C}$ & $\frac{P}{W}$ & FE & D (dB) & $\frac{P}{C}$ & $\frac{P}{W}$ \\
\hline 1.4 & 1.76 & 1.8 & 18.9 & 45 & 1.17 & 0.54 & 24 & 51 \\
\hline 2.8 & 3.18 & 3.9 & 15.6 & 31 & 1.85 & 1.7 & 18 & 38 \\
\hline 4.2 & 3.7 & 4.8 & 13 & 15 & 2.55 & 2.8 & 14 & 30 \\
\hline 5.6 & 4.6 & 6 & 9.8 & 10 & 2.88 & 3.4 & 10 & 14 \\
\hline 7 & 5.6 & 7.2 & 6.2 & 6 & 3.1 & 3.8 & 9.6 & 12 \\
\hline \hline 8.4 & 5.7 & 7.4 & 6 & 6 & 3.1 & 3.9 & 9.5 & 11 \\
\hline
\end{tabular}

Cuadro 5.4: Resumen del factor de ensanchamiento (FE) del pulso y del decremento de la amplitud del pico de potencia (D) causado por efecto de la dispersión, para señales de entrada de 3 y 8 ps. $l_{c}=1 \mathrm{~mm}$ 

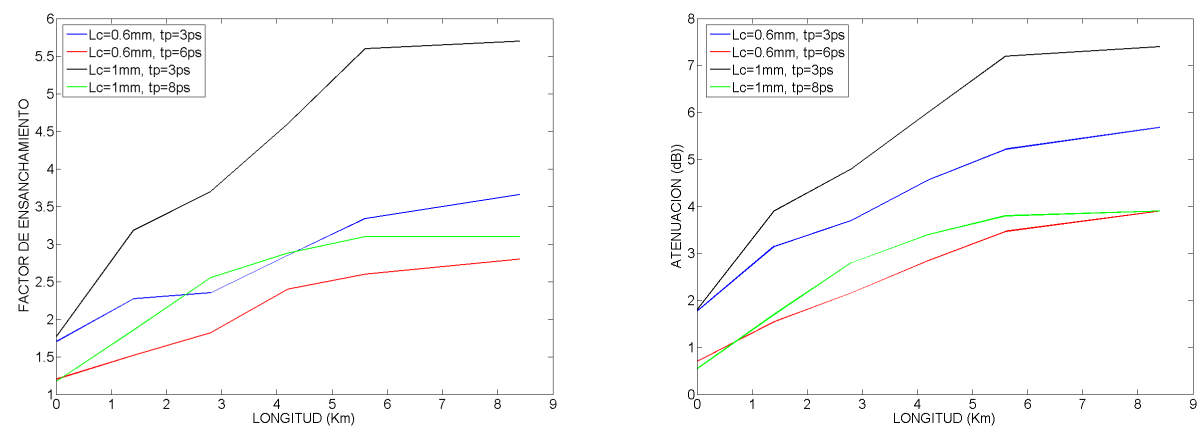

Figura 5.18: Curvas de Ensanchamiento vs. Longitud y de Decremento del pico de potencia vs. Longitud cuando se propaga la señal a través de una fibra óptica monomodo con un parámetro dispersión de $16 \mathrm{ps} \cdot \mathrm{nm} / \mathrm{km}$.

persión permiten ver que el comportamiento de una SSFBG con $L_{c}=0,6 m m$ y de una SSFBG con $L_{c}=1 \mathrm{~mm}$ son muy similares tanto en atenuación como en su factor de ensanchamiento. Esto es porque el $\sigma_{c}$ (ancho de los chips) que se ha asignado a las SSFBGs es el mismo para ambos casos, y mientras el tiempo de pulso sea inferior a $T_{c}$ las condiciones de codificación y decodificación no se modificará significativamente entre una y otra SSFBG.

Finalmente podemos decir que la implementación de sistemas OCDMA es viable en soluciones de última milla, ya que la dispersión no lo afecta de manera importante en distancias cortas. No hay que olvidar que el comportamiento de la señal recuperada dependerá en gran medida del tipo de código que se este utilizando, y que su uso en largas distancias deberá venir acompañado con el uso de fibras compensadoras de dispersión o mediante algún mecanismo que realice dicha compensación.

\subsection{Verificación Experimental}

Para verificar experimentalmente los datos mostrados en el apartado anterior, se realizó el montaje de la figura 5.19. Al igual que en los experimentos anteriores se trabajó con una fuente pulsada a $1.25 \mathrm{GHz}$, centrada a una longitud de onda de $1538 \mathrm{~nm}$, y que emite pulsos de aproximadamente 5 ps de duración. Los dispositivos E/Ds utilizados están basados en redes de difracción de Bragg a las cuales se les ha grabado las palabras código de Gold de 63 chips, correspondientes al código 1 y al código 2. Para el experimento se fabricaron dos parejas codificadoras decodificadoras, una de ellas con tamaño de chip de $0.6 \mathrm{~mm}$ y la otra con $1 \mathrm{~mm}$. Cada SSFBG fue puesta dentro de su caja controladora de temperatura para realizar la sintonía en longitud de onda, tal como se explicó en la sección 3.6. El codificador y el decodificador se interconectaron usando fibra óptica monomodo con un parámetro de dispersión de $16 \mathrm{ps} / \mathrm{nm} \cdot \mathrm{km}$. Más exactamente se usaron 4 rollos de $1.4 \mathrm{~km}$ y uno de $2.8 \mathrm{~km}$, para una máxima longitud de $8.4 \mathrm{~km}$.

Después del dispositivo codificador se utilizó un EDFA de ganancia fija igual a 


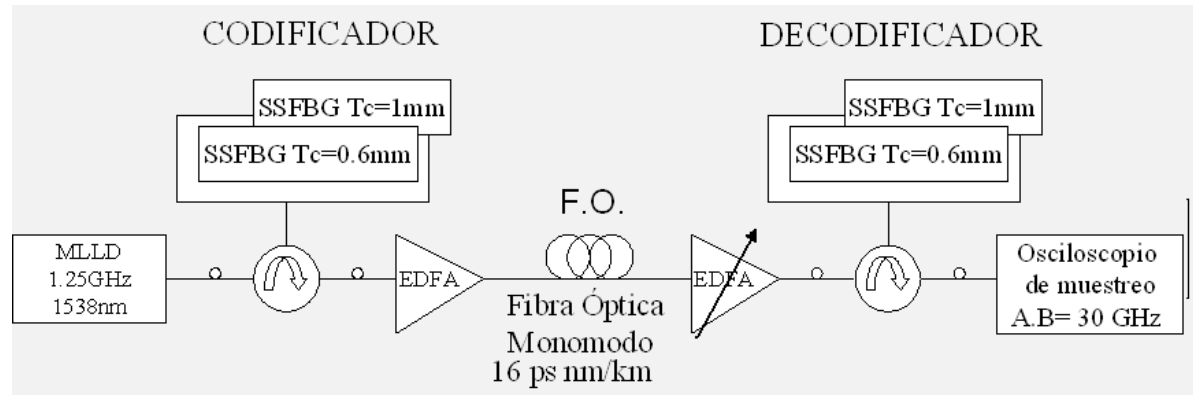

Figura 5.19: Diagrama de bloques del montaje realizado para medir el efecto de dispersión.

\begin{tabular}{|c|c|c|c|c|c|c|c|c|}
\hline & \multicolumn{3}{|c|}{ EXPERIMENTO } & \multicolumn{5}{c|}{ SIMULACIÓN } \\
\hline \hline Longitud (Km) & FE & $\mathrm{D}(\mathrm{dB})$ & $\frac{P}{C}$ & $\frac{P}{W}$ & FE & $\mathrm{D}(\mathrm{dB})$ & $\frac{P}{C}$ & $\frac{P}{W}$ \\
\hline 1.4 & 1.35 & 1.1 & 9 & 10 & 1.4 & 0.96 & 10 & 16 \\
\hline 2.8 & 1.83 & 2.3 & 7.5 & 8.5 & 1.86 & 2 & 7.8 & 12.6 \\
\hline 4.2 & 2.3 & 3.2 & 5.6 & 7 & 1.98 & 2.6 & 6.8 & 11 \\
\hline 5.6 & 2.7 & 4.5 & 4.3 & 6 & 2.39 & 3.3 & 5.7 & 9.2 \\
\hline 8.4 & 3.3 & 5.1 & 3 & 6 & 3 & 4.3 & 4.5 & 7.2 \\
\hline
\end{tabular}

Cuadro 5.5: Resultados experimentales vs. los de la simulación, del factor de ensanchamiento (FE) del pulso y del decremento de la amplitud del pico de potencia (D) causado por efecto de la dispersión. $l_{c}=0,6 \mathrm{~mm}$

20 dB que compensa las pérdidas de inserción del dispositivo. Además en seguida de la fibra también se conecto otro amplificador, pero esta vez de ganancia variable, con el objeto de compensar las pérdidas insertadas por cada tramo de fibra y así garantizar que siempre se tendría la misma potencia óptica promedio en el receptor. De esta manera se aseguraba que las mediciones realizadas, tanto de amplitud como de duración del pulso, fuesen correctas. Como elemento receptor se usó un osciloscopio de muestreo con un ancho de banda de $30 \mathrm{GHz}$.

En la figura 5.20 vemos los resultados experimentales obtenidos para el caso en que el chip tiene una longitud de $0.6 \mathrm{~mm}$, comparados con los obtenidos mediante simulación. Las medidas experimentales se aproximan relativamente bien a lo mostrado por la simulación. A medida que la señal avanza por la fibra óptica la dispersión actúa sobre ella produciendo un ensanchamiento del pulso y una disminución de potencia en el pico. Cabe aclarar que la disminución de la amplitud no significa una pérdida de potencia, ya que la potencia óptica promedio se mantiene. También se observa como después de los $5.6 \mathrm{~km}$ la señal además de ensancharse empieza a deformarse levemente. La tabla 5.5 compara los resultados de la simulación y los valores experimentales, mostrando una correspondencia en los valores obtenidos.

De la misma manera se realizaron los experimentos con los dispositivos E/Ds con longitud de chip de 1mm. Los resultados obtenidos mediante la simulación y su respectiva verificación experimental se encuentran dados en la figura 5.21. Al igual que en 


\begin{tabular}{|c|c|c|c|c|c|c|c|c|}
\hline & \multicolumn{4}{|c|}{ EXPERIMENTO } & \multicolumn{4}{c|}{ SIMULACION } \\
\hline \hline Longitud (Km) & FE (ps) & $\mathrm{D}(\mathrm{dB})$ & $\frac{P}{C}$ & $\frac{P}{W}$ & FE $(\mathrm{ps})$ & $\mathrm{D}(\mathrm{dB})$ & $\frac{P}{C}$ & $\frac{P}{W}$ \\
\hline 1.4 & 1.4 & 1 & 13 & 24 & 1.3 & 1.13 & 15.4 & 25 \\
\hline 2.8 & 2.7 & 3 & 8.3 & 17 & 2.4 & 3.1 & 11.5 & 18 \\
\hline 4.2 & 3.1 & 3.2 & 8 & 11 & 3 & 4 & 8.8 & 12 \\
\hline 5.6 & 4.1 & 5 & 6.6 & 7 & 3.6 & 4.9 & 6.6 & 10 \\
\hline 8.4 & 5 & 5.6 & 6 & 8 & 4.2 & 5.8 & 5.4 & 9 \\
\hline
\end{tabular}

Cuadro 5.6: Resultados experimentales vs. los de la simulación, del factor ensanchamiento (FE) del pulso y del decremento de la amplitud del pico de potencia (D) causado por efecto de la dispersión. $l_{c}=1 \mathrm{~mm}$

el caso anterior no existe una correspondencia exacta entre los datos experimentales con los simulados, no obstante es innegable que existen patrones similares. La diferencia se debe principalmente a que mientras en la simulación conocemos los valores asignados a las variables $\sigma_{c}$ y $t_{p}$, en los experimentos dichos parámetros son difíciles de determinar con la misma exactitud. Aun así podemos ver que el pulso recuperado con la SSFBG de $1 \mathrm{~mm}$ tiende a dividirse en dos tal y como sucede en la simulación, solo que no existe una coincidencia en la distancia. Los resultados para el experimento con la SSFBG de $1 \mathrm{~mm}$ quedan consignados en la tabla 5.6.

En conclusión podemos decir que la dispersión en los sistemas OCDMA es aceptable en distancias no superiores a los dos kilómetros y por ello su aplicabilidad en soluciones de última milla. Por ejemplo es posible implementar sistemas OCDMA en redes FTTH o FTTC, con las cuales se da acceso a múltiples usuarios, sin llegar a perder calidad como consecuencia por la dispersión. Sin embargo en aplicaciones donde la señal debe recorrer distancias largas, como por ejemplo direccionamiento mediante etiquetas ópticas, la opción de codificar y decodificar la señal deberá de ir acompañada de técnicas de compensación de la dispersión. 


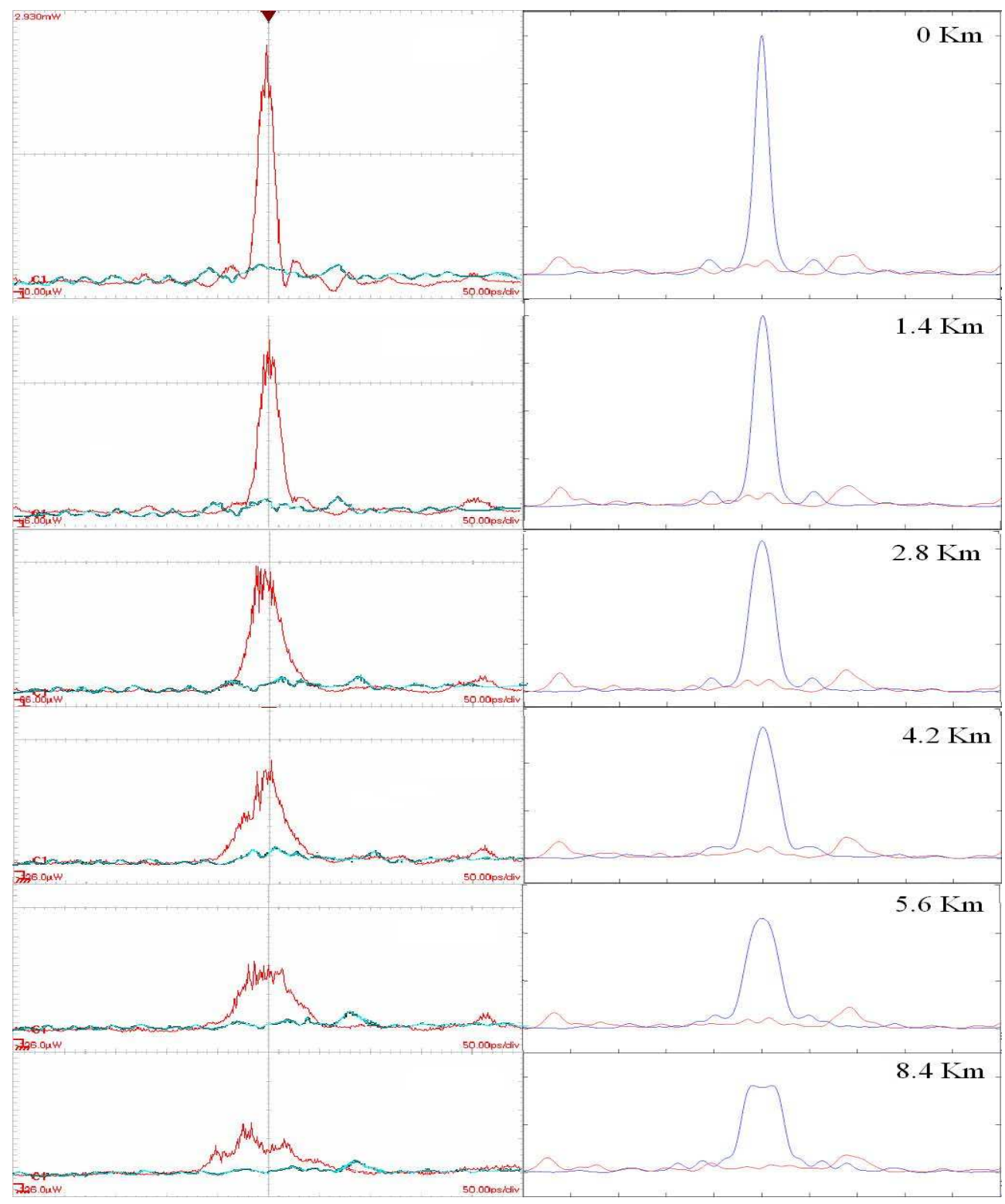

Figura 5.20: Comparación entre los resultados experimentales y los simulados para $\mathrm{E} / \mathrm{Ds} \operatorname{con} l_{c}=0,6 m m$ y $t_{p}=5 p s$. 


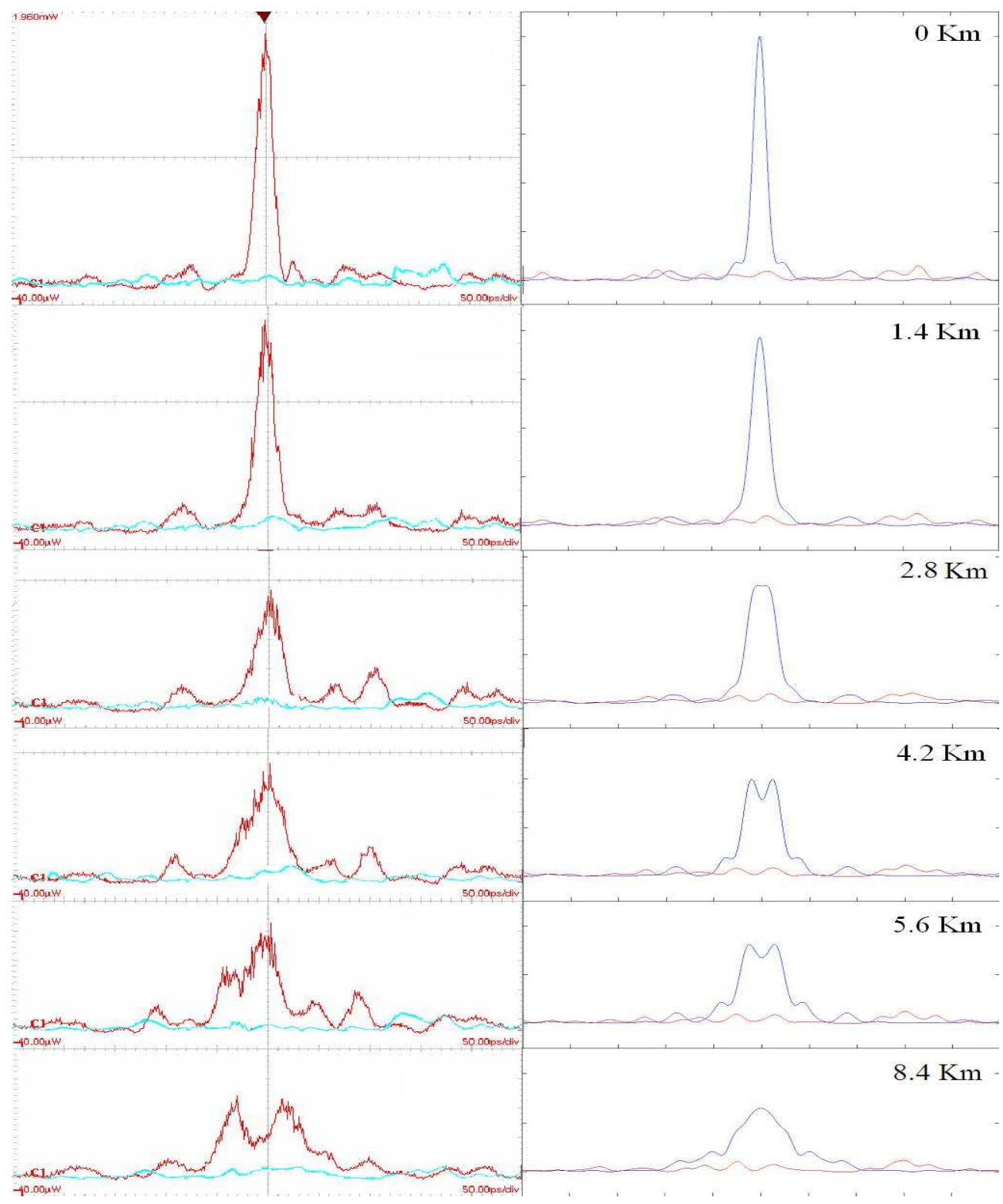

Figura 5.21: Comparación entre los resultados experimentales y los simulados para $\mathrm{E} / \mathrm{Ds} \operatorname{con} l_{c}=1 \mathrm{~mm}$ y $t_{p}=5 p s$. 



\section{Capítulo 6}

\section{SISTEMAS OCDMA INCOHERENTES 2D}

\subsection{Introducción}

Desde las primeras investigaciones realizadas para el desarrollo de sistemas OCDMA se han propuesto diferentes esquemas para su implementación. Básicamente existen dos posibilidades con muchas variantes en cada una de ellas, dichas posibilidades son: realizar una codificación de la potencia óptica con lo cual tendríamos una codificación de tipo incoherente, ó una codificación en campo con lo que obtendríamos una codificación de tipo coherente. Los sistemas coherentes se ven seriamente afectados por el ruido de batido, que se da cuando la señal decodificada correctamente se solapa con la interferencia de múltiple acceso, producida por los otros usuarios presentes en el sistema [11]. Se han planteado algunas soluciones para este problema, como por ejemplo coordinar los recursos de los usuarios, llegando a sincronizar a nivel de bit [45] ó asignando un slot de tiempo a cada bit [41]. Otra solución que en principio es bastante acertada es la de usar códigos muy largos para minimizar la amplitud del MAI y manteniendo la asincronía del sistema, no obstante en un código de 511 chips, por ejemplo, solo 10 de los 512 códigos posibles garantizan una BER inferior a $10^{-9}$ [32]. Por otra parte los sistemas incoherentes son menos susceptibles a la interferencia de tipo coherente [38] pero deficientes espectralmente. En los anteriores capítulos hemos trabajado con sistemas coherentes analizando sus ventajas y desventajas, en el presente capítulo describiremos brevemente lo que son los sistemas incoherentes y realizaremos un primer experimento para evaluar el grado de coherencia o incoherencia del sistema en condiciones de cierto solapamiento espectral. A continuación se aborda el montaje parcial de la propuesta hecha en [57] con sistemas incoherentes que trabajan con códigos $2 \mathrm{D}$ con objeto de obtener conclusiones de nivel práctico sobre la viabilidad de los sistemas incoherentes.

En los sistemas incoherentes a cada usuario se le asigna un código y se envía una señal codificada para representar un 1 y no se envía nada cuando se quiere representar un cero. Aunque también se ha propuesto que a cada usuario le sean asignados dos 
códigos, uno para transmitir los bits 1's y otro para codificar los bits 0's con posterior detección diferencial, teniendo como objetivo reducir el impacto del ruido y la interferencia [87]. En los sistemas OCDMA incoherentes se usan códigos unipolares, razón por la cual no existen componentes negativas de la señal. El uso de códigos unipolares hace que los sistemas incoherentes tengan una baja eficiencia espectral, ya que para conseguir óptimas propiedades de autocorrelación y correlación cruzada se requieren códigos bastante largos. Los sistemas OCDMA incoherente más conocidos, están basado en codificación en amplitud espectral [88], codificación espacial [89], ensanchamiento temporal [12, 2], y codificación en dos dimensiones, en longitud de onda y tiempo [90].

Las primeras demostraciones de sistemas OCDMA se basaban en codificación de tipo incoherente, más exactamente la conocida como de ensanchamiento temporal, en donde cada período de bit es dividido en $\mathrm{N}$ intervalos ( $\mathrm{N}$ es el número de chips del código) y se transmite un número de pulsos (chips) de acuerdo al peso del código que se este utilizando. Sin embargo este tipo de sistemas resultaba muy limitado por la larga longitud de los códigos que se deben utilizar y por la necesidad de usar pulsos estrechos [12]. Casi simultáneamente se trabajó con codificación espacial de diferentes formas; en sistemas de múltiples fibras usando líneas de retardo acopladas para decodificar [91], en transmisión paralela y acceso simultáneo de imágenes usando fibras multinúcleo [89], usando máscaras espaciales en 2D para codificación específica de patrones en secuencias de código, y esquemas temporal/espacial usando fibras multimodo[92]. En estos esquemas para poder construir los cod/decodificadores se presenta el inconveniente de requerir un acoplador en estrella por cada camino espacial que se este utilizando y a la vez el mismo número de caminos ópticos según los puertos del acoplador [93].

La codificación en amplitud espectral se realiza mediante la descomposición del espectro de una fuente de luz de banda ancha seguida de un elemento óptico que pueda modular la intensidad de cada componente antes de volverla a combinar. Como dispositivos codificadores se han usado redes de difracción con mascaras de amplitudespacial [94], y también filtros con función de transferencia espectral periódica[95]. Como fuentes de luz se han usado las de tipo incoherente como LED's (Light-Emitting Diode), diodos súper luminiscentes (SLD's) y fuentes basadas en Amplificadores de fibra dopada con Erbio (EDFA) con las que se ha demostrado la posibilidad de conseguir un acceso a la red a velocidades de $155 \mathrm{Mbps}$ sin control espectral ni estabilización de la longitud de onda [95], o de tipo coherente como fuentes pulsadas MLL (Mode Locked Laser) [96, 39] y fuentes de Supercontinuo [97].

En los sistemas incoherentes anteriormente citados se usan principalmente códigos ópticos ortogonales (OOCs) como los descritos en [98, 99], dichos códigos tienen la ventaja de ser fácilmente implementables pero el gran inconveniente de ser necesariamente largos, lo que produce la baja eficiencia espectral. No obstante, existe otro tipo de códigos que busca compensar las debilidades de los OOC, nos referimos a los códigos en dos dimensiones (2D). Existen diferentes tipos de códigos 2D, entre los cuales destacan; los de tiempo ensanchado y salto en frecuencia [4, 100], los de tipo DFS (Depth-First search) [101, 102], los códigos primos 2D [103, 104], los códigos sonar [92] y los códigos folded optimum Golomb ruler (FOGR) [105, 106].

Los códigos 2D tienen un mayor rendimiento porque consiguen obtener simultánea- 
mente las siguientes características [57]:

- Tener una alta cardinalidad $(>>10)$;

- Permitir una alta tasa de datos por usuario (>1Gbps);

- Tener una alta eficiencia espectral $(>0.1 \mathrm{bps} / \mathrm{Hz}$ y potencialmente hasta $0.5 \mathrm{bps} / \mathrm{Hz})$.

Dichos códigos combinan normalmente longitud de onda y tiempo como las dos dimensiones del código. De esta manera el sistema realiza primero una división en longitud de onda de la señal y posteriormente una asignación de tiempo a cada una de las componentes espectrales. La asignación de tiempo se realiza configurando un número de líneas de retardo de acuerdo al tamaño del código utilizado. El tamaño de cada slot de longitud de onda estará determinado por el dispositivo que se use para realizarlo, usualmente se usan AWG (Arrayed Waveguide Gratings) cuyo espaciado entre canales puede oscilar entre los 50 a $200 \mathrm{GHz}$.

No obstante, queda la pregunta de ¿Cuál debe ser el tamaño mínimo que se requiere para tener un sistema incoherente? o si ¿Es posible llegar a minimizar dicho tamaño de canal?. Con el objeto de responder esta pregunta, en el siguiente apartado se ha realizado un sencillo experimento que nos permite comprobar cual es el tamaño mínimo de canal que se necesita para implementar un sistema de este tipo. Y finalmente con el objeto de comprobar algunas características de los sistemas incoherentes se realizó un montaje parcial de la propuesta hecha en [57] y con cuyo informe concluiremos el presente capítulo.

\subsection{Diferencia Mínima de Frecuencia Entre Canales para Sistemas Incoherentes}

Para implementar un sistema incoherente con códigos 2D lo que se hace inicialmente es fraccionar el espectro disponible y asignar longitudes de onda y slots de tiempo a los usuarios de acuerdo al código asignado. El número de canales de frecuencia requeridos para la implementación, estará determinado por la estructura del código $2 \mathrm{D}$ que vayamos a utilizar. El tamaño de cada canal deberá garantizar la máxima eficiencia espectral y a la vez ser suficientemente grande para que no se introduzca en el sistema ruido por el batido de las señales interferentes. Para determinar el tamaño óptimo del canal se deben tener en cuenta varios criterios. Empezaremos por recordar la ecuación general (6.1) que describe la señal detectada mediante un fotodetector con respuesta de ley cuadrática, en un sistema OCDMA modelado como en la sección 2.2. Cuando analizábamos dicha ecuación nos deteníamos específicamente en los términos de batido de primer y segundo orden y mas exactamente en sus términos de fase. Decíamos que la coherencia o incoherencia del sistema dependería de que tan similares fuesen los valores del tiempo de coherencia de la luz $\left(\tau_{c}\right)$ y el tiempo de chip $\left(T_{c}\right)$. Si $\tau_{c}>T_{c}$ el sistema es coherente, pero si $\tau_{c}<T_{c}$ el sistema podía ser parcialmente o totalmente incoherente dependiendo de que tan mayor fuese $T_{c}$ con respecto a $\tau_{c}$. En términos prácticos podríamos decir que el sistema es incoherente cuando $T_{c}>10 \tau_{c}$, ya que por encima de este valor, la fase se comportará como un proceso 
aleatorio uniformemente distribuido entre $[-\pi, \pi]$ que ocasiona que los términos de batido desaparezcan. Si la diferencia es menor hay que tener en cuenta que existirá cierta cantidad de ruido de batido.

Como se ha comentado anteriormente, en general los sistemas incoherentes 2D se pueden implementar empleando tanto fuentes ópticas de naturaleza incoherente como LEDs o EDFAs, o bien fuentes ópticas pulsadas de tipo coherente como los MLL (Mode Locked Laser). En este último caso se aprovecha la mayor potencia óptica generada por las mismas frente a la baja densidad espectral obtenida con fuente de ruido ASE o de tipo LED. La "incoherencia" del sistema de codificación 2D en este caso debe venir asegurada por el nulo solapamiento espectral y/o temporal entre códigos.

$$
\begin{aligned}
& Z=\underbrace{T_{c} \Re P_{d}}_{\text {Dato }}+\underbrace{T_{c} \Re \sum_{i=1}^{m} P_{i}}_{M A I}+\underbrace{2 \Re \sum_{i=1}^{m} \sqrt{P_{d} P_{i}} \times \int_{0}^{T_{c}} \cos \left(\left(\omega_{i}-\omega_{d}\right) t-\omega_{i} \tau_{i}+\phi_{d}(t)\right) d t}_{\text {TERMINOS DE BATIDO DE PRIMERORDEN }} \\
& +\underbrace{2 \Re \sum_{j=i+1}^{m} \sum_{i=1}^{m-1} \sqrt{P_{i} P_{j}} \times \int_{0}^{T_{c}} \cos \left(\left(\omega_{i}-\omega_{j}\right) t-\omega_{i} \tau_{i}+\omega_{j} \tau_{j}+\phi_{i}\left(t-\tau_{i}\right)-\phi_{j}\left(t-\tau_{j}\right)\right) d t} \\
& \text { TERMINOS DE BATIDO DE SEGUNDOORDEN } \\
& +\underbrace{\int_{0}^{T_{c}} \eta_{0}(t) d t}_{R U I D O D E R E C E P T O R}
\end{aligned}
$$

En nuestro caso particular la fuente MLL proporciona pulsos de entre 2 ps y 5 ps lo que supone una extensión máxima del espectro de aproximadamente $500 \mathrm{GHz}$. Dicha franja se deberá aprovechar al máximo utilizando filtros AWG de $50 \mathrm{GHz}$ de banda pasante para obtener el máximo numero de canales de frecuencia del código $2 \mathrm{D}$, pero a la vez asegurando la mínima interferencia debida a batido coherente entre códigos.

Con el objeto de encontrar el punto a partir del cual se puede considerar el sistema como incoherente, se realizo el montaje que se muestra en la figura 6.1. Con este montaje mediremos el ruido de batido que se da entre dos canales adyacentes y con ello determinaremos la separación mínima entre canales.

El experimento planteado consiste en tomar dos canales, uno al que llamaremos canal de datos y otro que llamaremos canal interferente, los dos canales se irán superponiendo uno sobre el otro encontrando los valores para los cuales tenemos máxima interferencia y aquellos en que la interferencia podría asumirse como despreciable. Para este experimento se uso una fuente MLLD pulsada a $10 \mathrm{GHz}$ trabajando en tercera ventana, el tamaño del pulso emitido por la fuente es de 5 ps aproximadamente. La señal es dividida en partes iguales para ser aplicada a dos AWG's. El primer AWG truncara el espectro de la fuente, seleccionando el canal de datos. El segundo AWG hará lo mismo, pero en este caso el canal será usado como canal interferente. El canal de datos se mantendrá fijo en frecuencia mientras el espectro del canal interferente será desplazado usando el control de temperatura del segundo AWG, de esta 


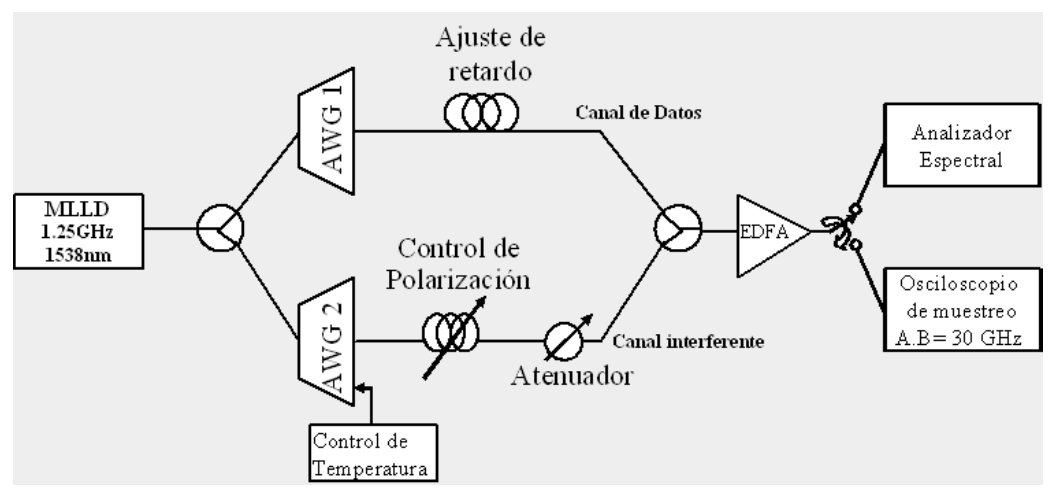

Figura 6.1: Diagrama de bloques para medir la separación mínima de frecuencia entre canales y el efecto de batido en campo.

forma podremos observar como influye la variación de frecuencias en la interferencia producida.

Para mostrar los canales que vamos a usar, se iluminaron con luz blanca los AWG obteniendo así los espectros que se ven en la figura 6.2. El espectro de datos corresponde al canal 15 del primer AWG y el espectro que se ha llamado interferente 1 corresponde al canal 6 del segundo AWG. El canal interferente se desplazara para realizar un barrido completo sobre el canal de datos. Como se puede observar el máximo del canal interferente no coincide con el máximo del canal de datos, por esta razón y para complementar las mediciones se usa el canal 5 del segundo AWG como un canal al que llamaremos interferente 2 .

Todos los canales tienen un ancho de banda de $100 \mathrm{GHz}(0.8 \mathrm{~nm})$. El canal de datos estará centrado a la misma longitud de onda que la fuente pulsada. La potencia de los canales interferentes dependerá de su posición con respecto a la longitud de onda, ya que si recordamos el espectro de la fuente pulsada mostrado en la figura 3.9 veremos que su potencia no es constante, por esta razón a medida que se aleja del centro del espectro, la potencia disminuye.

Para garantizar la mayor objetividad en el experimento se puede ver en la figura 6.1 que después del AWG que lleva la señal de datos existe un dispositivo que permite ajustar los tiempos de retardo. Este ajuste se realiza para que tanto la señal de datos como la interferente coincidan exactamente en tiempo. Adicionalmente después del AWG correspondiente al canal interferente se coloco un controlador de polarización que permite hacer barridos de todos los posibles estados de polarización descritos en una esfera de Poincare, de tal manera, que la señal interferente sea totalmente aleatoria tanto en polarización como en fase. Además como el espectro de la señal interferente será desplazado se podrá llegar a tener variaciones en potencia, por lo que se ajusta mediante un atenuador variable colocado a la salida del controlador de polarización .

Finalmente las señales son combinadas y amplificadas mediante un EDFA de 20 $\mathrm{dB}$, para ser medidas con el analizador de espectro óptico (OSA) y con el osciloscopio.

Para iniciar las mediciones se tomo como referencia el canal número 5 por ser 


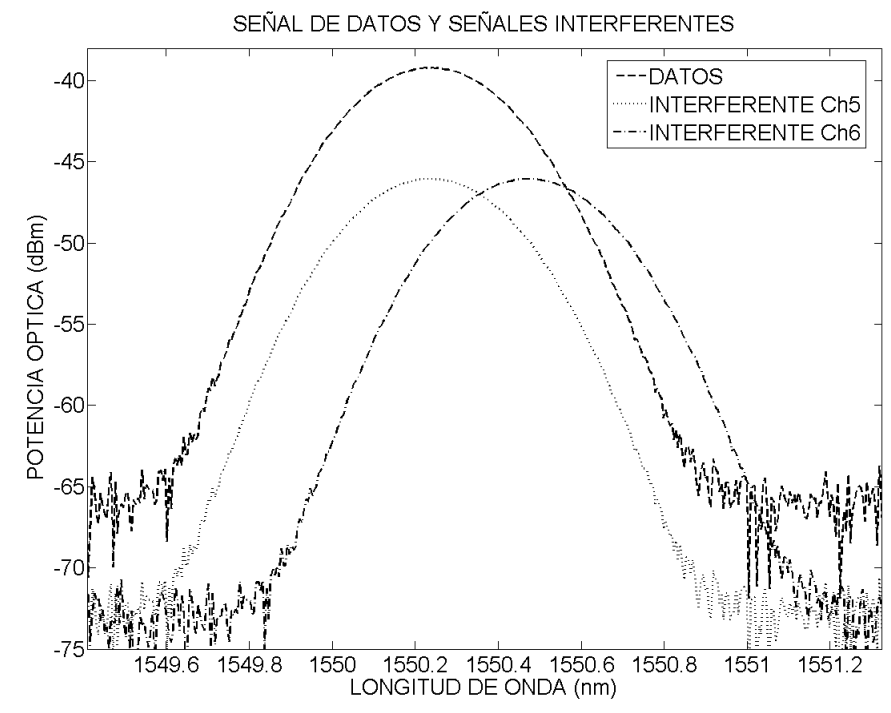

Figura 6.2: Espectros de los canales de los AWG's utilizados.

el canal con el que se logró la máxima interferencia. El espectro del canal de datos estará centrado a una longitud de $1550.27 \mathrm{~nm}$ y el canal que servirá como interferente 1 estará centrado en 1550.102 nm., lo que significa que estará desplazado hacia la izquierda del espectro de datos. La figura 6.3 muestra el espectro del canal de datos y el canal interferente, ambos obtenidos a partir del filtrado de la fuente pulsada por los AWG's correspondientes. La figura 6.3 también nos muestra el punto de inicio de desplazamiento del canal interferente hacia longitudes de onda mayores.

Según la figura 6.3 se puede ver que la diferencia de potencia entre las señales es de $6 \mathrm{~dB}$, y en longitud de onda $\Delta \lambda=168 \mathrm{pm}$. Estos mismos canales en el tiempo pueden ser vistos en la figura 6.4.

Lo que vemos en la figura 6.4 son realmente los histogramas del canal de datos y el interferente obtenidos con el osciloscopio de muestreo de 30GHz. De estas gráficas podemos observar varios aspectos, el primero es que al estar el osciloscopio limitado en ancho de banda el pulso sufre un ensanchamiento considerable. Segundo, las señales de ambos canales no están perfectamente delineadas, si no que por el contrario tienen una franja de incertidumbre causada por el ruido térmico de los elementos eléctricos y el jitter propio de la fuente.

La figura 6.4 es el histograma de las señales, cada color en la gráfica muestra una mayor o menor cantidad de ocurrencia ó pasos por determinando punto. En este caso el negro mostrara los valores que ocurren más frecuentemente y el amarillo para los menos frecuentes. Aunque la gama de colores puede no aparecer muy clara en estas figuras, se puede inferir que los valores de mayor ocurrencia estarán hacia el valor medio del pulso y a medida que se acercan a los bordes del pulso su ocurrencia será menor.

La figura 6.3(Der) muestra el resultado de combinar los pulsos mostrados en las 

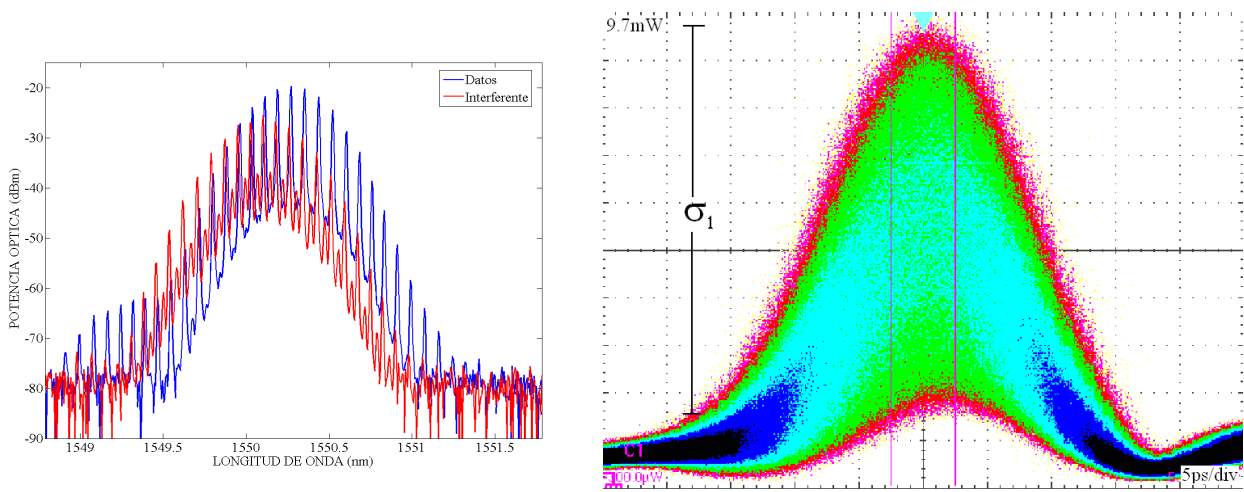

Figura 6.3: Posición inicial del los espectros del canal de datos y el canal interferente (Izq). Batido de la señal de datos e interferente (Der). $\Delta \lambda=168 \mathrm{pm}$.

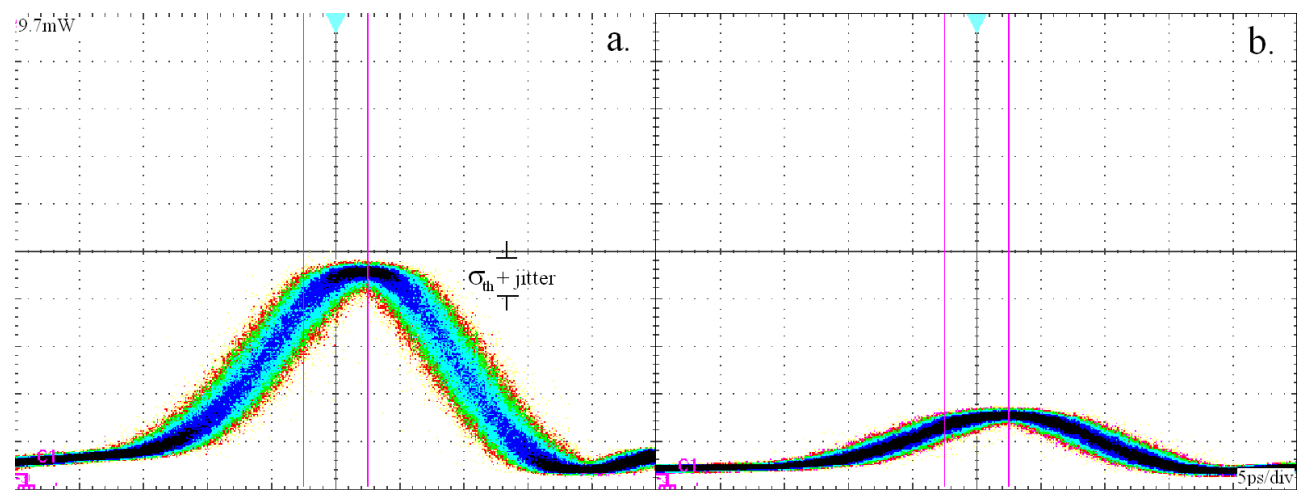

Figura 6.4: Canal de datos (a) e interferente en el dominio temporal (b). 

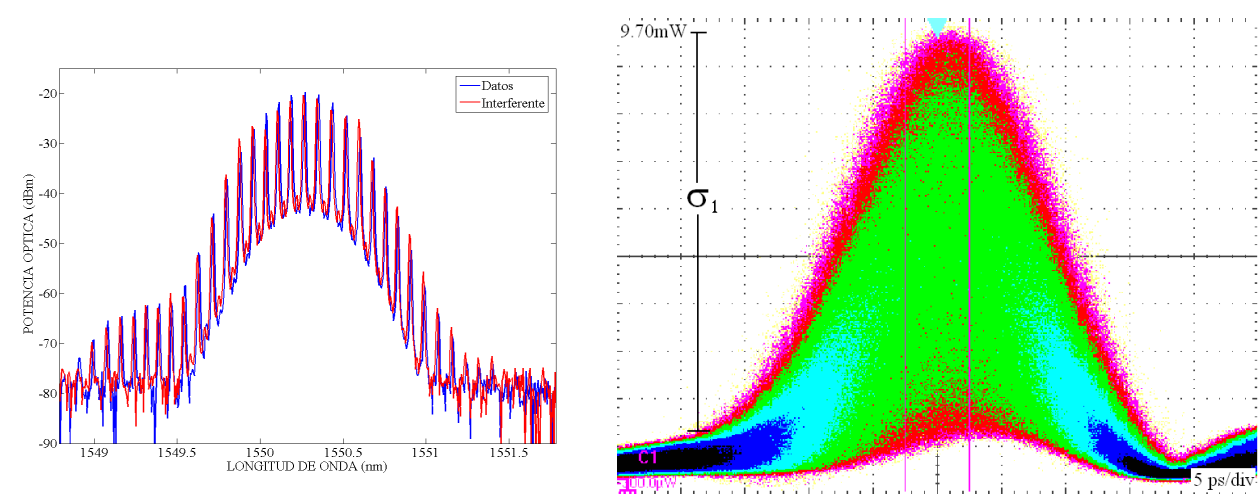

Figura 6.5: Espectros del canal de datos e interferente (Izq) y batido de la señal de datos e interferente (Der). $\Delta \lambda=12 p m$

figuras $6.4 \mathrm{a}$ y $6.4 \mathrm{~b}$. Se ha llamado $\sigma_{1}$ a la suma de batido primario, ruido térmico y jitter, en este caso es igual a $8.4 \mathrm{~mW}$. La componente principal de $\sigma_{1}$ es el batido primario producido entre el pulso de datos y el pulso interferente.

Vale la pena aclarar, al ver estas figuras, que cada una de las capturas ha sido hecha después de por lo menos 30 segundos de iniciado el experimento. Con ello se garantiza que el controlador de polarización ha podido realizar varios barridos, teniendo en cuenta todos los estados posibles de polarización de la señal interferente. De tal manera que el batido descrito es el máximo que se puede obtener.

El siguiente paso consiste en desplazar el canal 5 hacia la derecha buscando la mayor coincidencia posible de los espectros. El espectro del canal interferente ahora esta centrado en $1550.258 \mathrm{~nm}$, de tal forma que la diferencia es $\Delta \lambda=12 p m$. Este fue el punto de menor diferencia espectral conseguido en el laboratorio y en donde se pudo observar la mayor interferencia de batido. En la figura 6.5 se muestran los espectros respectivos y el ruido de batido.

En este caso el batido de la señal que se puede medir en la gráfica es $\sigma_{1}=9,02 \mathrm{~mW}$. Este valor es muy similar al encontrado teóricamente aplicando la ecuación 2.4 de la sección 2.2 en donde la fotocorriente quedaría igual a $P_{d}+P_{i}+2 \sqrt{P_{d} P_{i}}$. Aplicando esta formula el valor que obtenemos es $9.4 \mathrm{~mW}$, no es exacto, pero si muy aproximado, además que debemos recordar que para la deducción de esta formula se supone coincidencia espectral perfecta y pulso cuadrado y en el laboratorio se uso pulsos gausianos y la coincidencia espectral no es perfecta.

Como fue indicado anteriormente con el canal 5 se lograba la mayor interferencia sobre el canal de datos, sin embargo para continuar el desplazamiento hacia la derecha es necesario emplear el canal 6, iniciando con este canal centrado en $1550.534 \mathrm{~nm}$, consiguiendo un $\Delta \lambda=264 \mathrm{pm}$. En la figura 6.6 se pueden ver los espectros de ambos canales y la nueva señal de batido a partir de la cual se puede medir un $\sigma_{1}=8,64 \mathrm{~mW}$.

El mismo procedimiento se lleva a cabo 4 veces más, desplazando el espectro hacia la derecha hasta alcanzar los $0.800 \mathrm{~nm}$ de diferencia entre la longitud de onda del dato y la de la señal interferente. En este punto es donde teóricamente se logra que el sistema se transforme en incoherente. 

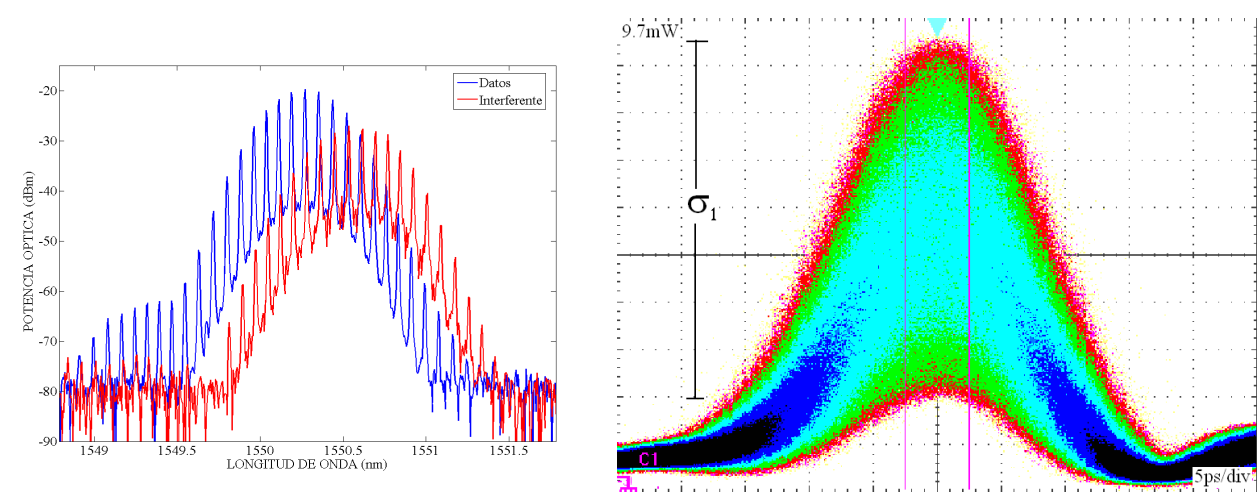

Figura 6.6: Espectros del canal de datos e interferente (Izq) y batido de la señal de datos e interferente (Der). $\Delta \lambda=264 \mathrm{pm}$

\begin{tabular}{|c|c|c|}
\hline$\Delta \lambda(p m)$ & $\sigma_{1}(m W)$ & $\mathrm{R}(\mathrm{dB})$ \\
\hline \hline 12 & 9.02 & 0 \\
\hline 168 & 8.4 & 0.39 \\
\hline 264 & 7.9 & 0.57 \\
\hline 492 & 6.2 & 1.6 \\
\hline 570 & 5.1 & 2.47 \\
\hline 720 & 4 & 3.35 \\
\hline 810 & 3.1 & 4.6 \\
\hline
\end{tabular}

Cuadro 6.1: Reducción del ruido de batido (R) a medida que se separan los canales en longitud de onda.

La figura 6.7 a la derecha muestra los sucesivos desplazamientos del espectro interferente hacia longitudes de onda superiores y su correspondiente efecto en la suma de las señales vistas en el dominio temporal, el cual lo podemos ver a la izquierda de cada uno de los diagramas espectrales.

A medida que aumenta la separación entre el espectro de datos y el espectro interferente el efecto de batido disminuye. Si suponemos que el ruido térmico y el jitter se mantienen constantes durante todo el experimento podemos entonces decir que el valor $\mathrm{R}$ de la tabla 6.1 corresponde a la reducción en $\mathrm{dB}$ de la amplitud del ruido de batido primario.

De acuerdo a los resultados mostrados en la tabla 6.1 como en la figura 6.8 el ruido de batido se acerca a cero a medida que la diferencia de longitud de onda entre canales se acerca a $800 \mathrm{pm}$. Podemos ver que $800 \mathrm{pm}$ corresponde con el ancho de un canal del AWG que en términos de frecuencia es de $100 \mathrm{GHz}$ y en tiempo son 10 ps. No obstante, es posible llegar a considerar el sistema como incoherente desde un valor anterior al de los $800 \mathrm{pm}$, por ejemplo, a partir del punto en que el ruido de batido cae por debajo de los $3 \mathrm{~dB}$, el cual es a los $700 \mathrm{pm}$ aproximadamente. Por otra parte si vemos la figura 6.8, el valor de penalización en la apertura del diagrama de ojo que puede ser soportado, oscilará entre 1 y $3 \mathrm{~dB}$, y en dado caso el tamaño del 

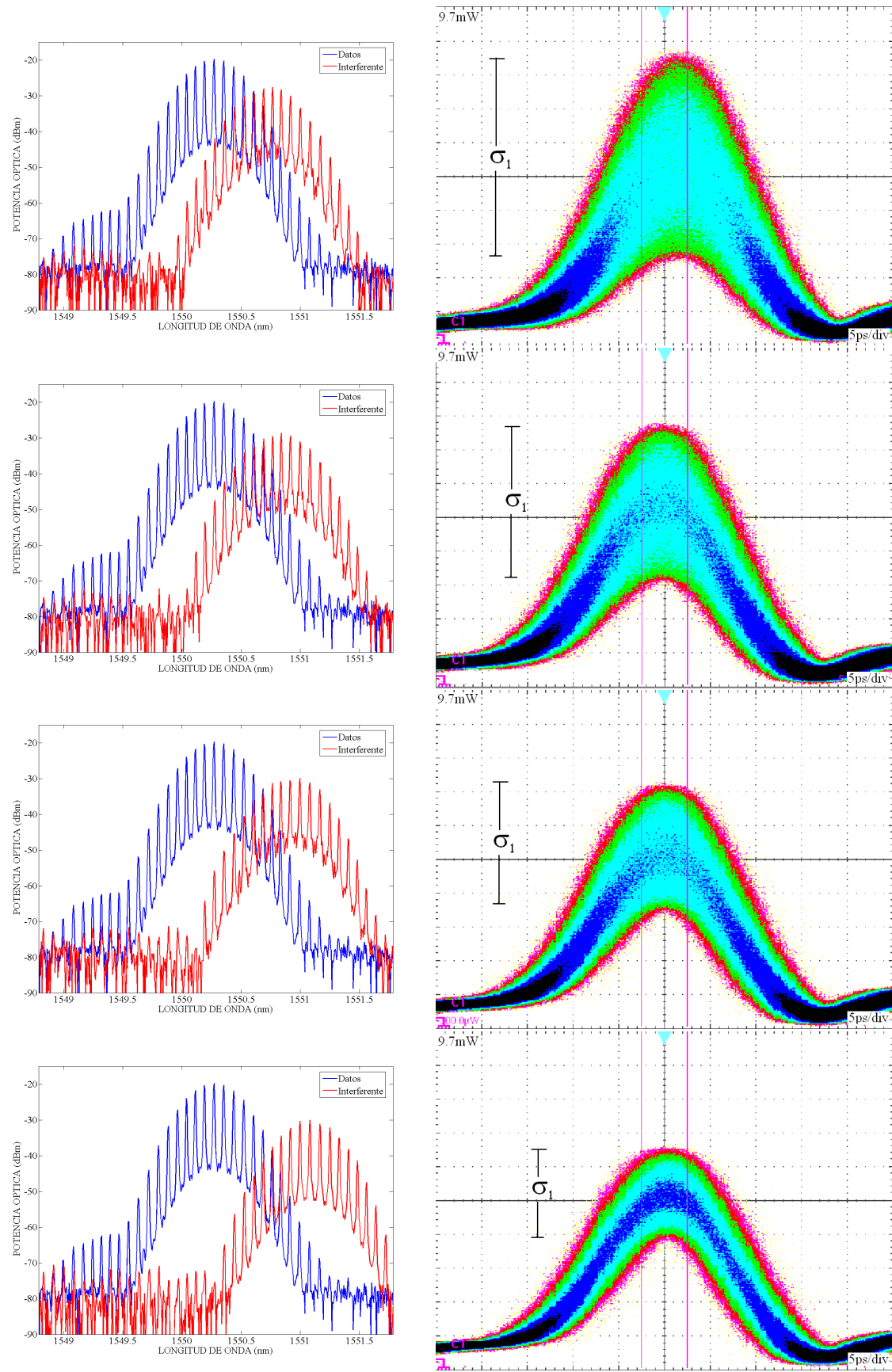

Figura 6.7: Espectros del canal de datos e interferente (Izq) y batido de la señal de datos e interferente (Der). a) $. \Delta \lambda=492 \mathrm{pm}, \mathrm{b}) \cdot \Delta \lambda=570 \mathrm{pm}, \mathrm{c}) \cdot \Delta \lambda=720 \mathrm{pm}$, d). $\Delta \lambda=810 \mathrm{pm}$. 


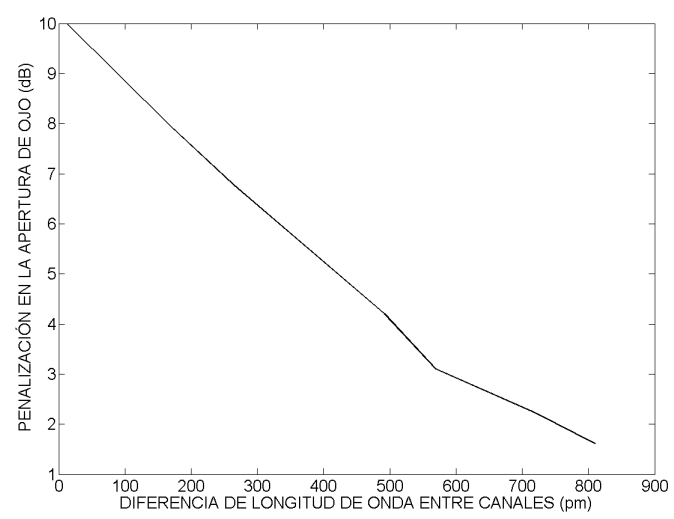

Figura 6.8: Penalización en la apertura de ojo cuando existe ruido de batido producido por la interferencia entre canales adyacentes.

canal puede ser reducido hasta 600 pm. Estas consideraciones están limitadas por el tipo de sistema que se este implementando, el ancho de los pulsos que se apliquen a la entrada, el hecho de que exista o no sincronismo ó que utilice técnicas de time gating o thresholding en el momento de detección de la señal.

\subsection{Sistemas OCDMA Incoherentes 2-D}

Los sistemas OCDMA de tipo incoherente han sido ampliamente estudiados debido a la facilidad con que pueden ser implementados si se trabaja a una tasa de bit relativamente baja $[107,108]$. La codificación se realiza con base en la potencia óptica y por lo tanto usa códigos unipolares $(0,1)$. Esto causa algunas desventajas, siendo quizás la más relevante la baja eficiencia espectral de los sistemas incoherentes. Para solucionar dichas desventajas se ha propuesto hacerlo eléctricamente, pero esto causa un cuello de botella en cuanto al ancho de banda optoelectrónico. Otra solución posible es el uso de códigos en dos dimensiones los cuales dan un mayor grado de libertad y tienen un mejor comportamiento en cuanto a su rendimiento de autocorrelación y correlación cruzada [37].

Desde el punto de vista de eficiencia espectral si comparamos un sistema OCDMA incoherente que use por ejemplo códigos 1-D y varias longitudes de onda (WDM/CDMA) para enviar la información contra otro que usa códigos matriciales (longitud de onda vs. tiempo $(\mathrm{W} / \mathrm{T})$ ) y envía la misma información, vemos que este último tendrá una mayor eficiencia espectral [57]. Estos métodos que usan longitud de onda y tiempo pueden ser descritos como: 1) Códigos en 2-D en los cuales $p$ (el peso de los códigos ) pulsos son puestos en una matriz de $W \times T$ formando una matriz de códigos ortogonales. Ó 2) Códigos WDM/CDMA, en los cuales un conjunto de $n$ códigos ortogonales (1-D) de peso $p$ es asociado con un número $W$ de longitudes de onda para formar un conjunto de códigos. 
La eficiencia espectral (SE) de un conjunto de $n$ códigos WDM/CDMA de peso $p$ y longitud $L$ es:

$$
S E=\frac{n}{L}
$$

en donde $L$ debe satisfacer que

$$
L>n \times \frac{p(p-1)}{2}
$$

y por lo tanto

$$
S E<\frac{2}{p(p-1)}
$$

con ello vemos que la eficiencia espectral solo es dependiente del peso del código.

Por otra parte una matriz de códigos $W \times T$, con $W$ longitudes de onda y $T$ slots de tiempo, contiene $p$ pulsos para representar cada código. En estos códigos la eficiencia espectral es

$$
S E=\frac{n}{T}
$$

Aquí $L>n \times \frac{p(p-1)}{2}$ y $W \times T>L$ y en consecuencia

$$
S E<\frac{2 W}{p(p-1)}
$$

A partir de 6.2 y de 6.3 se deduce que la eficiencia espectral es $W$ veces mayor en los sistemas OCDMA incoherentes que usan códigos 2-D (W/T).

En ambos casos la eficiencia espectral se deteriora con el incremento de $p$, pero es mucho más acentuado en los códigos WDM/CDMA, razón por la cual se han escogido para realizar este experimento los códigos 2D.

\subsubsection{Diseño de Códigos 2-D (Longitud de Onda/Tiempo) para Sistemas OCDMA}

Los sistemas OCDMA incoherentes han recibido un nuevo impulso gracias a la posibilidad de usar códigos en 2 dimensiones los cuales tienen una mayor cardinalidad y mayor eficiencia espectral que los códigos unipolares de 1 dimensión [109]. Adicionalmente esta clase de códigos es fácilmente adaptable a las tecnologías usadas en sistemas WDM, como por ejemplo los AWG $[4,103]$.

Existen múltiples clases de códigos en 2 dimensiones, tal y como se dijo al principio de este capítulo, de entre los cuales se seleccionaron los códigos FOGR para ser utilizados en nuestros experimentos. Para construir dichos códigos se parte de una regla de Golomb óptima la cual consiste en una secuencia de pulsos 0,1 en donde la distancia entre cualquiera de los pulsos, es un entero no repetido, de ahí que la distancia entre vecinos cercanos, los siguientes más cercanos, etc, pueda ser descrita como una diferencia triangular con una única entrada entera $[110,111]$. 


\begin{tabular}{|l|l|l|l|l|l|l|l|l|l|l|l|l|l|l|l|}
\hline \multicolumn{9}{|c|}{ M1 } & \multicolumn{9}{|c|}{ M9 } & \multicolumn{4}{|c|}{ M17 } & \multicolumn{3}{|c|}{ M25 } \\
\hline \hline 1 & 1 & 0 & 1 & 1 & 0 & 0 & 0 & 1 & 0 & 0 & 0 & 1 & 0 & 0 & 0 \\
\hline 0 & 0 & 1 & 0 & 0 & 0 & 0 & 0 & 0 & 1 & 0 & 0 & 0 & 0 & 1 & 0 \\
\hline 0 & 0 & 0 & 0 & 0 & 0 & 0 & 0 & 0 & 0 & 0 & 0 & 0 & 0 & 0 & 0 \\
\hline 0 & 0 & 0 & 0 & 1 & 0 & 0 & 0 & 0 & 0 & 0 & 0 & 0 & 0 & 0 & 0 \\
\hline 0 & 0 & 0 & 0 & 0 & 0 & 0 & 0 & 0 & 0 & 0 & 0 & 1 & 0 & 0 & 0 \\
\hline 0 & 0 & 0 & 0 & 0 & 0 & 0 & 0 & 0 & 0 & 1 & 0 & 0 & 0 & 0 & 0 \\
\hline 0 & 0 & 0 & 0 & 0 & 0 & 1 & 0 & 0 & 1 & 0 & 0 & 0 & 0 & 0 & 0 \\
\hline 0 & 0 & 0 & 0 & 0 & 0 & 1 & 0 & 0 & 0 & 0 & 0 & 0 & 1 & 0 & 0 \\
\hline
\end{tabular}

Cuadro 6.2: Matrices código generadas a partir de las reglas de Golomb

Vamos a generar una familia de 32 códigos partiendo de un conjunto de 4 reglas de Golomb de peso 4 y longitud 25, las cuales escribimos a continuación:

$$
\begin{aligned}
& g 1(4,4)=1000000010000000001000001 \\
& g 2(4,4)=1001000000000000000000110 \\
& g 3(4,4)=1000000001000010000001000 \\
& g 4(4,4)=1000100000000001010000000
\end{aligned}
$$

con estas 4 reglas y siguiendo el procedimiento descrito en [112, 105], en donde se ordena cada una de estas reglas de manera transpuesta ocupando una matriz de $8 \times 4$ generamos las matrices M1, M9, M17 Y M25.

En estas matrices de códigos, las filas indican el número de longitudes de onda que se usaran y las columnas los slots de tiempo. El producto de estos valores determinará el número de elementos del código (DC), en este caso $D C=W \times T=32$. La probabilidad de que otra matriz similar con el mismo peso interfiera sobre un pulso específico de la primera matriz es $\frac{p}{2 D C}$. Si todos los pulsos de todos los códigos tienen la misma energía E, entonces la varianza del ruido MAI en cualquier posición es

$$
\sigma_{M A I}=E^{2} \frac{p}{2 D C}
$$

por lo tanto la varianza de k-1 usuarios es

$$
\sigma_{M A I}(k-1)=(k-1) E^{2} \frac{p}{2 D C}
$$

Si ahora consideramos la relación señal a ruido del correlador, tendremos que el valor ideal de potencia que debe recuperar el dispositivo es $(p \times E)^{2}$. Los códigos interferentes introducirán una varianza igual a $\sigma_{M A I}(k-1)$ multiplicada por el peso.

$$
S N R=\frac{(p E)^{2}}{p(k-1) E^{2} \frac{p}{2 D C}}=\frac{2 D C}{k-1}
$$

La ecuación 6.4 muestra que la relación señal a ruido depende del número de elementos del código y de los usuarios presentes en la red. En un diagrama de ojo, este 
se cerraría cuando $\sqrt{\sigma_{M A I}}=\frac{\text { pico de seal }}{2}=\frac{p E}{2}$ lo que equivale a tener una $S N R=4$. Con este valor de SNR el máximo número de usuarios posibles en el sistema sería de 17. Este número es inferior al objetivo que es de 32 usuarios, por tal motivo se adiciona a las matrices mostradas en la tabla 6.24 columnas más que se rellenaran con ceros. Estos ceros se comportarán como un tiempo de guarda que permitirá aumentar el número de usuarios. Nótese que ahora $D C=8 \times 8=64$ y por lo tanto el máximo número de usuarios posibles ahora pasa a ser 33. Aunque de esta manera reducimos la eficiencia espectral, conseguimos un sistema con los 32 usuarios que se desean.

Así las matrices código cuyas dimensiones eran de $8 \times 4$, ahora pasan a ser de $8 \times 8$, en donde las ultimas 4 columnas estarán compuestas solo de ceros.

Estas matrices son las que llamaremos palabras código primarias. Realizando un desplazamiento cíclico a cada una de ellas, generamos las demás palabras código. A partir de M1 generamos las palabras código M2-M7, de M9 los matrices M10-M16, de M17 las palabras M18 a M24 y a partir de M25 las palabras código M26-M32.

Las palabras se generan mediante un desplazamiento cíclico cuyo operador se puede representar mediante la matriz $\mathrm{P}$ dada en:

\begin{tabular}{|l|l|l|l|l|l|l|l|}
\hline \multicolumn{10}{|c|}{$\mathrm{P}$} \\
\hline \hline 0 & 0 & 0 & 0 & 0 & 0 & 0 & 1 \\
\hline 1 & 0 & 0 & 0 & 0 & 0 & 0 & 0 \\
\hline 0 & 1 & 0 & 0 & 0 & 0 & 0 & 0 \\
\hline 0 & 0 & 1 & 0 & 0 & 0 & 0 & 0 \\
\hline 0 & 0 & 0 & 1 & 0 & 0 & 0 & 0 \\
\hline 0 & 0 & 0 & 0 & 1 & 0 & 0 & 0 \\
\hline 0 & 0 & 0 & 0 & 0 & 1 & 0 & 0 \\
\hline 0 & 0 & 0 & 0 & 0 & 0 & 1 & 0 \\
\hline
\end{tabular}

así las matrices $M_{i}$ son generadas mediante

$$
\begin{gathered}
M_{i}=P^{i} * M 1(M 9, M 17 M 25) \\
i=0 \ldots 7
\end{gathered}
$$

excepto los casos en que al realizar el producto de la matriz por $\mathrm{P}$ se desplace un 1 desde la última fila a la primera fila de la misma columna de la matriz resultante, en estos casos el operador de desplazamiento que se usa es:

$$
M_{1 j} \rightarrow M_{1 j+1}
$$

donde $M_{1 j}$ es el 1 que ha sido trasladado a la primera fila después de la multiplicación por el operador P. Esta operación es necesaria para ser consistentes con el algoritmo de [105] y preservar las propiedades de diferencia triangular, lo cual, después de todo es lo que le da las propiedades de ortogonalidad a los códigos.

Para ilustrar las dos posibilidades, mostraremos como se genera la matriz de código M2 y la matriz de código M10. Tomamos primero la matriz de código M1 desde donde generaremos M2 y la multiplicamos por el operador $\mathrm{P}$ así: 


\begin{tabular}{|c|c|c|c|c|c|c|c|c|c|c|c|c|c|c|c|c|c|c|c|c|c|c|c|c|}
\hline 0 & 0 & 0 & 0 & 0 & 0 & 0 & 1 & 1 & 1 & 0 & 1 & 0 & 0 & 0 & 0 & & 0 & 0 & 0 & 0 & 0 & 0 & 0 & 0 \\
\hline 1 & 0 & 0 & 0 & 0 & 0 & 0 & 0 & 0 & 0 & 0 & 0 & 0 & 0 & 0 & 0 & & 1 & 1 & 0 & 1 & 0 & 0 & 0 & 0 \\
\hline 0 & 1 & 0 & 0 & 0 & 0 & 0 & 0 & 0 & 0 & 1 & 0 & 0 & 0 & 0 & 0 & & 0 & 0 & 0 & 0 & 0 & 0 & 0 & 0 \\
\hline 0 & 0 & 1 & 0 & 0 & 0 & 0 & 0 & 0 & 0 & 0 & 0 & 0 & 0 & 0 & 0 & & 0 & 0 & 1 & 0 & 0 & 0 & 0 & 0 \\
\hline 0 & 0 & 0 & 1 & 0 & 0 & 0 & 0 & 0 & 0 & 0 & 0 & 0 & 0 & 0 & 0 & & 0 & 0 & 0 & 0 & 0 & 0 & 0 & 0 \\
\hline 0 & 0 & 0 & 0 & 1 & 0 & 0 & 0 & 0 & 0 & 0 & 0 & 0 & 0 & 0 & 0 & & 0 & 0 & 0 & 0 & 0 & 0 & 0 & 0 \\
\hline 0 & 0 & 0 & 0 & 0 & 1 & 0 & 0 & 0 & 0 & 0 & 0 & 0 & 0 & 0 & 0 & & 0 & 0 & 0 & 0 & 0 & 0 & 0 & 0 \\
\hline 0 & 0 & 0 & 0 & 0 & 0 & 1 & 0 & 0 & 0 & 0 & 0 & 0 & 0 & 0 & 0 & & 0 & 0 & 0 & 0 & 0 & 0 & 0 & 0 \\
\hline
\end{tabular}

Los ceros en negrita corresponden a las columnas adicionadas y que servirán como tiempo de guarda. Ahora para el segundo caso, tomamos la matriz de código M9 y la multiplicamos primero por $\mathrm{P}$

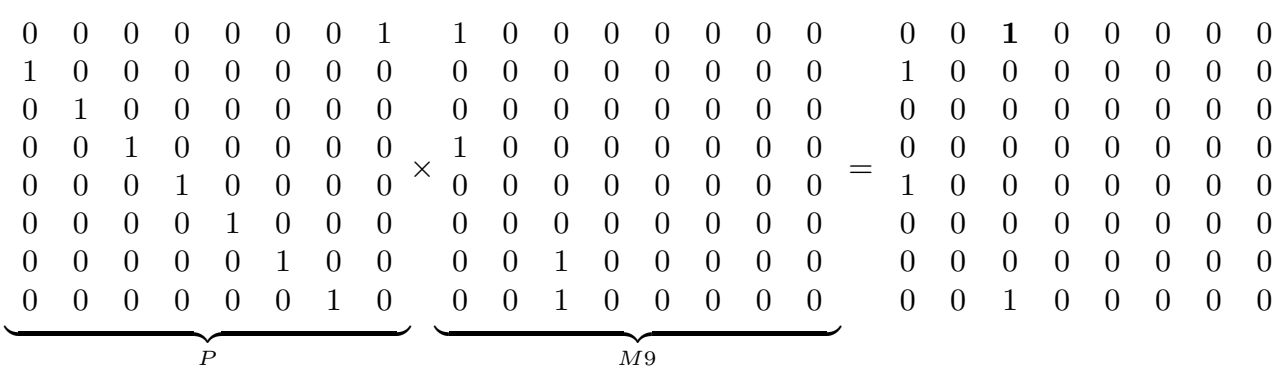

el 1 que aparece en resaltado en la anterior operación es al que debemos realizar el procedimiento indicado en la ecuación 6.5 quedando la matriz código M10 como:

$\underbrace{\begin{array}{llllllll}0 & 0 & 0 & \mathbf{1} & 0 & 0 & 0 & 0 \\ 1 & 0 & 0 & 0 & 0 & 0 & 0 & 0 \\ 0 & 0 & 0 & 0 & 0 & 0 & 0 & 0 \\ 0 & 0 & 0 & 0 & 0 & 0 & 0 & 0 \\ 1 & 0 & 0 & 0 & 0 & 0 & 0 & 0 \\ 0 & 0 & 0 & 0 & 0 & 0 & 0 & 0 \\ 0 & 0 & 0 & 0 & 0 & 0 & 0 & 0 \\ 0 & 0 & 1 & 0 & 0 & 0 & 0 & 0\end{array}}_{M 10}$

Siguiendo el procedimiento descrito, podemos obtener las 32 matrices código. De esos 32 códigos se escogieron 2 para ser utilizados en los experimentos que describimos a continuación.

\subsubsection{Demostrador Experimental}

Los códigos obtenidos a partir del diseño descrito en la sección anterior fueron matrices de $8 \times 8$ donde el número de filas indica el número de longitudes de onda necesarias y las columnas el número de slots de tiempo. De los 32 códigos posibles se seleccionaron 2 que permitirán mostrar los resultados obtenidos de la implementación 


\begin{tabular}{|l|l|l|l|l|l|l|l|l|l|l|l|l|l|l|l|}
\hline \multicolumn{1}{|c|}{ M9 } & \multicolumn{1}{|c|}{ M22 } \\
\hline \hline 1 & 0 & 0 & 0 & 0 & 0 & 0 & 0 & 0 & 0 & 0 & 0 & 0 & 0 & 0 & 0 \\
\hline 0 & 0 & 0 & 0 & 0 & 0 & 0 & 0 & 0 & 0 & 0 & 0 & 0 & 0 & 0 & 0 \\
\hline 0 & 0 & 0 & 0 & 0 & 0 & 0 & 0 & 0 & 0 & 0 & 1 & 0 & 0 & 0 & 0 \\
\hline 1 & 0 & 0 & 0 & 0 & 0 & 0 & 0 & 0 & 0 & 1 & 0 & 0 & 0 & 0 & 0 \\
\hline 0 & 0 & 0 & 0 & 0 & 0 & 0 & 0 & 0 & 0 & 0 & 0 & 0 & 0 & 0 & 0 \\
\hline 0 & 0 & 0 & 0 & 0 & 0 & 0 & 0 & 1 & 0 & 0 & 0 & 0 & 0 & 0 & 0 \\
\hline 0 & 0 & 1 & 0 & 0 & 0 & 0 & 0 & 0 & 1 & 0 & 0 & 0 & 0 & 0 & 0 \\
\hline 0 & 0 & 1 & 0 & 0 & 0 & 0 & 0 & 0 & 0 & 0 & 0 & 0 & 0 & 0 & 0 \\
\hline
\end{tabular}

Cuadro 6.3: Matrices de los códigos M9 y M22.

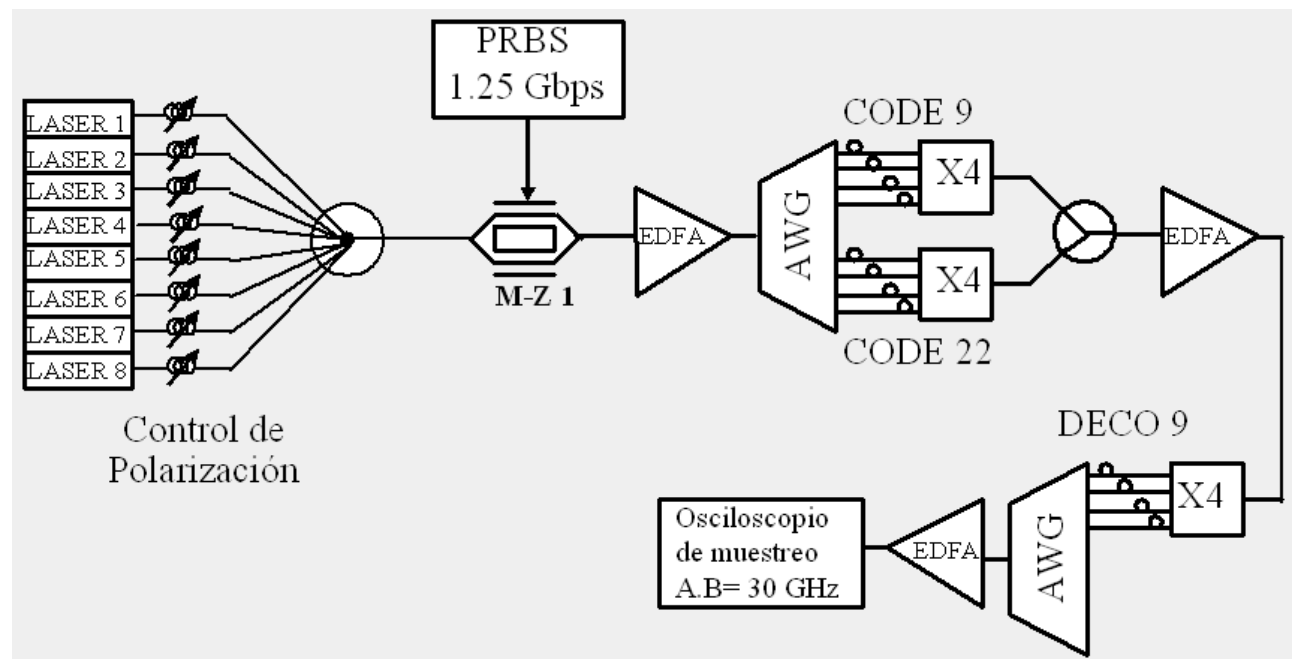

Figura 6.9: Diagrama de Bloques del Sistema Incoherente con dos códigos

parcial del demostrador experimental de un sistema OCDMA incoherente como el planteado en [90]. Las matrices código implementadas para tal fin fueron M9 y M22 (tabla 6.3).

La primera parte del experimento consistió en la implementación del diagrama de bloques mostrado en la figura 6.9 y cuyo montaje en laboratorio se puede ver en la figura 6.10. Para ello se uso una fuente láser multilongitud de onda (MWL) de la cual se usaron 8 longitudes de onda. Cada longitud de onda corresponde a un láser en particular y la salida de cada uno de ellos se instaló un control de polarización con el fin de garantizar que la contribución de cada uno fuera exactamente igual. Después de polarizar todas las señales correctamente se combinan mediante un acoplador $1 \times$ 8 y son moduladas con una secuencia de bits a 1.25 Gbps. Debido a las pérdidas introducidas por los dispositivos para el acondicionamiento de la señal de entrada es necesario instalar un amplificador óptico antes de codificar la señal.

El espectro de los 8 canales modulados los podemos ver en la figura 6.11. 


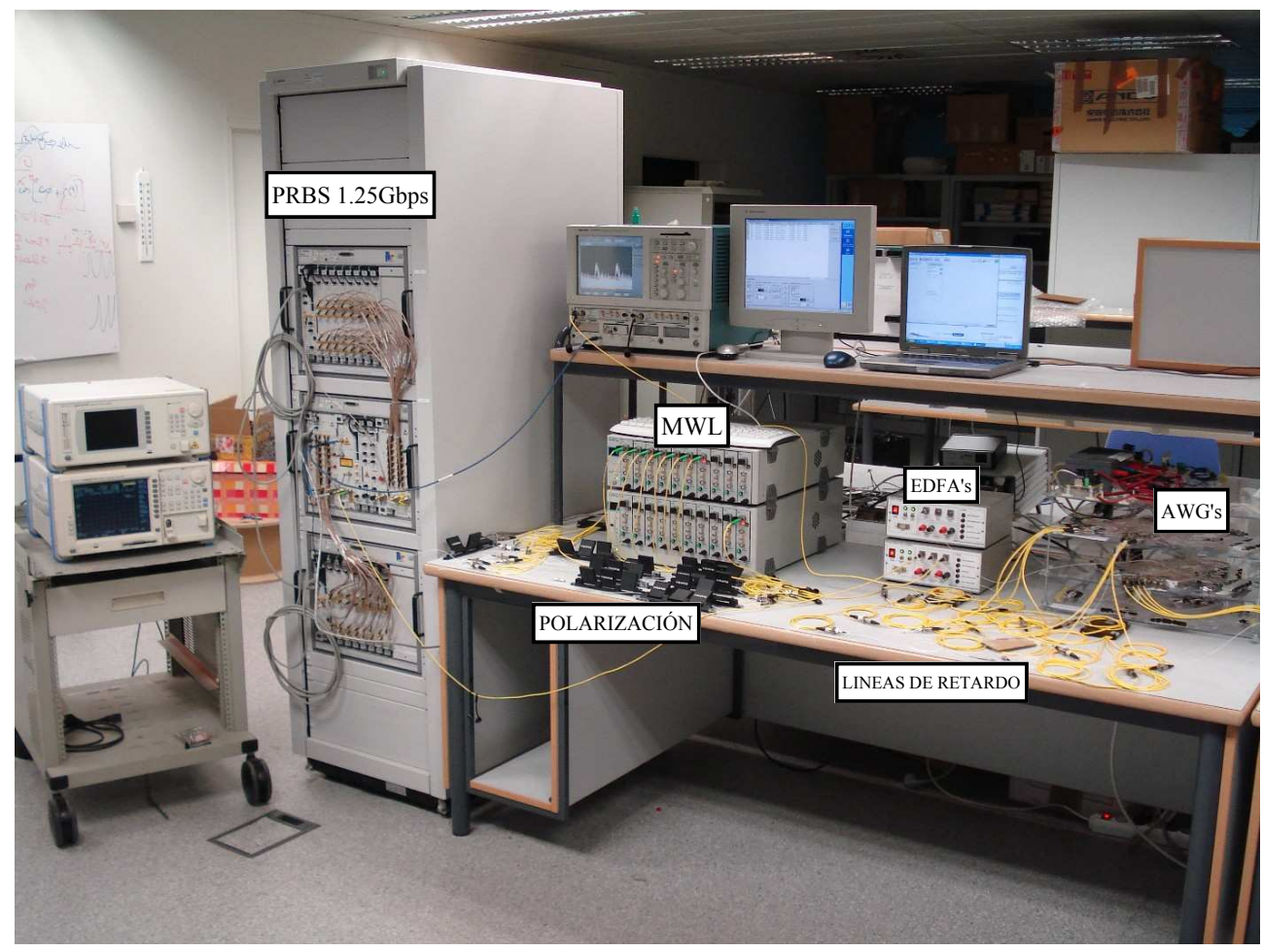

Figura 6.10: Montaje en laboratorio del Sistema Incoherente

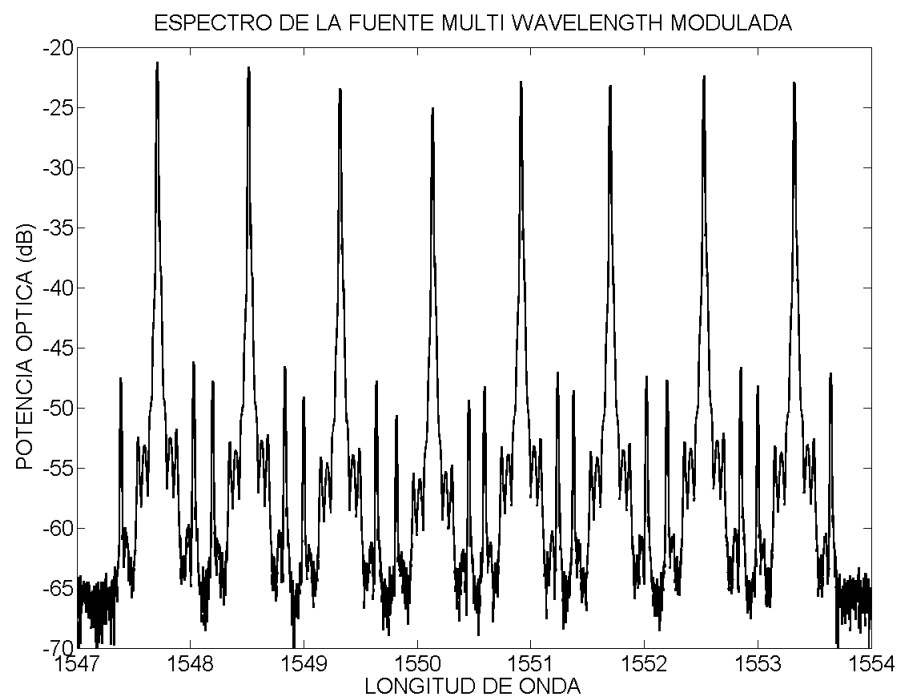

Figura 6.11: Espectro de los 8 canales modulados a 1.25 Gbps. 

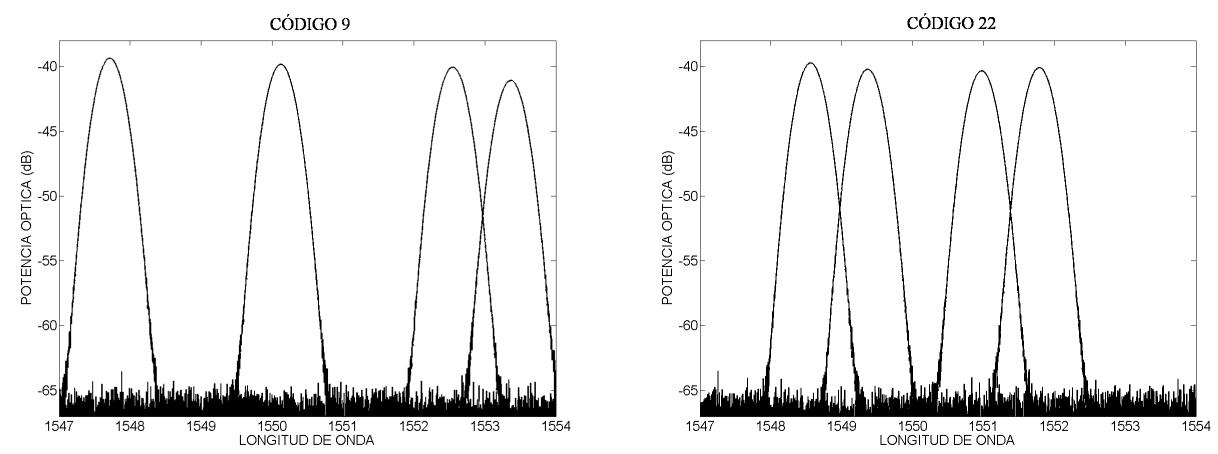

Figura 6.12: Espectro de los canales de los AWGs asignados a cada código

Para la implementación de los codificadores se uso un AWG para separar las longitudes de onda y un banco de líneas de retardo para la codificación en tiempo. Del AWG se seleccionaron 8 canales adyacentes de acuerdo a las frecuencias a las que se habían escogido los láseres. Aprovechando que el peso de cada código es de 4 se uso un mismo AWG para la implementación de los códigos 9 y 22 . Los canales del AWG se asignaron a cada código tal y como se muestra en la figura 6.12 y en la tabla a continuación.

\begin{tabular}{|c|c|c|c|c|c|c|c|c|c|c|c|c|c|c|c|c|c|}
\hline \multirow{2}{*}{\multicolumn{2}{|c|}{ CANALES }} & \multicolumn{8}{|c|}{ CÓDIGO 9} & \multicolumn{8}{|c|}{ CÓDIGO 22} \\
\hline & & 1 & 2 & 3 & 4 & 5 & 6 & 7 & 8 & $\overline{1}$ & 2 & 3 & 4 & 5 & 6 & 7 & 8 \\
\hline 1 & 1547.718 & 1 & & & & & & & & & & & & & & & \\
\hline 2 & 1548.519 & & & & & & & & & & & & 1 & & & & \\
\hline 3 & 1549.318 & & & & & & & & & & & 1 & & & & & \\
\hline 4 & 1550.120 & 1 & & & & & & & & & & & & & & & \\
\hline 5 & 1550.921 & & & & & & & & & 1 & & & & & & & \\
\hline 6 & 1551.724 & & & & & & & & & & 1 & & & & & & \\
\hline 7 & 1552.526 & & & 1 & & & & & & & & & & & & & \\
\hline 8 & 1553.331 & & & 1 & & & & & & & & & & & & & \\
\hline
\end{tabular}

La tasa de transmisión es de 1.25 Gbps y por lo tanto la distancia entre bits es de 800 ps. De tal forma que se asignó a cada slot un tamaño de 100 ps. Para que quede más claro, por ejemplo para el código 9 , a las longitudes de onda 1 y 4 no se les introduce retardo, dichos canales ocuparan entre 0 y 100 ps. Los canales del AWG 7 y 8 tendrán un retardo de dos slots de tiempo ocupando desde los 200 a los 300 ps. Los retardos se consiguieron mediante el uso de latiguillos de fibra óptica con las longitudes apropiadas. Cabe anotar que para la determinación de dichas longitudes fue necesario medir previamente de forma precisa los latiguillos de fibra óptica con los que vienen construidos tanto los AWG's como los acopladores $1 \mathrm{x} 4$ utilizados. Las mediciones son hechas para los dispositivos usados en la construcción de las matrices código 9 y 22, porque ambas deben estar perfectamente sincronizadas. Posteriormente se procedió a fabricar los latiguillos con los que se interconectarían los dispositivos y con los que se terminarían de ajustar las longitudes necesarias para la codificación. 


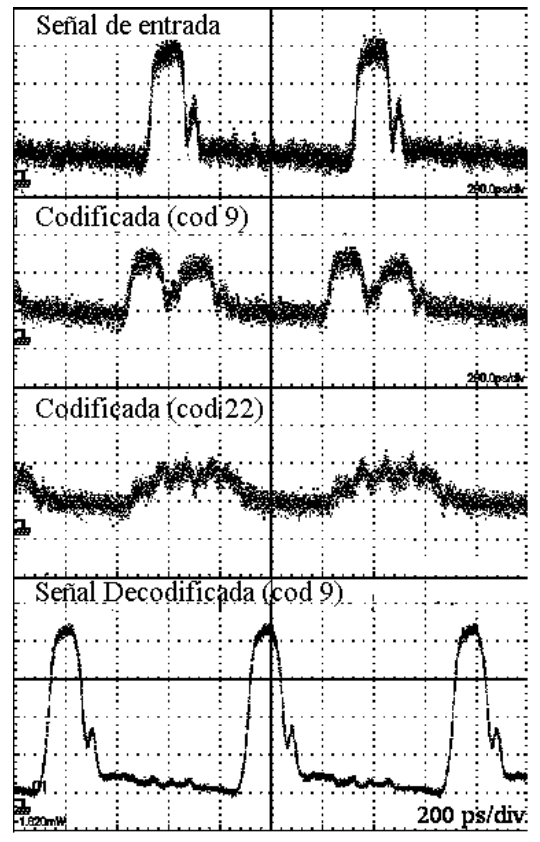

Figura 6.13: Secuencia de bits periódica, codificada con la matriz de código 9 y 22, y decodificada.

Este ajuste se realiza conociendo que una fibra óptica con índice de refracción igual a 1.45 retarda 100 ps aproximadamente por cada $2 \mathrm{~cm}$ de longitud.

Las pérdidas introducidas por los AWGs, los acopladores y la caracterización suman alrededor de los $15 \mathrm{~dB}$ razón por la cual en este punto se hace necesario volver a amplificar.

La señal moduladora para las primeras pruebas fue una secuencia periódica de bits a 1.25 Gbps. La figura 6.13 muestra la señal original y las versiones codificadas con las matrices de códigos 9 y 22. En la señal original se nota un pico adyacente al pico principal el cual es un defecto propio de la fuente utilizada y que no fue posible eliminar. La señal codificada con el código 9 tal y como se podía esperar tiene dos pulsos con la mitad de potencia que la señal original, dado que el código 9 tiene coincidencias temporales en la posición 1 y en la posición 3. Por su parte la señal codificada con el código 22 es una señal 4 veces inferior en potencia a la original, pero con pulsos en cada uno de los slots de tiempo. Recordemos que los otros 4 slots son el tiempo de guarda asignado a cada matriz de código.

El decodificador por su parte tiene la estructura inversa tal y como se muestra en la figura 6.9, es decir, la señal ingresa por el acoplador $1 \times 4$ y luego pasa por lo latiguillos de interconexión con los AWGs. Cada latiguillo ha sido implementado con la longitud necesaria para compensar las longitudes codificadoras del transmisor. Finalmente la señal ingresa al AWG donde son recombinadas las señales en frecuencia, recuperándose de esta manera la señal original. En la figura 6.13 podemos ver la señal 
recuperada, la cual es igual a la señal de entrada, con la salvedad que se ha ensanchado ligeramente por el efecto del filtrado múltiple que tiene al pasar por los AWGs y una amplitud mayor debido a la ganancia extra dada por los amplificadores. El efecto de la interferencia es prácticamente nulo ya que para este primer experimento los códigos usados no tienen coincidencias ni en frecuencia ni en tiempo.

La implementación física de cada matriz de código es una tarea bastante laboriosa y la escalabilidad del sistema no es fácil de conseguir, es decir, la adición de matrices código al sistema implica una reestructuración completa. Cada vez que se agregan nuevos usuario hay que medir las longitudes de los latiguillos que se vayan a implementar para volver a sincronizar todos los dispositivos. Por otra parte, se puede ver que la interferencia con la mayoría de los demás códigos se da con respecto a un solo chip (en tiempo, frecuencia o en ambos), por tal motivo se decidió que en lugar de implementar matrices de código completas se adicionaran canales que coincidieran en tiempo ó en tiempo y frecuencia y ver los efectos sobre la señal recuperada.

Para el siguiente experimento lo primero que se hizo fue cambiar la secuencia periódica por una secuencia pseudo-aleatoria a 1.25 Gbps. Adicionalmente, se aplicó la señal de un canal sin coincidencia temporal con ningún chip de M9 pero sintonizado a $1553.331 \mathrm{~nm}$ que corresponde a una de las longitudes de onda usadas por dicho código. La nueva señal interferente esta modulada con una secuencia aleatoria a 1.25 Gbps independiente a la que se va a codificar mediante M9 o M22.

Las señales esta vez fueron capturadas, haciendo uso de la opción "histograma" del osciloscopio, para poder ver el efecto sobre el diagrama de ojo de la señal recuperada. La señal original (figura 6.14a.), como era de esperar muestra un "ojo" cuyo nivel superior se produce cuando se transmite un uno y un nivel inferior que se produce cuando la señal transmitida corresponde a un cero. La señal codificada con el código 9 mostrada en la figura 6.14b. es muy similar al caso anterior, en cuanto a que tiene dos pulsos que la conforman, solo que ahora aparece al lado derecho un pulso adicional que corresponde a la nueva señal interferente que coincide en frecuencia. En la figura 6.14c. se muestra las señales interferentes, es decir la codificada con M22 y el pulso adicional. Finalmente la figura 6.14d. muestra la señal decodificada en donde se ve que aparece inevitablemente el pulso interferente en frecuencia.

Podemos concluir que los canales interferentes en frecuencia no podrán ser eliminados por el decodificador y que se requiere el uso de técnicas de time gating para filtrar solo el pulso deseado. El uso de técnicas de time gating exige tener la red sincronizada para saber el momento en que se debe realizar el muestreo en tiempo para la detección del pulso deseado, lo cual es una gran desventaja en este tipo de sistemas reduciendo la potencial versatilidad de los sistemas OCDMA.

El siguiente paso fue agregar un nuevo canal interferente, que coincide en tiempo y frecuencia con el primer chip de M9 $(\lambda=1547,718 \mathrm{~nm})$. Cada señal esta modulada con secuencias de bits a $1.25 \mathrm{Gbps}$, aleatorias e independientes entre si. La señal codificada con M9 más los dos canales interferentes la podemos ver en la figura 6.15a, donde es posible distinguir claramente los dos pulsos adicionales que se han agregado al sistema. Nótese que no hay batido entre las señales coincidentes en frecuencia a pesar de coincidir también en el tiempo, lo que se debe a que los láser usados son independientes y por lo tanto están incorrelados. También es posible ver que las secuencias moduladoras son independientes, ya que en el pulso donde se observa 

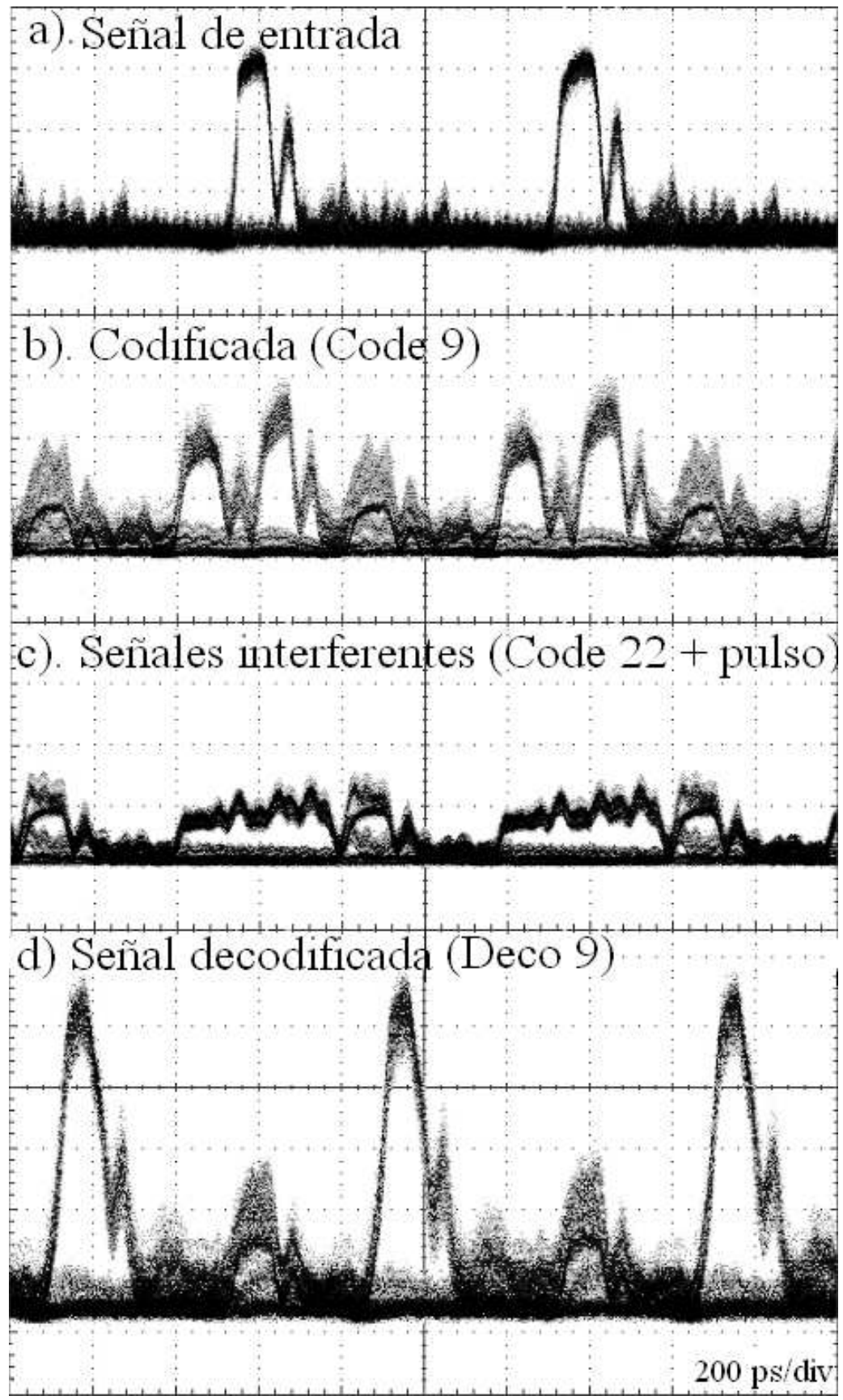

Figura 6.14: a). Secuencia de bits aleatoria, b). Codificada con la matriz de código 9 más canal interferente en frecuencia, c) Señales interferentes (codificada con M22 más canal interferente en frecuencia) y d) Decodificada. 
la coincidencia con el interferente en tiempo y frecuencia, es posible diferenciar 4 niveles de señal, tal como describe la figura 6.15a. El primer nivel se da cuando ambos transmiten un cero, el siguiente nivel cuando se transmite un uno por el canal interferente, el siguiente cuando se transmite un uno codificado con M9 y finalmente el último nivel cuando ambos transmiten un uno. La figura $6.15 \mathrm{~b}$, muestra el conjunto de señales interferentes, es decir, la señal codificada con el código 22 más los dos canales interferentes. En la figura $6.15 \mathrm{c}$, vemos la señal decodificada con el conjugado de M9. En la señal recuperada se ve que aparecen también las contribuciones de ruido producida por ambos interferentes. El que coincide en frecuencia pero no en tiempo, continua apareciendo al lado del pulso principal, mientras el interferente en tiempo y frecuencia deteriora la señal recuperada reduciendo la apertura del ojo. Eliminar la interferencia que afecta directamente al pulso principal, no es tan inmediato como en el caso que solo interfiere en frecuencia. Para ello es necesario el uso de técnicas de thresholding que determinen un valor umbral a partir del cual se realice la correcta discriminación del pulso en el detector. La figura 6.15d, muestra el resultado de la correlación cruzada, la cual para nuestro caso no es otra que las mismas señales interferentes.

Según [90] se puede llegar a recuperar la señal con una BER $1 \times 10^{-9}$ en un sistema con 16 usuarios transmitiendo simultáneamente sin el uso de receptores OHL (Optical Hard Limiter) y hasta 32 si son utilizados. Los receptores OHL optimizan el rendimiento del sistema ya que permiten excluir algunas combinaciones de patrones que llegan a estar altamente localizados en porciones del bit 1 [113].

Aunque nuestro experimento fue bastante limitado en cuanto al número de usuarios disponibles se puede ver que el sistema propuesto en [90] es posible de conseguir. La viabilidad del sistema se soporta en que las fuentes láser utilizadas son incorreladas y en que el sistema requiere una perfectamente sincronización. El hecho de que las fuentes sean independientes es algo que ocurrirá en un sistema de comunicaciones, sin embargo el hecho de requerir sincronismo hace que se pierda la versatilidad que se pretende lograr con los sistemas OCDMA. 


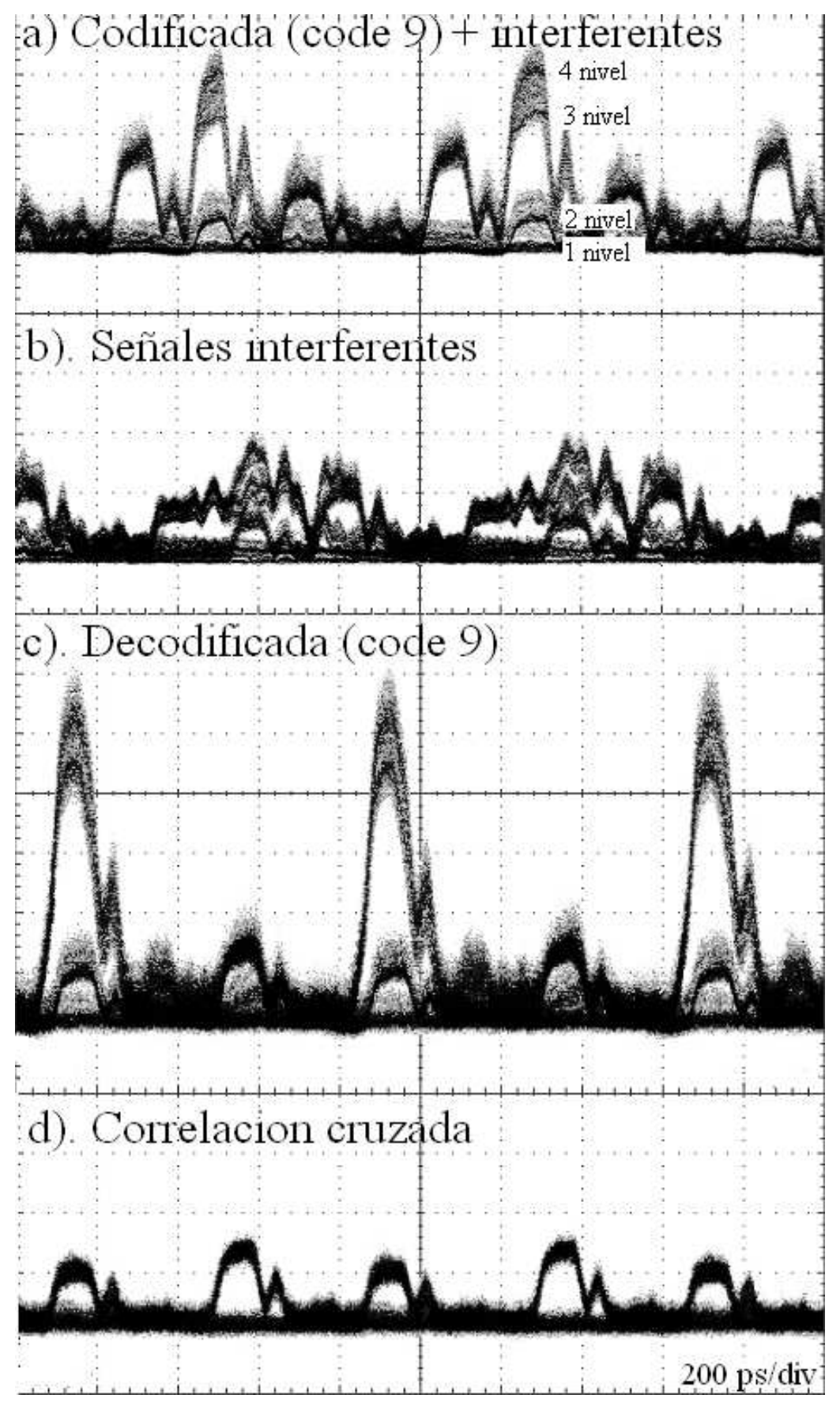

Figura 6.15: a). Codificada con la matriz de código 9 más canales interferentes en frecuencia y tiempo, b) Señales interferentes (codificada con M22 más canales interferentes en frecuencia y tiempo), c) Decodificada y d) Correlación cruzada. 



\section{Capítulo 7}

\section{CONCLUSIONES Y LINNEAS ABIERTAS}

\subsection{Conclusiones}

A lo largo de esta tesis se han estudiado los sistemas multiusuario OCDMA y los mecanismos ópticos de codificación tanto coherentes basados en SSFBGs como incoherentes basados en codificación 2D. Durante este estudio se trataron temas como el modelado matemático del ruido y de la calidad del sistema asociado a los sistemas OCDMA coherentes, el comportamiento de los dispositivos codificadores basados en redes de difracción de Bragg y alternativas a sus métodos de diseño. Con ello se encontró que efectivamente OCDMA es una técnica que puede brindar una solución como técnica de acceso al medio, trabajando sola o en asocio con técnicas como WDMA u OTDMA. Por otra parte, se estudiaron también las técnicas de codificación y decodificación óptica como alternativa para la conformación de etiquetas ópticas que permitan la identificación de ráfagas o paquetes en redes ópticas de conmutación de este tipo. Por último se trabajo en el diseño de códigos en dos dimensiones y la respectiva implementación del demostrador incoherente. A continuación se desglosa en más detalle los aspectos estudiados en cada uno de los capítulos.

En el capítulo 2, se desarrolló un completo modelo del ruido que afecta a los sistemas OCDMA de tipo coherente, partiendo de un modelo previo descrito en [37]. En primer lugar se amplió lo planteado en [37], incluyendo tres características nuevas; 1. Una función $s(t)$ que representa cualquier forma del pulso de entrada que se desee considerar, 2. Receptores con ancho de banda variables, para poder incluir el ruido fuera del tiempo de chip de la señal objetivo. De esta manera se tenían en cuenta, no solo sistemas que utilizasen técnicas de time gating sino también aquellos que tuviesen receptores con anchos de banda inferiores. Y 3. Respuesta impulsiva del receptor $h_{R C}(t)$ arbitraria. Estas primeras inclusiones proporcionaron un modelo más realista, que permitió evaluar la forma como la BER disminuye en el sistema a medida que el ancho de banda del receptor disminuye.

Por otra parte [37], solo planteaba el modelo para sistemas que utilizaban técnicas 
de modulación OOK, sin embargo conociendo las ventajas de la modulación DPSK y aprovechando su reciente demostración experimental en sistemas OCDMA [40, 114, 39], se adicionó el modelado usando este tipo de modulación. Con este nuevo modelo es posible ver que el comportamiento de la BER es casi 4 veces mejor cuando se usa modulación DPSK que cuando se usa modulación OOK.

Otro aspecto interesante cubierto dentro de este mismo capítulo, es el hecho de analizar el sistema bajo hipótesis asíncrona. Esta suposición se realiza conociendo que el ancho del chip $\left(\sigma_{c}\right)$ no es necesariamente igual al tiempo de chip $\left(T_{c}\right)$, y que el tráfico de cada usuario esta totalmente incorrelado. Considerando estos dos parámetros se realizó el análisis tanto para sistemas con modulación OOK como para modulación DPSK. En ambos casos se observo que el sistema mejoraba dependiendo del valor de la relación $\frac{\sigma_{c}}{T_{c}}$. A medida que dicha relación se hacia más pequeña la BER disminuía, no obstante, el aumento en el rendimiento del sistema implica un consumo superior de ancho de banda al requerir transmitir pulsos más estrechos.

Dos aspectos adicionales fueron estudiados dentro del modelo planteado en el capítulo 2, uno de ellos fue la inclusión de lo que se llamo ganancia de thresholding, que equivale a representar el uso de técnicas de thresholding. Con esta variable incluida, se pudo comprobar que es posible reemplazar las técnicas de time gating por la de thresholding, obteniendo como ventaja adicional el no requerir sincronización. Finalmente en este capítulo se analizó el efecto que tenia sobre la señal recuperada la polarización de las señales interferentes respecto a la señal objetivo. Se analizó el sistema suponiendo un comportamiento aleatorio de la polarización encontrando que el impacto sobre el sistema era despreciable.

Con respecto al diseño, construcción e implementación de los dispositivos codificadores y decodificadores en el capítulo 3 se realiza una completa reseña de los dispositivos basados en redes de difracción de Bragg superestructuradas. En este capítulo se parte de la teoría general de las redes de difracción de Bragg, haciendo énfasis en las FBGs superestructuradas. A continuación, se explicó la forma como se diseñaron los códigos Gold, que fueron implementados sobre las SSFBGs. Posteriormente se describió el procedimiento y las principales variables a tener en cuenta durante la construcción de las SSFBGs. Teniendo las SSFBGs construidas se procedió a describir el proceso de codificación y decodificación, los dispositivos usados y los equipos empleados para realizar las mediciones. Con los resultados obtenidos se observó la dependencia que existe entre la sintonía en longitud de onda y la temperatura y a partir de allí se realizó el estudio de dicha dependencia. De este estudio se concluyó: 1. El efecto de los cambios de temperatura es mayor en la medida que la longitud de la SSFBG aumenta, 2. Para poder mantener el sistema estable y sin pérdidas por desintonía la temperatura debe ser mantenida constante durante todo el proceso, en nuestro sistema se alcanzó una precisión de 0.1 grado centígrado. Por último, y basándonos en el estudio anterior se propuso que la desintonía en longitud de onda causada por los cambios de temperatura fuese utilizada como un factor de multiplexación adicional dentro de este tipo de sistemas. La desintonía requerida para conseguir un desvanecimiento total del pulso estaba entre los 10 y los 20 pm, lo cual corresponde a una pequeña fracción del espectro ocupado por la señal codificada que es cercano a los $2 \mathrm{~nm}$. Se verificó experimentalmente que la desintonía por longitud de onda permite obtener niveles equivalentes de MUI a los que se ob- 
tienen cuando se realiza un procedimiento estándar de codificación y decodificación. En consecuencia pudimos concluir que la desintonía se puede emplear para expandir el número de palabras código disponibles o para seleccionar activamente distintos pares codificador/decodificador sin requerir ancho de banda óptico adicional.

Una de las desventajas de las redes de difracción de Bragg son sus pérdidas de inserción. Para resolver este problema se ha propuesto por diferentes autores, apodizar el nivel de reflectividad local de la SSFBG, sin embargo esto produce una deformación de la respuesta impulsiva de las SSFBGs ya sea por las múltiples reflexiones o por las perdidas de potencia que se dan a medida que la señal recorre la red de difracción. Por ello en el capítulo 4 se analizó el comportamiento de las redes de alta reflectividad y se propuso el diseño de dispositivos cod/decodificadores basados en SSFBGs de alta reflectividad mediante el método de síntesis DLP. Con los dispositivos obtenidos gracias a este novedoso procedimiento, se dio una solución integral al problema, reduciendo las pérdidas de potencia y evitando la deformación que podría sufrir la respuesta impulsiva al elevar el índice de reflectividad como consecuencia de las múltiples reflexiones. Mediante el procesado de la señal realizado con las nuevas SSFBGs, se consiguen los mismo resultados que usando redes de baja reflectividad, como las descritas en el capítulo 3, pero consiguiendo reducir las perdidas de potencia en aproximadamente $5 \mathrm{~dB}$ por cada dispositivo cod/decodificador $(10 \mathrm{~dB}$ en el enlace completo).

La codificación óptica no solo es útil cuando se quiere identificar un usuario dentro de la red, también es posible utilizarla como técnica para generar etiquetas en redes de paquetes o ráfagas todo ópticas. Precisamente en el capítulo 5 se abordó esta aplicación, allí se describe brevemente en que consiste el uso de etiquetas ópticas y algunas de las propuestas realizadas para tal implementación. Las propuestas realizadas son, en su mayoría, muy novedosas pero al momento de una aplicación práctica debido a su complejidad pierden los objetivos buscados, como son disminuir la latencia y conseguir sistemas de sencilla operación. Por tal motivo en este capítulo se propuso la reutilización de los picos de autocorrelación que habían sido recuperados de procesos previos, para ser recodificados y vueltos a usar como etiquetas para nuevos paquetes. Mediante este procedimiento se consigue reducir el número de fuentes pulsadas en cada nodo y se evita la necesidad de sincronismo. La demostración del reuso de pulsos de autocorrelación se realizó primero mediante simulación y posteriormente se verificó experimentalmente su viabilidad. Con los experimentos planteados se demostró la posibilidad de realizar 4 saltos entre nodos ópticos sin perder la capacidad de detectar correctamente la etiqueta. Además se demostró que los receptores requeridos para la detección de dichos pulsos recodificados no deberían tener exigentes parámetros de ancho de banda o tener implementadas técnicas de time gating o thresholding.

En el capítulo 5 también se estudiaron los efectos que tiene la dispersión sobre las señales codificadas propagándose por una fibra óptica estándar. Con este estudio se pudo concluir que el efecto que pueda llegar a tener la dispersión sobre las señales dependerá no solo de la distancia recorrida por la señal, sino también de la palabra código que se este utilizando. En general se pudo comprobar que aplicaciones que usen cod/decodificación óptica pueden ser implementadas como soluciones de última milla sin requerir ningún tipo de compensación, pero en aquellas donde se supere dicha longitud se deberá verificar la necesidad de usar técnicas de compensación de 
dispersión.

El acceso múltiple por división en código también puede ser implementado usando códigos unipolares mediante codificación en amplitud. La codificación de códigos unipolares tiene grandes desventajas con respecto a la codificación coherente que usa códigos bipolares o multipolares, sin embargo tiene la ventaja de no ser afectada por el ruido de batido y ser sencilla de implementar. Si además agregamos que se puede codificar usando códigos en dos dimensiones, encontramos que es posible solucionar algunas de las desventajas de los sistemas incoherentes. Por ello el capítulo 6 se dedico a tratar el tema de los sistemas incoherentes. Lo primero que se midió fue la separación mínima requerida entre frecuencia de canales para que se pueda considerar el sistema como incoherente. El experimento realizado consistió en medir el ruido de batido producido entre dos canales superpuestos. Se verificó que el batido decrecía a medida que la coincidencia en longitud de onda disminuía. Para el experimento propuesto el ruido de batido casi desaparecía al alcanzar los 800 pm de separación en longitud de onda entre canales. Esta misma distancia es a partir de la cual consideramos el sistema como incoherente, aunque, podría ser algo menor si tenemos en cuenta que la magnitud del ruido cae $3 \mathrm{~dB}$ a los $700 \mathrm{pm}$ o que la penalización del diagrama de ojo nos podría permitir llegar a los $600 \mathrm{pm}$, de acuerdo a la calidad de los detectores, al tamaño del pulso de entrada o al sincronismo del sistema. Posteriormente se diseñó un código en dos dimensiones y se realizó la implementación práctica de 2 de ellos (codificadores y decodificadores) incluyendo para los experimentos canales de interferencia en tiempo y en frecuencia. Se demostró que en un sistema de este estilo debidamente sincronizado el ruido caerá por fuera de la señal objetivo y que con un adecuado enventanado de la señal se puede eliminar esta interferencia. El ruido que afecta directamente sobre la señal objetivo ocasiona un decremento en la apertura del ojo, no obstante al no existir batido entre las señales es posible su eliminación utilizando técnicas de thresholding.

\subsection{Líneas Abiertas}

Los sistemas OCDMA tienen aspectos muy diversos, en esta tesis se han estudiado algunos de ellos logrando obtener resultados satisfactorios y que a su vez ha generado posibles nuevas líneas de investigación. A continuación enumeramos dichas líneas agrupadas según los temas tratados en esta tesis.

\subsubsection{Modelado de Sistemas OCDMA.}

- Adicionar al modelo del capítulo 2, los efectos de la dispersión, las no linealidades de la fibra óptica, para evaluar su incidencia sobre la BER del sistema. Dentro de este modelo también seria posible considerar longitudes de código superiores sin disminuir la tasa de transmisión lo que permitiría evaluar hasta que punto el sistema puede ser inmune a la interferencia intersímbolo (ISI).

- Profundización en el modelado del ruido en los sistemas OCDMA de tipo incoherente. Así como se realizo en el capítulo 2, para los sistemas OCDMA de 
tipo coherente, así mismo se propone continuar con el modelado de los sistemas incoherentes.

\subsubsection{Diseño, Fabricación e Implementación de Dispositivos Codificadores y Decodificadores}

- Diseñar, fabricar e implementar dispositivos cod/decodificadores basados en SSFBGs con diferentes alternativas de códigos, ya sean de mayor extensión (127 ó 511 chips) o m-arios. Con el objeto de verificar las ventajas de contar con códigos más largos, es decir, con mejores propiedades de autocorrelación y correlación cruzada. También se puede con ello comprobar hasta que punto una mayor longitud de SSFBG seria inconveniente, en el sentido de percibir mayor desintonía en longitud de onda a causa de variaciones en la temperatura.

\subsubsection{Aplicaciones de las Tecnologías de Cod/decodificación Todo Óptica}

- Implementar un nodo para una red de conmutación de etiquetas o ráfagas ópticas que emplee el reuso de picos de autocorrelación, verificando su viabilidad y evaluando las ventajas que tiene un procesamiento completamente óptico.

- Realizar un estudio de las familias de códigos utilizadas en sistemas de conmutación de etiquetas ópticas, con el objetivo de encontrar los más apropiados para ser utilizados en este tipo de sistemas.

- Según el estudio realizado del efecto de la dispersión sobre las señales codificadas, se encontró que si el pulso es muy estrecho se vera más afectado por la dispersión, pero si es demasiado ancho puede disminuir la capacidad de codificación de los dispositivos. Por ello se debe profundizar en dicho estudio, procurando encontrar una relación óptima entre el tamaño del chip y el tamaño del pulso de entrada para conseguir una señal correctamente codificada y más resistente a la dispersión.

\subsubsection{Sistemas Incoherentes}

- Estudiar los códigos en 2 dimensiones buscando aquellos que proporcionen un apropiado rendimiento en términos de eficiencia espectral y que permitan realizar comunicaciones de tipo asíncrono.

- Proponer e Implementar un sistema OCDMA incoherente, con el máximo número de usuarios posibles y de forma asíncrona. Con este sistema se podrá medir el impacto del ruido sobre la BER del sistema y la posibilidad de transmitir señales codificadas de forma asíncrona. 



\section{Bibliografía}

[1] P. C. Teh, P. Petropoulos, M. Ibsen, and D. Richardson, "A comparative study of the performance of seven- and 63-chip optical code-division multiple-access encoders and decoders based on superstructured fiber bragg gratings," Lightwave Technology, Journal of, vol. 19, no. 9, pp. 1352-1365, Sept. 2001.

[2] J. Salehi, "Code-division multiple-access techniques in optical fiber networks part i. fundamental principles," IEEE Transactions on Communications, vol. 37, no. 8, pp. 824-833, Aug. 1989.

[3] C. Salehi, J.A.; Brackett, "Code-division multiple-access techniques in optical fiber networks - part ii. systems performance analysis," Communications, IEEE Transactions on, vol. 37, no. 8, pp. 834-842, Aug 1989.

[4] L. Tancevski and I. Andonovic, "Hybrid wavelength hopping/time spreading schemes for use in massive optical networks with increased security," Lightwave Technology, Journal of, vol. 14, no. 12, pp. 2636-2647, Dec. 1996.

[5] N. Wada, H. Sotobayashi, and K. Kitayama, "2.5 gbit/s timespread/wavelength-hop optical code division multiplexing using fibre bragg grating with supercontinuum light source," in Electronics Letters, vol. 36, no. 9, 27 April 2000, pp. 815-817.

[6] X. Wang and K. T. Chan, "A sequentially self-seeded fabry-perot laser for twodimensional encoding/decoding of optical pulses," Quantum Electronics, IEEE Journal of, vol. 39, no. 1, pp. 83-90, Jan 2003.

[7] X. Wang, N. Wada, T. Hamanaka, J. Kitayama, and A. Nishiki, "10-user, trulyasynchronous ocdma experiment with 511-chip ssfbg en/decoder and sc-based optical thresholder," in Optical Fiber Communication Conference, 2005. Technical Digest. OFC/NFOEC, vol. 6, 6-11 March 2005, p. 3pp.Vol.5.

[8] Z. Jiang, D. Seo, S.-D. Yang, D. Leaird, A. Weiner, R. Roussev, C. Langrock, and M. Fejer, "Four user, $2.5 \mathrm{gb} / \mathrm{s}$, spectrally coded o-cdma system demonstration using low power nonlinear processing," in Optical Fiber Communication Conference, 2004. OFC 2004, vol. 2, 23-27 Feb. 2004, p. 3pp.vol.2.

[9] H. Sotobayashi, W. Chujo, and K. Kitayama, "1.6-b/s/hz 6.4-tb/s qpsk$\mathrm{ocdm} / \mathrm{wdm}(4 \mathrm{ocdm} \times 40 \mathrm{wdm} \times 40 \mathrm{gb} / \mathrm{s})$ transmission experiment using optical 
hard thresholding," Photonics Technology Letters, IEEE, vol. 14, no. 4, pp. 555557, April 2002.

[10] Z. Jiang, D. Seo, S.-D. Yang, D. Leaird, R. Roussev, C. Langrock, M. Fejer, and A. Weiner, "Low-power high-contrast coded waveform discrimination at $10 \mathrm{ghz}$ via nonlinear processing," Photonics Technology Letters, IEEE, vol. 16, no. 7, pp. 1778-1780, July 2004.

[11] V. Hernandez, Y. Du, W. Cong, R. Scott, K. Li, J. Heritage, Z. Ding, B. Kolner, and S. Yoo, "Spectral phase-encoded time-spreading (spects) optical codedivision multiple access for terabit optical access networks," Lightwave Technology, Journal of, vol. 22, no. 11, pp. 2671-2679, Nov. 2004.

[12] P. Prucnal, M. Santoro, and T. Fan, "Spread spectrum fiber-optic local area network using optical processing," Lightwave Technology, Journal of, vol. 4, pp. 547-554, May 1986.

[13] K. Wada, N.; Kitayama, "A 10 gb/s optical code division multiplexing using 8chip optical bipolar code and coherent detection," Lightwave Technology, Journal of, vol. 17, no. 10, pp. 1758-1765, October 1999.

[14] R. Adams, J. Faucher, L. Thomas, D. Plant, and L. Chen, "Demonstration of encoding and decoding 2-d wavelength-time bipolar codes for ocdma systems with differential detection," Photonics Technology Letters, IEEE, vol. 17, no. 11, pp. 2490-2492, Nov. 2005.

[15] T. M. Bazan, D. Harle, and I. Andonovic, "Mitigation of beat noise in time\&avelength optical code-division multiple-access systems," Lightwave Technology, Journal of, vol. 24, no. 11, pp. 4215-4222, Nov. 2006.

[16] K. Li, W. Cong, V. Hernandez, R. Scott, J. Cao, Y. Du, J. Heritage, B. Kolner, and S. Yoo, "10 gbit/s optical cdma encoder-decoder ber performance using hnlf thresholder," Optical Fiber Communication Conference, 2004. OFC 2004, vol. 1, pp.-, Feb. 2004.

[17] P. Teh, M. Ibsen, J. Lee, P. Petropoulos, and D. Richardson, "Demonstration of a four-channel wdm/ocdma system using 255-chip 320-gchip/s quarternary phase coding gratings," Photonics Technology Letters, IEEE, vol. 14, no. 2, pp. 227-229, Feb. 2002.

[18] T. Koonen, "Fiber to the home/fiber to the premises: What, where, and when?" Proceedings of the IEEE, vol. 94, no. 5, pp. 911-934, May 2006.

[19] A. Stok and E. Sargent, "The role of optical cdma in access networks," Communications Magazine, IEEE, vol. 40, no. 9, pp. 83-87, Sep 2002.

[20] K. Kitayama, X. Wang, and N. Wada, "Ocdma over wdm pon-solution path to gigabit-symmetric ftth," Lightwave Technology, Journal of, vol. 24, no. 4, pp. 1654-1662, April 2006. 
[21] J. Kani, K. Iwatsuki, and T. Imai, "Optical multiplexing technologies for accessarea applications," Selected Topics in Quantum Electronics, IEEE Journal of, vol. 12, no. 4, pp. 661-668, July-Aug. 2006.

[22] K.-I. Kitayama and N. Wada, "Photonic ip routing," Photonics Technology Letters, IEEE, vol. 11, no. 12, pp. 1689 - 1691, December 1999.

[23] K. Fouli and M. Maier, "Ocdma and optical coding: Principles, applications, and challenges [topics in optical communications]," Communications Magazine, IEEE, vol. 45, no. 8, pp. 27-34, August 2007.

[24] B. K. Kim, S. Park, Y. Yeon, and B. W. Kim, "Radio-over-fiber system using fiber-grating-based optical cdma with modified pn codes," Photonics Technology Letters, IEEE, vol. 15, no. 10, pp. 1485-1487, Oct. 2003.

[25] M. Kitayama, K.-I.; Murata, "Versatile optical code-based mpls for circuit, burst, and packet switchings," Lightwave Technology, Journal of, vol. 21, no. 11, pp. 2753 - 2764, November 2003.

[26] J. Rosas-Fernandez, J. Penon, L. Rusch, and S. LaRochelle, "All-optical label stacking capacity for packet switching using spectral amplitude code labels," Lasers and Electro-Optics Society, 2006. LEOS 2006. 19th Annual Meeting of the IEEE, pp. 484-485, Oct. 2006.

[27] H. Fathallah and L. A. Rusch, "Network management solution for ps/pon, wdm/pon and hybrid ps/wdm/pon using ds-ocdm," Optical Fiber Communication and the National Fiber Optic Engineers Conference, 200\%. OFC/NFOEC 200\%. Conference on, pp. 1-3, March 2007.

[28] S. Yoshima, K. Onohara, N. Wada, F. Kubota, and K. Kitayama, "Multicastcapable optical code label switching and its experimental demonstration," Lightwave Technology, Journal of, vol. 24, no. 2, pp. 713-722, Feb. 2006.

[29] K. Kitayama, X. Wang, and H. Sotobayashi, "Gigabit-symmetric ftth - ocdma over wdm pon," in Optical Network Design and Modeling, 2005. Conference on, Feb. 7-9, 2005, pp. 273-281.

[30] S.-J. Park, C.-H. Lee, K.-T. Jeong, H.-J. Park, J.-G. Ahn, and K.-H. Song, "Fiber-to-the-home services based on wavelength-division-multiplexing passive optical network," Lightwave Technology, Journal of, vol. 22, no. 11, pp. 25822591, Nov. 2004.

[31] M. Nakamura, H. Ueda, S. Makino, T. Yokotani, and K. Oshima, "Proposal of networking by pon technologies for full and ethernet services in fttx," Lightwave Technology, Journal of, vol. 22, no. 11, pp. 2631-2640, Nov. 2004.

[32] T. Hamanaka, X. Wang, N. Wada, A. Nishiki, and K. Kitayama, "Ten-user truly asynchronous gigabit ocdma transmission experiment with a 511-chip ssfbg en/decoder," Lightwave Technology, Journal of, vol. 24, no. 1, pp. 95-102, Jan. 2006. 
[33] W. X. Kitayama, K. and H. Sotobayashi, "State of the art of ocdma, ocdm, and oc-label switchings," The 30th European Conference on Optical Communication (ECOC 2004), pp. 266-269, September 2004.

[34] K.-i. Kitayama, H. Sotobayashi, and N. Wada, "Optical code division multiplexing (ocdm) and its applications to photonic networks (special section on spread spectrum techniques and applications)," IEICE transactions on fundamentals of electronics, communications and computer sciences, vol. 82, no. 12, pp. 2616-2626, 1999. [Online]. Available: http://ci.nii.ac.jp/naid/110003208210/

[35] M. Marhic, "Coherent optical cdma networks," Lightwave Technology, Journal of, vol. 11, no. 5, pp. 854-864, May-Jun 1993.

[36] P. Seddighian, S. Ayotte, J. B. Rosas-Fernandez, J. Penon, L. A. Rusch, and S. LaRochelle, "Label stacking in photonic packet-switched networks with spectral amplitude code labels," Lightwave Technology, Journal of, vol. 25, no. 2, pp. 463-471, Feb. 2007.

[37] X. Wang and K. Kitayama, "Analysis of beat noise in coherent and incoherent time-spreading ocdma," Lightwave Technology, Journal of, vol. 22, no. 10, pp. 2226-2235, Oct. 2004.

[38] a. M. K. Wang X., Kitayama K., "Beat noise limitation in coherent timespreading ocdma network," Procedings 8th Optoelectronics Communication Conf. OECC 2003, no. Paper 16E2-4, pp. 727-728, 2003, shanghai, China.

[39] X. Wang, N. Wada, T. Miyazaki, G. Cincotti, and K. ichi Kitayama, "Field trial of 3-wdm x 10-ocdma x 10.71-gb/s asynchronous wdm/dpsk-ocdma using hybrid e/d without fec and optical thresholding," Lightwave Technology, Journal of, vol. 25, no. 1, pp. 207-215, Jan. 2007.

[40] X. Wang, N. Wada, T. Miyazaki, and K. Kitayama, "Coherent ocdma system using dpsk data format with balanced detection," Photonics Technology Letters, IEEE, vol. 18, no. 7, pp. 826-828, April 1, 2006.

[41] Z. Jiang, D. Seo, S. Yang, D. Leaird, R. Roussev, C. Langrock, M. Fejer, and A. Weiner, "Four-user 10-gbps spectrally phase-coded o-cdma system operating at $30 \mathrm{fj} /$ bit," Photonics Technology Letters, IEEE, vol. 17, no. 3, pp. 705-707, March 2005.

[42] J. Lee, P. Teh, Z. Yusoff, M. Ibsen, W. Belardi, T. Monro, and D. Richardson, "A holey fiber-based nonlinear thresholding device for optical cdma receiver performance enhancement," Photonics Technology Letters, IEEE, vol. 14, no. 6, pp. 876-878, June 2002.

[43] H. Sotobayashi, W. Chujo, and K. Kitayama, "Highly spectral efficient optical code-division multiplexing transmission system," Selected Topics in Quantum Electronics, IEEE Journal of, vol. 10, no. 2, pp. 250-258, March-April 2004. 
[44] X. Wang, N. Wada, and K. Kitayama, "Performance degradation in coherent ocdma due to receivers' bandwidth limit and improvement by using optical thresholding," in Procedings 18th Annual Meeting of Lasers and Electro-Optics Society, 2005. LEOS 2005., 22-28 Oct. 2005, pp. 638-639.

[45] R. Scott, W. Cong, K. Li, V. Hernandez, B. Kolner, J. Heritage, and S. Yoo, "Demonstration of an error-free $4 \times 10 \mathrm{gb} / \mathrm{s}$ multiuser spects o-cdma network testbed," Photonics Technology Letters, IEEE, vol. 16, no. 9, pp. 2186-2188, Sept. 2004.

[46] Z. Wang, C. Lin, K.-K. Chow, Y.-C. Ku, and A. Bjarklev, "Wavelengthtunable dispersion-imbalanced loop mirror based on dispersion-flattened highnonlinearity photonic crystal fiber and its application in suppression of the incoherent interferometric crosstalk," Photonics Technology Letters, IEEE, vol. 17, no. 9, pp. 1911-1913, Sept. 2005.

[47] S. Yegnanarayanan, A. Bhushan, and B. Jalali, "Fast wavelength-hopping timespreading encoding/decoding for optical cdma," Photonics Technology Letters, IEEE, vol. 12, no. 5, pp. 573-575, May 2000.

[48] Z. Jiang, D. Seo, S.-D. Yang, D. Leaird, A. Weiner, R. Roussev, C. Langrock, and M. Fejer, "Spectrally coded o-cdma system with four users at $2.5 \mathrm{gbit} / \mathrm{s}$ using low power nonlinear processing," in Electronics Letters, vol. 40, no. 10, 13 May 2004, pp. 623-625.

[49] J. H. Lee, P. C. Teh, P. Petropoulos, M. Ibsen, and D. Richardson, "Reduction of interchannel interference noise in a two-channel grating-based ocdma system using a nonlinear optical loop mirror," Photonics Technology Letters, IEEE, vol. 13, no. 5, pp. 529-531, May 2001.

[50] — "A grating-based ocdma coding decoding system incorporating a nonlinear optical loop mirror for improved code recognition and noise reduction," Lightwave Technology, Journal of, vol. 20, no. 1, pp. 36-46, Jan. 2002.

[51] D. Pastor, R. Amaya, W. García-Olcina, and S. S., "Coherent direct sequence optical code multiple access encoding-decoding efficiency versus wavelength detuning," Optics Letters, vol. 32, no. 13, pp. 1896-1898, June 2007.

[52] J. Salehi, "Emerging optical code-division multiple access communication systems," Network, IEEE, vol. 3, no. 2, pp. 31-39, March 1989.

[53] Z. Zhang, C. Tian, P. Petropoulos, D. J. Richardson, and M. Ibsen, "Distributedphase ocdma encoder\&ecoders based on fiber bragg gratings," Photonics Technology Letters, IEEE, vol. 19, no. 8, pp. 574-576, April15, 2007.

[54] K. Takiguchi, T. Shibata, and H. Takahashi, "Time-spreading/wavelengthhopping ocdma experiment using plc encoder/decoder with large spread factor," in Electronics Letters, vol. 42, no. 5, 2 March 2006, pp. 301-302. 
[55] X. Wang and N. Wada, "Demonstration of hybrid ocdma/ops networks based on optical code processing using superstructure fbg and plc encoder/decoders," in Communications, 2006 IEEE International Conference on, vol. 6, June 2006, pp. 2619-2623.

[56] T. P. B. T. J. J. Agarwal A., Menendez R. and E. S., "Enhanced confidentiality using ocdm-based code scrambling and self-obscuration," Optics Express, vol. 16, no. 3, pp. 1399-1404, february 2008.

[57] A. Mendez, R. Gagliardi, V. Hernandez, C. Bennett, and W. Lennon, "Highperformance optical cdma system based on 2-d optical orthogonal codes," Lightwave Technology, Journal of, vol. 22, no. 11, pp. 2409-2419, Nov. 2004.

[58] V. Hernandez, A. Mendez, C. Bennett, and W. Lennon, "Bit-error-rate performance of a gigabit ethernet o-cdma technology demonstrator (td)," in Lasers and Electro-Optics Society, 2004. LEOS 2004. The 17th Annual Meeting of the IEEE, vol. 2, 7-11 Nov. 2004, pp. 499-500Vol.2.

[59] M. Mokhtar, M. Ibsen, P. Teh, and D. Richardson, "Reconfigurable multilevel phase-shift keying encoder-decoder for all-optical networks," Photonics Technology Letters, IEEE, vol. 15, no. 3, pp. 431-433, March 2003.

[60] T. Erdogan, "Fiber grating spectra," Lightwave Technology, Journal of, vol. 15, no. 8, pp. 1277-1294, August 1997.

[61] P. R. Prucnal, Optical Code Division Multiple Access, P. R. Prucnal, Ed. Taylor \& Francis, 2006, vol. 1.

[62] J. Komo and J. Park, W.J., "Maximal-length pseudorandom number generator," in System Theory, 1989. Proceedings., Twenty-First Southeastern Symposium on, 26-28 March 1989, pp. 89-92.

[63] J. Komo and C.-C. Yuan, "Evaluation of code division multiple access systems," in Southeastcon '89. Proceedings. 'Energy and Information Technologies in the Southeast'., IEEE, 9-12 April 1989, pp. 849-854vol.2.

[64] E. H. Dinan and B. Jabbari, "Spreading codes for direct sequence cdma and wideband cdma cellular networks," IEEE Communications Magazine, vol. 36, no. 9, pp. 48-54, September 1998.

[65] P. Fan and M. Darnel, Sequence Design for Communications Applications, 1st ed. Research Studies Press, 1996.

[66] R. C. Dixon, Spread Spectrum Systems with Commercial Applications, J. W. . Sons, Ed., 1994.

[67] A. W. Lam and T. S., Theory and Applications of Spread-Spectrum Systems, IEEE, Ed. IEEE, 1994.

[68] K. O. Hill, B. malo, F. Bilodeau, and J. Albert, "Bragg gratings fabricated in monomode photosenitive optical fibre by uv exposure trough a phase mask," App. Phys. lett, vol. 62, no. 25, pp. 1035-1037, 1993. 
[69] D. Z. Anderson, V. Mizrahi, T. Erdogan, and A. E. White, "Production on infibre gratings using a diffraction optical element," Electronics Letters, vol. 29, no. 6, pp. 566-568, 1993.

[70] K. Hill and G. Meltz, "Fiber bragg grating technology fundamentals and overview," Journal of Lightwave Technology, vol. 15, no. 8, pp. 1263-1276, august 1997.

[71] R. Garcia-Olcina, "Sistema de fabricación de redes de difracción de bragg en fibra óptica de altas prestaciones y aplicaciones al campo de los sensores ópticos y a los sistemas de comunicaciones ópticas," Ph.D. dissertation, Universidad Politecnica de Valencia, 2008.

[72] X. Wang, W. Naoya, and K. Ken-ichi, "Inter-symbol interference and beat noise in flexible data-rate coherent ocdma and the ber improvement by using optical thresholding," Optics Express, vol. 13, no. 26, pp. 10 469-10 474, December 2005.

[73] A. C. J. A. M. Mora, J.; Diez, "A magnetostrictive sensor interrogated by fiber gratings for dc-current and temperature discrimination," Photonics Technology Letters, IEEE, vol. 12, no. 12, pp. 1680 - 1682, December 2000.

[74] K. Matsushima, X. Wang, S. Kutsuzawa, A. Nishiki, S. Oshiba, N. Wada, and K. Kitayama, "Experimental demonstration of performance improvement of 127chip ssfbg en/decoder using apodization technique," Photonics Technology Letters, IEEE, vol. 16, no. 9, pp. 2192-2194, Sept. 2004.

[75] N. A. Wang Xu and K. Ken-Ichi, "Improvement of the coding performance of ssfbg en/decoder by apodization technique," Microwave and Optical Technology Letters, vol. 43, pp. 247-250, 2004.

[76] A. N. N. W. Wang Xu, Koji Matsushima and K. ichi Kitayama, "High reflectivity superstructured fbg for coherent optical code generation and recognition," Optical Express, vol. 12, pp. 5457-5468, 2004.

[77] J. Skaar, L. Wang, and T. Erdogan, "On the synthesis of fiber bragg gratings by layer peeling," Quantum Electronics, IEEE Journal of, vol. 37, no. 2, pp. 165-173, Feb. 2001.

[78] L. Poladian, "Simple grating synthesis algorithm," Optics Letters, vol. 25, no. 11, pp. 787-789, june 2000 .

[79] M. M. M. Feced, R.; Zervas, "An efficient inverse scattering algorithm for the design of nonuniform fiber bragg gratings," Quantum Electronics, IEEE Journal of, vol. 35, no. 8, pp. 1105-1115, august 1999.

[80] J. M. J. Peral, E.; Capmany, "Iterative solution to the gel'fand-levitanmarchenko coupled equations and application to synthesis of fiber gratings," Quantum Electronics, IEEE Journal of, vol. 32, no. 12, pp. 2078-2084, December 1996 . 
[81] G. Cincotti, N. Wada, S. Yoshima, N. Kataoka, and K.-I. Kitayama, "200 gchip/s, 16-label simultaneous multiple-optical encoder/decoder and its application to optical packet switching," in Optical Fiber Communication Conference, 2005. Technical Digest. OFC/NFOEC, vol. 6, 6-11 March 2005, p. 3pp.Vol.5.

[82] N. S. H. Kitayama, K.; Wada, "Architectural considerations for photonic ip router based upon optical code correlation," Lightwave Technology, Journal of, vol. 18, no. 12, pp. 1834 - 1844, December 2000.

[83] T. P. I. M. L. J. Thomsen, B.C. and D. Richardson, "A multi-hop optical packet switching demonstration employing all-optical grating based header generation and recognition," Optical Communication, 2002. ECOC 2002. 28th European Conference on, vol. 2, pp. 1-2, september 2002.

[84] X. Wang and N. Wada, "Experimental demonstration of ocdma traffic over optical packet switching network with hybrid plc and ssfbg en/decoders," Lightwave Technology, Journal of, vol. 24, no. 8, pp. 3012-3020, Aug. 2006.

[85] G. Cincotti, "Full optical encoders/decoders for photonic ip routers," Lightwave Technology, Journal of, vol. 22, no. 2, pp. 337-342, february 2004.

[86] J.-F. Huang, Y.-T. Chang, C.-C. Sue, and C.-C. Hsu, "Hybrid wdm and optical cdma implemented with m-sequence coded waveguide gratings over fiber-to-thehome network," in Communications, Circuits and Systems Proceedings, 2006 International Conference on, vol. 3, 25-28 June 2006, pp. 1860-1864.

[87] T. Shake, "Confidentiality performance of spectral-phase-encoded optical cdma," Lightwave Technology, Journal of, vol. 23, no. 4, pp. 1652-1663, April 2005.

[88] M. Kavehrad and D. Zaccarin, "Optical code-division-multiplexed systems based on spectral encoding of noncoherent sources," Lightwave Technology, Journal of, vol. 13, no. 3, pp. 534-545, March 1995.

[89] K. Kitayama, "Novel spatial spread spectrum based fiber optic cdma networks for image transmission," Selected Areas in Communications, IEEE Journal on, vol. 12, no. 4, pp. 762 - 772, May 1994.

[90] V. Hernandez, A. Mendez, C. Bennett, R. Gagliardi, and W. Lennon, "Biterror-rate analysis of a 16-user gigabit ethernet optical-cdma (o-cdma) technology demonstrator using wavelength/time codes," Photonics Technology Letters, IEEE, vol. 17, no. 12, pp. 2784-2786, Dec. 2005.

[91] J. Hui, "Pattern code modulation and optical decoding - a novel code-division multiplexing technique for multifiber networks," Selected Areas in Communications, IEEE Journal on, vol. 3, no. 6, pp. 916 - 927, November 1985.

[92] A. G. E. Park, E.; Mendez, "Temporal/spatial optical cdma networks-design, demonstration, and comparison with temporal networks," Photonics Technology Letters, IEEE, vol. 4, no. 10, pp. 1160 - 1162, October 1992. 
[93] N. Sangin Kim; Kyungsik Yu; Park, "A new family of space/wavelength/time spread three-dimensional optical code for ocdma networks," Lightwave Technology, Journal of, vol. 18, no. 4, pp. 502 - 511, April 2000.

[94] D. Zaccarin and M. Kavehrad, "An optical cdma system based on spectral encoding of led," Photonics Technology Letters, IEEE, vol. 5, no. 4, pp. 479-482, April 1993.

[95] T. Pfeiffer, B. Deppisch, M. Witte, and R. Heidemann, "Operational stability of a spectrally encoded optical cdma system using inexpensive transmitters without spectral control," Photonics Technology Letters, IEEE, vol. 11, no. 7, pp. 916-918, July 1999.

[96] M. Rochette and L. Rusch, "Spectral efficiency of ocdma systems with coherent pulsed sources," Lightwave Technology, Journal of, vol. 23, no. 3, pp. 1033-1038, March 2005.

[97] C.-S. Bres, I. Glesk, and P. Prucnal, "Demonstration of an eight-user 115-gchip/s incoherent ocdma system using supercontinuum generation and optical time gating," Photonics Technology Letters, IEEE, vol. 18, no. 7, pp. 889-891, April $1,2006$.

[98] W. Kwong and G.-C. Yang, "Design of multilength optical orthogonal codes for optical cdma multimedia networks," Communications, IEEE Transactions on, vol. 50, no. 8, pp. 1258-1265, Aug. 2002.

[99] J. W. V. Chung, F.R.K.; Salehi, "Optical orthogonal codes: design, analysis and applications," Information Theory, IEEE Transactions on, vol. 35, no. 3, pp. 595 - 604, May 1989.

[100] H. Fathallah, L. Rusch, and S. LaRochelle, "Passive optical fast frequency-hop cdma communications system," Lightwave Technology, Journal of, vol. 17, no. 3, pp. 397-405, March 1999.

[101] L. Chen, "Flexible fiber bragg grating encoder/decoder for hybrid wavelengthtime optical cdma," Photonics Technology Letters, IEEE, vol. 13, no. 11, pp. 1233-1235, Nov. 2001.

[102] R. Yim, L. Chen, and J. Bajcsy, "Design and performance of 2-d codes for wavelength-time opticalcdma," Photonics Technology Letters, IEEE, vol. 14, no. 5, pp. 714-716, May 2002.

[103] W. Guu-Chang Yang; Kwong, "Two-dimensional spatial signature patterns," Communications, IEEE Transactions on, vol. 44, no. 2, pp. 184 - 191, February 1996.

[104] V. L. X. R. D. G. I. P. P. Patel, P.; Baby, "A scalable wavelength-hopping, time-spreading optical-cdma system," Lasers and Electro-Optics Society, 2003. LEOS 2003. The 16th Annual Meeting of the IEEE, vol. 2, pp. 1048 - 1049 vol.2, October 2003. 
[105] A. Mendez, R. Gagliardi, V. Hernandez, C. Bennett, and W. Lennon, "Design and performance analysis of wavelength/time $(\mathrm{w} / \mathrm{t})$ matrix codes for optical cdma," Lightwave Technology, Journal of, vol. 21, no. 11, pp. 2524-2533, Nov. 2003.

[106] V. B. C. L. W. G. R. Mendez, A.J.; Hernandez, "Optical cdma (o-cdma) technology demonstrator (td) for 2d codes," Lasers and Electro-Optics Society, 2003. LEOS 2003. The 16th Annual Meeting of the IEEE, vol. 2, pp. 1044-1045 vol.2, October 2003.

[107] I. Andonovic and L. Tancevski, "Incoherent optical code division multiple access systems," in Spread Spectrum Techniques and Applications Proceedings, 1996., IEEE 4th International Symposium on, vol. 1, 22-25 Sept. 1996, pp. 424430vol.1.

[108] L. Chen and P. Smith, "Demonstration of incoherent wavelength-encoding/timespreading optical cdma using chirped moire gratings," Photonics Technology Letters, IEEE, vol. 12, no. 9, pp. 1281-1283, Sept. 2000.

[109] W. Idler and J.-C. Antona, "Record spectral efficiencies and transmission capacities based on nx43 gbps systems," in Lasers and Electro-Optics Society, 2002. LEOS 2002. The 15th Annual Meeting of the IEEE, vol. 1, 10-14 Nov. 2002, pp. $255-256 \mathrm{vol} .1$.

[110] J. Robinson, "Optimum golomb rulers," Computers, IEEE Transactions on, vol. C-28, no. 12, pp. 943 - 944, December 1979.

[111] F. Khansefid, H. Taylor, and R. Gagliardi, "Design of $(0,1)$ sequence sets for pulsed coded systems," Communications Science Institute, 1988.

[112] J. M. J.-M. G. R. Mendez, A.J.; Lambert, "Synthesis and demonstration of high speed, bandwidth efficient optical code division multiple access (cdma) tested at $1 \mathrm{gb} / \mathrm{s}$ throughput," Photonics Technology Letters, IEEE, vol. 6, no. 9, pp. 1146 - 1149, September 1994.

[113] J.-J. Chen and Y. Guu-Chang, "Cdma fiber-optic systems with optical hard limiters," Journal of Lightwave Technology, vol. 19, no. 7, pp. 950-958, July 2001.

[114] X. Wang, N. Wada, T. Miyazaki, and K. Kitayama, "Demonstration of dpskocdma with balanced detection to improve mai and beat noise tolerance in ocdma system," in Optical Fiber Communication Conference, 2006 and the 2006 National Fiber Optic Engineers Conference, 5-10 March 2006, p. 3pp. 



\section{Apéndice A}

\section{PUBLICACIONES CIENTÍFICAS DEL AUTOR}

\section{A.1. Publicaciones en Revistas Internacionales}

- W. Amaya, D. pastor, J. Capmany, "Modeling Of A Time-Spreading OCDMA System Including Nonperfect Time Gating, Optical Thresholding, And Fully Asynchronous Signal/Interference Overlapping", Journal of Lightwave Technology, Volume 26, Issue 7, pp. $768-776,2008$.

- D. Pastor, W. Amaya, R. Garcia-Olcina "Design Of High Reflectivity Superstructured Fbg For Coherent Ocdma Employing Synthesis Approach", Electronics Letters, Volume 43, Issue 15, pp.824-825, 2007.

- D. Pastor, W. Amaya, R. Garcia-Olcina, S. Sales, "Coherent DS-OCDMA En/Decoding Efficiency v.s. Wavelength Detuning", Optics Letters, Vol. 32 Issue 13, pp. 1896-1898, 2007.

\section{A.2. Publicaciones en Congresos Internacionales}

- W. Amaya, D. Pastor, J. Capmany, "Full Passive Re-Use of Autocorrelation signal in All Optical Code based Label Optical Packet Networks", International Conference on Transparent Optical Networks - ICTON - 2008, Atenas, v.3. p.113 -116 .

- D. Pastor, W. Amaya, R. Garcia-Olcina, "Design Of High Reflectivity SSFBGOCDMA En/Decoders By DLP Synthesis Method", 20th Annual Meeting of the IEEE Lasers and Electro-Optics Society, 2007, Orlando-EEUU. 


\section{A.3. Publicaciones en Congresos Nacionales}

- W. Amaya, D. Pastor, J. Campany, "Reuso De Señales Autocorreladas En Redes Opticas Pasivas Basadas En Conmutacion De Etiquetas", XXIII Simposium Nacional de la Unión Científica Internacional de Radio (URSI 2008)

- Santiago Tainta, W. Amaya, Raimundo García, María José Erro Beltrán, María José Garde Alduncín, Daniel Pastor Abellán, Miguel Ángel Muriel Fernández, "Conformado de pulsos ópticos mediante el efecto Talbot en fibra", XXIII Simposium Nacional de la Unión Científica Internacional de Radio (URSI 2008)

- W. Amaya, D. Pastor, R. Garcia-Olcina, "Diseño De Cod/Decodificadores Eficientes Basados En SSFBG Para Sistemas OCDMA", XXII Simposium Nacional de la Unión Científica Internacional de Radio (URSI 2007).

- D. Pastor, W. Amaya, R. Garcia-Olcina, "Eficiencia Vs Desintonia En Longitud De Onda En Sistemás DS-OCDMA Coherentes", 5ta Reunión Española de OPTOELECTRÓNICA, OPTOEL'07.

- D. Pastor, W. Amaya, J. Capmany, "Estudio Del Ruido De Batido En Sistemas Con Multiplexación Por División En Código Óptico Coherentes.", XXI Simposium Nacional de la Unión Científica Internacional de Radio (URSI 2006). 
Apéndice B

PUBLICACIONES

INTERNACIONALES

(Texto Completo) 